\title{
Aerosol remote sensing in polar regions
}

by

Claudio Tomasi ${ }^{(1)}$, Alexander A. Kokhanovsky ${ }^{(2,3)}$, Angelo Lupi ${ }^{(1)}$, Christoph Ritter ${ }^{(4)}$, Alexander Smirnov ${ }^{(5,6)}$, Norman T. O’Neill ${ }^{(7)}$, Robert S. Stone ${ }^{(8,9)}$, Brent N. Holben ${ }^{(6)}$, Stephan Nyeki ${ }^{(10)}$, Christoph Wehrli ${ }^{(10)}$, Andreas Stohl ${ }^{(11)}$, Mauro Mazzola ${ }^{(1)}$, Christian Lanconelli ${ }^{(1)}$, Vito Vitale ${ }^{(1)}$, Kerstin Stebel ${ }^{(11)}$, Veijo Aaltonen ${ }^{(12)}$, Gerrit de Leeuw ${ }^{(12,13)}$, Edith Rodriguez ${ }^{(12)}$, Andreas B. Herber ${ }^{(14)}$, Vladimir F. Radionov ${ }^{(15)}$, Tymon Zielinski ${ }^{(16)}$, Tomasz Petelski ${ }^{(16)}$, Sergey M. Sakerin ${ }^{(17)}$, Dmitry M. Kabanov ${ }^{(17)}$, Stephen Broccardo ${ }^{(26)}$ and Stuart J. Piketh ${ }^{(27)}$

(1) Climate Change Division, Institute of Atmospheric Sciences and Climate (ISAC), Italian National Research Council (CNR), Bologna, Italy.

(2) Institute of Environmental Physics (IUP), University of Bremen, Bremen, Germany.

${ }^{(3)}$ EUMETSAT, Eumetsat Allee 1, D-64295 Darmstadt, Germany.

(4) Climate System Division, Alfred Wegener Institute for Polar and Marine Research, Potsdam, Germany.

${ }^{(5)}$ Sigma Space Corporation, Lantham, Maryland, USA.

${ }^{(6)}$ Biospheric Sciences Branch, NASA/Goddard Space Flight Center (GSFC), Greenbelt, Maryland, 24 USA.

$25{ }^{(7)}$ Canadian Network for the Detection of Atmospheric Change (CANDAC) and CARTEL, Dept. of Applied Geomatics, University of Sherbrooke, Sherbrooke, Québec, Canada.

(8) Global Monitoring Division (GMD), National Oceanic and Atmospheric Administration (NOAA), Boulder, Colorado, USA. 


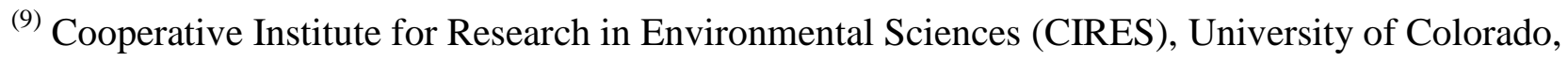
Boulder, Colorado, USA.

${ }^{(10)}$ Physikalisch-Meteorologisches Observatorium (PMOD)/World Radiation Centre (WRC), Davos, Switzerland.

${ }^{(11)}$ Norwegian Institute for Air Research (NILU), Kjeller, Norway.

${ }^{(12)}$ Climate and Global Change Division, Finnish Meteorological Institute (FMI), Helsinki, Finland.

${ }^{(13)}$ Department of Physics, University of Helsinki, Finland.

(14) Climate System Division, Alfred Wegener Institute for Polar and Marine Research, Bremerhaven, Germany.

${ }^{(15)}$ Arctic and Antarctic Research Institute (AARI), St. Petersburg, Russia.

${ }^{(16)}$ Institute of Oceanology (IO), Polish Academy of Sciences (PAS), Sopot, Poland.

${ }^{(17)}$ V. E. Zuev Institute of Atmospheric Optics (IAO), Siberian Branch (SB), Russian Academy of Sciences (RAS), Tomsk, Russia.

${ }^{(18)}$ Faculty of Life Sciences and Computing, London Metropolitan University, London, United Kingdom.

${ }^{(19)}$ Key Laboratory of Digital Earth Science, Institute of Remote Sensing and Digital Earth, Chinese Academy of Sciences, Beijing, 100094, China

${ }^{(20)}$ Brookhaven National Laboratory, Environmental and Climate Sciences Dept., Upton, NY, USA.

(21) Environment Canada, Downsview, North York, Ontario, Canada; now with Agriculture and Agri-food Canada.

${ }^{(22)}$ Institute of Geophysics, Polish Academy of Sciences (PAS), Warsaw, Poland.

${ }^{(23)}$ Arctic Research Center, Finnish Meteorological Institute (FMI), Sodankylä, Finland.

${ }^{(24)}$ Institute de l'Atmosphère de la Réunion (OPAR), Univ. de la Réunion - CNRS, Saint Denis de la Réunion, France.

${ }^{(25)}$ Institut Maurice-Lamontagne, Mont-Joli, Quebec, Canada.

(26) Geography, Archeology and Environmental Science, University of the Witwatersrand, Johannesburg, South Africa.

${ }^{(27)}$ Climatology Research Group, Unit for Environmental Sciences and Management, North-West University, Potchefstroom, South Africa.

Corresponding author: Claudio Tomasi

Phone: + 390516399594

Fax: + 390516399652

E-mail:c.tomasi@isac.cnr.it 
Abstract

Multi-year sets of ground-based sun-photometer measurements conducted at 12 Arctic sites and 9 Antarctic sites were examined to determine daily mean values of aerosol optical thickness $\tau(\lambda)$ at visible and near-infrared wavelengths, from which best-fit values of Ångström's exponent $\alpha$ were calculated. Analysing these data, the monthly mean values of $\tau(0.50 \mu \mathrm{m})$ and $\alpha$ and the relative frequency histograms of the daily mean values of both parameters were determined for winterspring and summer-autumn in the Arctic and for austral summer in Antarctica. The Arctic and Antarctic covariance plots of the seasonal median values of $\alpha$ versus $\tau(0.50 \mu \mathrm{m})$ showed: (i) a considerable increase in $\tau(0.50 \mu \mathrm{m})$ for the Arctic aerosol from summer to winter-spring, without marked changes in $\alpha$, and (ii) a marked increase in $\tau(0.50 \mu \mathrm{m})$ passing from the Antarctic Plateau to coastal sites, whereas $\alpha$ decreased considerably due to the larger fraction of sea-salt aerosol. Good agreement was found when comparing ground-based sun-photometer measurements of $\tau(\lambda)$ and $\alpha$ at Arctic and Antarctic coastal sites with Microtops measurements conducted during numerous AERONET/MAN cruises from 2006 to 2013 in three Arctic Ocean sectors and in coastal and offshore regions of the Southern Atlantic, Pacific, and Indian Oceans, and the Antarctic Peninsula. Lidar measurements were also examined to characterise vertical profiles of the aerosol

81 backscattering coefficient measured throughout the year at Ny-Ålesund. Satellite-based MODIS, MISR, and AATSR retrievals of $\tau(\lambda)$ over large parts of the oceanic polar regions during spring and summer were in close agreement with ship-borne and coastal ground-based sun-photometer measurements. An overview of the chemical composition of fine and accumulation/coarse mode particles is also presented, based on in-situ measurements at Arctic and Antarctic sites. Fourteen log-normal aerosol number size-distributions were defined to represent the average features of fine and accumulation/coarse mode particles for Arctic haze, summer background aerosol, Asian dust and boreal forest fire smoke, and for various background austral summer aerosol types at coastal 
89 and high-altitude Antarctic sites. The main columnar aerosol optical characteristics were determined

90 for all 14 particle modes, based on in-situ measurements of the scattering and absorption

91 coefficients. Diurnally averaged direct aerosol-induced radiative forcing and efficiency were

92 calculated for a set of multimodal aerosol extinction models, using various Bidirectional

93 Reflectance Distribution Function models over vegetation-covered, oceanic and snow-covered

94 surfaces. These gave a reliable measure of the pronounced effects of aerosols on the radiation

95 balance of the surface-atmosphere system over polar regions.

96

97 Key words:

98 Sun-photometer measurements

99 Aerosol optical thickness

100 Polar aerosol optical characteristics

101 Lidar backscattering coefficient profiles

102 Satellite aerosol remote sensing

103 Multimodal aerosol extinction models 


\section{Introduction.}

106 Aerosols are one of the greatest sources of uncertainty in climate modeling, as their microphysical, 107 chemical and optical characteristics as well as their concentration vary in time and in space, 108 inducing significant direct radiative forcing effects on the surface-atmosphere system. In addition, 109 they can alter cloud optical features and indirectly impact climate. The aim of this paper is to 110 present an overview of the optical characteristics of atmospheric aerosol observed in polar regions 111 during the past two decades, including recent measurements conducted with ground-based and ship112 borne sun-photometers, or retrieved from remote sensing data recorded with visible and infrared 113 sensors mounted onboard various satellite platforms. Optical instruments (e.g., lidars, sun114 photometers) measure the characteristics of the atmospheric light field (internal, reflected, or 115 transmitted). Specific procedures therefore need to be applied to convert optical signals to aerosol 116 characteristics, such as particle size and shape distributions, or chemical composition. Similar 117 procedures are also needed to derive the vertical concentration distribution from columnar 118 measurements. They are based on the solution of the inverse problem of radiative transfer theory 119 accounting for multiple light scattering, molecular and aerosol scattering and absorption, and 120 surface reflectance effects.

121 The presence of a visibility-reducing haze in the Arctic was already noted by early explorers in the $12219^{\text {th }}$ century (see Garrett and Verzella, 2008, for a historical overview). The explorers also 123 documented that haze particles were deposited on snow in remote parts of the Arctic (e.g., 124 Nordenskiöld, 1883) and haze layers were also observed later by pilots in the 1950s (Mitchell, 125 1957). The source of the haze was debated for almost a century but poorly understood until the 1261970 s when it was suggested that this "Arctic Haze" originated from emissions in northern mid127 latitudes and was transported into the Arctic over thousands of kilometers (Rahn et al., 1977, Barrie 128 et al., 1981). The seasonality of the haze, which peaks in winter and early spring, was explained by 129 the fact that removal processes are inefficient in the Arctic during that time of the year (Shaw, 130 1995). 
131 Polar aerosols originate from both natural and anthropogenic sources (Shaw, 1988, 1995). In the

132 Arctic regions, natural aerosols have been found to contain an oceanic sea-salt mass fraction that 133 frequently exceeds $50 \%$ on summer days, and a mass fraction of $30-35 \%$ due to mineral dust, with 134 lower percentages of non-sea-salt (nss) sulphate, methane sulphonic acid (MSA), and biomass 135 burning combustion products. In contrast, anthropogenic particles have higher concentrations of 136 sulphates, organic matter (OM) and black carbon (BC) with respect to natural aerosol (Quinn et al., 137 2002, 2007; Sharma et al., 2006). In fact, boreal forest fire (hereinafter referred to as BFF) smoke 138 transported from North America and Siberia often contributes to enhance soot concentration in 139 summer (Damoah et al., 2004; Stohl et al., 2006). Rather high aerosol mass concentrations of 140 anthropogenic origin are frequently transported from North America and especially Eurasia in the 141 winter and spring months, leading to intense Arctic haze episodes (Shaw, 1995). For instance, 142 Polissar et al. (2001) conducted studies on the BC source regions in Alaska from 1991 to 1999 143 finding that predominant contributions have been given by large-scale mining and industrial 144 activities in South and Eastern Siberia. In the North-European sector of the Arctic, the dominant 145 sources of sulphates and nitrates (and to a lesser extent of water-soluble OM and BC) are located in 146 Europe and Siberia, due to both urban pollution and industrial activities (Hirdman et al., 2010). 147 Episodes of Asian dust transport have also been observed over the past years in the North-American sector of the Arctic, especially in spring (Stone et al., 2007), together with local transport of soil particles mobilized by strong winds, which provisionally enhance the mass concentrations of elemental components, such as Al, Si, Mg and Ca (Polissar et al., 1998). The Arctic atmosphere's 151 stratification is highly stable, with frequent and strong inversions near the surface, which limit 152 turbulence and reduce the dry deposition of aerosols to the surface (Strunin et al., 1997). They also 153 decouple the sea ice inversion layer from the Arctic free troposphere, leading to very different 154 chemical and physical properties of aerosols in the sea ice inversion layer where aerosols are 155 depleted, and higher up where a sulphate-rich background aerosol typically of anthropogenic origin 156 is often found (Brock et al., 2011). In addition, organic-rich biomass burning layers occur in the free 
troposphere but rarely reach the surface (Brock et al., 2011; Warneke et al., 2010). The low-altitude

158 high-latitude atmosphere in the southern hemisphere is similarly stably stratified as the Arctic's but

159 also influenced strongly by katabatic winds bringing down air from the high altitudes of interior 160 Antarctica (Stohl and Sodemann, 2010).

161 On larger scales, the stable Arctic stratification leads to the so-called polar dome, where isentropes 162 form shells above the Arctic. As atmospheric transport tends to follow the isentropes, direct 163 transport of air masses from mid-latitude pollution source regions into the Arctic lower troposphere 164 is very inefficient. According to Stohl (2006), polluted air masses from lower latitudes typically 165 follow one of five major transport pathways (see Fig. 1): (1) lifting at the Arctic front, where wet 166 scavenging is efficient; (2) lifting at lower latitudes (at the polar front or convection), where wet 167 scavenging is even more efficient; (3) most importantly for Arctic surface aerosol concentrations, 168 low-level transport over land in winter where strong radiative cooling allows air masses to enter the 169 polar dome; (4) slow descent by radiative cooling of upper-tropospheric air masses into the polar 170 dome; (5) slow mixing across the lateral boundaries of the dome. Forest or agricultural fires are 171 important, as they produce strong aerosol plumes in the mid- to high-latitude free troposphere, 172 which can subsequently enter the Arctic by one of the previously mentioned processes.

173 In addition to long-range pollution transport, local emission sources can be important. For instance, 174 emissions from cruise ships can lead to measurable enhancements of $\mathrm{BC}$ and other aerosols in the 175 Svalbard archipelago (Eckhardt et al., 2013). Diesel generators can also locally pollute the 176 environment (Hagler et al., 2008). Aircraft emissions north of the Arctic circle are primarily 177 injected into the stratosphere where removal is inefficient and these emissions can slowly descend 178 (Whitt et al., 2011). All these local sources can also enhance the Arctic aerosol background; 179 however, quantification of their contribution relative to long-range transport of pollution from 180 sources outside the Arctic remains uncertain. In addition, sulphate and volcanic ash from high181 latitude eruptions can occasionally influence the Arctic troposphere (e.g., Hoffmann et al., 2010). 182 The stratospheric background aerosol in the Arctic as elsewhere can be perturbed by explosive 
volcanic eruptions (especially in the tropics) for several years. Some volcanic aerosol emission episodes have been observed by Bourassa et al. (2010) and O'Neill et al. (2012) over last few years, involving the low stratosphere over short periods of a few months.

Transport processes in the high-latitude southern hemisphere are similar to those sketched for the Arctic in Fig. 1. As in the northern hemisphere, polluted air masses from the lower-latitude continents are quasi-isentropically lifted to higher altitudes and, furthermore, there is no lowaltitude transport pathway over land in winter (i.e., the analogue to transport pathway number 3 in Fig. 1 is missing in the southern hemisphere). Consequently, as in the Arctic, the lowermost troposphere in the Antarctic is very isolated and, thus, contains little anthropogenic pollution transported from lower-latitude continents (Stohl and Sodemann, 2010). A major difference to the Arctic, however, is the high topography of the Antarctic continent. This means that the most isolated air masses (as measured by the time since last exposure to pollution sources at lowerlatitude continents) are not found close to the pole, as in the Arctic, but in the coastal areas surrounding Antarctica (Stohl and Sodemann, 2010). Descent over the Antarctic continent is stronger than over the Arctic and can also bring down air from the stratosphere, and air from the Antarctic interior is transported down to coastal areas by strong katabatic winds.

In Antarctica, aerosols sampled at coastal sites originate almost totally from natural processes, with a prevailing oceanic sea-salt mass content of 55-60\%, and lower percentages of nss sulphate (20$30 \%)$ and mineral dust (10-20\%) (Tomasi et al., 2012). Only very low mass fractions of nitrates, water-soluble $\mathrm{OM}$ and $\mathrm{BC}$ have been monitored in Antarctica, mainly associated with transport from remote anthropogenic sources (Wolff and Cachier, 1998) or biomass burning (Fiebig et al., 2009) in mid-latitude areas. More than $60-80 \%$ of particulate matter suspended over the Antarctic Plateau has been estimated to consist of nss sulphates formed from biogenic sulphur compounds and/or MSA, due to long-range transport in the free troposphere and subsequent subsidence processes. Therefore, aerosols sampled at these high-altitude sites contain only moderate mass 
208 fractions of nitrates, and minor or totally negligible mass percentages of mineral dust, water-soluble 209 OM and BC (Tomasi et al., 2007, 2012).

210 The paper is organized as follows. In the next section the ground-based remote sensing 211 measurements of atmospheric aerosol are reviewed (sun-photometers, lidars). Section 3 gives a 212 description of ship-borne aerosol remote sensing instruments. Section 4 discusses aerosol 213 backscattering coefficient profiles from lidar measurements, while Section 5 is dedicated to 214 airborne and satellite observations of polar aerosols. The last section presents the most important 215 optical characteristics and size-distribution features of polar aerosols, which are appropriate for 216 calculations of direct radiative forcing effects induced by aerosols on the climate system.

\section{Ground-based remote sensing measurements}

\subsection{Spectral measurements of aerosol optical thickness}

220 Ground-based remote sensing of the optical characteristics of aerosols in the atmospheric column is usually conducted with multi-wavelength sun-photometers. A sun-photometer is oriented towards the Sun to detect the solar radiation attenuated along the slant path from the top-of-atmosphere (TOA) to the ground. The atmospheric aerosol load leads to a decrease in the solar radiation transmitted through the atmosphere. This decrease depends on the aerosol optical thickness (hereinafter referred to as AOT and/or using symbol $\tau(\lambda)$ ), which is given by the integral of the volume aerosol extinction coefficient along the vertical path of the atmosphere.

The networks, sites and sun-photometers whose data were employed in this paper are defined and 228 characterized in Tables 1 and 2 for the Arctic and Antarctic regions, respectively. The largest networks of sun-photometers in the world are AERONET and SKYNET. Spectral measurements of $\tau(\lambda)$ are performed with AERONET sun-photometers (Holben et al., 1998) at 8 wavelengths 231 ranging from 0.340 to $1.600 \mu \mathrm{m}$, and with SKYNET instruments (Nakajima et al., 2007) at 10 232 wavelengths from 0.315 to $2.200 \mu \mathrm{m}$. The Cimel CE-318 sun-photometers of the AERONET 233 network are currently used at several Arctic sites: Barrow (since March 2002), Thule (since March 
2007), Hornsund (since April 2005), Sodankylä (since February 2007), Tiksi (since June 2010),

235 Resolute Bay (since July 2004), Eureka-OPAL (since April 2007) and Eureka-PEARL (since May 2007). The last three sites, located in the Nunavut region of Canada, are part of the AEROCAN/AERONET network. In addition, an AERONET sun-photometer has been intermittently used since 2002 by the Atmospheric Optics Group (GOA) (University of Valladolid, Spain) at the Arctic Lidar Observatory for Middle Atmosphere Research (ALOMAR), located on the Andøya Rocket Range, near Andenes (Northern Norway) (Toledano et al., 2012). AERONET sun-photometers have been used to obtain Level $2.0 \tau(\lambda)$ measurements at the South Pole (since November 2007), and occasionally at Dome Concordia (in January and December 2003) in Antarctica. AERONET Level 1.5 measurements of $\tau(\lambda)$ are available for McMurdo on the Ross Sea (from February to December 1997, in the austral summer 2001/2002, and in January-February 2011), at Marambio (Antarctic Peninsula) since October 2007, at Vechernaya Hill (Thala Hills, Enderby Land) since December 2008, and at Utsteinen (Dronning Maud Land) since February 2009. However, because these data were not promoted to Level 2.0, they were not considered in the present study. A PREDE POM-01L sun/sky radiometer was used in Antarctica during the 20012002 austral summer by Di Carmine et al., (2005) at the Mario Zucchelli station. PREDE instruments have been used since 2001 in Antarctica at Syowa (East Ongul Island, Lützow-Holm Bay) by the National Institute of Polar Research (NIPR, Tokyo, Japan) since 2001, at Rothera by the British Antarctic Survey (BAS) since January 2008, and at Halley by BAS since February 2009. In addition, Precision Filter Radiometer (PFR) sun-photometers (Wehrli, 2000; Nyeki et al., 2012) from the Global Atmosphere Watch (GAW) PFR network are currently used in the Arctic at Summit by PMOD/WRC (Switzerland), at Ny-Ålesund by NILU (Norway), and at Sodankylä by FMI (Finland), and in Antarctica at Marambio by FMI and at Troll by NILU. The instrumental and geometrical characteristics of the PFR sun-photometer are described by Wehrli (2000). The monochromatic total optical thickness $\tau_{\text {TOT }}(\lambda)$ of the atmosphere is commonly calculated in terms of the well known Lambert-Beer law for a certain sun-photometer output voltage $J(\lambda)$ taken 
within a spectral channel centred at wavelength $\lambda$ and for a certain apparent solar zenith angle $\theta_{0}$.

261 The monochromatic value of $\tau_{\text {TOT }}(\lambda)$ is given by (Shaw, 1976):

$$
\tau_{\text {TOT }}(\lambda)=(1 / m) \ln \left[R J_{O}(\lambda) / J(\lambda)\right] \quad,
$$

263 where:

264 (i) $m$ is the relative optical air mass calculated as a function of $\theta_{0}$ using a realistic model of the 265 atmosphere, in which wet-air refraction and Earth/atmosphere curvature effects on the direct solar 266 radiation passing through the atmosphere are properly taken into account (Thomason et al., 1983; 267 Tomasi and Petkov, 2014); (ii) $J(\lambda)$ is the output signal (proportional to solar irradiance) measured 268 by the ground-based solar pointing sun-photometer; (iii) $J_{O}(\lambda)$ is the output signal that would be measured by the sun-photometer outside the terrestrial atmosphere, at the mean Earth-Sun distance; and (iv) $R$ accounts for $J_{O}(\lambda)$ variations as a function of the daily Earth-Sun distance (Iqbal, 1983).

The solar radiation reaching the surface for cloud-free sky conditions is attenuated not only by aerosol extinction but also by Rayleigh outscattering as well as absorption by minor gases (mainly water vapour $\left(\mathrm{H}_{2} \mathrm{O}\right)$, ozone $\left(\mathrm{O}_{3}\right)$, nitrogen dioxide $\left(\mathrm{NO}_{2}\right)$ and its dimer $\left(\mathrm{N}_{2} \mathrm{O}_{4}\right)$, and oxygen dimer $\left.\left(\mathrm{O}_{4}\right)\right)$. The spectral values of $\tau(\lambda)$ within the main windows of the atmospheric transmission spectrum are accordingly calculated by subtracting the Rayleigh scattering and absorption optical thicknesses from $\tau_{T O T}(\lambda)$.

AOT is usually a smooth function of wavelength $\lambda$ (measured in $\mu \mathrm{m}$ ), which can be approximated by the following simple formula:

where $\alpha$ is the so-called Ångström (1964) wavelength exponent, and $\lambda_{0}$ is usually assumed to be equal to $1 \mu \mathrm{m}$. In reality, the analytical form defined in Eq. (2) can be convex or concave depending on the relative contents of fine and coarse particles in the atmospheric column. O'Neill et al. 283 (2001a) demonstrated that the variation in $\tau(\lambda)$ and its first and second spectral derivatives (named 
284 here $\alpha$ and $\alpha$, respectively) can be realistically described in terms of the spectral interaction 285 between the individual optical components of a bimodal size-distribution. O'Neill et al. (2001a) 286 then showed that one can exploit the spectral curvature information in the measured $\tau(\lambda)$ to permit a 287 direct estimate of a fine-mode Ångström exponent $\left(\alpha_{f}\right)$ as well as the optical fraction of fine-mode 288 particles. However, an analysis of $\alpha$ and $\alpha^{\prime}$ determined in real cases and taking into account that 289 both $\alpha(0.44-0.87 \mu m)$ and $\alpha^{\prime}$ are closely related to the spectral features of $\tau(\lambda)$ showed that 290 propagation of errors leads to an error $\Delta \alpha / \alpha \sim 2 \Delta \tau(\lambda) / \tau(\lambda)$ and an error $\Delta \alpha^{\prime} / \alpha^{\prime} \sim 5 \Delta \tau(\lambda) / \tau(\lambda)$, 291 respectively (Gobbi et al., 2007). These estimates yield values of $\Delta \alpha / \alpha$ and $\Delta \alpha^{\prime} / \alpha^{\prime}$ that are $>\sim 20 \%$ 292 and $>\sim 50 \%$, respectively, for $\tau(\lambda) \leq 0.10$ and a typical sunphotometry error equal to $\sim 0.01$. To 293 avoid relative errors $>\sim 30 \%$ in $\Delta \alpha^{\prime} / \alpha^{\prime}$, Gobbi et al. (2007) suggested using only observations of $294 \tau(\lambda)>0.15$. We applied the same criterion as a threshold for accepting outputs from the Spectral 295 Deconvolution Algorithm (SDA) of O’Neill et al. (2003) (notably the fine-mode Ångström 296 exponent, which offers an alternative refinement to the calculation of $\alpha$ ): our logic being that $\alpha$ and $297 \alpha$ ' are input parameters to SDA and we did not want to introduce unacceptable processing errors to 298 the extraction of a spectral exponent indicator. These limitations to the use of spectral values of $\alpha$ 299 and $\alpha$ ' were also applied by Yoon et al. (2012), who only considered observations with $\tau(0.44 \mu m)$ $300>0.15$ in order to avoid relative errors $>30 \%$ in $\alpha^{\prime}$. Tomasi et al. (2007) showed that for the period 301 1977-2006, $\tau(0.50 \mu \mathrm{m})$ did not exceed 0.15 for background summer aerosol conditions at Barrow, 302 Alert, Summit, Ny-Ålesund, Hornsund, Sodankylä and Andenes/ALOMAR in the Arctic, and was 303 greater than 0.15 only during very strong episodes of Arctic haze in late winter and spring, and BFF 304 smoke transport in summer. Similarly, Tomasi et al. (2012) found that (i) the measurements of $305 \tau(0.50 \mu \mathrm{m})$ recorded from 2000 to 2012 at Ny-Ålesund were estimated to exceed 0.15 in summer 306 (June to September) in only a few cases of strong transport of BFF smoke from lower latitudes; 307 even in winter (December to March), they were higher than 0.15 only for $10 \%$ of the cases, 308 typically associated with Arctic haze transport episodes; (ii) measurements of $\tau(0.50 \mu m)>0.15$ 
recorded at Barrow over the same period were observed only in a few percent of cases, as a result of

310 Arctic haze; and (iii) daily mean background summer values of $\tau(0.50 \mu \mathrm{m})$ measured at Tiksi in

311 Siberia were always lower than 0.08 during the summer 2010. With regard to Antarctic aerosol,

312 Tomasi et al. (2007) estimated that the daily mean values of $\tau(0.50 \mu \mathrm{m})$ were lower than 0.10 during

313 the austral summer months at Marambio, Neumayer, Aboa, Mirny, Molodezhnaya, Syowa, Mario

314 Zucchelli, Kohnen, Dome Concordia and South Pole. In particular, examining the sun-photometer 315 measurements carried out from 2005 to 2010, Tomasi et al. (2012) reported that the austral summer 316 values of $\tau(0.50 \mu \mathrm{m})$ measured at Neumayer and Mirny were $<0.10$ during the whole season, while 317 those measured at South Pole never exceeded 0.06.

318 Therefore, since the values of $\tau(0.44 \mu \mathrm{m})$ determined from the sun-photometer measurements 319 conducted in polar regions are mostly lower than 0.15 and thus below the value recommended by 320 Gobbi et al. (2007), we have decided not to determine the exponent $\alpha_{f}$ using the O'Neill et al. 321 (2001b) algorithm, but to calculate the best-fit value of the Ångström exponent $\alpha$ over the spectral 322 range $0.40 \leq \lambda \leq 0.87 \mu \mathrm{m}$ using Eq. (2). In real cases, the exponent $\alpha$ provides by itself a first rough 323 estimate of the optical influence of the fine particle component on $\tau(\lambda)$, since it gradually decreases 324 on average from cases where fine particle extinction predominates to cases where coarse particles 325 are optically predominant.

326 In all cases with relatively high values of $\tau(0.50 \mu \mathrm{m})$, the AERONET and SKYNET sun/sky 327 radiometers can also be used to provide regular measurements of sky-brightness along the solar 328 almucantar (an azimuthal circle around the local normal whose zenith angle equals the solar zenith 329 angle $\theta_{0}$ ) and also in the principal plane containing the direction to the Sun and the local normal. 330 The analysis of these measurements enables better constraints for solving the inverse problem 331 (while accounting for multiple scattering and surface reflectance effects) and allowing the following 332 parameters to be derived: (i) the aerosol single scattering albedo $\omega(\lambda)$, (ii) the phase function $P(\Theta)$, 
333 (iii) the particle number density size distribution $N(r)=d N(r) / d(\ln r))$ given as a function of particle 334 radius $r$, and (iv) the complex refractive index $n(\lambda)$ - i $k(\lambda)$ (King and Dubovik, 2013).

335 The data analysis performed in this paper was subject to certain data processing constraints across 336 networks of instruments. In the first instance, all network protocols differ in many (typically) minor 337 details such as the means of estimating molecular optical thicknesses and solar air masses, the 338 nominal time interval between measurements and calibration protocols. In general, all data sets 339 were cloud-screened using temporal-based criteria that were developed and rigorously tested by 340 each network group. Only Level 2.0 AERONET data were used: this corresponds to temporal-based 341 cloud-screened data (Smirnov et al., 2000) that has undergone a final quality assurance step. The 342 GMD/NOAA data acquired at Barrow and Alert were further cloud-screened using a spectral 343 criterion wherein $\tau(\lambda)$ spectra were eliminated for $\alpha<0.38$. This added cloud-screening feature was 344 found to be necessary in order to eliminate the influence of homogeneous, thin cirrus clouds that 345 has escaped the temporal cloud-screening step. Finally we note that the specific spectral ranges of 346 the $\alpha$ computations, while being nominally limited to $0.40 \leq \lambda \leq 0.87 \mu \mathrm{m}$ are given in Tables 1 and 3472 for each type of instrument (the $\alpha$ regression was carried out for all wavelength channels between 348 and including the wavelength extremes given in the "Spectral interval" column).

349 Before presenting the evaluations of the seasonal variations in parameters $\tau(0.50 \mu m)$ and $\alpha$ 350 measured at the various Arctic and Antarctic sites, it seems useful for the reader to give a measure 351 of the experimental errors and variability features associated with the aerosol optical characteristics 352 varying as a function of aerosol origin and their chemical composition evolutionary patterns:

353 (i) the mean experimental error of AOT measured with the most sophisticated sun-photometers 354 leads to an uncertainty of $\sim 0.01$ in the visible and near-IR, mainly due to calibration errors (Eck et 355 al., 1999); 
(ii) the relative errors of exponent $\alpha$ determined in terms of Ångström's (1964) formula is about twice the relative error of AOT (Gobbi et al., 2007), therefore leading to obtain at polar sites relative errors close to $30 \%$ and, hence, absolute errors of $~ 0.50$ (Mazzola et al., 2012); and

(iii) the spread of $\alpha$ arising from the natural variability of Arctic and Antarctic aerosol types has been estimated by Stone (2002), Tomasi et al. (2007) and Treffeisen et al. (2007) to yield average uncertainties of \pm 0.4 for Arctic summer background aerosols, \pm 0.6 for Arctic aerosols including particular cases (like Asian dust and boreal smoke particles), and \pm 0.5 for austral summer background aerosol observed at Antarctic sites.

\subsubsection{Measurements in the Arctic}

366 In order to define the seasonal variations in polar aerosol optical characteristics, sun-photometer measurements of $\tau(\lambda)$ conducted at various visible and near-infrared wavelengths can be conveniently examined to evaluate the exponent $\alpha$ in terms of Eq. (2). Such measurements have been carried out at various Arctic and Antarctic sites during the past decades, providing useful information on polar aerosol optical and microphysical features. In fact, $\tau(\lambda)$ gives a measure of the overall aerosol extinction along the vertical atmospheric path, while $\alpha$ depends on the combination of the different extinction effects produced by fine and accumulation/coarse mode particles. Values of $\alpha$ higher than 1.3 are usually observed in air masses where Aitken nuclei and very fine particles (having radii $r<\sim 0.12 \mu \mathrm{m}$ ) optically predominate, while relatively low values of $\alpha<1.0$ are observed when accumulation (over the $0.12 \leq r \leq 1.25 \mu \mathrm{m}$ range) and coarse (over the $r>1.25 \mu \mathrm{m}$ range) mode particles produce stronger extinction effects. The vertical profile of the aerosol volume backscattering coefficient can be determined by means of lidar measurements, allowing the classification of aerosol layers in the troposphere and lower stratosphere.

379 Direct solar radiation measurements have been regularly conducted for cloud-free sky conditions at 380 numerous polar sites over the past decades, using multi-spectral sun-photometers of different 
design. Tables 1 and 2 list the 12 Arctic sites and 9 Antarctic sites, whose data were employed in this study together with their geographical coordinates, measurement periods, the peak-wavelengths of the spectral channels used to measure AOT and determine the best-fit value of $\alpha$, and the main references where the technical characteristics of the instruments are detailed. The geographical location of these sites are separately indicated in Fig. 2 for Arctic and Antarctic regions.

The individual measurements of the spectral values of $\tau(\lambda)$ and of the exponent $\alpha$ obtained from the analysis of the field data recorded for cloud-free sky conditions were then averaged to yield daily means. Since the present analysis is devoted to tropospheric aerosols, the sun-photometer measurements conducted in the presence of stratospheric layers of volcanic particles were removed for the following sites and intervals at: (a) the Arctic sites, in May 2006 (Soufrière Hills eruption), October 2006 (Tavurvur eruption) (Stone et al., 2014), from mid-August to late September 2008 (Kasatochi eruption) (Hoffmann et al., 2010), from early July to early October 2009 (Sarychev eruption) (O’Neill et al., 2012), and in April 2010 (Eyjafjallajokull eruption), as well as the sun394 photometer data collected at Barrow during the periods that followed both the Okmok eruption in July 2008, and the Mt. Redoubt eruption in March 2009 (Tomasi et al., 2012); and (b) the Antarctic sites, for all data affected by volcanic features comparable to those of Mt. Pinatubo observed from late spring 1992 to late autumn 1994 (Stone et al., 1993; Stone, 2002). Actually, the Stratospheric Aerosol and Gas Experiment (SAGE II) observations made since 2000 over Antarctica did not provide evidence of appreciable extinction features produced by volcanic particle layers at stratospheric altitudes (Thomason and Peter, 2006; Thomason et al., 2008), as also confirmed by the analysis of sun-photometer measurements conducted at Mirny, Neumayer, Mario Zucchelli and South Pole from 2000 to 2010 (Tomasi et al., 2012). The remaining daily mean "tropospheric" data collected at each site were then subdivided into 404 monthly sub-sets consisting of data measured in different years, for which the multi-year monthly mean values of $\tau(0.50 \mu \mathrm{m})$ and $\alpha$ were determined. Relative frequency histograms (hereinafter referred to as RFHs) were defined separately using the daily mean values of $\tau(0.50 \mu \mathrm{m})$ and $\alpha$ 
407 411 background aerosols.

collected at Arctic sites during the following seasons: (i) winter-spring, from December to May, when Arctic haze events were most frequent, and (ii) the summer-autumn, from June to October, to characterize background aerosols in summer. For the Antarctic sites, RFHs were determined for austral summer (from late November to February), to define the mean optical characteristics of

\subsubsection{Measurements in Northern Alaska}

Two multi-year sets of sun-photometer measurements from Barrow, located on the Arctic Ocean coast, were analysed in the present study: (a) the first series, acquired with the Carter Scott sunphotometer, was conducted from March 2000 to September 2012 by GMD/NOAA (see Table 1) and consisted of spectral $\tau(\lambda)$ measurements, taken every minute on apparently cloud-free days and then cloud-screened by applying the GMD/NOAA selection procedure (for $\alpha(0.412 \mu \mathrm{m} / 0.675 \mu \mathrm{m}$ ) $<0.38$ ); and (b) the second series was AERONET data collected from March 2002 to September 2013 (see Table 1). The results are shown in Fig. 3 for the GMD/NOAA and AERONET measurements, where the data coverage is $94 \%$ and $78 \%$ of the overall 14-year period (March 2000 to September 2013), respectively. The GMD/NOAA monthly mean values of $\tau(0.50 \mu m)$ increase from about 0.07 in February to more than 0.12 in April and May, and then gradually decrease to less than 0.10 in June and July, and to around 0.05 in October, with (grey toned) standard deviations $\sigma_{\tau}>0.05$ from April to July, and $<\sim 0.03$ in the other months. Similar results were obtained for the AERONET measurements, which exhibited monthly mean values of $\tau(0.50 \mu \mathrm{m})$ that increased from about 0.12 in March to more than 0.16 in April, and then decreased to 0.10 in June and August and 0.05 in September and October, with $\sigma_{\tau}>0.05$ from April to August, and $<\sim 0.03$ for the other months. The monthly mean values of $\alpha$ determined from the GMD/NOAA and AERONET measurements were rather stable from February to April, varying from 1.10 to 1.20 , with a standard deviation $\sigma_{\alpha}=0.3$ on average, followed by a convex cap from April to August, with values close to 
433 shows the RFHs of the daily mean values of $\tau(0.50 \mu \mathrm{m})$ and $\alpha$ measured during the winter-spring 434 and summer-autumn seasonal periods. The analytical curves drawn to represent the RFHs are 435 normal curves and are normalized to yield unit (100\%) integration over the measured sampling 436 intervals of $\tau(0.50 \mu \mathrm{m})$ and $\alpha$ shown in Fig. 3. The RFHs for both instruments were very similar, 437 although showing appreciable discrepancies between the means and percentiles, which are in 438 general lower than the corresponding standard deviations. The seasonal mean values of $\tau(0.50 \mu m)$ 439 were equal to 0.12 and 0.13 in winter-spring, for the GMD/NOAA and AERONET data, 440 respectively, and close to 0.08 in summer-autumn for both data-sets. The RFHs also have long-tails 441 towards high values for winter-spring data, and larger kurtosis in summer-autumn. The long-tail 442 features could in part be ascribed to larger $\tau(0.50 \mu \mathrm{m})$ values in April and May (ranging from 0.12 443 to 0.16 ) attributable to the frequent Arctic haze cases observed in spring but would also be, in part, 444 due to the (asymmetrical) log-normal distribution that is arguably a better fit to the AOT RFHs in 445 general (c.f. O'Neill et al., 2000).

446 The small discrepancies found between the time-patterns of the monthly mean values of $\tau(0.50 \mu m)$ 447 and $\alpha$ defined for both data-sets as well as those between the RFHs of both parameters might well 448 be attributable to slight differences in the total observation periods of both sun-photometers and/or 449 differences in GMD/NOAA and AERONET cloud-screening. The different seasonal features of $450 \tau(0.50 \mu \mathrm{m})$ and $\alpha$ shown in Fig. 3 arise mainly from the origins of the aerosol load, associated with 451 the transport of continental polluted air masses mainly from North America and Asia, in winter452 spring (Hirdman et al., 2010). It can also be seen in Fig. 3 that the left-hand wings of the RFHs for $453 \alpha$ contain some values $<0.75$ : these are probably due to an optical predominance of coarse mode 454 sea-salt aerosols and/or local blown dust. Similarly, a fraction of values with $\alpha<1.20$ are 455 presumably related to Asian dust transport episodes (Di Pierro et al., 2011) that are most frequently 
observed in March and April, and which are generally characterised by persistent extinction features typical of coarse mineral dust particles (Stone et al., 2007).

\subsubsection{Measurements in Northern Canada (Nunavut)}

460 The results derived from the AERONET/AEROCAN measurements conducted at Resolute Bay and 461 Eureka-OPAL, and those carried out by GMD/NOAA at Alert (Canada) (see Table 1) over the past 462 decade are shown in Fig. 4, as obtained for air masses containing aerosols mainly transported from 463 the North American and Arctic Ocean areas (Hirdman et al., 2010) over these three Canadian sites. 464 The monthly mean values of $\tau(0.50 \mu \mathrm{m})$ exhibit: (i) rather high values related to Arctic haze in 465 March-April, varying between 0.10 and 0.15 , and (ii) relatively low values in the subsequent 466 months, decreasing to around 0.05 in September at all the three sites. The month-to-month 467 differences, varying on average from 0.05 at Resolute Bay and Alert in March-June to 0.01 at Alert 468 in September, are similar to or smaller than the monthly mean values of $\sigma_{\tau}$. The winter-spring RFHs 469 exhibit higher mean values of $\tau(0.50 \mu \mathrm{m})$, ranging from 0.09 to 0.12 , and broader right-hand wings compared to the summer-autumn period, where the RFHs are narrower, giving seasonal mean 471 values varying from 0.06 to no more than 0.08 .

472 Relatively small differences were found between the monthly mean values of $\alpha$ in winter-spring 473 and summer-autumn, with: (i) stable values close to 1.50 in March-June at Resolute Bay, gradually 474 decreasing to 1.0 in July-September; and (ii) values increasing from 1.0 to 1.5 in March-June at 475 Eureka and Alert, and remaining close to 1.50 from July to September (with $\sigma_{\alpha}<\sim 0.3$ ). The monthly mean values of $\alpha$ determined at Resolute Bay and Eureka-OPAL are appreciably higher 477 than those measured at Barrow, presumably as a result of the weaker extinction produced by coarse 478 sea-salt particles and/or local dust, and weaker contributions of Asian dust in the spring months. 479 Figure 4 shows that the seasonal RFHs of daily mean $\alpha$ values do not exhibit symmetrical shapes: 480 (i) the winter-spring RFHs are rather wide, showing long-tailed left-hand wings and mean values 
varying from 1.29 (at Alert) to 1.52 (at Resolute Bay), and (ii) the summer-autumn RFHs are 482 characterised by mean values varying from 1.46 (Alert) to 1.64 (Eureka). Only moderate, relative 483 increases in the coarse particle content occurred at Resolute Bay from winter-spring to summer, 484 while greater winter-spring to summer-autumn variations were measured at Eureka and Alert 485 presumably due to fine particle smoke transported from North American boreal forest fires (Stohl et 486 al., 2006). Finally, it is worth noting that a few cases were found with $\alpha<0.40$ at Alert, despite the $\alpha<0.38$ cloud-screening rejection criterion. They were presumably associated with prevailing extinction by coarse mode sea-salt aerosols transported from the Arctic Ocean, especially in the spring months.

\subsubsection{Measurements in Greenland}

492 Figure 5 shows the results derived from the multi-year sets of sun-photometer measurements conducted at: (i) the Thule AERONET site, in the north-western corner of Greenland; (ii) the 494 Summit PMOD/WRC site, located in the middle of the Central Greenland ice sheet; and (iii) 495 Ittoqqortoormiit AERONET site, on the eastern coast of Greenland (see Table 1 for details on these sites).

497 The monthly mean $\tau(0.50 \mu \mathrm{m})$ values at Thule decreased slowly from about 0.10 in April-May to around 0.05 in June-September, with $\sigma_{\tau} \sim 0.03$, while $\alpha$ was rather stable with monthly mean values ranging from 1.40 to 1.50 from March to September, with $\sigma_{\alpha} \sim 0.3$. The winter-spring $\tau(0.50 \mu m)$

500 RFH is characterized by a mean value of 0.093 and an asymmetric shape whose long-tailed, right501 hand wing is influenced by the frequent occurrences of Arctic haze episodes. The summer-autumn RFH for $\tau(0.50 \mu \mathrm{m})$ was more symmetric, with mean and median values equal to 0.058 and 0.049 ,

503 respectively, and values of the $25^{\text {th }}$ and $75^{\text {th }}$ percentiles relatively close to the median value, as can 504 be seen in Fig. 5. Very similar shapes of both seasonal RFHs for $\alpha$ were obtained, with mean values of 1.38 in winter-spring and 1.41 in summer-autumn, and similar values of the main percentiles 
from winter-spring to summer-autumn, indicating no relevant seasonal changes in the aerosol size-

507 distribution.

508 Rather stable monthly mean values of $\tau(0.50 \mu \mathrm{m})$ were obtained at the high-altitude Summit station, 509 equal to $0.05 \pm 0.03$ from March to August, and about $0.03 \pm 0.01$ in September and October. Both 510 seasonal RFHs of the daily mean $\tau(0.50 \mu \mathrm{m})$ values assumed very similar shapes, with mean values 511 close to 0.05 , and values of the main percentiles differing by no more than 0.01 from season to the 512 other. Greater differences were determined between the two seasonal RFHs of $\alpha$, with mean values 513 equal to 1.27 in winter-spring and 1.52 in summer-autumn, and the main percentiles differing by no 514 more than 0.3. These aerosol optical characteristics indicate that Summit is representative of the 515 Arctic free troposphere, influenced mainly by particulate transport from North America and Europe, 516 and only weakly by Siberian aerosols (Hirdman et al., 2010).

517 The monthly mean values of $\tau(0.50 \mu \mathrm{m})$ at Ittoqqortoormiit showed similar seasonal variations to 518 those at Thule, gradually decreasing from $\sim 0.08$ in March to less than 0.04 in September-October, 519 with $\sigma_{\tau}=0.05$ in spring, gradually decreasing in summer until reaching values of $\sim 0.01$ in autumn. 520 The monthly mean $\alpha$ values increase from $\sim 1.00$ in March to $\sim 1.50$ in summer, and slowly 521 decrease in September and October, varying around 1.40, with $\sigma_{\alpha}=0.2$ in March and close to 0.3 in 522 the other months. The RFHs for $\tau(0.50 \mu \mathrm{m})$ did not vary largely from winter-spring to summer523 autumn. The seasonal mean values were equal to 0.068 in winter-spring and 0.052 in summer524 autumn, which were not considerably different from the median values in both seasons. They give a 525 measure of the appreciable decrease in $\tau(0.50 \mu \mathrm{m})$ observed from winter-spring to summer-autumn. 526 The seasonal RFHs for $\alpha$ are more similar to those obtained at Summit than those of Thule. In fact, 527 the winter-spring mean value of $\alpha$ was equal to 1.28 , and the summer-autumn value equal to 1.45 . 528 These results suggest that the atmospheric content of fine mode particles increases considerably 529 from winter to summer at Ittoqqortoormiit. Such variations are probably associated with the marked 530 extinction effects produced by maritime accumulation/coarse mode particles in winter-spring and 
531 the predominant aerosol extinction effects produced by background continental particles mainly 532 transported in summer-autumn from Europe and North America and containing in general 533 significant loads of both anthropogenic and BFF particles.

534 The seasonal changes shown in Fig. 5 at the three Greenland sites can be mainly attributed to the 535 variations in aerosol transport processes from anthropogenic/polluted regions or remote oceanic 536 mid-latitude areas, and only rarely to Asian dust. Actually, the transport processes of anthropogenic 537 soot aerosols are known to appreciably enhance $\tau(\lambda)$, yielding rather high values of $\alpha$ in general 538 (Tomasi et al., 2007; Stone et al., 2008). This may also occur in free-tropospheric layers, as 539 observed during airborne measurements conducted at mid-altitudes over the Arctic Ocean (Stone et 540 al., 2010).

\subsubsection{Measurements in Spitsbergen (Svalbard)}

543 The results obtained at Ny-Ålesund, Barentsburg and Hornsund (Svalbard, Norway) from four 544 different series of measurements are shown in Fig. 6, as conducted by AWI (Bremerhaven, 545 Germany) and NILU (Kjeller, Norway) at Ny-Ålesund, IAO-SB-RAS (Tomsk, Russia) at 546 Barentsburg, and the Institute of Geophysics (Warsaw University, PAS, Poland) in cooperation with 547 NASA/GSFC (USA) at Hornsund (see Table 1).

548 The AWI monthly mean values of $\tau(0.50 \mu \mathrm{m})$ varied from 0.07 to 0.09 in winter-spring, and 549 considerably decreased in summer-autumn from about 0.05 in June to 0.02 in October, with $\sigma_{\tau}=$ $550 \quad 0.03$ on average. The NILU monthly mean values of $\tau(0.50 \mu \mathrm{m})$ were equal to $\sim 0.10$ from March to 551 May, and varied from 0.06 in June-July to less than 0.05 in August-September, with $\sigma_{\tau}$ equal to 5520.04 in spring and 0.03 in summer and autumn. The comparison between the AWI and NILU results 553 shows good agreement, although the NILU values were occasionally higher than those for AWI by 554 no more than $10 \%$ on average in spring, such discrepancies probably arising from the slightly 555 dissimilar measurement periods of 14 and 8 years, respectively. The AWI monthly mean values of $556 \alpha$ increased from less than 1.30 in March to 1.50 in May, and slowly decreased in summer-autumn 
until reaching a value $<1.20$ in September and becoming nearly equal to 1.50 in October, with $\sigma_{\alpha}=$ 0.30 on average, while the NILU values increased slowly from 1.20 in March to 1.50 in June, and slowly decreased to $\sim 1.30$ in September, with $\sigma_{\alpha}=0.20$ in all months. These discrepancies of no more than $15 \%$ are in general smaller than the monthly values of $\sigma_{\alpha}$. Therefore, it is not surprising that the RFHs found for the daily mean $\tau(0.50 \mu \mathrm{m})$ values derived from the AWI and NILU datasets differ considerably from one season to another: (i) the AWI and NILU winter-spring mean values were equal to 0.082 and 0.089 , respectively, with the main percentiles differing by no more than 0.007; and (ii) the AWI and NILU summer-autumn mean values of $\tau(0.50 \mu \mathrm{m})$ were equal to 0.052 and 0.059 , respectively, with $\sigma_{\tau}=0.04$ on average, and having differences between the main percentiles no greater than 0.02. The AWI seasonal RFHs of $\alpha$ yielded mean values of 1.32 in winter-spring and 1.28 in summer-autumn, while NILU RFHs gave mean values of 1.35 in winterspring and 1.38 in summer-autumn. Comparable values of the three main percentiles of the AWI and NILU RFHs were also obtained, differing by less than 0.1 in winter-spring and less than 0.2 in summer-autumn. Therefore, the analysis of the AWI and NILU RFHs of $\alpha$ showed: (i) more dispersed features of $\alpha$ in winter-spring, presumably due to the larger variability of fine and coarse particle concentrations during the frequent Arctic haze episodes, and (ii) values of $\alpha$ mainly varying from 1.00 to 1.60 in summer-autumn, due to the large variability of the fine particle mode atmospheric content (mainly related to BFFs smoke particle transport) with respect to that of accumulation/coarse mode particles (mainly of oceanic origin).

The data-sets of $\tau(0.50 \mu \mathrm{m})$ and $\alpha$ derived from the Barentsburg IAO measurements consisted of a number of daily measurements smaller than $10 \%$ of that given by the AWI and NILU Ny-Ålesund measurements. The monthly mean $\tau(0.50 \mu \mathrm{m})$ values varied from 0.07 to 0.10 , with $\sigma_{\tau}=0.02$ on average, and those of $\alpha$ increased from $\sim 0.90$ to 1.40 during summer, with $\sigma_{\alpha}=0.2$. Therefore, these measurements differ only slightly from those measured at Ny-Ålesund over longer multi-year periods. The RFHs of the daily mean values of $\tau(0.50 \mu \mathrm{m})$ and $\alpha$ were prepared only for the 
summer-autumn period, and were found to have a seasonal mean value of $\tau(0.50 \mu \mathrm{m})=0.078$, with

583 the main percentiles differing by less than 0.02 from the mean. These values are appreciably higher 584 than those determined at Ny-Ålesund from the AWI and NILU data-sets. A summer-autumn mean 585 value of $\alpha=1.29$ was obtained, with only slightly differing values of the main percentiles, and a considerably narrower RFH curve than those from the AWI and NILU data-sets measured at Ny587 Ålesund.

588 The Ny-Ålesund results can also be compared in Fig. 6 with the AERONET measurements 589 recorded at Hornsund. The Hornsund results are in close agreement with those of Ny-Ålesund, since 590 the Hornsund monthly mean values of $\tau(0.50 \mu \mathrm{m})$ varied from 0.10 to no more than 0.12 in winter591 spring, with $\sigma_{\tau}=0.04$ on average, and from 0.06 to 0.08 in summer autumn, with $\sigma_{\tau}<0.03$. The monthly mean values of $\alpha$ were rather stable at Hornsund, mainly ranging from 1.20 to 1.50 , and showing small differences with respect to the AWI and NILU results. The Hornsund RFHs of $\tau(0.50 \mu \mathrm{m})$ show that the winter-spring daily mean values were on average higher than those obtained in summer-autumn, by more than 0.03 , with differences between the main seasonal percentiles no higher than 0.04 . Small variations in $\alpha<0.07$ were observed from one season to the other between the seasonal mean values and the main percentiles. The long-tailed left-hand wings of the RFHs of $\alpha$ determined during both seasons suggest that important extinction effects were presumably produced by the sea-salt accumulation/coarse mode particles during both seasons.

600 The seasonal variations in $\tau(0.50 \mu \mathrm{m})$ shown in Fig. 6 are mainly due to the different aerosol 601 extinction features produced over the Svalbard region by Arctic haze, especially in spring, and by 602 background aerosol in summer. They are in part associated with the significant seasonal mean 603 decrease in the mean concentration of sulphate particles measured within the atmospheric ground604 layer. For instance, on the basis of long-range routine measurements of particulate chemical 605 composition conducted at the Zeppelin station $\left(78^{\circ} 58^{\prime} \mathrm{N}, 11^{\circ} 53^{\prime} \mathrm{E}, 474 \mathrm{~m}\right.$ a.m.s.1.), near Ny606 Ålesund (Svalbard), Ström et al. (2003) estimated that the mean mass concentration of nss sulphate 
607 ions decreases on average with season, changing from about $3 \times 10^{-1} \mu \mathrm{g} \mathrm{m}^{-3}$ in March-April (for 608 frequent Arctic haze episodes) to around $5 \times 10^{-2} \mu \mathrm{g} \mathrm{m}^{-3}$ in late summer (for background aerosol 609 conditions). These features arise from the fact that the frequent Arctic haze episodes observed in 610 winter and spring over the Svalbard region are mainly due to aerosol transport from the Eurasian 611 area, rather than from North America or East Asia (Hirdman et al., 2010). The region north of 70 $612{ }^{\circ} \mathrm{N}$ is isolated in summer from the mid-latitude aerosol sources, as demonstrated by Stohl et al. 613 (2006), who analysed aerosol transport patterns into the Arctic. BFF smoke particles are 614 episodically transported over the Svalbard region in summer, from the Siberian region and 615 sometimes from North America (Tomasi et al., 2007; Stone et al., 2008). For instance, huge 616 emissions from BFFs in North America reached Svalbard (Stohl et al., 2006) in July 2004, while 617 agricultural fires in Eastern Europe caused very strong pollution levels in the Arctic during spring 6182006 (Stohl et al., 2007; Lund Myhre et al., 2007).

\subsubsection{Measurements in Scandinavian and Siberian regions}

621 Figure 7 shows the time-patterns of the monthly mean values of $\tau(0.50 \mu \mathrm{m})$ and $\alpha$ and the winter622 spring and summer-autumn RFHs of both parameters, derived from the sets of FMI/PFR and 623 AERONET sun-photometer measurements carried out at Sodankylä (Northern Finland), and the set 624 of AERONET measurements conducted at Tiksi in Northern-Central Siberia (Russia) (see Table 1).

625 The FMI/PFR monthly mean values of $\tau(0.50 \mu \mathrm{m})$ slowly increased from $\sim 0.05$ in February to 0.08 626 in May, remained quite stable from June to August, then slowly decreased to 0.05 in September627 October, with comparable values of $\sigma_{\tau}$ ranging mainly from 0.04 to \pm 0.06 , without showing clear 628 variations from winter-spring to summer-autumn. The monthly mean values of $\alpha$ increased from 629 about 1.10 in February to over 1.50 in July, and then gradually decreased to 0.75 in November. 630 Different time-patterns of the monthly mean values of $\tau(0.50 \mu \mathrm{m})$ and $\alpha$ were obtained from the 631 AERONET measurements conducted at Sodankylä over a shorter 7-year period, including only 
about a third of the daily PFR observations, and giving monthly mean values of $\tau(0.50 \mu \mathrm{m})$ varying

633 from 0.05 to 0.09 in winter-spring, and from 0.06 to 0.11 in summer, which then decreased to less 634 than 0.04 in September-October. The monthly mean values of $\alpha$ varied from 1.20 to 1.40 in winter635 spring, increasing to more than 1.70 in July and decreasing to nearly 1.00 in October.

636 To provide a more complete picture of the atmospheric turbidity features over Northern 637 Scandinavia, the time-patterns of the PFR and AERONET monthly mean values of $\tau(0.50 \mu m)$ and $638 \alpha$ obtained at Sodankylä are compared in Fig. 7 with those determined by Toledano et al. (2012) 639 analysing the $\tau(0.50 \mu \mathrm{m})$ and $\alpha$ data-sets collected at: (i) Kiruna $\left(67^{\circ} 51^{\prime} \mathrm{N}, 20^{\circ} 13^{\prime} \mathrm{E}, 580 \mathrm{~m}\right.$ 640 a.m.s.l.) in Northern Sweden (270 km WNW from Sodankylä) using the GAW-PFR sun641 photometer of the Swedish Meteorological and Hydrological Institute (SMHI) from 2007 to 2010 by, and (ii) Andenes/ALOMAR (69 $18^{\prime} \mathrm{N}, 16^{\circ} 01^{\prime} \mathrm{E}, 380 \mathrm{~m}$ a.m.s.l.) in Northern Norway, using the AERONET/RIMA Cimel CE-318 sun-photometer from 2002 to 2007. The Kiruna PFR results 644 are compared in Fig. 7 with those recorded at Sodankylä. The Kiruna monthly mean values of $645 \tau(0.50 \mu \mathrm{m})$ were rather stable over the whole measurement period, with $\sigma_{\tau}$ varying from 0.01 to 6460.04 , while the monthly mean values of $\alpha$ increased from 1.10 in February to nearly 1.60 in July, 647 and then decreased gradually to $\sim 1.00$ in August and 1.20 in October, with values of $\sigma_{\alpha}$ varying 648 from 0.10 to 0.25 . Thus, the Kiruna monthly mean values of $\tau(0.50 \mu \mathrm{m})$ closely agree with those 649 measured at Sodankylä and only exhibit small differences between the August-October monthly 650 mean values of $\alpha$.

651 A similar comparison is also made in Fig. 7 between the AERONET/FMI results obtained at 652 Sodankylä and the ALOMAR results derived from the AERONET/RIMA Cimel CE-318 sun653 photometer measurements at Andenes, from 2002 to 2007. The ALOMAR monthly mean values of $654 \tau(0.50 \mu \mathrm{m})$ increased from about 0.04 in February to 0.13 in May, and then slowly decreased to 655 around 0.11 in September-October, having values of $\sigma_{\tau}$ mainly varying from 0.04 to 0.06 . 656 Therefore, the ALOMAR evaluations of $\tau(0.50 \mu \mathrm{m})$ were in general considerably higher than those 
measured at Sodankylä, with differences comparable to the standard deviations. The ALOMAR monthly mean values of $\alpha$ varied at Andenes from about 0.85 to 1.05 in February-May, increased in the following months to $\sim 1.30$, and subsequently decreased in late summer and autumn to reach a 660 value close to 1.00 in October, with $\sigma_{\alpha}$ varying mainly from 0.20 in winter-spring to 0.40 in 661 summer-autumn. These findings indicate that the ALOMAR monthly mean values of $\alpha$ were 662 considerably higher than the AERONET evaluations obtained at Sodankylä, by about $15 \%$ on 663 average, presumably because of the more pronounced extinction effects by maritime particles.

664 The time-patterns of the monthly mean values of $\tau(0.50 \mu \mathrm{m})$ and $\alpha$ shown in Fig. 7, as obtained by 665 us at Sodankylä, and at Kiruna and Andenes by Toledano et al. (2012) differ appreciably from those 666 typically observed at the other Arctic sites located at higher latitudes and shown in Figs. 3-6. The 667 reason for such differences is that the air masses reaching Northern Scandinavia during the year 668 originate from the Eurasian continent and mid-latitude Atlantic Ocean in $56 \%$ of cases, and from 669 the Arctic Basin and Northern Atlantic Ocean in the remaining 44\% (Aaltonen et al., 2006). Due to 670 the alternation of polluted air masses from Eurasia with sea-salt particles from ocean areas, the 671 monthly mean values of $\tau(\lambda)$ were rather stable over the entire year, while the monthly mean values 672 of $\alpha$ were higher in early summer, when the Arctic Basin was the principal aerosol source. Because 673 of the efficient transport processes taking place during the year from continental polluted or ocean 674 areas, the FMI/PFR and AERONET Sodankylä RFHs of $\tau(0.50 \mu m)$ did not exhibit significant 675 differences between the seasonal mean values and the main percentiles defined in winter-spring and 676 summer-autumn. These had monthly mean values of around 0.08 and 0.07 in winter-spring, 677 respectively, with the main percentiles differing by no more than 0.01 , and summer-autumn 678 monthly mean values close to 0.07 on average, with differences of about 0.01 between the main 679 percentiles. The FMI/PFR and AERONET Sodankylä monthly mean values of $\alpha$ decreased by 0.10 6800.20 on average, from winter-spring to summer-autumn. Clearer discrepancies over both seasonal 681 periods were found, with FMI mean values of about 1.32 and 1.52 in winter-spring and summer- 
autumn, respectively, and AERONET mean values equal to 1.23 and 1.44 in the same two seasons,

683 providing similar values of the main seasonal percentiles.

684 A comparison between the winter-spring and summer-autumn estimates of $\tau(0.50 \mu m)$ and $\alpha$ was 685 not made at Tiksi, since AERONET sun-photometer measurements have been routinely conducted 686 at this remote Siberian site only over the May-October period. The monthly mean values of $\tau(0.50$ $\mu m$ ) exhibit a clear increase from $\sim 0.13$ in May to 0.16 in July, with large average values of $\sigma_{\tau}=$ 0.14 , followed by a marked decrease in the subsequent months to about $0.05 \pm 0.03$ in October. Such large variations in $\tau(0.50 \mu \mathrm{m})$ were associated with a slow decrease in the monthly mean values of $\alpha$ from 1.9 in May to $\sim 1.5$ in September, for which $\sigma_{\alpha} \leq 0.2$. The rather high values of $\tau(0.50 \mu \mathrm{m})$ and $\alpha$ determined in summer were probably due to the frequent BFF smoke transport episodes from the inner regions of Siberia. In fact, the summer-autumn RFH of $\tau(0.50 \mu m)$ exhibits a mean value close to 0.09 and a value of the $75^{\text {th }}$ percentile equal to 0.12 , which are both appreciably higher than those measured at Sodankylä in summer. The RFH of $\alpha$ yields a mean value of 1.57 , and shows a long-tailed left-hand wing with $25^{\text {th }}$ percentile of 1.39 , and a long-tailed right-hand wing with $75^{\text {th }}$ percentile of 1.74 . This rather high value is probably associated with small fine particles generated by combustion processes, which dominate extinction effects.

In summary, the Arctic results provide evidence of the seasonality of $\tau(0.50 \mu \mathrm{m})$ and $\alpha$. A scatter plot of the median values of $\alpha$ versus those of $\tau(0.50 \mu \mathrm{m})$ is shown in Fig. 8a, separately for the winter-spring and summer-autumn seasonal periods. Figure 8a shows that the median values of $\alpha$ vary from 1.10 to 1.70 over the whole year, with: (i) winter-spring median values of $\tau(0.50 \mu \mathrm{m})$ ranging from 1.20 to 1.50 over the $0.04-0.12$ range, and (ii) summer-autumn median $\tau(0.50 \mu m)$ values all smaller than 0.08 and mainly ranging from 1.30 to 1.70 . These features suggest that appreciable differences characterize aerosol extinction in: (a) winter-spring, when the median values of $\tau(0.50 \mu \mathrm{m})$ vary greatly from one Arctic site to another. This results from their dependency on the importance of particulate transport from the most densely populated mid-latitude 
regions toward the Arctic, which is particularly strong in late winter and early spring; and (b)

708 summer, when the background aerosol composition varies from one site to another, as a result of 709 different extinction characteristics of fine and coarse mode particles transported from remote 710 regions.

\subsubsection{Measurements in Antarctica}

713 Ground-based sun-photometer measurements of aerosol optical parameters have been conducted in 714 Antarctica during the short austral summer period. In the present study, nine multi-year sets of measurements made since 2000 have been analysed (see Table 2), collected at six coastal sites (Marambio, Neumayer, Novolazarevskaya, Mirny, Syowa, and Mario Zucchelli), a mid-altitude station (Troll) and two high-altitude sites (Dome Concordia and South Pole).

\subsubsection{Measurements at coastal and mid-altitude sites}

720 The results obtained from the sun-photometer measurements carried out at Marambio, Neumayer 721 and Troll are presented in Fig. 9. The Marambio measurements were conducted from September to 722 April, and provided monthly mean values of $\tau(0.50 \mu \mathrm{m})$ varying from $\sim 0.03$ in January to 0.06 in 723 March (with $\sigma_{\tau}$ varying from 0.02 to 0.04 ) and $\alpha$ ranging from 0.50 in March to 1.50 in November724 January (with $\sigma_{\alpha}=0.50$ on average). The austral summer RFHs exhibit regular features with mean 725 values of $\tau(0.50 \mu \mathrm{m})=0.038$ and $\alpha=1.20$, probably due to sea-salt particles, which dominate 726 extinction. The Neumayer measurements were conducted over the September-April period, showing 727 rather stable time-patterns of the monthly mean values of $\tau(0.50 \mu \mathrm{m})$, ranging from 0.04 to 0.06 728 (with $\sigma_{\tau}=0.03$ on average) and associated with very stable values of $\alpha$ varying from 0.50 to 1.00 729 (with $\sigma_{\alpha}=0.3$ on average), which indicate that aerosols are mostly of oceanic origin. The RFHs of 730 both optical parameters are similar to those determined at Marambio, showing mean values of $731 \tau(0.50 \mu \mathrm{m})=0.041$ and $\alpha=0.82$, confirming that these stable extinction features are mainly 
produced by sea-salt particles. The time-patterns of the monthly mean values of $\tau(0.50 \mu m)$ and $\alpha$

733 measured at Troll, about $235 \mathrm{~km}$ from the Atlantic Ocean coast in the Queen Maud Land, were also 734 quite stable from September to April, yielding values of $\tau(0.50 \mu \mathrm{m})$ varying from $\sim 0.02$ to 0.03 735 (with $\sigma_{\tau}<0.005$ ), and values of $\alpha$ slowly increasing from 1.25 in September to $\sim 1.50$ in January, 736 and then decreasing to 1.00 in April. The RFH of $\tau(0.50 \mu m)$ exhibits nearly symmetrical features 737 with little dispersion, with a mean value of 0.023 , and $25^{\text {th }}$ and $75^{\text {th }}$ percentiles equal to 0.019 and 7380.026 , respectively, while the RFH of $\alpha$ was also quite symmetrical over the $0.60-2.10$ range, with a 739 mean value of 1.42 and $25^{\text {th }}$ and $75^{\text {th }}$ percentiles differing by less than 0.4 one from the other. These 740 estimates of $\tau(0.50 \mu \mathrm{m})$ and $\alpha$ differ appreciably from those obtained at Marambio and Neumayer, 741 showing that the aerosol extinction features are only in part produced by maritime aerosols at this 742 mid-altitude site, and in part by fine mode particles, such as nss sulphate aerosols.

743 Figure 10 shows the results obtained from the measurements conducted at Novolazarevskaya 744 (Queen Maud Land) and Mirny (on the Davis Sea coast), using various sun-photometer models 745 during different years, as reported in Table 2. The monthly mean values of $\tau(0.50 \mu m)$ obtained at 746 Novolazarevskaya were very close to $0.02 \pm 0.01$ over the whole period, while $\alpha$ varied from about 7470.80 in November to 1.10 in January, with $\sigma_{\alpha}$ equal to 0.10 in the first two months and 0.50 in January and February. The RFH of $\tau(0.50 \mu \mathrm{m})$ exhibited a leptokurtic curve, with mean value close 749 to 0.02 , while a more dispersed distribution curve was shown by the RFH of $\alpha$, with the mean value 750 close to unity, and $25^{\text {th }}$ and $75^{\text {th }}$ percentiles differing by less than 0.20 from it. The monthly mean 751 values of $\tau(0.50 \mu \mathrm{m})$ determined at Mirny varied from 0.02 to 0.03 (with $\sigma_{\tau}=0.01$ ), and those of $\alpha$ 752 from 1.50 to 2.00 in September-January, which then slowly decreased to $\sim 1.20$ in April. The RFH of $\tau(0.50 \mu \mathrm{m})$ exhibited features which had a nearly symmetrical peak, with a mean value of 0.025 , 754 only slightly differing from that obtained at Novolazarevskaya, while the RFH of $\alpha$ was found to be 755 dispersed and platykurtic, having a mean value of 1.60 , and $25^{\text {th }}$ and $75^{\text {th }}$ percentiles differing by 756 more than 0.40 from the mean value. Therefore, it can be concluded that the aerosol extinction 
features shown in Fig. 10 are predominantly produced by sea-salt particles generated by winds over

758 the ocean, yielding values of $\alpha$ mainly ranging from 0.50 to 1.30 .

759 The results derived from the measurements conducted at Syowa and Mario Zucchelli are shown in

760 Fig. 11, as obtained using various sun-photometer models over the different periods reported in 761 Table 2. The monthly mean values of $\tau(0.50 \mu \mathrm{m})$ varied from less than 0.02 to $\sim 0.04$ over the 762 September-April period (with $\sigma_{\tau}<0.03$ ), while the monthly mean values of $\alpha$ were also very stable, 763 and described a large maximum of around 1.30 in December, with minima of $\sim 1.00$ in September 764 and $\sim 0.90$ in April. The RFH of $\tau(0.50 \mu \mathrm{m})$ assumed a mesokurtic shape, skewed to the right, with 765 the mean value close to 0.02 , while the RFH of $\alpha$ exhibited mesokurtic and symmetrical features, 766 arising from sea-salt particles, which caused the predominant extinction. The ISAC-CNR 767 measurements conducted at Mario Zucchelli provided the time-patterns of the monthly mean values 768 of $\tau(0.50 \mu \mathrm{m})$ shown in Fig. 11, which were close to 0.02 in November and December (with $\sigma_{\tau}=$ 7690.01 ) and then increased to $\sim 0.04$ in January and February (with $\sigma_{\tau}=0.02$ ), while the monthly 770 mean values of $\alpha$ were stable and very close to 1.00 from November to January, and equal to $\sim 0.80$ 771 in February (with $\sigma_{\alpha}$ not exceeding 0.30). The RFHs of $\tau(0.50 \mu \mathrm{m})$ and $\alpha$ were found to exhibit 772 more dispersed features than those determined at Syowa and both Russian stations, giving mean 773 values equal to 0.04 and 0.96 , respectively. However, they clearly indicate that aerosol extinction is mainly due to sea-salt particles at this coastal site, yielding values of $\alpha$ ranging in general from 0.50 to 1.30 .

\subsubsection{Measurements at the high-altitude sites on the Antarctic Plateau}

778 The results obtained analysing the sun-photometer measurements conducted since 2000 at the Dome Concordia and South Pole high-altitude sites are shown in Fig. 12. The measurements were conducted by five groups using different instruments over distinct periods, as reported in Table 2 . 
subsidence processes on the aerosol load, the time-patterns of the monthly mean values of $\tau(0.50$ um) determined at Dome Concordia with different sun-photometers were found to be very stable, mainly ranging from 0.02 to 0.04 (with $\sigma_{\tau}$ evaluated to be $\leq 0.01$ ) in September-April. The corresponding monthly mean values of $\alpha$ mainly varied from 1.00 to 2.00 , with $\sigma_{\alpha}=0.20$ on average. The RFH of $\tau(0.50 \mu \mathrm{m})$ exhibited a well-marked leptokurtic shape, with a mean value close to 0.02 , while the RFH of $\alpha$ showed dispersed features over the 0.5-2.2 range, with a mean value close to 1.40 , and $25^{\text {th }}$ and $75^{\text {th }}$ percentiles equal to about 1.0 and 1.80 , respectively.

The South Pole multi-year measurements conducted by GMD/NOAA at the Amundsen-Scott base were found to provide very stable time-patterns of the monthly mean values of $\tau(0.50 \mu \mathrm{m})$, mainly ranging from September to March from $\sim 0.02$ and 0.04 (with $\sigma_{\tau}=0.01$ on average), and monthly mean values of $\alpha$ varying from 1.00 to 2.00, with the highest values in October and November (with $\sigma_{\alpha}=0.10$ on average). The AERONET monthly mean values of $\tau(0.50 \mu \mathrm{m})$ were found to increase from about 0.01 to 0.02 over the November-February period, with $\sigma_{\tau}=0.01$ on average, the uncertainty of these measurements being primarily due to both calibration (estimated by Eck et al. (1999) to be of $\sim 0.01$ in the visible), and forward scattered light entering the instrument (Sinyuk et al., 2012). Very stable monthly mean values of $\alpha \sim 1.00$ were correspondingly found, with $\sigma_{\alpha}=$ 0.50 on average. Both RFHs of $\tau(0.50 \mu \mathrm{m})$ derived from the GMD/NOAA and AERONET measurements assumed very narrow and "peaked" curves, with mean values of around 0.02 , which appeared to be slightly skewed to the right. The corresponding RFHs of $\alpha$ presented dispersed features over the 0.50-2.00 range, with mean values of 1.54 and 1.06. Although such clearly dispersed results suggest the presence of an important fraction of large-size particles, it is important to take into account that a predominant particulate mass fraction of around $66 \%$ was estimated to consist of nss sulphates at South Pole, with lower concentrations of nitrates and sea-salt particles (Arimoto et al., 2004; Tomasi et al.2012), mainly associated with the background transport of aerosols from very remote sources and the strong effects exerted by subsidence processes. A few 
cases showing values of $\alpha<0.50$ were probably caused by consistent loads of diamond dust icecrystals within the lower planetary boundary layer (hereinafter referred to as PBL), due to wind 809 mobilization.

810 The covariance of the median values of $\tau(0.50 \mu \mathrm{m})$ and $\alpha$ obtained at the nine Antarctic sun811 photometer stations is shown in Fig. 13a. There are two clusters: (i) the first at coastal sites, where 812 the median values of $\tau(0.50 \mu \mathrm{m})$ were in general considerably higher (at least by a factor two) than 813 those found at the high-altitude Antarctic sites, and the median values of $\alpha$ are in general smaller 814 than 1.20, and (ii) the second cluster, with lower median values of $\tau(0.50 \mu \mathrm{m})$ and median values of $815 \alpha>1.40$, for which aerosol extinction is predominantly due to sea-salt coarse particles. It is 816 interesting to note that lower median values of $\tau(0.50 \mu \mathrm{m})$ associated with higher values of $\alpha$ were 817 observed at the coastal sites of Mirny and Marambio, probably because of aeolian fine particles, 818 which dominated extinction effects when compared to sea-salt particles. The median values of $819 \tau(0.50 \mu \mathrm{m})$ and $\alpha$ determined at the Troll mid-altitude station indicate that the extinction effects 820 exhibit intermediate features at this non-coastal site. This can probably be attributed in part to sea821 salt aerosol and in part to background nss sulphate aerosol transported over large distances, which 822 themselves contribute toward an appreciable enhancement in $\alpha$. As can be seen in Fig. 13a, the 823 weak median values of $\tau(0.50 \mu \mathrm{m})$ and relatively strong median values of $\alpha$ at Dome Concordia and 824 South Pole (the latter being partially obscured by the DMC-OPAR symbol) show that atmospheric 825 aerosol extinction is rather weak above the Antarctic Plateau and mainly produced by fine particles 826 consisting of nss sulphates. The lower extremes of the $\alpha$ error bars and the low $\alpha$ value of the 827 AERONET South Pole point are likely due to near-surface diamond dust layers that are observed on 828 windy, cloud-free days at these sites.

\section{Ship-borne measurements.}


831 A large number of ship-borne measurements of the main columnar aerosol radiative parameters $\tau(\lambda)$

832 and $\alpha$ were made over the Arctic and Antarctic oceanic regions during the past 10 years. The 833 cruises were conducted by research groups and institutions from different countries, using hand834 held Microtops II sun-photometers calibrated at the NASA/GSFC calibration facility. As can be 835 seen in Fig. 2, large areas of the polar oceans were studied during these cruises, yielding an 836 exhaustive picture of aerosol optical characteristics in these high-latitude remote regions. These 837 ship-borne sun-photometer measurements were conducted as a part of the activities promoted and 838 developed in the framework of the Maritime Aerosol Network (MAN), which is a component of the 839 AERONET network (see http://aeronet.gsfc.nasa.gov/new_web/maritime_aerosol_network.html). 840 The measurements of $\tau(\lambda)$ were carried out at visible and near-infrared wavelengths. Arctic Ocean 841 cruises are listed in Table 3, while those taken in the oceanic regions around Antarctica are listed in 842 Table 4. The hand-held Microtops II sun-photometers are equipped with five narrow-band 843 interference filters with peak-wavelengths of 0.340 (or 0.380 ), $0.440,0.675,0.870$ and $0.936 \mu \mathrm{m}$ for 844 most cruises, or $0.440,0.500,0.675,0.870$ and $0.936 \mu \mathrm{m}$ in other cruises, as reported in Tables 3 845 and 4. The first four filters of each spectral set were used to measure the spectral values of $\tau(\lambda)$ and 846 determine the best-fit value of exponent $\alpha$ over the wavelength range from 0.440 to $0.870 \mu \mathrm{m}$, 847 while the measurements taken at $0.936 \mu \mathrm{m}$ were combined with those made within the nearby 848 channel centred at $0.870 \mu \mathrm{m}$ to evaluate precipitable water (Smirnov et al., 2009). Among the data849 sets available at the MAN website, we only selected measurements conducted since 2006 at 850 latitudes higher than $67^{\circ} \mathrm{N}$ in the Arctic and within ocean areas far by no more than $1000 \mathrm{~km}$ from 851 the Antarctic coasts. In addition, the measurement sets obtained by Tomasi et al. (2007) during the 852 RV Oceania cruises made in the summer months of 2003 and 2006 were included in the present 853 analysis. 
Fourteen Arctic Ocean cruises were selected for this study, as summarized in Table 3. The data-set

857 collected during the cruise of RV Polarstern (Alfred Wegener Institute (AWI), Bremerhaven, 858 Germany) in August-September 2009 was not examined to evaluate the background tropospheric 859 aerosol extinction features, because these measurements were found to be strongly affected by the 860 extinction of stratospheric volcanic aerosols generated by the Sarychev eruption in July-October 861 2009. No evidence of Sarychev volcanic particle extinction at stratospheric levels was found in 862 CALIPSO (Cloud-Aerosol Lidar and Infrared Pathfinder Satellite Observations) data recorded over 863 the Beaufort Sea (O'Neill et al., 2012) during the CCGS Amundsen cruise of August 2009. 864 Therefore, this set of measurements was used to calculate the extinction effects associated in 865 August 2009 with the BFF smoke particles transported from the North-American forests over the 866 Arctic Ocean. In order to study the aerosol extinction features of the Arctic Ocean, the 14 Microtops 867 sun-photometer data-sets collected during the above-selected MAN cruises were subdivided into 868 three sub-sets pertaining to the following large-scale oceanic sectors: (a) Northern Greenland Sea 869 and Norwegian Sea (hereinafter referred to as GNS sector), between $20^{\circ} \mathrm{W}$ and $30^{\circ}$ E longitudes; 870 (b) Barents Sea and West Siberian Sea (BWS sector), between $30^{\circ} \mathrm{E}$ and $130^{\circ} \mathrm{E}$ longitudes; and (c) 871 the North American Arctic Ocean (NAA sector), including the East Chukchi Sea, the Bering Strait, 872 the Beaufort Sea and the Amundsen Gulf, between $170^{\circ} \mathrm{W}$ and $110^{\circ} \mathrm{W}$ longitudes. No MAN 873 cruises were carried out in the East Siberian Sea and West Chukchi Sea sectors, at latitudes higher 874 than $67^{\circ} \mathrm{N}$ and longitudes ranging from $130^{\circ} \mathrm{E}$ to $170^{\circ} \mathrm{W}$, as well as in the Canadian sector from $875110^{\circ} \mathrm{W}$ to $20^{\circ} \mathrm{W}$ longitudes, including the Baffin Bay, the Davis Straits and the Northern Atlantic 876 Ocean.

877 The same criteria as used for the ground-based stationary sun-photometer measurements taken at 878 the various Arctic sites were also adopted to examine the ship-borne measurements, including the 879 selection of data made to reject all the measurements affected by stratospheric volcanic particle 880 extinction. The daily mean values of $\tau(0.50 \mu \mathrm{m})$ and $\alpha$ obtained from the data-sets collected within 881 each of the three oceanic sectors were subdivided into monthly sub-sets to determine the monthly 
mean values of both parameters, and define their RFHs separately for the winter-spring (Arctic haze) and summer-autumn (background aerosol) periods. The main purpose of the analysis was to provide evidence of the seasonal characteristics of aerosol optical parameters in the Arctic Ocean areas far from anthropogenic aerosol sources.

\subsubsection{Northern Greenland Sea and Norwegian Sea.}

Monthly mean values of $\tau(0.50 \mu \mathrm{m})$ and $\alpha$ derived from the Microtops measurements performed during nine cruises made in the Norwegian Sea, west of Spitsbergen, and one cruise in the northern Greenland Sea and Norwegian Sea are shown in Fig. 14a. Values of $\tau(0.50 \mu \mathrm{m})$ gradually decreased from less than 0.10 in April to nearly 0.05 in August, with values of $\sigma_{\tau}<0.03$ over the entire period. The monthly mean values of $\alpha$ were rather stable from April to August, ranging from 1.20 to 1.30 , with values of $\sigma_{\alpha}$ equal to 0.10 in spring and 0.40 in summer. These features suggest that the columnar aerosol content was mixed in spring, consisting of anthropogenic (Arctic haze) and natural sea-salt aerosols, and contained sea-salt aerosol mixed with BFF smoke particles in summer. In fact, the aerosol extinction parameters measured in spring and summer with the Microtops sunphotometers turn out to be very similar to those determined at Ittoqqortoormiit and Hornsund from the AERONET sun-photometer measurements, during spring (when polluted air masses are mainly transported from Europe) and summer (when polar air masses are transported from the Arctic land and oceanic regions toward the Svalbard Archipelago) (Rozwadowska et al., 2010; Rozwadowska and Sobolewski, 2010). These variable features can be more clearly seen by considering the seasonal RFHs of $\tau(0.50 \mu \mathrm{m})$ and $\alpha$ shown in Fig. 14b, derived from the measurements taken on 77 measurement days in the Greenland Sea and Norwegian Sea (GNS) sector. The RFH of $\tau(0.50 \mu m)$ exhibits a large peak over the $0.02-0.20$ range, with a mean value equal to 0.075 , and $25^{\text {th }}$ and $75^{\text {th }}$ percentiles equal to 0.054 and 0.094 , respectively, indicating significant variations even in the remote Arctic Ocean. The corresponding RFH of $\alpha$ is also rather wide, showing a mean value of 
9071.23 , and $25^{\text {th }}$ and $75^{\text {th }}$ percentiles equal to 1.02 and 1.47 , respectively, as a result of the 908 combination of natural maritime and anthropogenic/continental aerosol loads. It is worth noticing 909 that the GNS average values of $\tau(0.50 \mu \mathrm{m})$ and $\alpha$ agree fairly well with those determined at 910 Ittoqqortoormiit (Fig. 5) and Hornsund (Fig. 6) and exhibit similar relationships between $\alpha$ and $911 \tau(0.50 \mu \mathrm{m})$ to those of the above-mentioned AERONET stations (compare Fig. 8a with those of Fig. $9128 b)$.

\subsubsection{Barents Sea and West Siberian Sea}

915 Only the RV Polarstern 2012 cruise crossed the Barents Sea and West Siberian Sea (BWS) sector, 916 in August 2012 , at latitudes varying from $80^{\circ} \mathrm{N}$ to $84^{\circ} \mathrm{N}$ and longitudes ranging from $28^{\circ} \mathrm{E}$ to $120^{\circ}$ 917 E (see Fig. 2). Thus, the monthly mean values of $\tau(0.50 \mu \mathrm{m})$ and $\alpha$ were only calculated for three 918 measurement days, giving statistically poor values of $\tau(0.50 \mu \mathrm{m})=0.054 \pm 0.010$ and $\alpha=1.42 \pm$ 919 0.33. As noted in Fig. 14a, the above value of $\tau(0.50 \mu \mathrm{m})$ closely agrees with that measured within 920 the GNS sector on the same month, and $\alpha$ is slightly higher than that measured in August within the 921 same sector. Such results are typical of an oceanic area during relatively calm wind periods.

\subsubsection{North American Arctic Ocean}

924 Within the North American Arctic (NAA) oceanic sector, including the East Chukchi Sea, Bering 925 Strait, Beaufort Sea and Amundsen Gulf, only four cruises were considered among those reported in 926 Table 3. The time-patterns of the monthly mean values of $\tau(0.50 \mu \mathrm{m})$ and $\alpha$ calculated over the 927 March-September period are shown in Fig. 14a. Monthly mean value of $\tau(0.50 \mu \mathrm{m})$ were about 0.10 928 in March, peaked in April and May at 0.17 and 0.20, respectively, and decreased in the summer 929 months to 0.10 in June and 0.05 in September. No pronounced variations in $\alpha$ were obtained, with 930 values from 0.90 to 1.20 from March to September, and $\sigma_{\alpha}$ varying from 0.20 (in April) to 0.50 (in 931 July). An overall number of 58 measurement days was collected in this oceanic sector over the 7- 
month period from March to September, for which calculations of the RFHs were made, illustrating

933 a statistically robust data-set. The RFH of $\tau(0.50 \mu \mathrm{m})$ showed a more dispersed distribution curve 934 over the 0.02-0.25 range than that determined for the GNS sector, with a mean value of 0.16 , which 935 was considerably higher than that measured in the GNS sector, and also had wider right-hand 936 wings. The RFH of $\alpha$ exhibits a similar shape to that determined in the GNS sector, with a mean 937 value close to 1.10 .

938 The median values and the $25^{\text {th }}$ and $75^{\text {th }}$ percentiles of parameters $\tau(0.50 \mu \mathrm{m})$ and $\alpha$ were calculated 939 for the sets of daily mean values derived from the Microtops sun-photometer measurements 940 conducted over the GNS, BWS and NAA sectors. The results are shown in Fig. 8b for an easier 941 comparison with those derived from the ground-based sun-photometer measurements conducted at 942 Arctic sites. The ship-borne measurements provided median values of $\tau(0.50 \mu \mathrm{m})$ ranging from 0.04 943 to about 0.13 , which are therefore comparable with the mean background extinction parameter 944 measured in summer at the ground-based stations. The ship-borne median values of $\alpha$ varied mainly 945 from 1.10 to 1.50 , and were appreciably lower than those measured in summer-autumn at the land 946 stations: the scatter plot shown in Fig. 8b provides clear evidence of the prevailing oceanic origins 947 of these aerosol loads.

\subsection{Aerosol measurements in the Antarctic Ocean.}

950 Eighteen AERONET/MAN cruises were conducted from 2006 to early 2013 over the Antarctic

951 Oceans. They are listed in Table 4, together with the geographical areas covered by the various 952 cruises, the number of measurements days (see also Fig. 2), the measurement periods and the 953 spectral characteristics of the portable Microtops sun-photometers onboard the vessels. To analyze 954 the aerosol optical parameters more homogeneously, the sun-photometer data-sets recorded during 955 the 18 cruises were subdivided into the following four sub-sets: (1) the Southern Indian Ocean 956 (IND) sector, between $20^{\circ} \mathrm{E}$ and $150^{\circ}$ E longitudes; (2) the Southern Pacific Ocean (PAC) sector, 957 between $150^{\circ} \mathrm{E}$ and $75^{\circ} \mathrm{W}$ longitudes; (3) the Southern Atlantic Ocean (ATL) sector, between $50^{\circ}$ 
$958 \mathrm{~W}$ and $20^{\circ} \mathrm{E}$ longitudes; and (4) the oceanic region around the Antarctic Peninsula (APE), between $95975^{\circ}$ and $50^{\circ} \mathrm{W}$ longitudes. The daily mean values of $\tau(0.50 \mu \mathrm{m})$ and $\alpha$ measured with the portable 960 Microtops sun-photometers calibrated at NASA/GSFC facility (Smirnov et al., 2009, 2011) were 961 analysed separately for coastal data (for distances smaller than $300 \mathrm{~km}$ from the Antarctic coast) 962 and off-shore data (for distances of 300 to $1000 \mathrm{~km}$ from the coast), according to the criteria used 963 by Wilson et al. (2010) to distinguish the data related to a significant landmass from those of pure 964 oceanic origin (i.e., given for the large part by maritime aerosols generated by wind-related sources). The overall set of Microtops data was then examined following the same criteria adopted to analyse the Arctic ship-borne measurements, separately for the above-mentioned four oceanic 967 sectors.

\subsubsection{Southern Indian Ocean}

As can be seen in Table 4, eleven cruises were conducted in the Southern Indian Ocean, during

971 periods from December to March in the years from 2005/2006 to 2011/2012, collecting an overall 972 set of 226 coastal measurement days, and only nine off-shore measurement days (see Fig. 2). The 973 time-patterns of the monthly mean values of $\tau(0.50 \mu \mathrm{m})$ and $\alpha$ are shown in Fig. 15a for coastal and 974 off-shore data. AOT values of $\tau(0.50 \mu \mathrm{m})$ were rather stable from December to April over the 975 coastal areas, varying from 0.010 to 0.025 , with $\sigma_{\tau}= \pm 0.01$ on average, and were appreciably 976 greater over the off-shore area, being close to $\sim 0.06$ in January, 0.04 in November and December, 977 and 0.02 in February. The coastal values of $\alpha$ varied from 1.20 to 1.40 in the December-April 978 period, while the off-shore values decreased from 1.20 to less than 0.60 from November to 979 December, and then slowly increased to around 0.90 in February. These findings give a measure of 980 the increase in $\tau(\lambda)$ and the variations in $\alpha$, which are observed passing from coastal to off-shore 981 areas as a result of the stronger production of sea-salt coarse particles. The daily mean values of $982 \tau(0.50 \mu \mathrm{m})$ and $\alpha$ were derived over the Southern Indian Ocean on 226 measurement days near the 
Antarctic coasts, and on only nine days in off-shore areas. Therefore, only the RFHs of the coastal daily mean values of $\tau(0.50 \mu \mathrm{m})$ and $\alpha$ have been analysed: the RFH of $\tau(0.50 \mu \mathrm{m})$ shown in Fig. $15 \mathrm{~b}$ presents a very narrow curve, with a mean value of 0.024 , and $25^{\text {th }}$ and $75^{\text {th }}$ percentiles very close to the mean, while the RFH of $\alpha$ exhibits a broad curve, with a mean value of 1.20 and $25^{\text {th }}$ and $75^{\text {th }}$ percentiles equal to 0.84 and 1.51 . These findings clearly indicate that a large variability characterizes the sea-salt accumulation and coarse mode particle concentrations in coastal areas.

\subsubsection{Southern Pacific Ocean}

991 As reported in Table 4, only three AERONET/MAN cruises were conducted in the Southern Pacific 992 Ocean over the December-January periods of 2007/2008 to 2009/2010, over the area defined in Fig. 993 2, giving an overall number of 20 coastal and 5 off-shore measurement days. The monthly mean 994 values of $\tau(0.50 \mu \mathrm{m})$ and $\alpha$ varied from 0.03 to 0.04 near the coasts, and from 0.04 to 0.05 in the 995 off-shore areas, while the coastal monthly mean values of $\alpha$ decreased from $\sim 1.45$ in December to $996 \sim 1.00$ in January, and the off-shore values from 1.40 to 0.70 . The values of $\tau(0.50 \mu m)$ and $\alpha$ result 997 to closely agree with those measured at Neumayer, Novolazarevskaya, Mirny, Syowa, and Mario 998 Zucchelli, shown in Figs. 9-12. A coastal median value of $\tau(0.50 \mu \mathrm{m})$ equal to $\sim 0.04$ was obtained, 999 with the main percentiles differing by less than 0.02 , while the median value of $\alpha$ was equal to 1.20 , 1000 with the main percentiles differing by about 0.50 . The off-shore data-set provided a similar value of $1001 \tau(0.50 \mu \mathrm{m})$ and more distant main percentiles, with a median value of $\alpha=1.15$, and main 1002 percentiles differing by more than 0.40 .

\subsubsection{Southern Atlantic Ocean}

1005 A large set of AERONET/MAN sun-photometer measurements was collected in the Southern 1006 Atlantic Ocean during five cruises conducted in 2007/2008, 2011/2012 and 2012/2013, as reported 1007 in Table 4, giving 63 coastal and only 8 off-shore measurement days. The monthly mean values of 
$1008 \tau(0.50 \mu \mathrm{m})$ varied from 0.03 in December to less than 0.02 in April, with $\sigma_{\tau}=0.01$ on average,

1009 while those of $\alpha$ increased from $\sim 1.10$ in December to 1.50 in February, and then decreased to 1.30

1010 in April. The RFH of the coastal $\tau(0.50 \mu \mathrm{m})$ values was found to exhibit similar features to those

1011 determined in the coastal area of the Antarctic Indian Ocean, with a leptokurtic shape having a

1012 mean value of 0.025 and the $25^{\text {th }}$ and $75^{\text {th }}$ percentiles differing by less than 0.01 , while the RFH of

$1013 \alpha$ showed a rather broad shape over the 0.5-2.4 range, with a mean value of 1.39 and the $25^{\text {th }}$ and

$101475^{\text {th }}$ percentiles differing by about 0.30 , thus being similar to that determined for the Pacific Ocean 1015 coastal data-set.

1016

1017 3.2.4. Around the Antarctic Peninsula

1018 Numerous aerosol optical data were collected in coastal areas surrounding the Antarctic Peninsula 1019 during the seven AERONET/MAN cruises conducted from 2007/2008 to 2012/2013, as reported in 1020 Table 4, collecting an overall number of 49 measurement days, not far from the coasts. The time1021 patterns of monthly mean values of $\tau(0.50 \mu \mathrm{m})$ and $\alpha$ obtained from these measurements are shown 1022 in Fig. 15b. A very high value of $\tau(0.50 \mu \mathrm{m})$ close to 0.12 was obtained in October, followed by 1023 decreasing monthly mean values equal to 0.08 in November and lower than 0.06 in December, and 1024 then varying from 0.04 to 0.06 over the January-March period, with $\sigma_{\tau}=0.02$ on average. The 1025 monthly mean values of $\alpha$ were all rather low, varying from 0.50 to 1.00 over the October-February 1026 period, with $\sigma_{\alpha}=0.20$ on average. The exceptionally high monthly mean values of $\tau(0.50 \mu m)$ were 1027 determined in October and November for measurement days giving values of $\alpha$ varying from 0.24 1028 to 0.69 , and presenting prevailing transport of air masses from the off-shore areas of the Drake 1029 Passage. Similar aerosol optical characteristics were observed by Posyniak and Markowicz (2009) 1030 for flows from the North-Eastern quadrant, accompanied by low visibility conditions because of the 1031 transport of large amounts of sea-salt particles from the Drake Passage, with wind speed $>10 \mathrm{~m} / \mathrm{s}$. 1032 Relatively low daily mean values of $\alpha$ were measured on these days, ranging from 0.43 to 0.73 , due 
1033 to maritime aerosols generated by the strong winds, which dominated extinction. For southerly 1034 wind circulation, considerably lower values of $\tau(0.50 \mu \mathrm{m})$ were measured in this coastal area. 1035 Therefore, because of the large variability of wind directions, the RFH of $\tau(0.50 \mu m)$ determined 1036 over the October-March period exhibited rather dispersed features, with a mean value of $\sim 0.05$ and 1037 the $25^{\text {th }}$ and $75^{\text {th }}$ percentiles differing by less than 0.02 . These evaluations are higher by about a 1038 factor 2 than those obtained over the coastal areas of the Indian and Atlantic Oceans, because of the 1039 more significant contribution of sea-salt accumulation and coarse mode particles generated by 1040 stronger winds. The RFH of $\alpha$ shows a rather broad shape over the range $\alpha<1.5$, with a mean 1041 value close to 0.70 , which is about half of that measured over the Indian and Atlantic Ocean coastal 1042 areas, and the $25^{\text {th }}$ and $75^{\text {th }}$ percentiles differing by no more than 0.30 , due to the predominant 1043 extinction by maritime particles.

1044 The above results obtained from the coastal and off-shore data recorded over the four sectors of the 1045 Southern Antarctic Ocean are characterized by features of $\tau(0.50 \mu \mathrm{m})$ and $\alpha$ typical of sea-salt 1046 maritime particles, as can be clearly seen in Fig. 13b, in which the median values of $\alpha$ are plotted 1047 versus the median values of $\tau(0.50 \mu \mathrm{m})$, separately for the coastal and off-shore data. The 1048 comparison between these results and the scatter plot shown in Fig. 13a shows that they are very 1049 similar to those derived from the sun-photometer measurements conducted at the coastal Antarctic 1050 stations, since the cluster derived from the AERONET/MAN measurements of $\alpha$ and $\tau(0.50 \mu m)$ 1051 essentially covers the same domain of the ground-based measurements recorded at Marambio, 1052 Novolazarevskaya, Syowa, Neumayer, and Mario Zucchelli, although exhibiting slightly lower 1053 values of $\alpha$.

\section{Aerosol backscattering coefficient profiles from lidar measurements}

1056 Lidar sends a light pulse through the atmosphere and the telescope collects the backscattered lidar 1057 return signal. As the speed of light is known, one can easily calculate the exact atmospheric 
1058 position, from which the lidar signal has originated. Therefore, the determination of aerosol vertical 1059 structure is possible, at least over the altitude range in which the image of the laser is completely 1060 within the field-of-view of the recording telescope. Lidar pulses can be generated at several 1061 wavelengths and polarization elements can also be used at the point of light entrance to the 1062 telescope. This enables a determination of the shape of scatterers because spherical particles do not 1063 depolarize light, while non-spherical particles normally do.

1064 Overcoming the considerable operational and logistic difficulties, various lidar systems have been 1065 deployed in the polar regions to measure: (i) the vertical profiles of backscatter and extinction 1066 coefficients of the various aerosols, cloud droplets and ice crystals, as well as their microphysical 1067 and radiative characteristics; (ii) the vertical distribution of temperature and water vapour mixing 1068 ratio; and (iii) the ozone concentration at stratospheric levels, to more thoroughly investigate the 1069 role of Polar Stratospheric Clouds in destroying ozone molecules at polar latitudes. Actually, most 1070 of these measurements were conducted to study the dynamic features of the ozone hole in 1071 Antarctica and ozone depletion in the Arctic region associated with the polar vortex occurrences, 1072 and the physical characteristics of tropospheric clouds, while relatively few measurement 1073 campaigns were specifically conducted with lidar techniques to investigate the optical 1074 characteristics of tropospheric aerosols at polar latitudes. An exhaustive description of the lidar 1075 measurements conducted in polar regions over the past few decades was recently made (Nott and 1076 Duck, 2011). Lidar activities were conducted in the Arctic at the following sites:

1077 (i) Barrow (Northern Alaska), where long-term lidar measurements were recorded and a micropulse 1078 lidar is currently used to carry out cloud climatology studies that have evaluated average seasonal 1079 cloud occurrences of $65 \%$ in winter, $68 \%$ in spring, $83 \%$ in summer, and $89 \%$ in autumn, with an 1080 annual mean decrease of $-4.8 \%$ per year over the past 10 years (Dong et al., 2010).

1081 (ii) Eureka (Nunavut, Canada)), where an elastic lidar was used from 1993 to 1997 to carry out 1082 winter-time aerosol measurements for studying the occurrences of clouds and Arctic haze. 1083 Backscatter peaks due to haze particle layers were frequently observed at altitudes lower than $3 \mathrm{~km}$, 
1084 and more occasionally at altitudes of $3-5 \mathrm{~km}$, for relative humidity $<60 \%$ over ice, while clouds

1085 dominate at $>80 \%$ over ice. Spectral measurements of the aerosol backscatter coefficient $\beta_{b s}(\lambda)$ and 1086 depolarization ratio $\delta_{V}(\lambda)$ were regularly conducted from 2005 to 2010, over the height range from $108770 \mathrm{~m}$ up to approximately $15 \mathrm{~km}$, using a High Spectral Resolution Lidar (HSRL) of the University 1088 of Wisconsin (USA), at the wavelengths 0.532 and $1.064 \mu \mathrm{m}$, for the aerosol backscatter coefficient $1089 \beta_{b s}(\lambda)$, and $0.532 \mu \mathrm{m}$ only for $\delta_{V}(\lambda)$ and $\beta_{\text {ext }}(\lambda)$. This lidar system was used together with a 1090 millimeter cloud radar to classify the various cloud particle types. Since 2008, a troposphere ozone1091 DIAL (Differential Absorption Lidar) and a Raman lidar have been operated simultaneously, 1092 equipped with aerosol channels in the visible and ultraviolet light and water vapour and rotational 1093 Raman temperature channels.

1094 (iii) Alert (Nunavut, Canada), where an elastic lidar was operated in 1984-1986 to measure the 1095 vertical profiles of aerosol backscatter coefficient.

1096 (iv) Summit (Central Greenland), where a depolarization lidar and a micropulse lidar were used 1097 since 2010, to characterize the aerosol types suspended over the Greenland ice-sheet.

1098 (v) Ny-Ålesund (Spitsbergen, Svalbard), where various lidar models were used, such as: (a) a 1099 stratospheric lidar since 1988; (b) the KARL (Koldewey-Aerosol-Raman-Lidar) since 1999, this 1100 system being equipped with aerosol channels, depolarization and ultraviolet and visible water 1101 vapour channels, and subsequently rebuilt in 2008 with enhanced multi-wavelength aerosol 1102 channels to cover the 0.45-30 km altitude range; and (c) an automated micropulse lidar (Hoffmann 1103 et al., 2009) since 2003, as a part of the MPLNET and NDACC networks, which provided cloud 1104 and aerosol measurements in March and April 2007, useful to characterise air masses as a function 1105 of depolarization and backscatter ratios.

1106 (vi) Hornsund (Spitsbergen, Svalbard), where an automated lidar has been operated since 2009, to 1107 measure the vertical profiles of volume extinction coefficient $\beta_{\text {ext }}(0.532 \mu \mathrm{m})$ produced by aerosols 
1108 during transport episodes of unpolluted air masses from the Greenland Sea and Norwegian Sea

1109 areas; and

1110 (vi) Andøya Rocket Range (Arctic Lidar Observatory for Middle Atmosphere Research,

1111 ALOMAR), near Andenes (Northern Norway), where a tropospheric lidar was installed in 2005 and

1112 a polarization-sensitive bistatic lidar system has been used since 2006 to study the vertical

1113 distribution features of polar aerosols and their optical characteristics.

1114 The above-mentioned field measurements provided vertical profiles of the most significant aerosol 1115 scattering parameters, illustrating that the Arctic haze particles are in general present below the 3

$1116 \mathrm{~km}$ level during severe haze events, and occasionally at 3-5 $\mathrm{km}$ altitudes, as shown by the 1117 measurements conducted at Eureka (Nott and Duck, 2011). During the dense haze episode observed 1118 with the KARL lidar at Ny-Ålesund on May 2, 2006, strong extinction features were recorded from 1119 the ground up to $2.5 \mathrm{~km}$ altitude, which showed multi-layered profiles of the aerosol backscattering 1120 coefficient $\beta_{b s}(0.532 \mu \mathrm{m})$ decreasing on average from $3.5 \mathrm{~km}^{-1}$ near the ground to below $0.5 \mathrm{~km}^{-1}$ at $11212.5 \mathrm{~km}$ altitude. Conversely, for unpolluted air conditions, the scale height of $\beta_{b s}(0.532 \mu m)$ was 1122 often found to vary from 1.0 to $1.3 \mathrm{~km}$ at Ny-Ålesund, as estimated for instance by Hoffmann et al. 1123 (2012) who examined the backscatter ratio measurements conducted with the KARL lidar over the 1124 whole of 2007.

1125 However, so far our knowledge of Arctic haze from a lidar point of view is still incomplete, because 1126 the majority of published results are based on case studies. Therefore, the yearly cycle of aerosols 1127 has been studied in this paper on the basis of the lidar measurements conducted at Ny-Ålesund over 1128 the period from 1 November, 2012, to 31 October, 2013, examining the overall set of KARL lidar 1129 measurements taken without cloud interferences and with resolutions of $60 \mathrm{~m}$ in height and 10 1130 minutes in time, according to Ansmann (1992). To guarantee a homogeneous data set, only lidar 1131 profiles with identical technical settings have been considered. Moreover, cloud screening was 1132 conducted and the lowest $800 \mathrm{~m}$ were removed from the analysis due to overlap (Weitkamp, 2005). 1133 Finally, the data derived from the Vaisala RS-92 radiosonde data collected at the site have been 
1134

1135 lidar observation does not coincide with the launch of the radiosonde should cause errors no higher than $5 \%$ in evaluating the aerosol backscatter coefficient. This is probably even an upper bound, 1137 since Rogers et al. (2011) only estimated a 3\% bias for the CALIOP (Cloud-Aerosol Lidar with 1138 Orthogonal Polarization) lidar on board the CALIPSO satellite. Figure 16 shows the monthly 1139 averaged profiles of the aerosol volumetric backscatter coefficient $\beta_{b s}(0.532 \mu \mathrm{m})$ from January to 1140 May and the three bi-monthly averaged profiles from June to December, providing evidence of 1141 significant variations in this optical parameter throughout the year. A clear annual cycle of the 1142 aerosol backscatter coefficient can be seen, which increased in February mainly in the low 1143 troposphere and reached its maximum values during March and April in the whole troposphere, 1144 subsequently decreasing appreciably in May. The months June to January were relatively clear, 1145 always showing appreciably lower values at all altitudes. Another view of the same data is shown in 1146 Fig. 17, where the monthly averaged values of $\beta_{b s}(0.532 \mu \mathrm{m})$ were integrated over five partial 1147 height-intervals and the total range from 0.8 to $7.0 \mathrm{~km}$. The results show that the Arctic haze layer 1148 starts to form at low altitudes early in the season and lasts until May not only in the low troposphere 1149 but also at high altitudes. In fact, the maximum values below $2.5 \mathrm{~km}$ altitude have been found in 1150 March, while the largest values of $\beta_{b s}(0.532 \mu \mathrm{m})$ occur in April at $1.5-2.5 \mathrm{~km}$ altitudes. It can be 1151 also noted in Fig. 17 that the haze season starts more rapidly than it disappears, since the increase in 1152 backscatter observed between January and March is steeper, whereas the decline lasts from April 1153 till August.

1154 The annual cycle of the lidar ratio $S_{a}(0.532 \mu \mathrm{m})$ between the aerosol extinction coefficient $1155 \beta_{\text {ext }}(0.532 \mu \mathrm{m})$ and the aerosol backscatter coefficient $\beta_{b s}(0.532 \mu \mathrm{m})$ is presented in Fig. 18, 1156 separately calculated over the altitude sub-ranges $z<3.5 \mathrm{~km}$ and $z>3.5 \mathrm{~km}$ and over the whole 1157 altitude range, for the KARL lidar measurements conducted from early November 2012 to late 1158 October 2013. It shows that $S_{a}(0.532 \mu \mathrm{m})$ takes the highest values in June-July and generally 
increases with altitude. However, its annual cycle is not very pronounced below $3.5 \mathrm{~km}$ altitude,

1160 where most of the aerosol is located, presenting values varying from 30 to 35 sr. This is typical of 1161 clean continental aerosol (Winker et al., 2009). Conversely, the monthly mean values of $S_{a}(0.532$ $1162 \mu \mathrm{m}$ ) calculated above $3.5 \mathrm{~km}$ were estimated to vary from 30 to $40 \mathrm{sr}$ in winter, i.e. assuming values 1163 typical of clean continental aerosol and dust, and to increase until reaching surprisingly high values 1164 of 60 - $70 \mathrm{sr}$ in summer, which are normally typical of BFF smoke and polluted continental aerosol. 1165 However, one has to keep in mind that the lidar ratio depends not only on the chemical composition 1166 but also on the shape and size-distribution of aerosols. It also agrees well with the evaluations of $1167 S_{a}(0.532 \mu \mathrm{m})$ made by Ackermann (1998) for different aerosol types suspended in air for relative 1168 humidity conditions ranging from $40 \%$ to $50 \%$, estimated to be of 27 sr for maritime aerosols and 1169 around 55 sr for continental aerosol suspended in relatively dry air masses, like those frequently 1170 observed in the polar atmosphere over land (which probably indicate a decrease in the influence of 1171 marine air masses with altitude). Due to the contributions of both low and high tropospheric 1172 regions, the overall values of $S_{a}(0.532 \mu \mathrm{m})$ were estimated to range mainly from 30 to $50 \mathrm{sr}$.

1173 To quantify the direct radiative forcing of Arctic haze, it is very important to know the 1174 morphological and optical features of atmospheric aerosols, as well as the multimodal size1175 distribution, the refractive index and the particle shape. The ratio of the perpendicular to parallel 1176 polarized backscatter returns from aerosols at a certain wavelength $\lambda$ gives the volume 1177 depolarization ratio $\delta_{V}(\lambda)$, which provides an effective range-resolved method of determining 1178 whether the laser pulse has been backscattered by spherical or non-spherical aerosols (Winker et al., 1179 2009). Bearing in mind that spherical particles do not depolarize the incoming solar radiation, the 1180 scatter plot of the monthly (from January to May) and bi-monthly (from June to December) 1181 averaged values of depolarisation ratio percentage are shown in Fig. 19 versus the aerosol 1182 backscatter coefficient $\beta_{b s}(0.532 \mu \mathrm{m})$, as obtained from the KARL lidar measurements conducted 1183 from early November 2012 to late October 2013. Generally quite low values of aerosol 1184 depolarization ratio $\delta_{V}(0.532 \mu \mathrm{m})$ have been found (appreciably lower for instance than those of 
1185 desert dust), with the lowest values in January, and values ranging from $2.0 \%$ to $2.6 \%$ in October1186 December, over the range of $\beta_{b s}(0.532 \mu \mathrm{m})<4.5 \times 10^{-4} \mathrm{~km}^{-1} \mathrm{sr}^{-1}$. Remarkably higher depolarisation 1187 values, greater than $2.6 \%$, have been found during the maximum of the haze season, in March and 1188 April, for values of $\beta_{b s}(0.532 \mu \mathrm{m})$ ranging from $4.0 \times 10^{-4}$ to $5.5 \times 10^{-4} \mathrm{~km}^{-1} \mathrm{sr}^{-1}$. This means that 1189 Mie theory, while being a fair assumption to model the forcing of Arctic aerosol during most of the 1190 year, is less accurate during spring time.

1191 Lidar measurements were taken at the coastal Antarctic stations of Syowa, Mario Zucchelli, 1192 McMurdo and Dumont d'Urville (66 40' S, $140^{\circ} 01^{\prime} \mathrm{E}$ ), and at the Antarctic Plateau sites of Dome 1193 Concordia and South Pole over the past decades (see the Antarctic map in Fig. 2), to monitor the 1194 microphysical parameters of clouds at various altitudes (for cloud climatology studies), and only 1195 occasionally to measure the vertical profile of the tropospheric aerosol scattering coefficient $1196 \beta_{\text {ext }}(0.532 \mu \mathrm{m})$. It was found in general that the cloud-free vertical profile of aerosol scattering does 1197 not exhibit particularly dense layers near the surface, but shows that $\beta_{\text {ext }}(0.532 \mu m)$ decreases 1198 rapidly with height, to reach the free troposphere "background aerosol" conditions immediately 1199 above the marine PBL. The first lidar measurements were conducted during the 1974/1975 austral 1200 summer at South Pole, where regular measurements have also been carried out with a micro-pulse 1201 system since 1999, mainly to study the microphysical characteristics of diamond dust and blowing 1202 snow events. Ground-based lidar measurements have also been regularly conducted at Dome 1203 Concordia since 2007, by using the elastic-backscatter and depolarization lidar system of the IFAC1204 CNR Institute (Florence, Italy). Analysis of these data revealed that "diamond dust" ice-crystals are 1205 often present during windy conditions at this remote site, within the boundary-layer of 100-200 m 1206 depth, while aerosols contribute to yield slowly decreasing values of $\beta_{\text {sca }}(0.532 \mu m)$ with height, 1207 until rapidly reaching the background conditions of the free troposphere.

1208 Diamond dust episodes were also frequently observed over the Arctic Ocean. Ground-based lidar 1209 and radar were used for this purpose during the Surface Heat Budget of the Arctic Ocean (SHEBA) 1210 programme, determining the physical characteristics of diamond dust ice-crystals and assessing the 
1211 surface radiative effects induced by such particles under cloud-free sky conditions. Examining a set 1212 of 188 diamond dust or ice crystals episodes over the western Arctic Ocean between November 12131997 and May 1998, Intrieri and Shupe (2004) found that diamond dust episodes covered about $121413 \%$ of the time between November and mid-May over the Arctic Ocean and were never observed 1215 from mid-May to October. Lidar measurements highlighted that the diamond dust vertical depth 1216 varied from $100 \mathrm{~m}$ to $1000 \mathrm{~m}$ on the various cloud-free sky days, although it was most frequently 1217 observed to involve the lower $250 \mathrm{~m}$ of the troposphere on average, thus contributing to induce only 1218 small radiative effects on the sea ice surface.

1219 Airborne lidar measurements of vertical profiles of aerosol extinction and backscatter coefficients 1220 were conducted in the Arctic, over the Svalbard area in spring 2000, 2004 and 2007, during the 1221 ASTAR (Arctic Study of Aerosol Clouds and Radiation) campaigns, together with complementary 1222 ground-based lidar measurements at Ny-Ålesund (Spitsbergen). The ASTAR 2000 campaign ran 1223 from 12 March until 25 April 2000 with extensive flight operations over the Svalbard region using 1224 the AWI aircraft POLAR 4. Simultaneous ground-based measurements were conducted at Ny1225 Ålesund (at both German Koldewey and Japanese Rabben stations as well as at the Zeppelin 1226 station). Vertical profiles of various aerosol parameters were measured during the campaign and 1227 provided evidence of the strong temporal variability of the Arctic spring aerosol with height. A 1228 strong haze event occurred between 21 and 25 March, in which AOT measured from ground-based 1229 observation was 0.18 , i.e. largely greater than the aerosol background value measured in summer. 1230 The airborne measurements made on 23 March showed a high aerosol layer with an extinction 1231 coefficient of $0.03 \mathrm{~km}^{-1}$ or more up to $3 \mathrm{~km}$. The chemical analyses of airborne measurements 1232 showed that such an aerosol transported from anthropogenic sources mainly consisted of sulphate, 1233 soot and sea-salt particles (Yamanouchi et al., 2005). Lidar measurements of 532/355 nm colour 1234 ratio were obtained by Lampert et al. (2009) during the ASTAR 2007 experiment, indicating the 1235 presence of particles with an effective diameter $<5 \mu \mathrm{m}$. However, Lampert et al. (2010) found 1236 rather low Arctic haze levels in spring 2007, examining lidar measurements of cloud and aerosol 
1237 layers. As pointed out by Hoffmann et al. (2009), the Arctic haze optical thickness $\tau(0.50 \mu m)$ 1238 measured during such a seasonal period was evaluated to vary mainly from 0.05 to 0.08 , compared 1239 to a 14 -year average value of 0.10 . The PBL extended up to $2.5 \mathrm{~km}$ altitude and predominantly 1240 contained well-hydrated particles, such as local sea-spray derived sulphates.

1241 Various airborne lidar measurements were conducted as part of the POLARCAT programme during 1242 the 2007-2008 International Polar Year, to define the aerosol radiative characteristics. In particular, 1243 analysing the backscatter measurements provided by the LEANDRE multi-channel lidar mounted 1244 on the ATR-42 aircraft, cases of aerosol transport from Europe and Eastern Asia were monitored in 1245 April 2008 by de Villiers et al. (2010). These studies showed that anthropogenic aerosols 1246 originating in Europe exhibited in general smaller sizes than Asian particles within the PBL below a 1247 height of $0.8 \mathrm{~km}$ and within layers at heights ranging from 2.8 to $4.5 \mathrm{~km}$, consisting mainly of 1248 biomass burning substances and urban/industrial particulate matter, with aerosol backscatter 1249 coefficient $\beta_{b s}(0.532 \mu \mathrm{m})$ ranging from $1.2 \times 10^{-3}$ to $2.2 \times 10^{-3} \mathrm{~km}^{-1} \mathrm{sr}^{-1}$, and depolarization ratio 1250 varying from $1.6 \%$ to $2.1 \%$ (with standard deviations of $0.3 \%$ on average). Conversely, the Asian 1251 dust plume observed in April 2008 was estimated to contain larger particles, presenting some well1252 defined aerosol layers at altitudes from 1.7 to $5.6 \mathrm{~km}$, with $\beta_{b s}(0.532 \mu \mathrm{m})$ varying from $1.6 \times 10^{-3}$ to $12533.9 \times 10^{-3} \mathrm{~km}^{-1} \mathrm{sr}^{-1}$, and depolarization ratio values equal to $2.0 \%$ (smoke particles), $3.0-5.0 \%$ 1254 (clean continental aerosol), 8.0\% (dust), and $4.0-10.0 \%$ (polluted dust).

1255 The above results were obtained using also the Level 2.0 products given by the CALIOP lidar 1256 mounted on the CALIPSO satellite, which was launched in April 2006 (Winker et al., 2009, 2010) 1257 as a part of the A-train constellation of satellites, and has an orbit inclination of $98.2^{\circ}$, thus 1258 providing coverage to $82^{\circ}$ latitude. This wide coverage has proven immensely important in polar 1259 regions, where ground-based installations are few and far between. The CALIOP lidar operates at 1260 wavelengths of 0.532 and $1.064 \mu \mathrm{m}$, with a depolarization ratio measured at $0.532 \mu \mathrm{m}$, and was 1261 used to characterize the various aerosol types by assuming in such an approach a set of values of 1262 lidar ratios $S_{a}(0.532 \mu \mathrm{m})$ and $S_{a}(1.064 \mu \mathrm{m})$ equal to 20 and $45 \mathrm{sr}$ for clean marine aerosol, 35 and 30 
1263 sr for clean continental aerosol, 40 and $30 \mathrm{sr}$ for dust, 65 and $30 \mathrm{sr}$ for polluted dust, 70 and $30 \mathrm{sr}$ 1264 for polluted continental aerosol, and 70 and $40 \mathrm{sr}$ for combustion smoke particles, respectively 1265 (Winker et al., 2009).

1266 A first airborne campaign referred to as the Polar Airborne Measurements and Arctic Regional 1267 Climate Model Simulation Project (PAMARCMiP) took place during April 2009 in the Arctic, 1268 using a pair of downward-looking lidars, a depolarization aerosol lidar and a tropospheric ozone 1269 DIAL mounted onboard the Polar 5 research aircraft of the Alfred Wegener Institute (AWI) for 1270 Polar and Marine Research (Germany). On the basis of the evaluations made by Rogers et al. 1271 (2011), it can be assumed that a relative 3\% bias of aerosol backscatter coefficient $\beta_{b s}(0.532 \mu m)$ 1272 was made on average, due to a wrong assumption of the Rayleigh backscatter coefficient used to 1273 correct the overall lidar backscatter coefficient. A series of flights was conducted from 1274 Longyearbyen (Svalbard) across the western Arctic to Barrow (Alaska), reaching Station Nord 1275 (Greenland), Alert, NP-36 (at 88 40’ N latitude), Eureka, Resolute Bay, Sachs Harbor, Inuvik, and 1276 Fairbanks, while complementary ground-based lidar measurements were regularly conducted at Ny1277 Ålesund, Eureka and Barrow (Stone et al., 2010). Significant aerosol backscatter and extinction 1278 effects were measured over the entire region, mainly caused by haze particles with diameters 1279 ranging from 0.13 to $0.20 \mu \mathrm{m}$. The PAMARCMiP lidar measurements showed that the aerosol 1280 extinction coefficient decreased in general with height from the surface to the top-level of the 1281 thermal inversion layer, found to be on average equal to $4 \mathrm{~km}$, and often presented a secondary peak 1282 above. A second PAMARCMiP airborne campaign was conducted with the Polar 5 aircraft during 1283 April 2011, following the route from Longyearbyen to Barrow, flying over Station Nord, Alert, 1284 Eureka, Resolute Bay and Inuvik (Herber et al., 2012). During both campaigns, black carbon was 1285 observed at all altitudes sampled but at relatively low concentrations compared with historical 1286 values.

1287 A climatological study of Arctic aerosols was made by Devasthale et al. (2011) examining the 1288 CALIOP measurements recorded from June 2006 to May 2010. The study showed that the bulk of 
1289 the aerosol particles are confined within the first $1000 \mathrm{~m}$ of the troposphere, from about $65 \%$ of

1290 cases in winter to $45 \%$ in summer, while the rest is mainly suspended within the middle 1291 troposphere, at altitudes ranging from 3 to $5 \mathrm{~km}$, especially in spring. The relative occurrences of

1292 aerosol types in the vertical profiles show that clean continental aerosol is the largest contributor in

1293 all seasons except in summer, while polluted continental aerosols are the second largest contributor

1294 to the total number of observed aerosol layers in winter and spring, and clean marine aerosol is the

1295 second largest contributor in summer and autumn. The average vertical profile of aerosol extinction 1296 coefficient was found to exhibit a pronounced peak at heights of about 0.4-0.7 km. Associated with

1297 the intrusions from mid-latitudes, polluted continental and smoke aerosols presented much broader 1298 distributions of optical and geometrical thicknesses, appearing to be more often optically thicker 1299 and higher up in the troposphere.

1300

$1301 \quad$ 5. Airborne and satellite measurements

$1302 \quad$ 5.1. Basic remarks

1303 Airborne sun-photometry employs ground-based techniques adapted to the special requirements

1304 (notably solar tracking) of an aircraft environment. Relatively frequent measurements can be made 1305 during ascending or descending profiles to achieve vertically stratified AOT measurements, which 1306 are sensitive to the aerosol vertical structure and can be converted to volume extinction coefficient 1307 profiles, which are analogous to the aerosol backscatter coefficient profiles derived from lidar 1308 measurements and shown in Fig. 16 (see Section 4). It is also possible to carry out measurements 1309 onboard airplanes flying above and below pollution plumes. These aircraft measurements offer the 1310 possibility of surveying large areas in relatively short time-periods, which is not possible, e.g., for 1311 ship-borne measurements. In particular, airborne measurements of this kind were made during the 1312 PAMARCMiP airborne campaign of April 2009 (Stone et al., 2010), in which various airborne lidar 1313 systems and a multi-wavelength sun-photometer were mounted onboard the AWI Polar 5 research 1314 aircraft to perform numerous measurements of volume aerosol scattering and extinction coefficients 
1315 were conducted over the wide area from Svalbard across the western Arctic to Barrow, from the 1316 European to the Alaskan Arctic, and from sub-Arctic latitudes to near the Pole. The sun-photometer 1317 measurements were performed using a 8-channel sun-photometer system manufactured by 1318 NOAA/GMD (Boulder, Colorado, USA) in cooperation with ISAC-CNR (Bologna, Italy), and 1319 equipped with narrow-band visible and near-IR channels centred at wavelengths ranging from 0.355 1320 to $1.064 \mu \mathrm{m}$, while the lidar measurements were conducted using a pair of downward-looking 1321 lidars, a depolarization aerosol lidar and a tropospheric ozone DIAL. Additional independent in-situ 1322 measurements of particle size-distribution were also made onboard the AWI Polar 5 aircraft, and 1323 light extinction data were derived from the airborne lidar measurements to investigate the spectral 1324 effects produced by haze particles.

1325 The measurements revealed that the spatial variations in $\tau(\lambda)$ observed during the most turbid 1326 period of the 2009 haze season were closely related to the atmospheric circulation patterns regulated 1327 by a dominant airflow from Eurasian anthropogenic sources. In addition, lidar observations showed 1328 the presence of elevated aerosol layers, as shown at Ny-Ålesund by Treffeisen et al. (2007) in early 1329 May 2006 during a transport event of biomass burning aerosols from agricultural fires in eastern 1330 Europe, and by Stock et al. (2012) in March 2008 during a BFF smoke pollution event over the 1331 European Arctic region.

1332 Background values of $\tau(0.50 \mu \mathrm{m})$ not exceeding 0.06 were determined in the most remote areas, 1333 while haze values of $\tau(0.50 \mu \mathrm{m})$ varying from 0.12 to around 0.35 were measured, with the highest 1334 values found in the Beaufort Sea region toward the end of April. Such values of $\tau(\lambda)$ were 1335 anomalously high compared with those measured in the previous three years, because of the 1336 transport of haze particles from the industrial regions in Europe and Northern Asia. Arctic haze 1337 particles were frequently found to be concentrated within and just above the surface-based 1338 temperature inversion layer, showing in general bimodal size-distribution features, consisting of an 1339 accumulation mode of moderately small (water-soluble) particles and an additional mode mainly 1340 composed of insoluble coarse particles. In addition, the in-situ sampling and optical measurements 
1341 revealed a marked decrease in the mean particle size with increasing altitude from the surface to 4 $1342 \mathrm{~km}$, yielding values of the Ångström exponent $\alpha(0.412-0.675 \mu \mathrm{m})$ varying from 1.40 to 1.70 . The 1343 airborne measurements showed that black carbon (BC) was highest near the North Pole, suggesting 1344 long-range transport from combustion sources. However, the BC concentration measurements 1345 performed near the surface were nearly an order of magnitude lower than those reported from 1346 similar campaigns in the 1980s. Enhanced opacity at higher altitudes during the campaign was 1347 attributed to an accumulation of industrial pollutants in the upper troposphere, consisting of residual 1348 aged aerosol and soot particles originating from coal burning in China, in combination with 1349 volcanic aerosol resulting from the March-April 2009 eruptions of Mount Redoubt in Alaska and 1350 perhaps minor contributions from aircraft emissions. The Arctic haze particles observed during 1351 April 2009 were estimated to have reduced the net short-wave irradiance by -2 to $-5 \mathrm{~W} \mathrm{~m}^{-2}$, 1352 resulting in a slight cooling of the surface. Examining the data recorded during the second 1353 PAMARCMiP airborne campaign in April 2011, and some aerosol measurements coordinated with 1354 satellite flyovers of NASA's CALIPSO mission, Herber et al. (2012) found that such satellite-borne 1355 data can be useful to validate aerosol retrievals from the lidar and sun-photometer measurements 1356 made onboard the Polar 5 aircraft.

1357 Even larger areas than those covered by airborne sun-photometer campaigns can be monitored by 1358 means of satellite observations. The retrieval of aerosol properties from satellite-based 1359 measurements is an ill-posed problem. The satellite retrieved aerosol optical thickness over bright 1360 surfaces such as snow and ice is often biased and leads to errors when estimating aerosol-radiation 1361 interactions (IPCC, 2013). Polar-orbit satellite-mounted sensors like MODIS (Moderate Resolution 1362 Imaging Spectroradiometer) and MERIS (Medium Resolution Imaging Spectrometer) utilize multi1363 spectral information to characterize surface properties. The NASA/MODIS "dark-target" (DT) 1364 approach developed for the retrieval of aerosol properties uses the $2.1 \mu \mathrm{m}$ band to estimate the 1365 reflectance in visible bands (Kaufman et al., 1997). The empirical relationships between the surface 1366 reflectance of visible channels and $2.1 \mu \mathrm{m}$ channel were improved by considering the effect of 
1367 geometry and surface types (Levy et al., 2007), while information on global aerosol properties was 1368 determined as a function of location and season by performing cluster analysis of in-situ 1369 measurements (Levy et al., 2010). The major limitation of the MODIS DT algorithm is that no 1370 retrievals are performed when the surface reflectance of the $2.1 \mu \mathrm{m}$ channel is higher than 0.25 1371 (Levy et al., 2007). For the retrieval over bright surfaces, such as desert and urban regions, Hsu et al 1372 (2004) developed the Deep Blue (DB) algorithm utilizing the fact that the surface is much darker in 1373 the short blue spectral channels compared with longer wavelengths. The second generation of DB 1374 algorithm, the so-called Enhanced Deep Blue algorithm, improved estimates of the surface 1375 reflectance, aerosol model selection and cloud screening schemes (Sayer et al., 2012; Hsu et al., 1376 2013). The current MODIS Collection 6.0 AOT product is created from three separate retrieval 1377 algorithms for different surface types (Levy et al., 2013): they are two DT algorithms for dark ocean 1378 surface as well as the vegetated/dark-soiled land and a DB algorithm over desert/arid land. MODIS 1379 Collection 6 also provides a $3 \mathrm{~km}$ AOT product compared to Collection 5 (Remer et al., 2013). The 1380 Bremen AErosol Retrieval (BAER) algorithm for MERIS (von Hoyningen-Huene et al., 2003, 1381 2011) utilizes the Normalized Difference Vegetation Index (NDVI). Polar-orbit satellites with 1382 multi-view observations such as AATSR (Advanced Along Track Scanning Radiometer) (Curier et 1383 al., 2009) and MISR (Multi-angle Imaging Spectroradiometer) (Diner et al., 2005a) make use of the 1384 Bidirectional Reflectance Distribution Function (hereinafter referred to as BRDF) surface properties 1385 to constrain the ill-posed inverse problem. A time series method is the most popular aerosol 1386 retrieval method for geostationary satellite based on the assumption that the surface reflectance does 1387 not change significantly during a short period of time (Knapp et al. 2002; Govaerts et al., 2010; Mei 1388 et al., 2012). The retrievals based on POLDER (Polarization and Directionality of the Earth's 1389 Reflectances) (Deuze, et al., 2001; Dubovik et al., 2011) intensity and degree of polarization 1390 measurements provide more accurate AOT products with the advantage that the contribution of land 1391 surfaces to the degree of polarization at the TOA is generally smaller in the visible as compared to 1392 the contribution of the underlying surface to the light intensity as measured on a satellite. 
1393 Among the various satellite-based observations, those provided by MODIS (Justice et al., 1998)

1394 mounted on the Terra and Aqua platforms are particularly useful for evaluating the AOT features in 1395 the polar regions, over the ocean and ice-free land surfaces, and studying aerosol climatology 1396 associated with the sources, transport and sinks of specific aerosol types (e.g., sulphates and 1397 biomass-burning smoke particles). The twin MODIS sensors have been flying on the Terra platform 1398 since 2000 and on the Aqua platform since 2002, giving a large data-set of aerosol products using a 1399 number of algorithms over the past decades to retrieve columnar aerosol parameters over sea and 1400 land (Tanré et al., 1997; Kaufman et al., 1997; Hsu et al., 2004; Remer et al., 2005; Levy et al., 1401 2013; Xue et al., 2014). To define the average seasonal maps of $\tau(0.55 \mu \mathrm{m})$, we downloaded data1402 sets of MODIS/Terra and MODIS/Aqua monthly Level-3 data (Atmosphere Monthly Global $1 \times 1$ 1403 Degrees Products MOD08_M3.051 and MYD08_M3.051, for the Terra and Aqua platforms, 1404 respectively) from the Giovanni website (http://disc.sci.gsfc.nasa.gov/giovanni). These had been 1405 collected for cloud-free atmospheric conditions over the eight years from January 2005 to 1406 December 2012, at Arctic latitudes $\geq 67^{\circ} \mathrm{N}$ and Antarctic latitudes $\geq 62{ }^{\circ} \mathrm{S}$. The cloud-screened 1407 Arctic AOT data-set was divided into seasonal sub-sets of $\tau(0.55 \mu \mathrm{m})$ for spring (March to May) 1408 and summer (June to August), separately for Terra and Aqua observations. The seasonal average 1409 maps of Level-3 AOT $\tau(0.55 \mu \mathrm{m})$ derived from MODIS/Aqua and MODIS/Terra are separately 1410 shown in Fig. 20, for $1^{\circ} \times 1^{\circ}$ pixels over oceans and land areas not covered by snow and ice. The 1411 values of $\tau(0.55 \mu \mathrm{m})$ in the summer months are mainly lower than 0.15 , with some areas 1412 characterized by average values ranging from 0.15 to 0.30 over the Central and Western Siberian 1413 Sea, and the Chukchi Sea, as well as over the Beaufort Sea, presumably due to the transport of BFF 1414 aerosol from Siberia and North America, respectively. The spring average values of $\tau(0.55 \mu \mathrm{m})$ 1415 range mainly from 0.10 to 0.25 , with peaks of more than 0.30 in the Siberian, North American and 1416 North European sectors, associated with dense Arctic haze transported from the anthropogenic mid1417 latitude sources. These findings closely agree with the results obtained from the ground-based sun- 
1418 photometer measurements conducted at coastal sites (Fig. 8a) and from the ship-borne 1419 AERONET/MAN measurements (Fig. 8b). Figure 20 also shows that AOT cannot be retrieved from 1420 the MODIS data using the operational MODIS algorithm over Greenland and the North Pole in both 1421 spring and summer, and over large regions of Northern America and Siberia in spring, because of 1422 the high reflectance of the surfaces covered by sea ice and snow and also because of generally small 1423 values of AOT in these areas.

1424 Reliable maps of exponent $\alpha$ cannot be retrieved from MODIS data over both land and ocean 1425 surfaces because of the low values of AOT in the polar regions and the relevant uncertainties 1426 affecting the MODIS aerosol products (Mishchenko et al., 2010; Kahn et al., 2011). In particular, 1427 Levy et al. (2013) determined the Collection 6 MODIS aerosol products to retrieve AOT and 1428 aerosol size-parameters from MODIS-observed spectral reflectance data and found that the 1429 Ångström exponent product over land cannot be reliably used. These findings were confirmed by 1430 Mielonen at al. (2011) who stated that MODIS data do not provide quantitative information about 1431 aerosol size and parameter $\alpha$ over land. Similarly, as a result of a validation study of Collection 5 1432 MODIS Level-2 Aqua and Terra AOT and $\alpha$ products over ocean, Schutgens et al. (2013) found 1433 that these products exhibit significant biases due to wind speed and cloudiness of the observed 1434 scene, being significantly affected by AOT and $\alpha$ random errors due to cloud fraction contributions. 1435 On the basis of these results, we have decided to examine here only the MODIS AOT data and 1436 exclude from the present analysis the MODIS $\alpha$ products obtained over snow- and ice-free land and 1437 ocean regions, since they were presumably affected by considerable uncertainties arising from: (i) 1438 the presence of cloud-fractions within the $1^{\circ} \times 1^{\circ}$ pixels that cannot be correctly evaluated, and (ii) 1439 the variability of AOT at visible and near-infrared wavelengths, due to cloud extinction effects, 1440 which may efficiently contribute to lower exponent $\alpha$. On the basis of the AERONET/MAN 1441 measurements, this parameter was evaluated to range from less than 1.00 to around 1.75 over the 
1442 Arctic Ocean sectors in spring and summer, and from less than 0.50 to about 2.00 in Antarctica,

1443 with in general lower values over the off-shore areas far from the Antarctic coasts.

1444 The Antarctic aerosol data-set downloaded from the Giovanni website over the latitude range $\geq 62^{\circ}$

1445 S covers not only the land region of the Antarctic continent but also the off-shore ocean areas no

1446 further than $1000 \mathrm{~km}$ from the coasts. Only the MODIS/Aqua and MODIS/Terra data collected

1447 from December to February were separately examined to determine the maps of average $\tau(0.55$

$1448 \mu \mathrm{m}$ ), limited in practice to the oceanic areas only (Fig. 21). The results indicate that such seasonal

1449 average values of $\tau(0.55 \mu \mathrm{m})$ are lower than 0.10 over all ocean areas close to the Antarctic coasts

1450 and sometimes can exceed 0.10 over the off-shore areas, in close agreement with the values derived

1451 from ground-based sun-photometer measurements at coastal Antarctic sites (Fig. 13a) and from

1452 AERONET/MAN measurements (Fig. 13b).

1453 Figure 21 also shows that no useful information is available from MODIS observations over the 1454 interior of Antarctica when using the traditional retrieval procedures. The retrieval of $\tau(\lambda)$ over a 1455 bright surface is indeed a very difficult task, because it is hard to separate the radiance contributions 1456 by the reflecting surface and atmospheric aerosol back-scattering to the overall radiance observed 1457 by a satellite-borne sensor at the TOA-level, especially for the very large solar zenith angles typical 1458 of polar latitudes. Mei et al. (2013a) overcame the above difficulties by following a synergetic 1459 approach based on the use of both MODIS/Terra and MODIS/Aqua data, together with: (i) the $a$ 1460 priori assumption of aerosol optical parameters retrieved over snow made with the Aerosol 1461 Properties Retrieval over Snow (APRS) algorithm, and (ii) an appropriate model of the BRDF 1462 reflectance representing snow-covered surfaces. The APRS algorithm was based on the operational 1463 bi-angle approach proposed by Xue and Cracknell (1995) to retrieve non-absorbing aerosol 1464 extinction parameters over land surfaces (Tang et al., 2005; Wang et al., 2012), in which particulate 1465 absorption was considered, and a two-stream approximation was adopted. This new algorithm was 1466 found reliable by Mei et al. (2013a) by means of an extended comparison between the values of $1467 \tau(0.55 \mu \mathrm{m})$ retrieved from MODIS data and simultaneous AERONET measurements made at six 
1468 high-latitude Arctic stations (Andenes, Barrow, Ittoqqortoormiit, OPAL, Thule, and PEARL) in 1469 April 2010 and April 2011 (i.e., during periods in which Arctic haze frequently occurs). A 1470 regression line with slope coefficient equal to +0.764 was found by applying the least squares 1471 method to a set of 70 MODIS retrieved values of $\tau(0.55 \mu \mathrm{m})$ obtained with a $10 \mathrm{~km} \times 10 \mathrm{~km}$ 1472 resolution plotted versus the corresponding AERONET measurements, with a regression coefficient 1473 equal to +0.81 and a root mean square error $\mathrm{RMSE}=0.079$. In particular, comparing the MODIS 1474 retrieved values of $\tau(0.55 \mu \mathrm{m})$ with the AERONET measured values at the above stations, Mei et al. 1475 (2013a) found relative discrepancies between them ranging from a few percent to more than $30 \%$ in 1476 cases with $\tau(0.55 \mu \mathrm{m})>0.20$, presumably associated with strong Arctic haze extinction.

1477 These results demonstrate the considerable potential of the APRS algorithm to retrieve $\tau(\lambda)$ at 1478 visible wavelengths over the Arctic, for highly reflective snow/ice surfaces and large solar zenith 1479 angles, as can be seen in the maps of $\tau(0.55 \mu \mathrm{m})$ derived from the MODIS/Aqua observations made 1480 on 29 March and 3 May in 2006 (Fig. 22), using the method of Mei et al. (2013a).

\subsection{Aerosol optical thickness retrievals over snow and ice using backscattered solar light}

1483 Of particular relevance for remote sensing applications in polar regions, are the multiple-view 1484 (MISR) and double-view (AATSR) sensors. The measurements made with these instruments allow 1485 the contribution from underlying bright surfaces (e.g., snow and ice) to be removed, assuming that 1486 the atmosphere is the same for observations made at different angles, in all cases where the 1487 atmosphere is not filled with broken clouds. MISR is a sensor built by the Jet Propulsion Laboratory 1488 (JPL) and hosted on the NASA Terra platform, which was launched on 18 December 1999, and 1489 became operational in February 2000. It was designed to measure the intensity of solar radiation 1490 reflected by the surface-atmosphere system in various directions and spectral bands, with the main 1491 mission of measuring the intensity of solar radiation reflected and absorbed by the Earth. The 1492 device is composed of nine separate digital cameras, each with four spectral bands (blue, green, red, 1493 and near-infrared), that view the Earth at nine different angles (Diner et al., 1998). The algorithms 
1494 for AOT retrieval from the MISR observations are discussed in Martonchik et al. (1998a, 1998b)

1495 and Diner et al. (2005a), and further assessed by Martonchik et al. (2002) and Kahn et al. (2005, 1496 2010). Examining the MISR monthly Level-3 data (Monthly Global $0.5^{\circ}$ x $0.5^{\circ}$ Aerosol Product, 1497 MIL3MAE.004) recorded during the 2005-2012 period, the regional maps of monthly average AOT 1498 were determined in the present study, over the Arctic region for latitudes $\geq 67^{\circ} \mathrm{N}$, and the Antarctic 1499 region for latitudes $\geq 62{ }^{\circ} \mathrm{S}$. The monthly average values of $\tau(0.55 \mu \mathrm{m})$ collected over the Arctic 1500 region under cloudless sky conditions were separated into a pair of seasonal sub-sets for spring 1501 (March-April-May) and summer (June-July-August), from which the seasonal average maps of $1502 \tau(0.55 \mu \mathrm{m})$ shown in Fig. 23 were obtained. It can be seen that these results are very similar to those 1503 retrieved from the MODIS data in Fig. 20, with spring average values of $\tau(0.55 \mu \mathrm{m})$ varying mainly 1504 from 0.10 to 0.25 , and being higher than 0.20 (and sometimes exceeding 0.30) over large areas of 1505 Central and Eastern Siberia as in the North American sector, presumably associated with dense 1506 Arctic haze transport episodes. The average summer values of $\tau(0.55 \mu \mathrm{m})$ were found to mainly 1507 range from 0.05 to 0.15 , showing similar features to those detected by MODIS observations. With 1508 regard to this, it is worth mentioning that Campbell et al (2012) examined (i) MODIS and MISR 1509 observations made over the Arctic regions in 2007, obtaining estimates of $\tau(0.55 \mu m)$ all lower than 1510 0.10, and (ii) a CALIOP data-set collected in 2007, determining mean day-time and night-time 1511 values of $\tau(0.532 \mu \mathrm{m})$ all lower than 0.15 . In addition, examining the CALIOP data recorded over 1512 the Arctic in 2008, Winker et al. (2013) obtained mean cloud-free day-time values of $\tau(0.532 \mu \mathrm{m})$ 1513 mainly lower than 0.05 and mean cloud-free night-time values of $\tau(0.532 \mu \mathrm{m})$ not exceeding $0.10 \mathrm{in}$ 1514 March-May and September-February. In particular, they determined average values of $\tau(0.532 \mu \mathrm{m})$ 1515 from the CALIOP observations made from 2007 to 2011 that were lower than: (i) 0.02 over inner 1516 Greenland, (ii) 0.08 over the GNS sector surrounding the Svalbard region, (iii) 0.12 over the 1517 Scandinavian area, (iv) 0.12 over the Western Siberian Sea sector, (v) 0.05 over the Eastern 1518 Siberian Sea sector, and (vi) 0.06 over the North-American sector of the Arctic Ocean. These data 
1519 are in good agreement with ground-based sun-photometer measurements (Figs. 3-8) and 1520 AERONET/MAN ship-borne measurements (Figs. 8b and 14), which showed that $\tau(0.50 \mu \mathrm{m})$ 1521 mainly varies from 0.08 to 0.16 in spring and from 0.04 to 0.10 in summer.

1522 The same procedure was also followed in the analysis of MISR data recorded over Antarctica 1523 during the austral summer from 2005 to 2012 (Fig. 23), which indicates that the seasonal average 1524 values of $\tau(0.55 \mu \mathrm{m})$ are lower than 0.10 over the greater part of the coastal ocean areas around 1525 Antarctica and vary mainly from 0.10 to 0.25 over the off-shore areas very far from the coasts, due 1526 to effective sea-salt production by strong winds. These features are very similar to those obtained 1527 from MODIS observations (Fig. 21) and those derived from the AERONET/MAN measurements 1528 carried out in the coastal and off-shore ocean areas surrounding the Antarctic continent (Fig. 13b).

1529 The AATSR sensor is a dual-view (nadir and $55^{\circ}$ forward) radiometer on board the European Space 1530 Agency (ESA) Environmental Satellite (ENVISAT), which was launched in March 2002 and is one 1531 of the satellite instruments designed for providing a well-calibrated long-term global data-set of 1532 satellite data for climate research (Grey and North, 2009). ENVISAT was on a sun-synchronous 1533 orbit with an equator passing time of about $10 \mathrm{am}$. AATSR has a ground pixel resolution which is 1534 equal to $1 \times 1 \mathrm{~km}^{2}$ at nadir and a swath width of $500 \mathrm{~km}$, thus taking about six days to achieve full 1535 global coverage (three days at mid-latitudes). Observations in both views are made at seven 1536 wavelengths: $0.55 \mu \mathrm{m}, 0.66 \mu \mathrm{m}, 0.87 \mu \mathrm{m}, 1.6 \mu \mathrm{m}, 3.7 \mu \mathrm{m}, 11 \mu \mathrm{m}$ and $12 \mu \mathrm{m}$, the spectral 1537 resolution of visible channels is approximately $20 \mathrm{~nm}$, which avoids atmospheric water vapour 1538 absorption regions in the electromagnetic spectrum. Contact was lost with ENVISAT on April 2012 1539 after 10 years of service. The follow-up SLSTR mission as currently foreseen on Sentinel-3 will 1540 ensure the continuity of the multi-view-angle method into the future.

1541 The reflectance at the TOA-level can be described as the sum of the atmospheric path reflectance 1542 (black surface reflectance) and the atmosphere-surface interaction (Kaufman et al., 1997). With the 1543 use of AATSR dual-view observations, the ratio between observations in the forward and nadir 1544 directions can be determined by calculating the difference between TOA reflectance and 
1545 atmospheric path reflectance in both directions and taking features of the total atmospheric 1546 transmission into account (Istomina et al., 2010; Mei et al., 2013b). It is worth mentioning that the 1547 ratio of both AATSR directional observations is not sensitive to the snow albedo, which reduces the 1548 high snow albedo effect on AOT retrieval over the Arctic region. For pure snow, Istomina et al. 1549 (2009) used an analytical snow BRDF model to estimate the ratio of both directional observations 1550 with a correction for TOA reflectance, where this approach was affected by the shape of the BRDF 1551 and not by its magnitude (Vermote et al., 1997a). Mei and Xue (2013) used an equivalent snow and 1552 ice mixture pixel for the spectral surface reflectance: it is constructed using a linear mixing model 1553 of snow and ice spectra tuned by the Normalized Difference Snow Index (NDSI) as an indicator of 1554 snow cover. Before calculating NDSI, cloud and free water were masked and a Look-Up-Table 1555 method was used to retrieve AOT.

1556 Current operational AOT retrieval algorithms, such as MODIS DT (Levy et al., 2013), MISR 1557 algorithm (Diner et al.2005b; Kahn et al. 2010) and AATSR (Holzer-Popp et al., 2013), can 1558 determine AOT over the Arctic Ocean (Glantz et al., 2014). Evaluation of the MODIS/Aqua AOT 1559 product over Svalbard using a 9-year set of AERONET observations gives an accuracy of $\pm 0.03 \pm$ 1560 0.05 AOT (Glantz et al., 2014). The AOT maps defined by Holzer-Popp et al. (2013) in September 15612008 qualitatively show an overestimation over the Arctic Ocean compared with the 9-year mean 1562 values from the MODIS Aqua product, AERONET and Alfred Wegener Institute (AWI) 1563 observations, which have been separately estimated, giving values of AOT equal to $\pm 0.031 \pm 0.021$, $1564 \pm 0.031 \pm 0.022$, and $\pm 0.024 \pm 0.052$, respectively (Glantz et al., 2014). However, due to the high 1565 reflectance of surface encountered for large solar zenith angles in the Arctic (Mei et al., 2013a, 1566 Macdonald et al., 2014), it is very difficult to quantitatively retrieve AOT over snow and ice. 1567 Stamnes et al (2004) pointed out that the TOA reflectance is sensitive to AOT over both very bright 1568 and dark surfaces, demonstrating the possibility of retrieving AOT over Arctic regions. Recent 1569 publications (Istomina et al., 2011; Mei et al., 2013a; Mei et al., 2013b) show promising AOT 1570 results over snow/ice covered regions, as described below. 
1571 Preliminary attempts based on the above concepts were tried by Istomina et al. (2010) to

1572 individualise cloud-free snow-covered areas using AATSR measurements, and to discriminate clear 1573 snow fields for the retrieval of AOT. In addition to the aerosol retrieval method at the above1574 mentioned visible and near-infrared wavelengths (Istomina et al., 2009), the AATSR measurements 1575 in the $3.7 \mu \mathrm{m}$ channel were also utilized to retrieve AOT (Istomina et al., 2011). Radiative transfer 1576 simulations for the accumulation and coarse particle modes of four main aerosol components were 1577 conducted in order to represent the retrieved $\tau(\lambda)$ in the visible region of the spectrum. The 1578 advantage of this algorithm is that it can be used over any blackbody-like surface (open ocean, sea 1579 ice, snow-covered land). An example of its usage is shown in Fig. 24.

1580 Improved results were obtained by Mei et al. (2013b) using the Dual-View Multi-Spectral (DVMS) 1581 approach, in which the dual view is used to separately evaluate the contributions made by 1582 atmospheric aerosols and underlying surfaces to the reflectance measured by this satellite sensor at 1583 the TOA-level. The algorithm uses an analytical snow BRDF model to estimate the ratio of snow 1584 reflectances in the nadir and forward views, and the atmospheric contribution to the TOA-level 1585 reflectance, obtained using the dark pixel method over the adjacent ocean surface, by assuming that 1586 this value applies over nearby land surfaces in the absence of significant sources across the 1587 coastline. An iteration involving all four AATSR spectral channels in the visible and near-infrared 1588 is used to retrieve the most relevant $\tau(0.55 \mu \mathrm{m})$ information. The method was illustrated for AATSR 1589 overpasses over Greenland in April 2009, during cloud-free sky periods.

1590 Some examples of the results achieved by Mei et al. (2013b) in Fig. 25 show the daily maps of $1591 \tau(0.55 \mu \mathrm{m})$ retrieved from AATSR data recorded on four days in April 2009 with $1 \mathrm{~km} \times 1 \mathrm{~km}$ 1592 resolution over the western part of Greenland, under cloud-free sky conditions. It can be seen that $1593 \tau(0.55 \mu \mathrm{m})$ had very low values smaller than 0.10 , with little spatial variation for moderate 1594 contributions of sea spray aerosol associated with the very low wind speeds at the surface, as 1595 observed on the chosen days. 
1596 A comparison test between the values of $\tau(0.55 \mu \mathrm{m})$ retrieved using the DVMS approach for high1597 quality AATSR observations and the corresponding AERONET values measured at Thule (North1598 western Greenland) during April 2009 exhibited a good correlation, with a regression coefficient 1599 equal to +0.76 (Mei et al., 2013b). However, it should be mentioned that such good results were 1600 obtained for a selected set of measurements, containing a high number of cases with $\tau(0.55 \mu m)>$ 16010.12 , due to the frequent occurrence of Arctic haze episodes in April. A synergetic approach to 1602 retrieve aerosol optical characteristics over the Arctic, using data from the MODIS sensor mounted 1603 onboard the Terra and Aqua platforms and prior knowledge of aerosol optical parameters retrieved 1604 over snow (as assumed in the APRS procedure), was presented by Mei et al. (2013a). Bearing in 1605 mind that cloud contamination can cause abnormally high retrieved values of AOT, the analysis of 1606 MODIS data was limited to only clear-sky pixels selected through MODIS cloud products and 1607 visual inspection. In applying the APRS procedure, it was realistically assumed that the aerosol 1608 optical parameters do not change during the time between the overpasses of Terra and Aqua 1609 platforms. A comparison was also made between the values of $\tau(0.55 \mu \mathrm{m})$ retrieved over Greenland 1610 from MODIS observations following the APRS procedure and those derived from AATSR data 1611 with the DVMS method. This comparison showed that the APRS values of $\tau(0.55 \mu m)$ ranged from 16120.07 to 0.09 over the monitored areas, while the DVMS ones were mainly $\sim 0.09$, and exhibited a 1613 maximum value just $0.6 \%$ lower than that derived from MODIS data.

1614 It has to be mentioned that the global application of the above-cited AOT retrieval algorithms for 1615 both MODIS and AATSR is still very much limited due to several challenges which are listed 1616 below. For instance, one of the major issues is the cloud masking over snow and ice. Cloud 1617 screening for AOT retrieval in the Arctic is a challenge due to the similarity of snow/ice and cloud 1618 reflective properties in the visible region of the spectrum. The sensitivity of AOT retrievals over 1619 snow to atmospheric particulate matter implies a potentially high contamination of the aerosol 1620 product with eventually unscreened clouds. It is for these two reasons that many cloud masking 1621 algorithms developed for a general case of multiple surface types, such as open water, vegetation 
and various soils, are of questionable quality over snow and ice. An example of this is the operational AATSR cloud mask provided with the level 1b AATSR product (Istomina et al., 2010). The main approach to distinguishing clouds from the underlying surface is that clouds are generally brighter and colder than the underlying surface. However, this is not always the case over snow/ice covered regions such as the Arctic. A prominent spectral signature of snow and ice makes it possible to discriminate clouds using NIR and TIR channels. At the same time, not all sensors have such channels. Therefore, cloud screening algorithms over snow differ from sensor to sensor in order to most effectively utilize the available features (which are not only the spectral and spatial resolution, but also different observation directions and polarization measurements). The resulting cloud mask over snow and ice obtained from different sensors also differs in quality. Employing absolute or relative thresholds (e.g. NDSI or NDVI) in the available VIS, NIR and IR channels to separate clouds from snow and ice is a commonly used approach which gives a robust cloud mask over snow for common applications (MERIS, AATSR, SCIAMACHY) (Allen et al., 1990; Istomina et al., 2010; Schlundt et al., 2011). However, as the thresholds are often empirically derived and based on a limited data set, this approach might have drawbacks when it comes to particular surface or cloud types, e.g. ice clouds over snow. Possible mis-classification here could be: (1) mistaking heavy aerosol loads for clouds, as e.g. might be the case of MODIS test BT11 BT3.9 (Ackerman et al., 2010), or (2) mistaking snow surfaces for clouds as in MODIS test BT11 BT12, which is used to detect cirrus over many surface types also covered by snow and ice (Ackerman et al., 2010). Mis-classification may occur due to snow emissivity being sensitive to grain size at these wavelengths, and creating a difference between the brightness temperatures BTs recorded in the 11 and $12 \mu \mathrm{m}$ channels (Hori et al., 2006).

A snow BRDF model can also be used to derive the threshold value for the NIR spectral channel, as shown by Spangenberg et al. (2001) and Trepte et al. (2001). This approach might have difficulties in distinguishing cloudy conditions from cloud-free but aerosol-polluted scenarios. The best results can be obtained by combining the various approaches such as thresholding, image clustering, 
1648 supervised and unsupervised classification, usage of oxygen and water vapour absorption bands if

1649 available (e.g. MERIS) (Gomez-Chova et al., 2007) together with usage of external topography 1650 data, land/water masks, ecosystem maps and daily operational snow/ice products (MODIS, MISR) 1651 (Ackerman et al., 1998; Liu et al., 2004; Shi et al., 2002, 2007). The MODIS cloud mask product 1652 with confidence cloudy flag generally works well for thick warm clouds over the Arctic by using 19 1653 channels and auxiliary inputs such as the topography, but will have difficulties with optically thin 1654 cold clouds such as cirrus due to the similarity of both cloud types. A comprehensive combined 1655 cloud mask is also available for AVHRR (Saunders and Kriebel, 1988; Gesell, 1989; Key and 1656 Barry, 1989; Han et al., 1999). However, the challenge of applying a cloud mask over snow is still 1657 current even for radiometers equipped with IR and NIR bands.

1658 Another challenge of any AOT retrieval over snow is the variability of snow and sea ice types in the 1659 field, the effect of surface melt or ageing, pollution, and regarding sea ice the effect of varying sea 1660 ice concentrations. All these effects make it difficult to reliably account for the surface signal 1661 contribution to AOT for retrievals over snow surfaces even when double-viewing observational 1662 techniques (e.g. AATSR or simultaneous MODIS Terra and Aqua usage) are used. At the same 1663 time, as the AOT in the Arctic is rather low (background values 0.05, up to 0.1-0.3 during haze 1664 events with occasionally higher peaks), the surface signal is responsible for the greatest part of the 1665 TOA signal measured by satellites. Multispectral AOT retrievals are in addition challenged by a 1666 high variability in ice and snow surface types, depending on grain size, pollution, density, etc 1667 (Warren and Wiscombe, 1980; Negi et al., 2010). The variability of the aerosol types, which 1668 includes a varying scattering phase function shape, spectral behaviour and particle size distribution, 1669 makes it even more challenging to reliably retrieve the AOT, especially when spectral information 1670 on both the surface and atmosphere is used simultaneously. The sensitivity to complex polar 1671 atmospheric conditions and temperature inversions (especially for IR channels used for the retrieval 1672 or the cloud mask) are currently not taken into account and also need to be investigated. The 1673 satellite-retrieval algorithms proposed by Istomina et al. (2011), Mei et al. (2013a) and Mei et al. 
1674 (2013b) can only be used for an initial qualitative evaluation of the atmospheric aerosol load and

1675 only for selected apparently cloud-free scenes. They are able to give a correct impression of spatial 1676 and temporal AOT distributions on a regional scale under the assumption that the surface and

1677 aerosol properties do not change, but need to be further improved with more flexibility regarding

1678 surface types, their extensive validation and specifically developed cloud masking being the first 1679 priorities. Due to the above listed issues and challenges, application on a global basis is currently 1680 not possible.

\section{Optical characteristics of Arctic and Antarctic aerosols}

1683 To obtain a realistic representation of the optical properties of atmospheric aerosol derived from 1684 ground-based and ship-borne sun-photometer measurements, a set of aerosol extinction models has 1685 been defined here by taking into account the evaluations of aerosol radiative parameters determined 1686 from sun-photometric and in-situ optical measurements made at various Arctic and Antarctic sites. 1687 The main results obtained for the fine, accumulation and coarse mode particles are presented in the 1688 following two sub-sections for four Arctic and four Antarctic aerosol types.

\subsection{Arctic aerosol particle size-distributions and optical characteristics}

1691 Multi-year measurements of aerosol chemical composition and light scattering and absorption 1692 coefficients were conducted at Barrow by Quinn et al. (2002), separately for the sub-micron and 1693 super-micron particle modes, showing that: (i) extinction effects are dominated by sulphate fine 1694 particles during the spring-time Arctic haze episodes, and by sea-salt accumulation mode particles 1695 formed from wind-driven sea spray in winter, and (ii) sub-micron sulphate and sea-salt particles 1696 efficiently contribute during summer to attenuate the incoming solar radiation. Both sulphate and 1697 sea-salt particle concentrations followed well-defined annual cycles at Barrow, Alert and Arctic 1698 EMEP sites (Quinn et al., 2007). Bimodal features of the aerosol size-distribution were reported at 1699 Barrow by Delene and Ogren (2002), who found that the overall visible light scattering and 
1700 absorption at the ground-level is given over the entire year by two particle modes: (i) an 1701 accumulation mode (with mode diameter $D_{c}<1 \mu \mathrm{m}$ ) yielding annual mean values of volume 1702 scattering coefficient $\beta_{\text {sca }}=6.17 \pm 3.61 \mathrm{Mm}^{-1}$, volume absorption coefficient $\beta_{a b s}=0.36 \pm 0.38 \mathrm{Mm}^{-}$ 1703 , ground-level Ångström exponent $\alpha_{o}=1.67 \pm 0.36$, and ground-level single-scattering albedo $\omega_{o}=$ $17040.954 \pm 0.028$; and (ii) a coarse mode (with $D_{c}<10 \mu \mathrm{m}$ ), giving annual mean values of $\beta_{\text {sca }}=9.76$ $1705 \pm 5.20 \mathrm{Mm}^{-1}, \beta_{a b s}=0.39 \pm 0.41 \mathrm{Mm}^{-1}, \alpha_{o}=1.11 \pm 0.39$, and $\omega_{o}=0.965 \pm 0.023$

1706 Multimodal features of the fine particle size-distribution were also reported by Ström et al. (2003) 1707 on examining particulate matter sampled at the Zeppelin station (near Ny-Ålesund) with a 1708 Differential Mobility Particle Sizer (DMPS) over the $D<1 \mu \mathrm{m}$ diameter range. For such 1709 multimodal characteristics of the sub-micron aerosols and considering that $\alpha$ varies throughout the 1710 year from more than 1.8 (for prevailing extinction by fine particles) to less than 1 (for predominant 1711 attenuation by coarse particles), a set of particulate extinction models is proposed here, each given 1712 by a linear combination of a fine particle mode with an accumulation or coarse particle mode, to 1713 represent the optical properties of airborne aerosols. In this approach, the overall size distribution 1714 can be defined for a certain value of $\alpha$ by varying the percentage number density concentrations of 1715 both modes until the measured value of $\alpha$ is fitted.

1716 Each aerosol unimodal size-distribution curve was represented by a log-normal curve having the 1717 analytical form,

$$
N(r)=d N(r) / d(\log r)=\frac{N_{o}}{\sqrt{2 \pi}(\ln 10)(\log \sigma)} \exp \left[-\frac{1}{2}\left(\frac{\log r-\log r_{c}}{\log \sigma}\right)^{2}\right]
$$

1719 where $N_{o}$ is the total particle number concentration (measured in $\mathrm{cm}^{-3}$ ), $\mathrm{ln} 10$ is a constant 1720 approximately equal to $2.3026, \log$ is the decadal logarithm (with base $=10$ ), $\sigma$ is the geometric 1721 standard deviation, and $r_{c}$ is the mode radius (measured in $\mu \mathrm{m}$ ). Thus, the following size1722 distribution curves were defined to represent four different Arctic aerosol types: 
1723 (1) The size-distribution curve of winter-spring Arctic haze particles, consisting of: (i) a fine

1724 particle mode of dry-air Arctic water-soluble aerosol, and (ii) an accumulation particle mode of sea1725 salt particles, according to the Hess et al. (1998) OPAC models.

1726 (2) The average size distribution of summer background aerosols, consisting of: (i) a fine particle 1727 mode predominantly composed of mineral dust nuclei and water-soluble substances, and (ii) a 1728 coarse particle mode of sea-salt particles, as defined by Hess et al. (1998).

1729 (3) The average size distribution curve of Asian dust, consisting of: (i) a mineral dust nuclei mode, 1730 and (ii) a mineral coarse particle mode, having features similar to those represented by Hess et al. 1731 (1998) in the mineral dust OPAC models, and chosen to simulate an episode of Asian dust transport 1732 over a ground-layer of unpolluted aerosol observed by Stone et al. (2007) at Barrow.

1733 (4) The overall size-distribution curve of a summer background aerosol model containing BFF 1734 smoke, assumed to consist of: (i) a fine combustion particle mode, and (ii) an accumulation particle 1735 mode. Both modes were assumed to consist of a mixture of combustion dust and soot particles 1736 giving a ratio of 12.86 between the scattering and absorption coefficients, leading to a single1737 scattering albedo value $\omega=0.928$, as indicated by the in-situ measurements conducted by Mielonen 1738 et al. (2013) for Russian wildfire particles.

1739 Each of the above eight modes was represented in terms of Eq. (3) for the values of shape1740 parameters $r_{c}$ and $\sigma$ given in Table 5, while the unimodal optical/chemical characteristics were 1741 represented assuming the mass percentages of the $6 \mathrm{~S}$ dry-air components defined by Vermote et al. 1742 (1997a) and provided in Table 5 for each pair of modes, according to the chemical composition 1743 estimates made by Quinn et al. (2007) and Tomasi et al. (2012).

1744 The spectral values of the real $n(\lambda)$ and imaginary $k(\lambda)$ parts of the particle refractive index obtained 1745 for the Arctic aerosol models given in Table 5 were found to decrease very slowly with wavelength 1746 over the $0.40-1.0 \mu \mathrm{m}$ spectral range. They are reported in Table 5 for $\lambda=0.55 \mu \mathrm{m}$, together with 1747 values of the single-scattering albedo $\omega(0.55 \mu \mathrm{m})$, asymmetry factor $g(0.55 \mu \mathrm{m})$, volume extinction 1748 coefficient $\beta_{\text {ext }}(0.55 \mu \mathrm{m})$, and exponent $\alpha$. It can be seen in Table 5 that the single-scattering albedo 
$1749 \omega(0.55 \mu \mathrm{m})$ of the fine Arctic haze particle mode is equal to 0.86 and that of the accumulation mode 1750 is equal to 0.937 . Therefore, using the present bimodal model, $\omega(0.55 \mu \mathrm{m})$ is made to vary over the 1751 0.86-0.94 range as a function of the mass fractions of the fine and accumulation particles. The 1752 assumptions made for this optical parameter agree very well with ground-level measurements of $1753 \omega_{o}(0.55 \mu \mathrm{m})$ obtained from in-situ nephelometer and aethalometer ${ }^{(*)}$ measurements carried out by: 1754 (i) Bodhaine (1995), who estimated a monthly mean value of 0.928 in March at Barrow, (ii) Sharma 1755 et al. (2006), who determined an average value of 0.94 from February to May at Barrow, and (iii) 1756 Ström et al. (2003), who estimated a monthly mean value $\omega_{o}(0.55 \mu \mathrm{m})=0.94$ in spring at Zeppelin, 1757 and monthly mean values varying from 0.84 to 0.91 in late autumn and winter.

1758 The calculations presented in Table 5 provide a single-scattering albedo value $\omega(0.55 \mu m)=0.93$ 1759 for the Arctic summer background fine particle mode, and 0.81 for the corresponding coarse 1760 particle mode, suggesting that $\omega(0.55 \mu \mathrm{m})$ varies mainly over the 0.81-0.93 range during the Arctic 1761 summer. The results do not differ considerably from those of: (i) Ström et al. (2003), who found 1762 that $\omega_{o}(0.55 \mu \mathrm{m})$ assumes values varying mainly from 0.94 to 0.98 in spring and summer at 1763 Zeppelin, and (ii) Tomasi et al. (2012), who obtained monthly mean values of $\omega_{o}(0.55 \mu m)$ equal to $17640.93 \pm 0.04$ in June, $0.86 \pm 0.09$ in July, $0.91 \pm 0.08$ in August, and $0.89 \pm 0.09$ in September, 1765 yielding a seasonal average value of $0.90 \pm 0.07$ at $\mathrm{Ny}$-Ålesund during summer 2010. The values of $1766 \omega(0.55 \mu \mathrm{m})$ assumed in Table 5 for the Asian dust are close to 0.96 for the fine particle mode and 17670.67 for the coarse particle mode, indicating that this parameter is presumably subject to decrease 1768 gradually as $\alpha$ assumes lower values as a result of the increase in the relative super-micron dust 1769 content. The fine and coarse particle components of the BFF smoke were both found to yield values 1770 of $\omega(0.55 \mu \mathrm{m})$ close to 0.90 , according to Mielonen et al. (2013).

\footnotetext{
${ }^{(*)}$ for detailed technical characteristics of the two instruments, see Bodhaine (1995), and Anderson and Ogren (1998).
} 
1771 The angular distribution curves of phase function $P(\Theta)$ determined for the eight unimodal size-

1772 distribution curves defined in Table 5 to represent the four Arctic aerosol types are shown on the

1773 left-hand side of Fig. 26. The calculations clearly show that the most pronounced forward scattering

1774 lobe is produced by the Asian dust coarse mode and, to a lesser extent, by the coarse mode of Arctic

1775 summer background aerosol, which yields the lowest lateral scattering (at $\Theta=90^{\circ}$ ) and the

1776 strongest backward scattering (at $\Theta=180^{\circ}$ ).

1777 The linear combinations of fine and accumulation/coarse particle modes considered in Table 5 for 1778 the four Arctic aerosol types were made to vary until best-fit values of $\alpha$ were obtained from field 1779 sun-photometer measurements, which provide the unimodal column particle number concentrations 1780 for each field-measured value of $\tau(0.50 \mu \mathrm{m})$. The following four cases were examined: (a) the 1781 winter-spring aerosol case recorded at Eureka during the Arctic haze periods of 2007 and 2008, 1782 with average values of $\tau(0.50 \mu \mathrm{m})=0.12$ and $\alpha=1.48$, (b) the summer background aerosol case 1783 determined at Tiksi, giving mean values of $\tau(0.50 \mu \mathrm{m})=0.08$ and $\alpha=1.60$, (c) the Asian dust 1784 transport episode observed at Barrow on 16 April, 2002, yielding average daily values of $\tau(0.50$ $1785 \mu m)=0.22$ and $\alpha=0.26$, and (d) the BFF smoke case observed by Stock et al. (2012) at Ny1786 Ålesund on 23 March, 2008, giving average daily values of $\tau(0.50 \mu m)=0.22$ and $\alpha=1.50$. The 1787 best-fit bimodal size-distribution curves determined for the four cases are presented on the left-hand 1788 side of Fig. 27, together with the corresponding column particle number concentration of the fine 1789 mode $\left(N_{f}\right)$ and accumulation/coarse mode $\left(N_{a / c}\right)$. The bimodal size-distribution curves obtained for 1790 the winter-spring case (a) and the BFF smoke case (d) exhibit in practice a nearly unimodal shape, 1791 since $N_{a / c}$ is lower than $N_{f}$ by about 7 orders of magnitude in case (a) and by more than 4 orders of 1792 magnitude in case (d). Conversely, the bimodal size-distribution curves obtained in cases (b) and 1793 (c), each using one of the coarse particle modes defined in Table 5, exhibit rapidly decreasing right1794 hand wings of the columnar number content over the whole super-micron radius range, associated 1795 with sea-salt and dust particle loads. 
1798 Multimodal characteristics of the aerosol size-distribution curves were also reported at Antarctic 1799 coastal and high-altitude sites. Analyzing a set of size-segregated particle samples collected at 1800 Mario Zucchelli (Terra Nova Bay) in austral summer 1995, over the 0.035-16 $\mu$ m aerodynamic 1801 diameter range, Hillamo et al. (1998) found that the particle size distribution usually consists of four 1802 modes: (i) a mode of Aitken nuclei and fine particles, with mode diameter $D_{c}=0.07 \mu \mathrm{m}$, which 1803 contributes $\sim 1 \%$ to the total particulate mass content, (ii) an accumulation particle mode with $D_{c} \approx$ $18040.30 \mu \mathrm{m}$, contributing 14\%, (iii) a large particle mode with $D_{c} \sim 2 \mu \mathrm{m}$ (22\%), and (iv) a coarse 1805 particle mode with $D_{c} \approx 6.5 \mu \mathrm{m}(63 \%)$. Similar results were obtained by Weller and Lampert (2008) 1806 at Neumayer, revealing a seasonal cycle characterized by nss sulphate particles in austral summer,

1808 They found an average aerosol mass concentration at ground-level close to $1.1 \mu \mathrm{g} \mathrm{m}^{-3}$ in austral 1809 winter and $1.3 \mu \mathrm{g} \mathrm{m}^{-3}$ in austral summer. The average chemical composition of particulate mass 1810 consisted of: (i) $48 \%$ sea-salt, $33 \%$ nss sulphate, $12 \%$ MSA, and 7\% nitrates mixed with mineral 1811 dust and ammonium during the austral summer, and (ii) 93\% sea-salt particles, with a few percent 1812 of nss sulphate, nitrate, MSA, ammonium and mineral dust in the austral winter. Minikin et al. 1813 (1998) found that the nss sulphate and MSA concentrations measured in the austral summer at the 1814 coastal stations of Neumayer, Halley and Dumont d'Urville are closely correlated, showing a 1815 regular sequence of pronounced peaks of both such biogenic sulphur aerosol components, mainly 1816 formed from dimethyl sulfide (DMS).

1817 The aerosol chemical composition was investigated at the Finnish station of Aboa, about $150 \mathrm{~km}$ 1818 from the Atlantic Ocean coast in Queen Maud Land, by Kerminen et al. (2000), Teinilä et al. (2000) 1819 and Koponen et al. (2003), who analysed sets of regular aerosol sampling measurements conducted 1820 from December 1997 to February 1998. The sea-salt particle concentration was estimated to be 
1821 considerably lower than those measured at Mario Zucchelli and Neumayer. Multimodal features of

1822 the particle size distribution curve were detected in most cases over the $0.045 \leq D \leq 15 \mu \mathrm{m}$ range,

1823 with five principal modes: (i) a first mode of fine particles, over the 0.03-0.10 $\mu \mathrm{m}$ range, consisting

1824 of $63 \%$ nss sulphate, $29 \%$ ammonium, and $8 \%$ MSA mass percentages, (ii) two accumulation 1825 particle modes, with average values of $D_{c}$ close to 0.30 and $0.65 \mu \mathrm{m}$, both consisting on average of $182661 \%$ nss sulphate, $22 \%$ MSA, and 14\% ammonium, besides a few percents of sea-salt particles, 1827 (iii) a large particle mode, with $D_{c}$ varying from 1.4 to $1.9 \mu \mathrm{m}$, and consisting of $52 \%$ sea-salt, $27 \%$ 1828 nss sulphate, $12 \%$ MSA, and minor percentages of nitrates and ammonium ions, and (iv) a coarse 1829 particle mode, with daily mean values of $D_{c}$ varying from 2 to $5 \mu \mathrm{m}$, and containing on average $183063 \%$ sea-salt, $16 \%$ nitrate, $14 \%$ nss sulphate, $5 \%$ MSA and 2\% ammonium. These compositional 1831 characteristics indicate that biogenic sulphur compounds constitute on average more than $90 \%$ of 1832 the aerosol mass concentration of sub-micron particles, $\sim 50 \%$ of the accumulation mode particle 1833 mass, and $\sim 30 \%$ of the coarse mode particle mass. Correspondingly, sea-salt particles were found 1834 to mainly contribute to the super-micron aerosol mode by more than $60 \%$ on average. The above 1835 results were substantively confirmed by Virkkula et al. (2006), who analysed a large set of 1836 particulate samples collected in January 2000 using a 12-stage low-pressure impactor, and observed 1837 a pair of sea-salt particle modes centred at $D_{c} \approx 0.8 \mu \mathrm{m}$ and $D_{c} \approx 3 \mu \mathrm{m}$, respectively, and a pair of 1838 nitrate particle modes centred at diameters $D_{c}$ of $\sim 1.2 \mu \mathrm{m}$ and $\sim 3 \mu \mathrm{m}$.

1839 The Antarctic Plateau aerosol size-distribution were found to consist of a fine particle mode mainly 1840 composed of nss sulphate and MSA substances at South Pole during the austral summer (Hara et 1841 al., 2004), when aerosols are predominantly due to strong subsidence effects from the free 1842 troposphere. However, sea-salt accumulation and coarse particles can be often transported over the 1843 Antarctic Plateau in air masses with relatively high mass concentrations on days characterised by 1844 intense advection of oceanic air masses over the interior of Antarctic continent, associated with 1845 large storm systems (Shaw, 1988). Therefore, in the particular cases yielding values of $\alpha$ 
1846 appreciably lower than 1.8, the overall particle size-distribution was represented using a bimodal

1847 size-distribution model consisting of a fine particle mode mainly containing nss sulphates and a sea1848 salt coarse particle mode.

1849 On the basis of the above measurements, the following size-distribution curves were considered:

1850 (a) The average size distribution of Antarctic austral summer coastal aerosol was assumed to be 1851 bimodal, since the extinction effects produced by the Aitken nuclei and very fine particle modes 1852 reported by Hillamo et al. (1998) were neglected. It was represented by the linear combination of: 1853 (i) a first particle mode consisting of fine nss sulphate and sea-salt accumulation mode aerosols, 1854 with low contents of mineral nuclei and soot particles, and (ii) a coarse mode mainly composed of 1855 sea-salt particles. The composition of both modes was defined using the 6S (Vermote et al., 1997b) 1856 mass percentages reported in Table 5, according to the composition data calculated by Tomasi et al. 1857 (2012) at Mario Zucchelli and Neumayer. In both particle modes, the soot mass concentration was 1858 assumed taking into account the low values of BC mass concentration measured by Wolff and 1859 Cachier (1998) at Halley during the austral summer, ranging in general from 1.0 to $2.0 \mathrm{ng} \mathrm{m}^{-3}$.

1860 (b) The average size distribution of austral summer background aerosol over the Antarctic Plateau 1861 was represented by: (i) a fine particle mode mainly containing nss sulphates and minor percentages 1862 of sea-salt and dust particles, with a soot content equal to $40 \%$ of that estimated by Wolff and 1863 Cachier (1998) at a coastal site. and (ii) a coarse particle mode composed mainly of sea-salt 1864 particles, and containing lower mass percentages of water-soluble and dust-like 6S (Vermote et al., 1865 1997b) components, as given in Table 5.

1866 (c) The average size-distribution of Antarctic austral winter aerosol at coastal sites was not based on 1867 sun-photometer measurements, as such measurements have neither been conducted during the 1868 austral winter at coastal sites (for $66^{\circ}-75^{\circ} \mathrm{S}$ latitudes) nor at Antarctic Plateau stations. In order to 1869 achieve reliable evaluations of complex refractive index $n(\lambda)-i k(\lambda)$ and the other radiative 1870 parameters during the austral winter, the chemical composition data determined by Minikin et al. 1871 (1998) at Neumayer and other Antarctic coastal sites over the 14-year period from 1983 to 1996 
1872

1873

1874

1875

1876

1877 1878 Conversely, the sea-salt particle mass concentration was estimated by Weller and Lampert (2008) to

1879

1880

were taken into account. These in-situ measurements showed a regular sequence of pronounced mass concentration minima of biogenic sulphur aerosol components originating from DMS in austral winter and some marked peaks in summer. In particular, they found that: (i) the nss sulphate mass concentration decreased on average from 50 to $4 \mathrm{ng} \mathrm{m}^{-3}$ (i.e. by $92 \%$ ) from austral summer to winter, and (ii) MSA mass concentration decreased from 17 to $2 \mathrm{ng} \mathrm{m}^{-3}$ (i.e. by more than $88 \%$ ), because of a strong reduction in biogenic sources of both chemical species during the local winter. increase at Neumayer by more than $40 \%$, passing from an average summer value of $597 \pm 830 \mathrm{ng}$ $\mathrm{m}^{-3}$ to an average winter value of $844 \pm 1100 \mathrm{ng} \mathrm{m}^{-3}$. Despite the plausible strong decrease in seasalt particle concentration caused by the ice coverage of the ocean areas near the Antarctic continent, the observed austral winter increase in the sea-salt concentration was probably due to the more intense transport of maritime particles from the lower latitude oceanic ice-free areas characterised by higher wind speed conditions at the sea-surface.

On the basis of these remarks, it was decided to use a bimodal model to represent the austral winter aerosol at coastal sites, consisting of: (i) a fine water-soluble particle mode, and (ii) an accumulation particle mode composed mainly of sea-salt particles transported from remote ocean areas. Each mode of the three Antarctic bimodal size-distribution curves was assumed to have an analytical form given by Eq. (3) for the values of shape-parameters $r_{c}$ and $\sigma$ reported in Table 5, and to consist of the mass percentages defined in Table 5 for the four 6S (Vermote et al., 1997b) basic components.

Because of the predominant mass fractions of nss sulphate in the fine particle mode and of sea-salt in the accumulation/coarse mode, the three bimodal size-distributions of Antarctic particles considered above provided the unimodal average values of refractive index parts $n(0.55 \mu m)$ and $k(0.55 \mu m)$ given in Table 5. For these aerosol extinction models, values of $\omega(0.55 \mu m)$ ranging from $\sim 0.80$ (for the coarse mode of coastal aerosols) to 0.99 (for the accumulation mode of austral winter aerosol) were obtained (see Table 5). These estimates of $\omega(0.55 \mu \mathrm{m})$ agree very well with the 
1898 in-situ evaluations made by: (i) Virkkula et al. (2006a, 2006b) at Aboa, who obtained values of $1899 \omega_{o}(0.55 \mu \mathrm{m})>0.95$ for about $93 \%$ of in-situ measurements, and $<0.90$ for only $3.5 \%$ of cases, (ii)

1900 Weller and Lampert (2008) at Neumayer, who estimated that $\omega_{o}(0.55 \mu \mathrm{m})$ varied from 0.97 to 1.00 1901 in more than $95 \%$ of samples, and (iii) Tomasi et al. (2012), who found values of $\omega_{o}(0.55 \mu m)$ 1902 mainly ranging from 0.95 to 0.98 for the particulate chemical composition measurements made by 1903 Hillamo et al. (1998) and Fattori et al. (2005) at Mario Zucchelli, and those conducted by Weller 1904 and Wagenbach (2007), Weller et al. (2008), and Weller and Lampert (2008) at Neumayer. These 1905 findings are in good agreement with the in-situ evaluations made by: (i) Bodhaine (1995), who 1906 obtained monthly mean values of $\omega_{o}(0.55 \mu \mathrm{m})$ at South Pole, varying from 0.942 to 0.972 during 1907 the austral summer, and an annual mean value of $\omega_{o}(0.55 \mu m)=0.97$, (ii) Heintzenberg et al. (1997), 1908 who determined an annual average value of $\omega_{o}=0.965$ in the visible at South Pole; and (iii) Tuncel 1909 et al. (1989) and Arimoto et al. (2004) at South Pole, and Piel et al. (2006) at Kohnen, who obtained 1910 values of $\omega_{o}(0.55 \mu \mathrm{m})$ ranging from 0.95 to 0.98 .

1911 The daily mean values of $\tau(0.55 \mu \mathrm{m})$ retrieved by Campbell et al. (2012) from the 2007 MODIS and

1912 MISR satellite observations recorded over Antarctica were all lower than 0.10 throughout the whole 1913 year. Reliable measurements of AOT were not retrieved by Winker et al. (2010) from the CALIOP 1914 lidar observations during the Antarctic "polar night", since they were lower than the lidar detection 1915 limit. This was confirmed by Winker et al. (2013), who showed that the CALIPSO mean cloud-free 1916 day-time and night-time values of $\tau(0.532 \mu \mathrm{m})$ were all lower than 0.05 over the Antarctic continent 1917 and the peri-Antarctic regions during the long austral winter, from March to November. Therefore, 1918 the AOT contribution exhibited by fine particles is in general $<0.01$ in the austral winter months, 1919 while that of sea-salt accumulation mode particles increases appreciably yielding daily values of $1920 \tau(0.50 \mu \mathrm{m})$ varying from 0.02 to 0.05 during the coldest season, and values of $\alpha$ mainly ranging 1921 from 0.50 to 0.70 over the peri-Antarctic regions (Winker et al., 2013). 
1922 The angular diagrams of phase function $P(\Theta)$ obtained for the unimodal size-distribution curves 1923 defined in Table 5 for the three Antarctic aerosol types are presented on the right-hand side of Fig.

192426 as a function of scattering angle $\Theta$. The most pronounced forward scattering lobe is given by the 1925 coarse particle mode of the austral summer coastal aerosol, while the austral summer coarse particle 1926 mode of the Antarctic Plateau size-distribution yields a slightly lower forward scattering lobe and 1927 the most marked backward and lateral (at $\Theta=90^{\circ}$ ) scattering intensities. As a result, four case 1928 studies of Antarctic aerosol were analysed to determine the corresponding best-fit linear 1929 combinations of fine and accumulation/coarse particle modes, for the following sets of $\tau(0.50 \mu \mathrm{m})$ 1930 and $\alpha$ : (i) the austral summer coastal aerosol case (e) obtained at Mario Zucchelli for the mean 1931 values of $\tau(0.50 \mu \mathrm{m})=0.030$ and $\alpha=0.90$, (ii) the austral summer coastal aerosol case (f)

1932 determined at Neumayer for the mean values of $\tau(0.50 \mu \mathrm{m})=0.043$ and $\alpha=0.68$, (iii) the austral 1933 summer Antarctic Plateau aerosol case (g) defined at South Pole for the mean values of $\tau(0.50 \mu m)$ $1934=0.018$ and $\alpha=1.49$, and (iv) the austral winter aerosol case (h) defined on the basis of in-situ 1935 aerosol measurements conducted during the austral winter months at Neumayer and evaluated to 1936 give the average seasonal values of $\tau(0.50 \mu \mathrm{m})=0.035 \pm 0.015$ and $\alpha=0.65 \pm 0.10$. The bimodal 1937 size-distribution curves obtained by applying the best-fit procedure for the four values of $\alpha$ given 1938 above are shown on the right-hand side of Fig. 27, where the columnar number contents $N_{f}$ and $N_{a / c}$ 1939 are also given. The size-distribution curves obtained in cases (e), (f) and (g) by assuming the 1940 presence of a coarse mode are characterized by robust right-hand wings over the super-micron 1941 radius range. In fact, in the two coastal cases (e) and (f), the columnar number content $N_{a / c}$ is lower 1942 than $N_{f}$ by more than 6 and 5 orders of magnitude, respectively. Figure 27 also shows that the 1943 relative contribution of sea-salt coarse mode particles is appreciably higher at Neumayer than at 1944 Mario Zucchelli, according to the results shown in Figs. 9 and 11, respectively. Considerably 1945 different values of $N_{f}$ and $N_{a / c}$ by at least nine orders of magnitude were found in case (g) for the 1946 Antarctic Plateau aerosol, giving a measure of the large differences characterizing the atmospheric 
1947

1948

1949 1950

concentrations of nss sulphate fine mode and sea-salt coarse mode particles. By contrast, the accumulation mode used in case (h) to represent the sea-salt particles during the austral winter seems to contribute more weakly (by only 4 orders of magnitude) to enhance $N_{a / c}$, with respect to $N_{f}$

\subsection{Evaluations of direct aerosol-induced radiative forcing effects in polar regions}

Atmospheric aerosols are known to affect the radiation balance of the surface-atmosphere system (i) directly through interaction with solar (short-wave) radiation (Haywood and Boucher, 2000) and terrestrial (long-wave) radiation (Lubin et al., 2002), and (ii) indirectly, by acting as cloud condensation nuclei and modifying cloud albedo characteristics (Schwartz and Andreae, 1996). They can considerably modify the horizontal and vertical distribution of radiant energy passing through the atmosphere (Stone et al., 2008), generally causing more intense changes in the outgoing flux of solar radiation at TOA-level than those affecting the long-wave radiation, as clearly indicated by Mie (1908) theory. For this reason, the direct aerosol-induced radiative forcing (hereinafter referred to as DARF) is commonly evaluated by only considering variations induced by airborne aerosols on the short-wave radiation flux and by neglecting those affecting long-wave radiation. Instantaneous DARF effects can vary on a diurnal basis as a function of solar zenith angle $\theta_{0}$, and closely depend on: (a) aerosol scattering and absorption characteristics (represented in terms of parameters $\tau(\lambda), \alpha, n(\lambda), k(\lambda), P(\Theta), g(\lambda)$, and $\omega(\lambda)$ at solar wavelengths), and (b) the spectral and geometrical features of surface reflectance. Three different instantaneous DARF terms are usually considered in these calculations: (i) at the TOA-level, as the difference $\Delta F_{T O A}(t)$ estimated at a certain time $t$ between the upward solar radiation fluxes emerging from the real atmosphere with aerosols and from the pristine atmosphere without aerosols (Hänel et al., 1999), (ii) at the bottom-of-atmosphere (BOA) level (i.e. at the surface), as the difference $\Delta F_{B O A}(t)$ estimated at a certain time $t$ between the net short-wave fluxes determined at surface-level in the atmosphere with aerosols and in the same atmosphere assumed without aerosols (Satheesh and Ramanathan, 2000), 
1973 and (iii) within the atmosphere, as the difference $\Delta F_{A T M}(t)$ between terms $\Delta F_{T O A}(t)$ and $\Delta F_{\mathrm{BOA}}(t)$

1974 (Ramanathan et al., 2001). To give an average measure of the daily DARF effects, the instantaneous

1975 terms $\Delta F_{T O A}(t), \Delta F_{B O A}(t)$ and $\Delta F_{A T M}(t)$ are generally evaluated at pre-fixed hours of the day, and 1976 then integrated over the entire period from sunrise to sunset, and divided by the 24-hour period. The 1977 corresponding diurnally averaged DARF terms $\triangle F_{T O A}, \Delta F_{B O A}$ and $\triangle F_{A T M}$ were calculated by 1978 following such a procedure, based on the Bush and Valero (2003) criteria. Negative values of $\Delta F_{T O A}$ 1979 indicate that aerosols cause an increase in the radiation budget of the surface-atmosphere system at 1980 TOA-level, producing direct cooling effects on the climate system, while positive values of $\Delta F_{T O A}$ 1981 indicate the occurrence of a warming effect during the day. Term $\triangle F_{B O A}$ at the surface gives a 1982 measure of the perturbation induced by airborne aerosols in the net flux reaching the surface, which 1983 may be positive (warming) or negative (cooling), while term $\Delta F_{A T M}=\Delta F_{T O A}-\Delta F_{B O A}$ defines the 1984 radiation surplus (or deficit) induced by aerosols within the atmosphere. In practice, $\Delta F_{A T M}$ is the 1985 amount of latent heat released in the atmosphere by aerosols and internally redistributed with the 1986 effects of modifying both temperature gradients and atmospheric circulation.

1987 Calculations of $\Delta F_{T O A}, \Delta F_{B O A}$ and $\Delta F_{A T M}$ have been made by Tomasi et al. (2014) using the 1988 radiative transfer 6S code of Vermote et al. (1997a) for the aerosol loads and composition, and 1989 optical characteristics defined in Table 6, pertaining to 11 Arctic aerosol types and 4 Antarctic 1990 background austral summer aerosol types. The calculation procedure consisted of the following 1991 seven steps:

1992 (i) Determination of the columnar aerosol extinction parameters $\tau(\lambda)$ and $\alpha$ from the field sun1993 photometer measurements collected at Barrow, Ny-Ålesund, Summit, Sodankylä, Tiksi, Mario 1994 Zucchelli, Neumayer, Dome Concordia and South Pole, from which the average values of $\tau(0.50$ 1995 $\mu m)$ and $\alpha(0.40-0.87 \mu m)$ given in Table 6 were obtained. 
1996 (ii) Calculation of the spectral values of parameters $n(\lambda)$ and $k(\lambda)$ for the chemical composition data 1997 based on the OPAC mass percentages of fine and accumulation/coarse particles defined by Hess et 1998 al. (1998) for the six OPAC basic components reported in Table 6 at 50\% relative humidity of air.

1999 (iii) Definition of the multimodal linear combinations of the size-distribution curves for the 15 2000 aerosol types considered in Table 6 to fit the values of $\alpha(0.40-0.87 \mu \mathrm{m})$ given in Table 6.

2001 (iv) Calculation of the aerosol single scattering albedo $\omega(0.55 \mu \mathrm{m})$ reported in Table 6 for the 15 2002 multimodal size-distribution curves defined at the previous step.

2003 (v) Selection of the BRDF surface reflectance models of Tomasi et al. (2013) to represent the 2004 surface reflectance characteristics of the land surfaces described in terms of MODIS Level 3.0 2005 MCD43C3 products around the principal sun-photometer stations, and those of Arctic and Antarctic 2006 oceanic surfaces. The analysis of such observational data suggested that the following models were 2007 suitable in the present calculations: (a) the BRDF ocean surface reflectance model OS1, defined for 2008 surface wind velocity $V_{w}=2 \mathrm{~m} \mathrm{~s}^{-1}$ and giving a value of broadband albedo $A_{b}\left(\theta_{0}=60^{\circ}\right)=0.193$, (b) 2009 the BRDF surface reflectance model VS1, yielding a value of $A_{b}\left(\theta_{0}=60^{\circ}\right)=0.155$, and used to 2010 represent a land area covered by tundra and conifer forests in the surroundings of Barrow, 2011 Sodankylä and Tiksi, (c) the BRDF land surface reflectance model PS1 for land surfaces covered by 2012 snow-fields and glaciers, giving a value of $A_{b}\left(\theta_{0}=60^{\circ}\right)=0.854$, and used to represent the surface 2013 reflectance characteristics observed around Summit in the Arctic and Neumayer, Dome Concordia 2014 and South Pole in Antarctica for fresh snow conditions, (d) the BRDF surface albedo model PS2, 2015 yielding a value of $A_{b}\left(\theta_{0}=60^{\circ}\right)=0.775$, which was adopted to represent the surface reflectance 2016 characteristics for land areas covered by slightly polluted snow (at Sodankylä) and not entirely 2017 snow-covered areas (Mario Zucchelli, Neumayer, and other coastal sites), (e) the BRDF model PS3, 2018 giving $A_{b}\left(\theta_{0}=60^{\circ}\right)=0.564$, which was chosen to represent the surface albedo characteristics 2019 observed over Spitsbergen in late winter and early spring, and (f) the BRDF model PS4, yielding 
$2020 A_{b}\left(\theta_{0}=60^{\circ}\right)=0.329$, which realistically represents the mixed ice-covered and ice-free land areas 2021 around Ny-Ålesund in late spring and summer.

2022 (vi) Calculations of the daily time-patterns of instantaneous and diurnally averaged DARFs were 2023 made using the 6S (Vermote et al., 1997a) radiative transfer code for: (a) the values of $\tau(0.50 \mu \mathrm{m})$ 2024 and $\alpha(0.40-0.87 \mu \mathrm{m})$ defined in Table 6 for the various aerosol types and assumed to be stable from 2025 sunrise to sunset, (b) the values of angle $\theta_{0}$ calculated at the various hours of the day, for the above 2026 stations and seasonal periods, (c) the multimodal size-distribution curves determined at step (iii), 2027 (d) the spectral values of $\omega(\lambda)$ for each of the multimodal size-distribution curves determined at step 2028 (iv), and (e) the surface albedo models chosen at step (v) for the various Arctic and Antarctic sites. 2029 The time-patterns of $\Delta F_{T O A}(t), \Delta F_{B O A}(t)$ and $\Delta F_{A T M}(t)$ were then integrated to calculate the daily 2030 values of $\triangle F_{T O A}, \Delta F_{B O A}$ and $\triangle F_{A T M}$ given in Table 6 for the various aerosol types and BRDF surface 2031 albedo models.

2032 Examining the results given in Table 6, it can be seen that $\triangle F_{T O A}$ varies appreciably at Barrow as 2033 one passes from the OS1 to VS1 model in the Asian dust (AD) case, and from the OS1 to PS2 2034 model in the BFF smoke case, while only limited variations of $\Delta F_{T O A}$ from about $-10 \mathrm{~W} \mathrm{~m}^{-2}$ to no 2035 more than $+10 \mathrm{~W} \mathrm{~m}^{-2}$ were obtained for the background summer aerosol and Arctic haze cases 2036 considered at the 5 above-chosen Arctic sites. Similar features were also noted for $\triangle F_{B O A}$, 2037 illustrating larger variations in the $\mathrm{AD}$ and $\mathrm{BFF}$ aerosol cases monitored at Barrow, and mainly 2038 ranging from -5 to $+5 \mathrm{~W} \mathrm{~m}^{-2}$ in all the background summer aerosol and Arctic haze cases. 2039 Correspondingly, rather large variations in $\triangle F_{A T M}$ were obtained not only for the Barrow $\mathrm{AD}$ and 2040 BFF cases but also for the Arctic haze cases observed at Barrow and Ny-Ålesund for $\tau(0.50 \mu m)>$ 2041 0.10. In particular, we have estimated an Asian dust value of $\Delta F_{T O A} \approx 9 \mathrm{~W} \mathrm{~m}^{-2}$ for $\tau(0.50 \mu \mathrm{m})=$ $2042 \quad 0.20$ measured at Barrow.

2043 The diurnally averaged DARF terms $\Delta F_{T O A}, \Delta F_{B O A}$ and $\Delta F_{A T M}$ given in Table 6 for four Antarctic 2044 background austral summer aerosol cases indicate that larger variations have been estimated at 
2045 Mario Zucchelli and Neumayer, passing from the low surface reflectance oceanic model OS1 to the 2046 land surface albedo model PS2 characterised by highly reflecting and snow-covered surfaces. 2047 Conversely, very limited variations in the three DARF terms have been obtained at the four 2048 Antarctic sites, when passing from one PS land surface albedo model to another, since they all 2049 pertain to land surfaces covered by glaciers and snow fields that do not exhibit marked differences 2050 in their reflectance characteristics. Actually, it is important to mention that the above DARF 2051 evaluations may be affected by large uncertainties, associated with the numerous approximations 2052 made in the above calculations when: (a) assuming constant time-patterns of AOT and stable 2053 aerosol optical parameters throughout the day, (b) neglecting the occurrence of variations in the 2054 scattering, absorption and extinction properties of aerosol with height, and assuming that the 2055 vertical profiles of such optical parameters did not exhibit multi-layered features, (c) using 2056 simplified radiative transfer codes in a cloud-free atmosphere, which can lead to significant errors 2057 in estimating the DARF effects, as pointed out by Valero and Bush (1999), and (d) choosing 2058 inappropriate surface reflectance models to represent the surface albedo characteristics, as would 2059 especially be the case for the VS1 and OS1 models, which may differ considerably in some cases 2060 from the real surface conditions, as pointed out by Stone et al. (2008). With regard to this, 2061 calculations of the DARF effects made by Tomasi et al. (2014) using the sets of four oceanic 2062 surface (OS) and four vegetation-covered (VS) BRDF models indicate that changes varying from $206310 \%$ to $50 \%$ may affect the calculations of $\Delta F_{T O A}$ and $\Delta F_{B O A}$, and consequently even greater 2064 differences can be found in evaluating $\Delta F_{A T M}$. Therefore, it is fair to highlight that the present 2065 evaluations of $\Delta F_{T O A}, \Delta F_{B O A}$ and $\Delta F_{A T M}$ obtained using the OS1 calm-wind ocean model could 2066 differ appreciably from those occurring for stronger winds causing higher surface reflectance 2067 conditions in sea areas.

2068 Calculations of the DARF efficiency parameters $E_{T O A}, E_{B O A}$ and $E_{A T M}$ were finally made by dividing 2069 the values of $\Delta F_{T O A}, \Delta F_{B O A}$ and $\Delta F_{A T M}$ given in Table 6 for the various polar aerosol types by the 2070 corresponding mean values of $\tau(0.50 \mu \mathrm{m})$. The evaluations of $E_{T O A}, E_{B O A}$ and $E_{A T M}$ are shown in 
2071 Fig. 28 as a function of the broadband albedo $A_{b}\left(\theta_{0}=60^{\circ}\right)$ determined for the various BRDF surface 2072 reflectance models chosen above. The values of $E_{T o A}, E_{B o A}$ and $E_{A t m}$ obtained at the five Arctic sites 2073 for various aerosol types indicate that DARF efficiencies are subject to large variations when 2074 passing from the low surface albedo characteristics of the VS1 and OS1 models to the high 2075 reflectance surfaces of the PS models. The results shown in Fig. 28 indicate that:

2076 (a) $E_{T O A}$ increases from less than $-100 \mathrm{~W} \mathrm{~m}^{-2}$ over the VS1 surface (for BG summer aerosol over 2077 sea, at $\mathrm{Ny}$-Alesund) to more than $+100 \mathrm{~W} \mathrm{~m}^{-2}$ over the PS4 surface (for Arctic dense summer 2078 aerosol at Ny-Ålesund), and assumes slightly positive values as the broadband albedo increases 2079 from 0.56 to 0.85 , ranging from about $+30 \mathrm{~W} \mathrm{~m}^{-2}$ (over the PS2 surface for Arctic haze at 2080 Sodankylä and for BG summer aerosol at Dome Concordia) to no more than $+92 \mathrm{~W} \mathrm{~m}^{-2}$ (over the 2081 PS2 surface, for Asian dust at Barrow). These estimates had relative standard deviations varying on 2082 average from $10 \%$ over the PS4 surface to $50 \%$ over the VS1 and OS1 surfaces (i.e from 6 to $26 \mathrm{~W}$ $\left.2083 \mathrm{~m}^{-2}\right)$.

2084 (b) $E_{B O A}$ varies from less than $-100 \mathrm{~W} \mathrm{~m}^{-2}$ over the VS1 surface (for BG summer aerosol at Tiksi) to 2085 around $+80 \mathrm{~W} \mathrm{~m}^{-2}$ over the OS1 surface (for Arctic haze at Barrow). The estimates of $E_{B O A}$ obtained 2086 for the high-reflectance PS surface reflectance models did not vary by much with the aerosol type, 2087 ranging from $-57 \mathrm{~W} \mathrm{~m}^{-2}$ (for Arctic $\mathrm{BG}$ aerosol at $\mathrm{Ny}-\AA \AA^{1}$ lesund) to $+20 \mathrm{~W} \mathrm{~m}^{-2}$ (for Antarctic BG 2088 summer aerosol at Dome Concordia).

2089 (c) $E_{A T M}$ varies from about $-240 \mathrm{~W} \mathrm{~m}^{-2}$ over the OS1 surface (for Antarctic BG summer aerosol at 2090 Mario Zucchelli) to more than $+150 \mathrm{~W} \mathrm{~m}^{-2}$ over the PS4 surface (for Arctic dense summer aerosol 2091 at Ny-Ålesund). Figure 28 shows that $E_{A T M}$ exhibits a large range over the VS1 and OS1 surfaces, 2092 and then assumes stable and positive values over the PS surfaces, varying from $+10 \mathrm{~W} \mathrm{~m}^{-2}$ (for 2093 Antarctic BG summer aerosol at Dome Concordia) to $+151 \mathrm{~W} \mathrm{~m}^{-2}$ over the PS4 surface (for dense 2094 Arctic haze at Ny-Ålesund). 
2095 The present DARF efficiency evaluations are affected by considerable uncertainties, since they 2096 were determined with relative standard deviations varying from about $\pm 10 \%$ (over the PS4 surface) 2097 to around $\pm 50 \%$ (over the VS1 and OS1 surfaces).

2098 The results shown in Fig. 28 have been obtained for various Arctic and Antarctic aerosol types with 2099 values of $\omega(0.55 \mu \mathrm{m})$ ranging from about 0.76 (for BFF smoke at Barrow) to nearly 1.00 (for 2100 Antarctic background aerosol at Dome Concordia). The value of $E_{T O A}$ for the BFF smoke load 2101 observed at Barrow was found to be of $-68 \pm 27 \mathrm{~W} \mathrm{~m}^{-2}$ over the tundra (VS1) surface, while Stone 2102 et al. (2008) estimated an average efficiency value of $-20 \mathrm{~W} \mathrm{~m}^{-2}$ in summer 2004. The 2103 corresponding value of $E_{B O A}$ was estimated by us at $-95 \pm 36 \mathrm{~W} \mathrm{~m}^{-2}$, while Stone et al. (2008) 2104 estimated a lower average efficiency of about $-40 \mathrm{~W} \mathrm{~m}^{-2}$. Thus, we obtained a value of $E_{A T M}$ equal 2105 to $+27 \pm 63 \mathrm{~W} \mathrm{~m}^{-2}$, against an estimate of $+20 \mathrm{~W} \mathrm{~m}^{-2}$ by Stone et al. (2008), resulting in an 2106 atmospheric warming rate of about $1 \mathrm{~K}$ per day.

2109 Monthly mean values of $\tau(0.50 \mu \mathrm{m})$ and Ångström exponent $\alpha$ determined from multi-year sets of 2110 ground-based sun-photometer measurements at 21 polar sites, yielded a comprehensive picture of 2111 atmospheric turbidity conditions due to polar aerosols. The results are presented as a function of the 2112 winter-spring and summer periods over the whole Arctic region and include observations conducted 2113 in Alaska, Northern Canada, Greenland, Svalbard, Northern Scandinavia and Northern-Central 2114 Siberia. The analysis of the measurements acquired at the 12 Arctic sites listed in Table 1 2115 highlighted the seasonality of columnar aerosol extinction parameters, showing that $\alpha$ ranges 2116 mainly from 1.0 to 1.6 throughout the year at all stations, and $\tau(0.50 \mu \mathrm{m})$ values were mainly lower 2117 than 0.08 in summer (for background aerosol) and appreciably higher during the winter-spring 2118 period. The latter phenomenon is associated with the occurrence of dense Arctic haze episodes that 2119 are often observed at remote Arctic sites as the result of the transport of anthropogenic polluted 
aerosols from the industrialized and most densely populated areas of mid-latitude North America,

2121 Europe and Asia.

2122 Sun-photometer measurements collected during the Antarctic summer were analysed for six coastal 2123 sites (Marambio, Neumayer, Novolazarevskaya, Mirny, Syowa, Mario Zucchelli), one mid-altitude 2124 station (Troll) and two high-altitude bases on the Antarctic Plateau (Dome Concordia and South 2125 Pole). Monthly mean $\tau(0.50 \mu \mathrm{m})$ values usually ranged from less than 0.02 on the Antarctic Plateau to no more than 0.06 at the coastal stations, with $\alpha$ decreasing respectively from extremes of 1.8 (at 2127 South Pole and Dome Concordia, for aerosols dominated by nss sulphates), to around 0.6 at Mario 2128 Zucchelli, Neumayer and the other coastal sites (where aerosol light extinction is predominantly 2129 influenced by sea-salt particles).

2130 Ship-borne sun-photometer measurements were conducted during 14 spring and summer 2131 AERONET/MAN cruises across the Greenland Sea and Norwegian Sea, the West Siberian Sea and 2132 the North-American Arctic Ocean. The results yielded monthly mean estimates of $\tau(0.50 \mu m)$ and $\alpha$ 2133 that were found to be comparable with results obtained from ground-based sun-photometer 2134 measurements taken at the stations located on the coasts of the same oceanic sectors during the 2135 March to September period, thus confirming the covariance features of $\tau(0.50 \mu m)$ and $\alpha$ 2136 determined at the ground-based sun-photometer sites. The analysis of ship-borne sun-photometer 2137 measurements performed during the 18 AERONET/MAN cruises conducted in the coastal and off2138 shore Antarctic areas of the Indian, Pacific and Atlantic Oceans and along the Antarctic Peninsula 2139 coasts showed that the monthly mean values of $\tau(0.50 \mu \mathrm{m})$ varied between the extremes of 0.02 and 21400.06 from December to April, while decreasing from 0.12 in October to 0.07 in November for 2141 measurements acquired around the Antarctic Peninsula. The large magnitude AOTs in the latter 2142 case were likely the result of stronger winds from the northern and western quadrants producing 2143 more sea-salt particles, which are transported toward the continent, while the rapidly decreasing 2144 trend results from a rapid decrease in the amplitude of these winds (a contention that is further 2145 supported by the corresponding increase in $\alpha$ values, between October and January, while $\tau(0.50$ 
$\mu m$ ) systematically decreases). In more general terms we would argue that scattergrams of $\alpha$ versus

$2147 \tau(0.50 \mu \mathrm{m})$ for the ensemble of both land-based and ship-borne based sun-photometry showed a 2148 roughly inverse relationship of high $\alpha$, small $\tau(0.50 \mu \mathrm{m})$ to low $\alpha$, high $\tau(0.50 \mu \mathrm{m})$ that was 2149 representative of a progressive transformation from fine mode dominated nss sulphates above the 2150 Antarctic Plateau to sea-salt dominated aerosols for coastal sites.

2151 The vertical distribution of the aerosol extinction coefficient was investigated with ground-based 2152 lidars at Arctic and Antarctic sites. In particular, the monthly mean vertical profiles of backscatter 2153 coefficient, along with lidar ratio trends and depolarisation ratio covariance with backscattering 2154 coefficient were illustrated for tropospheric altitudes using data acquired at Ny-Ålesund by the AWI 2155 KARL lidar from 1 November, 2012, to 31 October, 2013. As part of this investigation, we 2156 illustrated the seasonal variations of integrated backscatter coefficient and lidar ratio, as influenced 2157 by Arctic haze episodes in late winter and spring, and the background aerosol in summer.

2158 Evaluations of AOT in the visible have been obtained using the operational algorithms applied to 2159 MODIS (Levy et al., 2013; Glantz et al., 2014), MISR (Diner et al., 2005b; Kahn et al., 2010) and 2160 AATSR (Holzer-Popp et al., 2013) satellite observations, which were found to substantially agree 2161 with the values of AOT obtained from the ground-based and ship-borne sun-photometer 2162 measurements conducted in the Arctic and Antarctic open-water regions. Reliable evaluations of $2163 \tau(0.55 \mu \mathrm{m})$ have also been retrieved from the AATSR measurements recorded over the Arctic 2164 oceanic and land regions covered by sea ice, land ice and snow using observations taken in different 2165 spectral channels (Istomina et al., 2011), and by using the DVMS method (Mei et al., 2013b). These 2166 retrievals allow the aerosol spatial distribution (e.g., pollution events) to be analyzed on short term 2167 scales, but may contain an AOT offset due to many challenges connected to virtually unknown 2168 surface types and aerosol optical properties. The global application of these procedures is at present 2169 a challenging problem because of the very high sensitivity of the retrievals to unscreened thin 2170 clouds. In fact, these data are already affected by large uncertainties and need to be further 2171 validated, to overcome the errors that may arise from cloud contamination and the complex picture 
2172 of polar conditions (low values of AOT, various aerosol/cloud types, atmospheric inversions, 2173 variable features of snow- and ice-covered surface reflectance,....).

2174 The main characteristics of multimodal particle size-distribution curves have been defined by: (i) 2175 taking into account the in-situ aerosol sampling measurements conducted at various Arctic sites 2176 (Barrow, Ny-Ålesund, Sodankylä) and Antarctic sites (Mario Zucchelli, Neumayer, Aboa, South 2177 Pole, Dome Concordia), and (ii) assuming that the overall size-distribution curves determined at the 2178 various sites consist in general of a fine particle mode and an accumulation or coarse particle mode, 2179 linearly combined to give a bimodal aerosol columnar load for each value of $\alpha$ obtained from the 2180 field measurements. Eight log-normal curves were defined for the Arctic stations on the basis of in2181 situ particle samples collected for Arctic haze, summer background aerosol, Asian dust and BFF 2182 smoke. They can be used for each spectral set of sun-photometer $\tau(\lambda)$ measurements to fit the 2183 derived value of $\alpha$. The radiative parameters of the eight unimodal curves were defined by taking 2184 into account the complex refractive index and single scattering albedo derived from in-situ 2185 measurements conducted with nephelometers and aethalometers and/or using the simulations of the 2186 aerosol optical properties made with the aerosol extinction models given by the $6 \mathrm{~S}$ code. Six log2187 normal curves were defined to represent the unimodal size-distribution curves of Antarctic fine, 2188 accumulation and coarse particles, using field data obtained from the aerosol collected at coastal 2189 and high-altitude sites. The optical properties of particulate matter were defined according to the 2190 data provided by the in-situ active remote sensing measurements, and used to determine the optical 2191 characteristics of six Antarctic log-normal size-distribution curves shown in Table 5.

2192 Assumptions about the aerosol optical properties are totally based on the particulate chemical 2193 composition measured at the ground and, therefore, may differ appreciably from airborne particles 2194 suspended within the upper layers of the atmosphere in all cases of aerosol transport from remote 2195 areas (like Arctic haze, Asian dust, and BFF smoke), as shown for instance by the PAMARCMiP 2196 airborne measurements conducted in April 2009 (Stone et al., 2010). However, the best-fit 2197 procedure to combine the fine particle mode with the accumulation/coarse particle mode to fit the 
2198 value of $\alpha$ will have probably allowed us to evaluate the average spectral features of the column 2199 loading consisting of larger particles.

2200 The bimodal size-distribution curves of Arctic and Antarctic aerosol obtained as linear 2201 combinations of the fine particle and accumulation/coarse particle modes have been defined by 2202 varying their columnar number contents until a best-fit value of $\alpha$ was obtained for each spectral 2203 series of $\tau(\lambda)$. All these bimodal models were assumed to exhibit the well-defined optical properties 2204 given in Table 5 and to represent the most relevant optical characteristics of Arctic and Antarctic 2205 columnar aerosol. Additional realistic multimodal extinction models of fine, accumulation and 2206 coarse particles have been defined as linear combinations of the OPAC components proposed by 2207 Hess et al. (1998), which fit the mean values of $\alpha$ determined for different columnar aerosol types. 2208 Using these multimodal aerosol extinction models, instantaneous and diurnally averaged DARF 2209 effects induced by atmospheric aerosol at the TOA- and BOA-levels, and within the atmosphere 2210 have been calculated over sea and land surfaces by using the sets of BRDF surface reflectance 2211 models determined by Tomasi et al. (2013) for vegetation-covered, oceanic, and polar snow2212 covered surfaces. The results indicate that the diurnally averaged DARF terms vary strongly as a 2213 function of $\tau(0.50 \mu \mathrm{m})$, aerosol single scattering albedo and surface albedo. The corresponding 2214 efficiency at the TOA-level was found to increase appreciably as surface albedo over sea and land 2215 increases until higher and more stable values over the snow- and ice-covered surfaces are attained. 2216 Less variable values and a more limited dependence of the BOA-level DARF efficiency on surface 2217 albedo were found, so that the atmospheric DARF efficiency resulted in: (1) a stronger increase 2218 when passing from vegetation-covered and oceanic surfaces to surfaces covered only in part by 2219 snow, and (2) more stable positive values over the polar surfaces covered by fresh snow and clean 2220 glaciers in the Arctic and Antarctic regions.

\section{Acknowledgments.}


2223 The present study was developed as a part of the CLIMSLIP (Climate Impacts of Short-Lived 2224 Pollutants in the Polar Regions) joint project, approved by the European Polar Consortium and coordinated by A. Stohl at NILU (Kjeller, Norway), and supported by the Italian Research Programme in Antarctica (PNRA). The authors gratefully acknowledge the Office of Antarctic Observation of the Japan Meteorological Agency (Tokyo, Japan), for supplying the data-set of EKO sun-photometer measurements carried out at Syowa (Antarctica) from 2000 to 2011. In general we acknowledge the support provided by the AERONET network in the Arctic and Antarctica and the AEROCAN / AERONET sub-network in the Canadian Arctic. The Cimel sun-photometer data at Barrow (Alaska) were collected by the U.S. Department of Energy as part of the Atmospheric Radiation Measurement Program Climate Research Facility (ARM) and processed by AERONET. James H. Butler (Global Monitoring Division, Earth System Research Laboratory (ERL), National Oceanic and Atmospheric Administration (NOAA), Boulder, Colorado, USA) is acknowledged for his effort in establishing and maintaining the activities at the AERONET South Pole AmundsenInstitute of Atmospheric Optics (IAO), Siberian Branch, Russian Academy of Sciences, Tomsk, 2238 Russia) are also acknowledged for their participation to field measurements conducted at 2239 Barentsburg and in Antarctica. Author's acknowledgements are also due to the managerial and 2240 operational support given by M. Fily (LGGE, CNRS, Grenoble, France) at the AERONET Antarctic Dome Concordia station, and to the P.I.s of the AERONET/MAN cruises conducted in the Arctic and Antarctic Oceans, during which Microtops measurements of aerosol optical thickness 2243 were performed and examined in the present analysis: Patricia K. Quinn (NOAA Pacific Marine 2244 Environmental Laboratory, Seattle, Washington, USA), Andrey Proshutinsky (Woods Hole 2245 Oceanographic Institution, Woods Hole, Massachusetts, USA), Carlos Duarte (Instituto 2246 Mediterráneo de Estudios Avanzados, Esporles, Mallorca, Spain), Simon Bélanger (Université du 2247 Québec, Rimouski, Québec, Canada), Elizabeth A. Reid (Naval Research Laboratory, Monterey, 2248 California, USA), Gennadi Milinevsky (Space Physics Laboratory, Taras Shevchenko National 
2249 University of Kyiv, Kyiv, Ukraine), and Heitor Evangelista (Rio de Janeiro State University, 2250 Brazil). The analyses and visualizations used in this paper to obtain the sets of MODIS and MISR 2251 daily aerosol optical thickness Level-3 data over the Arctic and Antarctic regions were produced 2252 with the Giovanni online data system, developed and maintained by the NASA GES DISC. 


\section{References}

Aaltonen, V., Lihavainen, H., Kerminen, V.-M., Komppula, M., Hatakka, J., Eneroth, K., Kulmala,

Ackermann, J., 1998. The extinction-to-backscatter ratio of tropospheric aerosol: A numerical study. Journal of Atmospheric and Oceanic Technology 15, 4, 1043-1050, doi:10.1175/1520-

M., Viisanen, Y., 2006. Measurements of optical properties of atmospheric aerosols in Northern Finland. Atmospheric Chemistry and Physics 6, 1155-1164, doi:10.5194/acp-61155-2006. 0426(1998)015<1043:TETBRO>2.0.CO;2.

Ackerman, S. A., Strabala, K. I., Menzel, W. P., Frey, R. A., Moeller, C. C., Gumley, L. E., 1998. Discriminating clear sky from clouds with MODIS, Journal of Geophysical Research 103, D24, 32141-32157, doi:10.1029/1998JD200032.

Ackerman, S. A., Frey, R., Strabala, K., Liu, Y., Gumley, L., Baum, B., Menzel, P., 2010. Discriminating Clear-Sky from Cloud with MODIS - Algorithm Theoretical Basis Document. Products: MOD35. ATBD Reference Number: ATBD-MOD-06 (http://modisatmos.gsfc.nasa.gov/MOD35_L2/atbd.html).

Allen, R. C. Jr., Durkee, P. A., Wash, C. H., 1990. Snow/cloud discrimination with multispectral satellite measurements. Journal of Applied Meteorology 29, 10, 994-1004, doi:10.1175/15200450(1990)029<0994:SDWMSM>2.0.CO;2.

Ångström, A., 1964. The parameters of atmospheric turbidity. Tellus 16, 64-75, doi:10.1111/j.21533490.1964.tb00144.x.

Anderson, T. L., Ogren, J. A., 1998. Determining aerosol radiative properties using the TSI 3563 Integrating Nephelometer. Aerosol Science and Technology 29, 57-69, doi:10.1080/02786829808965551.

Ansmann, A., Wandinger, U., Riebesell, M., Weitkamp, C., Michaelis, W., 1992. Independent measurement of extinction and backscatter profiles in cirrus clouds by using a combined 
Raman elastic-backscatter lidar. Applied Optics 31, 33, 7113-7131, doi:10.1364/AO.31.007113.

2282

2283

Arimoto, R., Hogan, A., Grube, P., Davis, D., Webb, J., Schloesslin, C., Sage, S., Raccah, F., 2004. Major ions and radionuclides in aerosol particles from the South Pole during ISCAT-2000. Atmospheric Environment 38, 5473-5484, doi:10.1016/j.atmosenv.2004.01.049.

Barrie, L. A., Hoff, R. M., Daggupaty, S. M., 1981. The influence of mid-latitudinal pollution sources on haze in the Canadian Arctic. Atmospheric Environment 15, 8, 1407-1419, doi:i:10.1016/0004-6981(81)90347-4.

Bodhaine, B. A., 1995. Aerosol absorption measurements at Barrow, Mauna Loa and South Pole. Journal of Geophysical Research 100, 8967-8975, doi:10.1029/95JD00513.

Bourassa, A. E., Degenstein, D. A., Elash, B. J., Llewellyn, E. J., 2010. Evolution of the stratospheric aerosol enhancement following the eruptions of Okmok and Kasatochi: OdinOSIRIS measurements. Journal of Geophysical Research 115, D2, D00L03. doi:10.1029/2009JD013274.

Brock, C. A., Cozic, J., Bahreini, R., Froyd, K. D., Middlebrook, A. M., McComiskey, A., Brioude, J., Cooper, O. R., Stohl, A., Aikin, K. C., de Gouw, J. A., Fahey, D. W., Ferrare, R. A., Gao, R.-S., Gore, W., Holloway, J. S., Huebler, G., Jefferson, A., Lack, D. A., Lance, S., Moore, R. H., Murphy, D. M., Nenes, A., Novelli, P. C., Nowak, J. B., Ogren, J. A., Peischl, J., Pierce, R. B., Pilewskie, P., Quinn, P. K., Ryerson, T. B., Schmidt, K. S., Schwarz, J. P., Sodemann, H., Spackman, J. R., Stark, H., Thomson, D. S., Thornberry, T., Veres, P., Watts, L. A., Warneke, C., Wollny, A. G., 2011. Characteristics, sources, and transport of aerosols measured in spring 2008 during the Aerosol, Radiation, and Cloud Processes Affecting Arctic Climate (ARCPAC) project. Atmospheric Chemistry and Physics 11, 6, 2423-2453, doi:10.5194/acp-11-2423-2011.

Bush, B. C., Valero, F. P. J., 2003. Surface aerosol radiative forcing at Gosan during the ACE-Asia campaign. Journal of Geophysical Research 108, D23, 8660, doi: 10.1029/2002JD003233. 
2306 Campbell, J. R., Tackett, J. L., Reid, J. S., Zhang, J., Curtis, C. A., Hyer, E. J., Sessions, W. R., 2307 Westphal, D. L., Prospero, J. M., Welton, E. J., Omar, A. H., Vaughan, M. A., Winker, D. M., 2012. Evaluating nighttime CALIOP $0.532 \mu \mathrm{m}$ aerosol optical depth and extinction coefficient

Curier, L., de Leeuw, G., Kolmonen, P., Sundstrom, A.-M., Sogacheva, L., Bennouna, Y., 2009. Aerosol retrieval over land using the (A)ATSR dual-view algorithm. In "Satellite Aerosol Remote Sensing over Land” (A. A. Kokhanovsky and G. de Leeuw, eds.), Chichester (UK),

Damoah, R., Spichtinger, N., Forster, C., James, P., Mattis, I., Wandinger, U., Beirle, S., Wagner, T., Stohl, A., 2004. Around the world in 17 days - hemispheric-scale transport of forest fire smoke from Russia in May 2003. Atmospheric Chemistry and Physics 4, 1311-1321, doi:10.5194/acp-4-1311-2004.

Delene, D. J., Ogren, J. A., 2002. Variability of aerosol optical properties at four North American surface monitoring sites. Journal of the Atmospheric Sciences 59, 1135-1150, doi:10.1175/1520-0469(2002)059<1135:VOAOPA>2.0.CO;2.

Deuzé, J. L., Bréon, F. M., Devaux, C., Goloub, P., Herman, M., Lafrance, B., Maignan, F., Marchand, A., Nadal, F., Perry, G., Tanré, D., 2001. Remote sensing of aerosol over land surfaces from POLDER-ADEOS-1 polarized measurements. Journal of Geophysical Research 106, D5, 4913-4926, doi:10.1029/2000JD900364.

Devasthale, A., Tjernströ, M., Omar, A. H., 2011. The vertical distribution of thin features over the Arctic analysed from CALIPSO observations. Part II: Aerosols. Tellus 63B, 1, 86-95, doi:10.1111/j.1600-0889.2010.00517.x.

de Villiers, R. A., Ancellet, G., Pelon, J., Quennehen, B., Schwarzenboeck, A., Gayet, J. F., Law, K. S., 2010. Airborne measurements of aerosol optical properties related to early spring transport 
of mid-latitude sources into the Arctic. Atmospheric Chemistry and Physics 10, 11, 50115030, doi:10.5194/acp-10-5011-2010.

2333 Di Carmine, C., Campanelli, M., Nakajima, T., Tomasi, C., Vitale, V., 2005. Retrievals of Antarctic aerosol characteristics using a Sun-sky radiometer during the 2001-2002 austral summer campaign. Journal of Geophysical Research 110, D13202, doi:10.1029/2004JD005280.

Diner, D. J., Beckert, J. C., Reilly, T. H., Bruegge, C. J., Conel, J. E., Kahn, R. A., Martonchik, J. 2337 V., Ackerman, T. P., Davies, R., Gerstl, S. A.W., Gordon, H. R., Muller, J.-P., Myneni, R. B., Sellers, P. J., Pinty, B., Verstraete, M. M., 1998. Multi-angle Imaging SpectroRadiometer (MISR) instrument description and experiment overview. IEEE Transactions on Geoscience and Remote Sensing 36, 4, 1072-1087, doi: 10.1109/36.700992.

Diner, D. J., Martonchik, J. V., Kahn, R. A., Pinty, B., Gobron, N., Nelson, D. L., Holben, B. N., 2005a. Using angular and spectral shape similarity constraints to improve MISR aerosol and surface retrievals over land. Remote Sensing of Environment, 94, 2, 155-171, doi:10.1016j.rse.2004.09.009.

Diner, D. J., Braswell, B. H., Davies, R., Gobron, N., Hu, J., Jin, Y., Kahn, R. A., Knyazikhin, Y., Loeb, N., Muller, J.-P., Nolin, A. W., Pinty, B., Schaaf, C. B., Seiz, G., Stroeve, J., 2005b. The value of multiangle measurements for retrieving structurally and radiatively consistent properties of clouds, aerosols, and surfaces. Remote Sensing of Environment 97, 4, 495-518, doi:10.1016/j.rse.2005.06.006.

Di Pierro, M., Jaeglé, L., Anderson, T. L., 2011. Satellite observations of aerosol transport from East Asia to the Arctic: three case studies. Atmospheric Chemistry and Physics, 11, 22252243, doi:10.5194/acp-11-2225-2011.

Dong, X., Xi, B., Crosby, K., Long, C. N., Stone, R. S., Shupe, M. D., 2010. A 10 year climatology of Arctic cloud fraction and radiative forcing at Barrow, Alaska. Journal of Geophysical Research 115, D17212, doi:10.1029/2009JD013489. 
Dubovik, O., Herman, M., Holdak, A., Lapyonok, T., Tanré, D., Deuzé, J. L., Ducos, F., Sinyuk, A., and Lopatin, A., 2011. Statistically optimized inversion algorithm for enhanced retrieval of aerosol properties from spectral multi-angle polarimetric satellite observations. Atmospheric Measurement Techniques, 4, 975-1018, doi:10.5194/amt-4-975-2011.

Eck, T. F., Holben, B. N., Reid, J. S., Dubovik, O., Smirnov, A., O’Neill, N. T., Slutsker, I., Kinne, S., 1999. Wavelength dependence of the optical depth of biomass burning, urban, and desert dust aerosols, Journal of Geophysical Research 104, D24, 31333-31349, doi:10.1029/1999JD900923.

Eckhardt, S., Hermansen, O., Grythe, H., Fiebig, M., Stebel, K., Cassiani, M., Baecklund, A., Stohl, A., 2013. The influence of cruise ship emissions on air pollution in Svalbard - a harbinger of a more polluted Arctic?, Atmospheric Chemistry and Physics 13, 8401-8409, doi:10.5194/acp13-8401-2013.

Fattori, I., Becagli, S., Bellandi, S., Castellano, E., Innocenti, M., Mannini, A., Severi, M., Vitale, V., Udisti, R., 2005. Chemical composition and physical features of summer aerosol at Terra Nova Bay and Dome C, Antarctica. Journal of Environmental Monitoring 7, 1265-1274.

Fiebig, M., Lunder, C. R., Stohl, A., 2009. Tracing biomass burning aerosol from South America to Troll Research Station, Antarctica. Geophysical Research Letters 36, L14815, doi:10.1029/2009GL038531.

Garrett, T. J., Verzella, L.L., 2008. Looking back: An evolving history of Arctic aerosols. Bullettin of the American Meteorological Society 89, 299-302, doi: 10.1175/BAMS-89-3-299.

Gesell, G., 1989. An algorithm for snow and ice detection using AVHRR data. An extension to the APOLLO software package, International Journal of Remote Sensing 10, 4-5, 897-905, doi:10.1080/01431168908903929.

Glantz, P., Bourassa, A., Herber, A., Iversen, T., Karlsson, J., Kirkevåg, A., Maturilli, M., Seland, Ø., Stebel, K., Struthers, H., Tesche, M., Thomason, L., 2014. Remote sensing of aerosols in 
the Arctic for an evaluation of global climate model simulations. Journal of Geophysical Research 119, 13, 8169-8188, doi:10.1002/2013JD021279.

2383 Gobbi, G. P., Kaufman, Y. J., Koren, I., Eck, T. F., 2007. Classification of aerosol properties derived from AERONET direct sun data. Atmospheric Chemistry and Physics 7, 2, 453-458, doi:10.5194/acp-7-453-2007.

Govaerts, Y. M., Wagner, S., Lattanzio, A., Watts, P. , 2010. Joint retrieval of surface reflectance

Gomez-Chova, L., Camps-Valls, G., Calpe-Maravilla, J., Guanter, L., Moreno, J., 2007. CloudScreening Algorithm for ENVISAT/MERIS Multispectral Images. IEEE Transactions on Geoscience and Remote Sensing 45, 12, 4105-4118, doi:10.1109/TGRS.2007.905312. and aerosol optical depth from MSG/SEVIRI observations with an optimal estimation approach: 1. Theory. Journal of Geophysical Research 115, D2, doi:10.1029/2009JD011779.

Grey, W. M. F., North, P. R. J., 2009. Aerosol optical depth from dual-view (A)ATSR satellite observations. In Satellite Aerosol Remote Sensing Over Land (Kokhanovsky, A.A., and G. de Leeuw, eds.), Springer-Praxis (Berlin), 2009, ISBN 978-3-540-69396-3, 388 pp.

Hagler, G. S. W., Bergin, M. H., Smith, E. A., Town, M., Dibb, J. E., 2008. Local anthropogenic impact on particulate elemental carbon concentrations at Summit, Greenland. Atmospheric Chemistry and Physics 8, 2485-2491, doi:10.5194/acp-8-2485-2008.

Han, W., Stamnes, K., Lubin, D., 1999. Remote sensing of surface and cloud properties in the Arctic from AVHRR measurements. Journal of Applied Meteorology 38, 7, 989-1012, doi:10.1175/1520-0450(1999)038<0989:RSOSAC>2.0.CO;2.

Hänel, G., Adam, W., Bundke, U., Komguem, L., Leiterer, U., 1999. Optical properties of boundary layer particles, columnar absorption and direct radiative forcing by particles in the solar spectral region. Journal of Aerosol Science 30, Suppl. 1, S171-S172.

Hara, K., Osada, K., Kido, M., Hayashi, M., Matsunaga, K., Iwasaka, Y., Yamanouchi, T., Hashida, G., Fukatsu, T., 2004. Chemistry of sea-salt particles and inorganic halogen species in 
Antarctic regions: Compositional differences between coastal and inland stations. Journal of Geophysical Research 109, D20208, doi:10.1029/2004JD004713.

2408

Haywood, J., Boucher, O., 2000. Estimates of the direct and indirect radiative forcing due to tropospheric aerosols: A review. Reviews of Geophysics 38, 4, 513-543, doi: 10.1029/1999RG000078.

Heintzenberg, J., Charlson, R. J., Clarke, A. D., Liousse, C., Ramaswamy, V., Shine, K. P., Wendisch, M., Helas, G., 1997. Measurements and modelling of aerosol single scattering albedo: progress, problems and prospects. Contribution to Atmospheric Physics 70, 249-263.

Herber, A., Thomason, L. W., Gernandt, H., Leiterer, U., Nagel, D., Schulz, K., Kaptur, J., Albrecht, T., Notholt, J., 2002. Continuous day and night aerosol optical depth observations in the Arctic between 1991 and 1999. Journal of Geophysical Research 107, D10, 4097, doi:10.1029/2001JD000536.

Herber, A. B., Haas, C., Stone, R. S., Bottenheim, J. W., Liu, P., Li, S.-M., Staebler, R. M., Strapp, J. W., Dethloff, K., 2012. Regular airborne surveys of Arctic sea ice and atmosphere. EOS 93, 4, 41-48, doi:10.1029/2012EO040001.

Hess, M., Koepke, P., Schult, I., 1998. Optical properties of aerosols and clouds: The software package OPAC. Bulletin of the American Meteorological Society 79, 5, 831-844, doi: 10.1175/1520-0477(1998)079<0831:OPOAAC>2.0.CO;2.

Hillamo, R., Allegrini, I., Sparapani, R., Kerminen, V.-M., 1998. Mass size distributions and precursors gas concentrations of major inorganic ions in Antarctic aerosol. International Journal of Environmental Analytical Chemistry 71, 353-372, doi:10.1080/03067319808032638.

Hirdman, D., Sodemann, H., Eckhardt, S., Burkhart, J. F., Jefferson, A., Mefford, T., Quinn, P. K., Sharma, S., Ström, J., Stohl, A., 2010, Source identification of short-lived air pollutants in the Arctic using statistical analysis of measurement data and particle dispersion model output. Atmospheric Chemistry and Physics 10, 669-693, doi:10.5194/acp-10-669-2010. 
Hoffmann, A., Ritter, C., Stock, M., Shiobara, M., Lampert, A., Maturilli, M., Orgis, T., Neuber, R., Herber, A., 2009. Ground-based lidar measurements from Ny-Ålesund during ASTAR 2007. Atmospheric Chemistry and Physics 9, 22, 9059-9081, doi:10.5194/acp-9-9059-2009.

Hoffmann, A., Ritter, C., Stock, M., Maturilli, M., Eckhardt, S., Herber, A., Neuber, R., 2010. Lidar measurements of the Kasatochi aerosol plume in August and September 2008 in Ny-Ålesund, Spitsbergen. Journal of Geophysical Research 115, D00L12, doi:10.1029/2009JD013039.

Hoffmann, A., Osterloh, L., Stone, R., Lampert, A., Ritter, C., Stock, M., Tunved, P., Hennig, T., Bockmann, C., Li, S.-M., Eleftheriadis, K., Maturilli, M., Orgis, T., Herber, A., Neuber, R., Dethloff, K., 2012. Remote sensing and in-situ measurements of tropospheric aerosol, a PAMARCMiP case study. Atmospheric Environment 52C, 56-66, doi:10.1016/j.atmosenv.2011.11.027.

Holben, B. N., Eck, T. F., Slutsker, I., Tanré, D., Buis, J. P., Setzer, A., Vermote, E., Reagan, J. A., Kaufman, Y. J., Nakajima, T., Lavenu, F., Jankowiak, I., Smirnov, A., 1998. AERONET - A federated instrument network and data archive for aerosol characterization. Remote Sensing of Environment 66, 1, 1-16, doi: S0034-4257(98)00031-5.

Holzer-Popp, T., de Leeuw, G., Griesfeller, J., Martynenko, D., Klüser, L., Bevan, S., Davies, W., Ducos, F., Deuzé, J. L., Graigner, R. G., Heckel, A., von Hoyningen-Hüne, W., Kolmonen, P., Litvinov, P., North, P., Poulsen, C. A., Ramon, D., Siddans, R., Sogacheva, L., Tanré, D., Thomas, G. E., Vountas, M., Descloitres, J., Griesfeller, J., Kinne, S., Schulz, M., Pinnock, S., 2013. Aerosol retrieval experiments in the ESA Aerosol_cci project. Atmospheric Measurement Techniques 6, 8, 1919-1957, doi:10.5194/amt-6-1919-2013.

Hori, M., Aoki, T., Tanikawa, T., Motoyoshi, H., Hachikubo, A., Sugiura, K., Yasunari, T. J., Eide, H., Storvold, R., Nakajima, Y., Takahashi, F., 2006. In-situ measured spectral directional emissivity of snow and ice in the 8-14 $\mu \mathrm{m}$ atmospheric window. Remote Sensing of Environment 100, 4, 486-502, doi:10.1016/j.rse.2005.11.001. 
Hsu, N. C., Tsay, S. C., King, M. D., Herman, J. R., 2004. Aerosol properties over bright reflecting source regions. IEEE Transactions on Geoscience and Remote Sensing, 42, 3, 557-569, doi: $10.1117 / 12.975846$.

Hsu, N. C., Jeong, M.-J., Bettenhausen, C., Sayer, A. M., Hansell, R., Seftor, C. S., Huang, J., Tsay, S.-C., 2013. Enhanced Deep Blue aerosol retrieval algorithm: The second generation. Journal of Geophysical Research (Atmospheres) 118, 16, 9296-9315, doi:10.1002/jgrd.50712.

Intrieri, J. M., Shupe, M. D., 2004. Characteristics and radiative effects of diamond dust over the Western Arctic ocean region. Journal of Climate 17, 15, 2953-2960, doi:10.1175/15200442(2004)017<2953:CAREOD>2.0.CO;2.

IPCC, 2013. Climate Change 2013: The Physical Science Basis, Fifth Assessment Report of the United Nations “Intergovernmental Panel on Climate Change (IPCC), Chapter 7, Clouds and Aerosols, Cambridge University Press, Cambridge (UK) (http://www.climatechange2013.org/images/report/WG1AR5_Chapter07_FINAL.pdf).

Iqbal, M. (1983), An Introduction to Solar Radiation, Academic Press, Toronto, 390 pp (see Table 1.2.1 at pages $4-5)$.

Istomina, L.G., von Hoyningen-Huene, W., Kokhanovsky, A. A., Burrows, J. P., 2009. Retrieval of aerosol optical thickness in Arctic region using dual-view AATSR observations, Proceedings of ESA Atmospheric Science Conference, ESA SP-676, Barcelona (Spain), 7-11 September 2009.

Istomina, L. G., von Hoyningen-Huene, W., Kokhanovsky, A. A., Burrows, J. P., 2010. The detection of cloud-free snow-covered areas using AATSR measurements. Atmospheric Measurement Techniques 3, 1005-1017, doi:10.5194/amt-3-1005-2010.

Istomina, L. G., von Hoyningen-Huene, W., Kokhanovsky, A. A., Schultz, E., Burrows, J. P., 2011. Remote sensing of aerosols over snow using infrared AATSR observations, Atmospheric Measurement Techniques 4, 1133-1145, doi:10.5194/amt-4-1133-2011. 
2482 Justice, C. O., Vermote, E., Townshend, J. R. G., Defries, R., Roy, D. P., Hall, D. K., Salomonson, 2483 V. V., Privette, J. L., Riggs, G., Strahler, A., Lucht, W., Myneni, R. P., Knyazikhin, Y., 2484 Running, S. W., Nemani, R. R., Wan, Z., Huete, A. R., van Leeuwen, W., Wolfe, R. E., 2485 Giglio, L., Muller, J.-P., Lewis, P., Barnsley, M. J., 1998. The Moderate Resolution Imaging 2486 Spectroradiometer (MODIS): Land Remote Sensing for Global Change Research. IEEE 2487 Transactions on Geoscience and Remote Sensing 36, 4, 1228-1249, doi:10.1109/36.701075.

2488 Kahn, R. A., Li, W.-H., Martonchik, J. V., Bruegge, C. J., Diner, D. J., Gaitley, B. J., Abdou, W., 2489

Kahn, R. A., Gaitley, B. J., Garay, M. J., Diner, D. J., Eck, T. F., Smirnov, A., Holben, B. N., 2010. Multiangle Imaging SpectroRadiometer global aerosol product assessment by comparison with the Aerosol Robotic Network. Journal of Geophysical Research 115, D23209, doi:10.1029/2010JD014601.

Kahn, R. A., Garay, M. J., Nelson, D. L., Levy, R. C., Bull, M. A., Diner, D. J., Martonchik, J. V., Hansen, E. G., Remer, L. A., Tanré, D., 2011. Response to "Toward unified satellite climatology of aerosol properties. 3. MODIS versus MISR versus AERONET', Journal of Quantitative Spectroscopy and Radiative Transfer 112, 5, 901-909, doi:10.1016/j.jqsrt.2009.11.003.

Kaufman, Y. J., Tanré, D., Remer, L., Vermote, E. F., Chu, A., Holben, B. N., 1997. Operational remote sensing of tropospheric aerosol over the land from EOS-MODIS. Journal of Geophysical Research 102, D14, 17051-17067, doi:10.1029/96JD03988.

Kerminen, V.-M., Teinilä, K., Hillamo, R., 2000. Chemistry of sea-salt particles in the summer Antarctic atmosphere. Atmospheric Environment 34, 2817-2825, doi:10.1016/S13522506 2310(00)00089-3. 
Key, J., Barry, R. G., 1989. Cloud cover analysis with Arctic AVHRR data. 1. Cloud detection. Journal of Geophysical Research 94, D15, 18521-18535, doi:10.1029/JD094iD15p18521.

King, M. D., Dubovik, O., 2013. Determination of aerosol optical properties from inverse methods. In Aerosol Remote Sensing (J. Lenoble, L. Remer, and D. Tanré, Eds.), Springer-Verlag, pp. 101-136.

Koponen, I. K., Virkkula, A., Hillamo, R., Kerminen, V.-M. , Kulmala, M., 2003. Number size distributions and concentrations of the continental summer aerosols in Queen Maud Land, Antarctica. Journal of Geophysical Research 108, D18, 4587, doi:10.1029/2003JD003614.

Knapp, K. R., Vonder Haar, T. H., Kaufman, Y. J., 2002. Aerosol optical depth retrieval from GOES-8: Uncertainty study and retrieval validation over South America, Journal of Geophysical Research (Atmospheres) 107, D7, AAC 2-1 - AAC 2-12, doi:10.1029/2001JD000505.

Lambert, A., Ehrlich, A., Dörnbrack, A., Jourdan, O., Gayet, J.-F., Mioche, G., Shcherbakov, V., Ritter, C., Wendisch, M., 2009. Microphysical and radiative characterization of a subvisible midlevel Arctic ice cloud by airborne observations a case study. Atmospheric Chemistry and Physics 9, 8, 2647-2661, doi:10.5194/acp-9-2647-2009.

Lambert, A., Ritter, C., Hoffmann, A., Gayet, J.-F., Mioche, G., Ehrlich, A., Doernbrack, A., Wendisch, M., Shiobara, M., 2010. Lidar characterization of the Arctic atmosphere during ASTAR 2007: four cases studies of boundary layer, mixed-phase and multi-layer clouds. Atmospheric Chemistry and Physics 10, 6, 2847-2866, doi: doi:10.5194/acp-10-2847-2010.

Law, K. S., Stohl, A., Quinn, P. K., Brock, C., Burkhart, J., Paris, J.-D., Ancellet, G., Singh, H. B., Roiger, A., Schlager, H., Dibb, J., Jacob, D. J., Arnold, S. R., Pelon, J., Thomas, J. L., 2014. Arctic air pollution: 1 New insights from POLARCAT-IPY. Bulletin of the American Meteorological Society, doi:10.1175/BAMS-D-13-00017.1. In press.

Levy, R. C., Remer, L. A., Mattoo, S., Vermote, E. F., Kaufman, Y. J., 2007. Second-generation operational algorithm: Retrieval of aerosol properties over land from inversion of Moderate 
Resolution Imaging Spectroradiometer spectral reflectance. Journal of Geophysical Research 112, D13211, doi:10.1029/2006JD007811.

Levy, R. C., Remer, L. A., Kleidman, R. G., Mattoo, S., Ichoku, C., Kahn, R., Eck, T. F., 2010. Global evaluation of the Collection 5 MODIS dark-target aerosol products over land. Atmospheric Chemistry and Physics 10, 10399-10420, doi:10.5194/acp-10-10399-2010.

Levy, R. C., Mattoo, S., Munchak, L. A., Remer, L. A., Sayer, A. M., Patadia, F., Hsu, N. C., 2013. The Collection 6 MODIS aerosol products over land and ocean. Atmospheric Measurement Techniques 6, 2989-3034, doi:10.5194/amt-6-2989-2013.

Liu, Y., Key, J. R., Frey, R. A., Ackerman, S. A., Menzel, W. P., 2004. Nighttime polar cloud detection with MODIS, Remote Sensing of Environment 92, 2, 181-194, doi:10.1016/j.rse.2004.06.004.

Lubin, D., Satheesh, S., McFarquar, G., Heymsfield, A., 2002. Longwave radiative forcing of Indian Ocean tropospheric aerosol. Journal of Geophysical Research 107, D19, 8004, doi:10.1029/2001JD001183.

Macdonald, M., Anderson, P., Carrea, L., Dobke, B., Embury, O., Merchant, C., Bensi, P., 2014. Concepts for a geostationary-like polar missions. In: Sensors, Systems and Next-Federation Satellites XVIII. Proceedings of the SPIE 2014 (Meynart, R., Neeck, S. P., and Shimoda, H., eds.), Vol. 9421, ISBN 9781628413045.

Martonchik, J. V., Diner, D. J., Kahn, R. A., Ackerman, T. P., Verstraete, M. M., Pinty, B., Gordon, H. R., 1998a. Techniques fot the retrieval of aerosol properties over land and ocean using multi-angle imagery. IEEE Transactions on Geoscience and Remote Sensing 36, 4, 1212 1227, doi:10.1109/36.701027.

Martonchik, J. V., Diner, D. J., Pinty, B., Verstraete, M. M., Myneni, R. B., Knyazikhin, Y., Gordon, H. R., 1998b. Determination of land and ocean reflective, radiative, and biophysical properties using multiangle imaging. IEEE Transactions on Geoscience and Remote Sensing 36, 4, 1266-1281, doi:10.1109/36.701077. 
Martonchik, J. V., Diner, D. J., Crean, K. A., Bull, M. A., 2002. Regional aerosol retrieval results from MISR. IEEE Transactions on Geoscience and Remote Sensing 40, 7, 1520-1531, doi:10.1109/TGRS.2002.801142.

Mazzola, M., Stone, R. S., Herber, A., Tomasi, C., Lupi, A., Vitale, V., Lanconelli, C., Toledano, C., Cachorro, V. E., O’Neill, N.T., Shiobara, M., Aaltonen, V., Stebel, K., Zielinski, T., Petelski, T., Ortiz de Galisteo, J. P., Torres, B., Berjon, A., Goloub, P., Li, Z., Blarel, L., Abboud, I., Cuevas, E., Stock, M., Schulz, K.-H., Virkkula, A., 2012. Evaluation of sun photometer capabilities for retrievals of aerosol optical depth at high latitudes: The POLARAOD intercomparison campaigns, Atmospheric Environment 52C, 1-14, doi:10.1016/j.atmosenv.2011.07.042.

Mei, L., Xue, Y., 2013. Aerosol optical thickness retrieval over snow-covered surface using AATSR data, The 2013 IEEE International Geoscience and Remote Sensing Symposium (IGARSS), Melbourne, Australia, 21-26 July 2013.

Mei, L., Xue, Y., de Leeuw, G., Holzer-Popp, T., Guang, J., Li, Y., Yang, L., Xu, H., Xu, X., Li, C., Wang, Y., Wu, C., Hou, T., He, X., Liu, J., Dong, J., Chen, Z., 2012. Retrieval of aerosol optical depth over land based on a time series technique using MSG/SEVIRI data. Atmospheric Chemistry and Physics 12, 9167-9185, doi:10.5194/acp-12-9167-2012.

Mei, L., Xue, Y., de Leeuw, G., von Hoyningen-Huene, W., Kokhanovsky, A. A., Istomina, L., Guang, J., Burrows, J. P., 2013a. Aerosol optical depth retrieval in the Arctic region using MODIS over snow. Remote Sensing of Environment 128, 234-245, doi:10.1016/j.rse.2012.10.009.

Mei, L., Xue, Y., Kokhanovsky, A. A., von Hoyningen-Huene, W., Istomina, L., de Leeuw, G., Burrows, J. P., Guang, J., Jing, Y., 2013b. Aerosol optical depth retrieval over snow using AATSR data, International Journal of Remote Sensing 34, 14, 5030-5041, doi:10.1080/01431161.2013.786197. 
Mei, L., Xue, Y., Kokhanovsky, A. A., von Hoyningen-Huene, W., de Leeuw, G., Burrows, J. P., 2014. Retrieval of aerosol optical depth over land surfaces from AVHRR data, Atmospheric Measurement Techniques, in press.

Mie, G., 1908. Beiträge zur Optik trüber Medien, speziell kolloidaler Metallösungen. Annalen der Physik, Vierte Folge, 25, 3, 377-445.

Mielonen, T., Levy, R. C., Aaltonen, Komppula, M., de Leeuw, G., Huttunen, J., Lihavainen, H., Kolmonen, P., Lehtinen, K. E. J., Arola, A., 2011. Evaluating the assumptions of surface reflectance and aerosol type selection within the MODIS aerosol retrieval over land: the problem of dust type selection. Atmospheric Measurement Techniques 4, 201-214, doi:10.5194/amt-4-201-2011.

Mielonen, T., Aaltonen, V., Lihavainen, H., Hyvärinen, A.-P., Arola, A., Komppula, M., Kivi, R., 2013. Biomass burning aerosols observed in Northern Finland during the 2010 wildfires in Russia. Atmosphere 4, 17-34, doi:10.3390/atmos4010017.

Minikin, A., Legrand, M., Hall, J., Wagenbach, D., Kleefeld, C., Wolff, E., Pasteur, E. C., Ducroz, F., 1998. Sulfur-containing species (sulfate and MSA) in coastal Antarctic aerosol and precipitation. Journal of Geophysical Research 103, D9, 10975-10990, doi:10.1029/98JD00249.

Mishchenko, M. I., Liu, L., Geogdzhayev, I. V., Travis, L. D., Cairns, B., Lacis, A. A., 2010. Toward unified satellite climatology of aerosol properties. 3. MODIS versus MISR versus AERONET. Journal of Quantitative Spectroscopy and Radiative Transfer 111, 4, 540-552, doi:10.1016/j.jqsrt.2009.11.003.

Mitchell, J. M., 1957. Visual range in the polar regions with particular reference to the Alaskan Arctic. Journal of Atmospheric and Terrestrial Physics, Special Supplement, 195-211.

Moore, C. W., Obrist, D., Steffen, A., Staebler, R. M., Douglas, T. A., Richter, A., Nghiem, S. V., 2014. Convective forcing of mercury and ozone in the Arctic boundary layer induced by leads in sea ice. Nature, 506, 7486, 81-84. doi:10.1038/nature12924. 
2610 Nakajima, T., Yoon, S. C., Ramanathan, V., Shi, G. Y., Takemura, T., Higurashi, A., Takamura, T., Aoki, K., Sohn, B. J., Kim, S. W., Tsuruta, H., Sugimoto, N., Shimizu, A., Tanimoto, H., Sawa, Y., Lin, N. H., Lee, C. T., Goto, D., Schutgens, N., 2007. Overview of the Atmospheric Brown Cloud East Asian Regional Experiment 2005 and a study of the aerosol direct radiative forcing in east Asia. Journal of Geophysical Research 112, D24S91, doi:10.1029/2007JD009009.

Negi, H. S., Singh, S. K., Kulkarni, A. V., Semwal, B. S., 2010. Field-based spectral reflectance measurements of seasonal snow cover in the Indian Himalaya. International Journal of Remote Sensing 31, 9, 2393-2417, doi:10.1080/01431160903002417.

Nghiem, S. V., Rigor, I. G., Richter, A., Burrows, J. P., Shepson, P. B., Bottenheim, J., Barber, D. G., Steffen, A., Latonas, J., Wang, F., Stern, G., Clemente-Colón, P., Martin, S., Hall, D. K., Kaleschke, L., Tackett, P., Neumann, G., Asplin, M. G., 2012. Field and satellite observations of the formation and distribution of Arctic atmospheric bromine above a rejuvenated sea ice cover. Journal of Geophysical Research 117, D17, doi:10.1029/2011JD016268.

Nordenskiöld, A. E., 1883. Nordenskiöld on the inland ice of Greenland. Science 2, 732-739.

Nott, G. J., Duck, T. J., 2011. Lidar studies of the polar troposphere. Meteorological Applications 18, 3, 383-405, doi:10.1002/met.289.

Nyeki, S., Halios, C. H., Baum, W., Eleftheriadis, K., Flentje, H., Gröbner, J., Vuilleumier, L., Wehrli, C., 2012. Ground-based aerosol optical depth trends at three high-altitude sites in Switzerland and southern Germany from 1995 to 2010. Journal of Geophysical Research 117, D18202, doi:10.1029/2012JD017493.

Ohno, T., 2005. Aerosol routine observation operated by the Japan Meteorological Agency. In "WMO/GAW Experts Workshop on a Global Surface Based Network for Long Term Observations of Column Aerosol Optical Properties”, GAW Rep. 162, WMO TD 1287, pp. 70-71, World Meteorological Organization, Geneva, Switzerland. 
2635 O'Neill, N. T., Ignatov, A., Holben, B. N., Eck, T. F., 2000. The lognormal distribution as a 2636 reference for reporting aerosol optical depth statistics; Empirical tests using multi-year, multisite AERONET Sunphotometer data. Geophysical Research Letters 27, 20, 3333-3336, doi:10.1029/2000GL011581.

O’Neill, N. T., Dubovik, O., Eck, T. F., 2001a. Modified Ångström exponent for the characterization of submicrometer aerosol. Applied Optics 40, 15, 2368-2375, doi:10.1364/AO.40.002368.

O’Neill, N. T., Eck, T. F., Holben, B. N., Smirnov, A., Dubovik, O., Royer, A., 2001b. Bimodal size distribution influences on the variation of Ångström derivatives in spectral and optical depth space. Journal of Geophysical Research 106, D9, 9787-9806, doi:10.1029/2000JD900245.

2646 O’Neill, N. T., Eck, T. F., Smirnov, A., Holben, B. N., Thulasiraman, S., 2003. Spectral 2647 discrimination of coarse and fine mode optical depth. Journal of Geophysical Research 108,

O’Neill, N. T., Perro, C., Saha, A., Lesins, G., Duck, T. J., Eloranta, E. W., Nott, G. J., Hoffmann,

A., Karumudi, M. L., Ritter, C., Bourassa, A., Abboud, I., Carn, S. A., Savastiouk, V., 2012.

Piel, C., Weller, R., Huke, M., Wagenbach, D., 2006. Atmospheric methane sulfonate and non-seaProperties of Sarychev sulphate aerosols over the Arctic. Journal of Geophysical Research salt sulfate records at the European Project for Ice Coring in Antarctica (EPICA) deep-drilling site in Dronning Maud Land, Antarctica. Journal of Geophysical Research 111, D03304, doi:10.1029/2005JD006213.

Polissar, A. V., Hopke, P. K., Paatero, P., Malm, W. C., Sisler, J. F., 1998. Atmospheric aerosol over Alaska. 2. Elemental composition and sources. Journal of Geophysical Research 103, D15, 19045-19057, doi:10.1029/98JD01212. 
2660 Polissar, A.V., Hopke, P. K., Harris, J. M., 2001. Source regions for atmospheric aerosol measured 2661 at Barrow, Alaska. Environmental Science Technology 35, 4214-4226, doi:10.1021/es0107529.

2663 Posyniak, M., Markowicz, K., 2009. Measurement of aerosol optical thickness over the Atlantic Ocean and in West Antarctica, 2006-2007. Acta Geophysica 57, 2, 494-508, doi:10.2478/s11600-009-0002-0.

2666 Quinn, P. K., Miller, T. L., Bates, T. S., Ogren, J. A., Andrews, E., Shaw, G. E., 2002. A 3-year record of simultaneously measured aerosol chemical and optical properties at Barrow, Alaska. Journal of Geophysical Research 107, D11, AAC8-1-AAC8-15, doi:10.1029/2001JD001248.

Quinn, P., Shaw, G., Andrews, E., Dutton, E. G., Ruoho-Airola, T., Gong, S. L., 2007. Arctic haze: current trends and knowledge gaps. Tellus 59B, 1, 99-114, doi: 10.1111/j.16000889.2006.00238.x.

Radionov, V. F., 2005. Temporal variability of the aerosol optical characteristics of the atmosphere in the Russian Arctic (Historical review). In WMO/GAW Experts Workshop on a Global Surface Based Network for Long Term Observations of Column Aerosol Optical Properties, GAW Rep. 162, WMO TD 1287, pp. 82-85, World Meteorological Organization, Geneva,

\section{Switzerland.}

Radionov, V. F., Lamakin, M. V., Herber, A., 2002. Changes in the aerosol optical depth of the Antarctic atmosphere. Izvestia, Atmospheric and Oceanic Physics 38, 179-183.

2681 Ramanathan, V., Crutzen, P. J., Kiehl, J. T., Rosenfeld, D., 2001. Aerosols, climate and the 2682

Rahn, K.A., Borys, R. D., Shaw, G. E., 1977. Asian source of Arctic haze bands. Nature 268, 713715, doi: 10.1038/268713a0. hydrological cycle. , Science 294, 2119-2124, doi: 10.1126/science.1064034.

Remer, L. A., Kaufman, Y. J., Tanré, D., Mattoo, S., Chu, D. A., Martins, J. V., Li, R.-R., Ichoku, C., Levy, R. C., Kleidman, R. G., Eck T. F., Vermote, E., Holben, B. N., 2005. The MODIS 
aerosol algorithm, products, and validation. Journal of the Atmospheric Sciences, 62, 4, 947973, doi: 10.1175/JAS3385.1.

Remer, L. A., Mattoo, S., Levy, R. C., Munchak, L. A., 2013. MODIS 3 km aerosol product: algorithm and global perspective. Atmospheric Measurement Techniques 6, 1829-1844, doi:10.5194/amt-6-1829-2013.

Rogers, R. R., Hostetler, C. A., Hair, J. W., Ferrare, R. A., Liu, Z., Obland, M. D., Harper, D. B., Cook, A. L., Powell, K. A., Vaughan, M. A., Winker, D. M., 2011. Assessment of the CALIPSO Lidar $532 \mathrm{~nm}$ attenuated backscatter calibration using the NASA LaRC airborne High Spectral Resolution Lidar. Atmospheric Chemistry and Physics 11, 1295-1311, doi:10.5194/acp-11-1295-2011.

Rozwadowska, A., Zielinski, T., Petelski, T., Sobolewski, P., 2010. Cluster analysis of the impact of air back-traiectories on aerosol optical properties at Hornsund, Spitsbergen. Atmospheric Chemistry and Physics 10, 3, 877-893, doi:10.5194/acp-10-877-2010.

Rozwadowska, A., Sobolewski, P., 2010. Variability in aerosol optical properties at Hornsund, Spitsbergen. Oceanologia 52, 4, 599-620, doi:10.5697/oc.52-4.599.

Sakerin, S. M., Kabanov, D. M., Rostov, A. P., Turchinovich, S. A., 2009. Portative Solar Photometer. Pribory i Tekhnika Eksperimenta (Instruments and Experimental Techniques) 2, 181-182 (in Russian).

Sakerin, S. M., Chernov, D. G., Kabanov, D. M., Kozlov, V. S., Panchenko, M. V., Polkin, V. V., Radionov, V. F., 2012. Preliminary results of studying the aerosol characteristics of the atmosphere in the region of Barentsburg, Spitsbergen. Problems of the Arctic and Antarctica 1, 91, 20-31 (in Russian).

Sakerin, S. M., Andreev, S. Yu., Kabanov, D. M., Nikolashkin, S. V., Prakhov, A. N., Radionov, V. F., Turchinovich, Ju. S., Chernov, D. G., Holben, B. N., Smirnov, A., Sorokin, M. G., 2014. On results of studies of atmospheric aerosol optical depth in Arctic regions. Atmospheric and Oceanic Optics 27, No. 5. 413-423 (in Russian). 
2711 Satheesh, S. K., Ramanathan, V., 2000. Large differences in tropical aerosol forcing at the top of 2712 the atmosphere and Earth's surface. Nature 405, 60-63, doi: 10.1038/35011039.

2713 Saunders, R. W., Kriebel, K. T., 1988. An improved method for detecting clear sky and cloudy radiances from AVHRR data. International Journal of Remote Sensing 9, 1, 123-150, doi:10.1080/01431168808954841.

Sayer, A. M., Hsu, N. C., Bettenhausen, C., Jeong, M.-J., Holben, B. N., Zhang, J., 2012. Global and regional evaluation of over-land spectral aerosol optical depth retrievals from SeaWiFS, Atmospheric Measurement Techniques 5, 1761-1778, doi:10.5194/amt-5-1761-2012.

Schlundt, C., Kokhanovsky, A. A., von Hoyningen-Huene, W., Dinter, T., Istomina, L., Burrows, J. P., 2011. Synergetic cloud fraction determination for SCIAMACHY using MERIS. Atmospheric Measurement Techniques 4, 2, 319-337, doi:10.5194/amt-4-319-2011.

Schutgens, N. A. J., Nakata, M., Nakajima, T., 2013. Validation and empirical correction of MODIS AOT and AE over ocean. Atmospheric Measurement Techniques 6, 2455-2475, doi:10.5194/amt-6-2455-2013.

Schwartz, S. E., Andreae, M. O., 1996. Uncertainty in climate change caused by aerosols. Science 272, 5265, 1121-1122, doi:10.126/science.272.5265.1121.

Sharma, S., Andrews, E., Barrie, L. A., Ogren, J. A., Lavoué, D., 2006. Variations and sources of 2728 equivalent black carbon in the high Arctic revealed by long-term observations at Alert and Barrow: 1989-2003. Journal of Geophysical Research 111, D14208, doi:10.1029/2005JD006581.

Shaw, G. E., 1976. Error analysis of multi-wavelength sun photometry 114, 1, 1-14, doi:10.1007/BF00875487.

Shaw, G. E., 1988. Antarctic aerosols: A review. Reviews of Geophysics 26, 1, 89-112, doi: 10.1029/RG026i001p00089.

Shaw, G. E., 1995. The arctic haze phenomenon. Bulletin of the American Meteorological Society 76, 12, 2403-2413, doi: 10.1175/1520-0477(1995)076<2403:TAHP>2.0.CO;2. 
Shi, T., Yu, B., Braverman, A. J., 2002. MISR Cloud Detection over Ice/Snow Using Linear Correlation Matching.Technical Report 630, University of California, Department of Statistics, Berkeley, CA.

Shi, T., Clothiaux, E. E., Yu, B., Braverman, A. J., Groff, D.N., 2007. Detection of daytime arctic clouds using MISR and MODIS data. Remote Sensing of Environment 107, 1-2, 172-184, doi:10.1016/j.rse.2006.10.015.

Sinyuk, A., Holben, B. N., Smirnov, A., Eck, T. F., Slutsker, I., Schafer, J. S., Giles, D. M., Sorokin, M., 2012. Assessment of error in aerosol optical depth measured by AERONET due to aerosol forward scattering. Geophysical Research Letters 39, L23806, doi:10.1029/2012GL053894.

Six, D., Fily, M., Blarel, L., Goloub, P., 2005. First aerosol optical thickness measurements at Dome C (East Antarctica), summer season 2003-2004. Atmospheric Environment 39, 28, 5041-5050, doi:10.1016/j.atmosenv.2005.05.010.

Smirnov, A., Holben, B. N., Eck, T. F., Dubovik, O., Slutsker, I., 2000. Cloud-screening and quality control algorithms for the AERONET database. Remote Sensing of Environment 73, 3, 337 349, doi:10.1016/S0034-4257(00)00109-7.

Smirnov, A., Holben, B. N., Slutsker, I., Giles, D. M., McClain, C. R., Eck, T. F., Sakerin, S. M., Macke, A., Croot, P., Zibordi, G., Quinn, P. K., Sciare, J., Kinne, S., Harvey, M., Smyth, T. J., Piketh, S., Zielinski, T., Proshutinsky, A., Goes, J. I., Nelson, N. B., Larouche, P., Radionov, V. F., Goloub, P., Moorthy, K. K., Matarrese, R., Robertson, E. J., Jourdin, F, 2009. Maritime Aerosol Network as a component of Aerosol Robotic Network. Journal of Geophysical Research, 114, D06204, doi:10.1029/2008JD011257.

Smirnov, A., Holben, B. N. , Giles, D. M., Slutsker, I., O’Neill, N. T., Eck, F., Macke, A., Croot, P., Courcoux, Y., Sakerin, S. M., Smyth, T. J., Zielinski, T., Zibordi, G., Goes, J. I., Harvey, M. J., Quinn, P. K., Nelson, N. B., Radionov, V. F., Duarte, C. M., Losno, R., Sciare, J., Voss, K. J., Kinne, S., Nalli, N. R., Joseph, E., Krishna Moorthy, K., Covert, D. S., Gulev, S. K., 
Milinevsky, G., Larouche, P., Belanger, S., Horne, E., Chin, M., Remer, L. A., Kahn, R. A.,

Reid, J. S., Schulz, M., Heald, C. L., Zhang, J., Lapina, K., Kleidman, R. G., Griesfeller, J.,

Gaitley, B. J., Tan, Q., Diehl, T. L., 2011. Maritime aerosol network as a component of

AERONET - first results and comparison with global aerosol models and satellite retrievals.

Spangenberg,

D. A., Chakrapani, V., Doelling,

D. R., Minnis, P., Arduini, R. F., 2001.

Development of an automated Arctic cloud mask using clear sky satellite observations taken over the SHEBA and ARM NSA sites. Proceedings of the AMS 6th Conference on Polar Meteorology and Oceanography, San Diego, CA, May 14-18, 2001, pp. 246-249.

Stamnes, K., Li, W., Spurr, R., Eide, H. A., Stamnes, J. J., 2004. Simultaneous retrieval of aerosol and surface properties over bright targets including snow and ice using multi- and

Stock, M., Ritter, C., Herber, A., von Hoyningen-Huene, W., Baibakov, K., Gräser, J., Orgis, T.,

Stohl, A., 2006. Characteristics of atmospheric transport into the Arctic troposphere. Journal of 2780 Geophysical Research 111, D11306, doi:10.1029/2005JD006888.

Stohl, A., Andrews, E., Burkhart, J. F., Forster, C., Herber, A., Hoch, S. W., Kowal, D., Lunder, C., concentrations due to North American boreal forest fires during summer 2004. Journal of Geophysical Research 111, D22214, doi:10.1029/2006JD007216.

Stohl, A., Sodemann, H., 2010. Characteristics of atmospheric transport into the Antarctic troposphere. Journal of Geophysical Research 115, D02305, doi:10.1029/2009JD012536. 
Stone, R. S., 2002. Monitoring aerosol optical depth at Barrow, Alaska, and South Pole; historical overview, recent results and future goals. SIF Conference Proceedings 80, 123-144.

Stone, R. S., Key, J. R., Dutton, E. G., 1993. Properties and decay of stratospheric aerosols in the Arctic following the 1991 eruptions of Mount Pinatubo. Geophysical Research Letters 20, 21, 2359-2362, doi:10.1029/93GL02684.

Stone, R. S., Anderson, G. P., Andrews, E., Dutton, E. G., Shettle, E. P., Berk, A., 2007. Incursions and radiative impact of Asian dust in northern Alaska. Geophysical Research Letters 34, L14815. doi:10.1029/2007GL029878.

Stone, R. S., Anderson, G. P., Shettle, E. P., Andrews, E., Loukachine, K., Dutton, E. G., Schaaf, C., Roman III, M. O., 2008. Radiative impact of boreal smoke in the Arctic: Observed and modeled. Journal of Geophysical Research 113, D14S16, doi:10.1029/2007JD009657.

Stone, R. S., Herber, A., Vitale, V., Mazzola, M., Lupi, A., Schnell, R. C., Dutton, E. G., Liu, P. S. K., Li, S.-M., Dethloff, K., Lampert, A., Ritter, C., Stock, M., Neuber, R., Maturilli, M., 2010. A three-dimensional characterization of Arctic aerosols from airborne Sun photometer observations: PAM-ARCMIP, April 2009. Journal of Geophysical Research 115, D13203, doi:10.1029/2009JD013605.

Stone, R. S., Sharma, S., Herber, A., Eleftheriadis, K., Nelson, D. W., 2014. A characterization of Arctic aerosols on the basis of aerosol optical depth and black carbon measurements. Elementa: Science of Anthropocene 2, 22 pp, doi:10.12952/journal.elementa.000027.

Ström, J., Umegård, J., Tørseth, K., Tunved, P., Hansson, H.-C., Holmén, K., Wismann, V., Herber, A., König-Langlo, G., 2003. One year of particle size distribution and aerosol chemical composition measurements at the Zeppelin station, Svalbard, March 2000-March 2001. Physics and Chemistry of the Earth 28, 1181-1190, doi:10.1016/j.pce.2003.08.058.

Strunin, M. A., Postnov, A. A., Mezrin, M. Y., 1997. Meteorological potential for contamination of Arctic troposphere: Boundary layer structure and turbulent diffusion characteristics. Atmospheric Research, 44, 37-51, doi:10.1016/S0169-8095(97)00008-2. 
2814 Teinilä, K., Kerminen, V.-M., Hillamo, R., 2000. A study of size-segregated aerosol chemistry in 2815 the Antarctic atmosphere. Journal of Geophysical Research 105, D3, 3893-3904, doi:10.1029/1999JD901033.

Tang, J., Xue, Y., Yu, T., Guan, Y., 2005. Aerosol optical thickness determination by exploiting the synergy of TERRA and AQUA MODIS. Remote Sensing of Environment, 94, 3, 327-334, doi:10.1016/j.rse.2004.09.013.

Tanré, D., Kaufman, Y. J., Herman, M., Mattoo, S., 1997. Remote sensing of aerosol properties over oceans using the MODIS/EOS spectral radiances. Journal of Geophysical Research 102. D14, 16971-16988, doi:10.1029/96JD03437.

Thomason, L. W., Herman, B. M., Reagan, J. A., 1983. The effect of atmospheric attenuators with structured vertical distributions on air mass determinations and Langley plot analyses. Journal of the Atmospheric Sciences 40, 7, 1851-1854, doi:10.1175/15200469(1983)040<1851:TEOAAW >2.0.CO;2.

Thomason, L. W., Peter, T. (eds.), 2006. Assessment of stratospheric aerosol properties (ASAP). SPARC Report N 4 (Stratospheric Aerosol Properties and their Role in Climate), WCRP-124, WMO/TD-No. 1295.

Thomason, L.W., Burton, S. P., Luo, B.-P., Peter, T., 2008. SAGE II measurements of stratospheric aerosol properties at non-volcanic levels. Atmospheric Chemistry and Physics 8, 4, 983-995, doi:10.5194/acp-8-983-2008.

Toledano, C., Cachorro, V. E., Gausa, M., Stebel, K., Aaltonen, V., Berjón, A., Ortiz de Galisteo, J. P., De Frutos, A. M., Bennouna, Y., Blindheim, S., Myhre, C. L., Zibordi, G., Wehrli, C., Kratzer, S., Hakansson, B., Carlund, T., de Leeuw, G., Herber, A., Torres, B., 2012. Overview of sun photometer measurements of aerosol properties in Scandinavia and Svalbard. Atmospheric Environment 52C, 18-28, doi:10.1016/j.atmosenv.2011.10.022.

Tomasi, C., Vitale, V., Lupi, A., Di Carmine, C., Campanelli, M., Herber, A., Treffeisen, R., Stone, R. S., Andrews, E., Sharma, S., Radionov, V., von Hoyningen-Huene, W., Stebel, K., Hansen, 
G. H., Myhre, C.L., Wehrli, C., Aaltonen, V., Lihavainen, H., Virkkula, A., Hillamo, R., Ström, J., Toledano, C., Cachorro, V. E., Ortiz, P., de Frutos, A. M., Blindheim, S., Frioud, M., Gausa, M., Zielinski, T., Petelski, T., Yamanouchi, T., 2007. Aerosols in polar regions: a historical overview based on optical depth and in situ observations. Journal of Geophysical Research 112, D16205, doi:10.1029/2007JD008432.

Tomasi, C., Petkov, B. H., Stone, R. S., Benedetti, E., Vitale, V., Lupi, A., Mazzola, M., Lanconelli, C., Herber, A., von Hoyningen-Huene, W., 2010. Characterizing polar atmospheres and their effect on Rayleigh-scattering optical depth. Journal of Geophysical Research 115, D02205, doi:10.1029/2009JD012852.

Tomasi, C., Lupi, A., Mazzola, M., Stone, R. S., Dutton, E. G., Herber, A., Radionov, V. F., Holben, B. N., Sorokin, M. G., Sakerin, S. M., Terpugova, S. A., Sobolewski, P. S., Lanconelli, C., Petkov, B. H., Busetto, M., Vitale, V., 2012. An update on polar aerosol optical properties using POLAR-AOD and other measurements performed during the International Polar Year. Atmospheric Environment 52C, 29-47, doi:10.1016/j.atmosenv.2012.02.055.

Tomasi, C., Lanconelli, C., Lupi, A., Mazzola, M., 2013. Dependence of direct aerosol radiative forcing on the optical properties of atmospheric aerosol and underlying surface. Light Scattering Reviews 8 (Kokhanovsky, A. A., ed.), Chapter 11, 505-626, Springer-Praxis Books in Environmental Sciences, Heidelberg, Germany.

Tomasi, C., Petkov, B. H., 2014. Calculations of relative optical air masses for various aerosol types and minor gases in Arctic and Antarctic atmospheres. Journal of Geophysical Research: Atmospheres 119, 3, 1363-1385, doi:10.1002/2013JD020600.

Tomasi, C., Lanconelli, C., Lupi, A., Mazzola, M., 2014. Diurnally averaged direct aerosol-induced radiative forcing from cloud-free field measurements performed during seven regional experiments. Light Scattering Reviews 9, (Kokhanovsky, A. A., ed.), Chapter 8, 297-425, 
Springer-Praxis Books in Environmental Sciences, Heidelberg, Germany, November 2014, in press.

Treffeisen, R., Tunved, P., Ström, J., Herber, A., Bareiss, J., Helbig, A., Stone, R. S., von characteristics during a record smoke event in the European Arctic and its radiative impact.

Trepte, Q., Arduini, R. F., Chen, Y., Sun-Mack, S., Minnis, P., Spangenberg, D. A., Doelling, D. Atmospheric Chemistry and Physics 7, 3035-3053, doi:10.5194/acp-7-3035-2007. R., 2001. Development of a daytime polar cloud mask using theoretical models of near infrared bidirectional reflectance for ARM and CERES. Proceedings of the AMS 6th Conference on Polar Meteorology and Oceanography, San Diego, CA, May 14-18, 2001, pp. 242-245.

Tuncel, G., Aras, N. K., Zoller, W. H., 1989. Temporal variations and sources of elements in the South Pole atmosphere. 1. Non enriched and moderately enriched elements. Journal of Geophysical Research 94, D10, 13025-13038, doi:10.1029/JD094iD10p13025.

Vermote, E. F., Tanré, D., Deuzé, J. L., Herman, M., Morcrette, J.-J., 1997a. Second simulation of the satellite signal in the solar spectrum (6S): An overview. IEEE Transactions on Geoscience and Remote Sensing 35, 3, 675-686, doi: 10.1109/36.581987.

Vermote, E., Tanré, D., Deuzé, J. L., Herman, M., Morcrette, J. J., 1997b. Second Simulation of the Satellite Signal in the Solar Spectrum (6S), 6S User Guide Version 2, July 1997. Universitè de Lille, France, 218 pp.

Virkkula, A., Teinilä, K., Hillamo, R., Kerminen, V.-M., Saarikoski, S., Aurela, M. , Koponen, I. K., Kulmala, M., 2006a. Chemical size distributions of boundary layer aerosol over the Atlantic Ocean and at an Antarctic site. Journal of Geophysical Research 111, D05306, doi:10.1029/2004JD004958. 
Virkkula, A., Koponen, I. K., Teinilä, K., Hillamo, R., Kerminen, V.-M., Kulmala, M., $2006 b$. Effective real refractive index of dry aerosols in the Antarctic boundary layer. Geophysical Research Letters 33, L06805, doi:10.1029/2005GL024602.

von Hoyningen-Huene, W., Freitag, M., Burrows, J. P., 2003. Retrieval of aerosol optical thickness over land surface from top-of-atmosphere radiance, Journal of Geophysical Research 108, D9, doi:10.1029/2001JD002018.

von Hoyningen-Huene, W., Yoon, J., Vountas, M., Istomina, L. G., Rohen, G., Dinter, T., Kokhanovsky, A. A., Burrows, J. P., 2011. Retrieval of spectral aerosol optical thickness over land using ocean color sensors MERIS and SeaWiFS. Atmospheric Measurement Techniques 4, 151-171, doi:10.5194/amt-4-151-2011.

Wang, Y., Xue, Y., Li, Y., Guang, J., Mei, L., Xu, H.,Ai, J., 2012. Prior knowledge-supported aerosol optical depth retrieval over land surface at $500 \mathrm{~m}$ spatial resolution with MODIS data. International Journal of Remote Sensing, 33, 3, 674-691, doi:10.1080/01431161.2011.577832.

Warneke, C., Froyd, K. D., Brioude, J., Bahreini, R., Brock, C. A., Cozic, J., de Gouw, J. A., Fahey, D. W., Ferrare, R., Holloway, J. S., Middlebrook, A. M., Miller, L., Montzka, S., Schwarz, J. P., Sodemann, H., Spackman, J. R., Stohl, A., 2010. An important contribution to springtime Arctic aerosol from biomass burning in Russia. Geophysical Research Letters 37, L01801, doi:10.1029/2009GL041816.

Warren, S. G., Wiscombe, W. J., 1980. A model for the spectral albedo of snow. II: Snow containing atmospheric aerosols. Journal of the Atmospheric Sciences 37, 12, 2734-2745, doi:10.1175/1520-0469(1980)037<2734:AMFTSA>2.0.CO;2.

Wehrli, C., 2000. Calibrations of filter radiometers for determination of atmospheric optical depths. Metrologia, 37, 419-422.

Weitkamp, C. (Ed.), 2005. Lidar: Range-Resolved Optical Remote Sensing of the Atmosphere. Springer Series in Optical Sciences, Vol. 102, ISBN 978-0-387-40075-4, 455 pp. 
2914 Weller, R., Wagenbach, D., 2007. Year-round chemical aerosol records in continental Antarctica 2915 obtained by automatic samplings. Tellus 59C, 755-765, doi:10.1111/j.16000889.2007.00293.x.

2917 Weller, R., Lampert, A., 2008. Optical properties and sulfate scattering efficiency of boundary layer aerosol at coastal Neumayer Station, Antarctica. Journal of Geophysical Research 113, D16208, doi:10.1029/2008JD009962.

Weller, R., Wöltjen, J., Piel, C., Resenberg, R., Wagenbach, D., König-Langlo, G., Kriews, M., 2921 2008. Seasonal variability of crustal and marine trace elements in the aerosol at Neumayer Station, Antarctica. Tellus 60B, 742-752, doi:10.1111/j.1600-0889.2008.00372.x.

Whitt, D. B., Jacobson, M. Z., Wilerson, J. T., Naiman, A. D., Lele, S. K., 2011. Vertical mixing of commercial aviation emissions from cruise altitude to the surface. Journal of Geophysical Research 116, D14109, doi:10.1029/2010JD015532.

Wilson, D. I., Piketh, S. J., Smirnov, A., Holben, B. N., Kuyper, B., 2010. Aerosol optical properties over the South Atlantic and Southern Ocean during the $140^{\text {th }}$ cruise of the M/V S.A. Agulhas. Atmospheric Research 98, 2 - 4, 285-296, doi:10.1016/j.atmosres.2010.07.007.

Winker, D. M., Vaughan, M. A., Omar, A., Hu, Y., Powell, K. A, 2009. Overview of the CALIPSO mission and CALIOP data processing algorithms. Journal of Atmospheric and Oceanic Technology 26, 11, 2310-23231, doi:10.1175/2009JTECHA1281.1.

Winker, D. M., Pelon, J., Coakley, J. A. Jr., Ackerman, S. A., Charlson, R. J., Colarco, P. R., Flamant, P., Fu, Q., Hoff, R. M., Kittaka, C., Kubar, T. L., Le Treut, H., McCormick, M. P., Mégie, G., Poole, L., Powell, K., Trepte, C., Vaughan, M. A., Wielicki, B. A., 2010. The CALIPSO mission: A global 3D view of aerosols and clouds. Bulletin of the American Meteorological Society 91, 9, 1211-1229, doi:10.1175/2010BAMS3009.1.

Winker, D. M., Tackett, J. L., Getzewich, B. J., Liu, Z., Vaughan, M. A., Rogers, R. R., 2013. The global 3-D distribution of tropospheric aerosols as characterized by CALIOP. Atmospheric Chemistry and Physics 13, 9, 3345-3361, doi:10.5194/acp-13-3345-2013. 
2940 Wolff, E. W., Cachier, H., 1998. Concentrations and seasonal cycle of black carbon in aerosol at a 2941 coastal Antarctic station. Journal of Geophysical Research 103, D9, 11033-11041, 2942 doi:10.1029/97JD01363.

2943 Xue, Y., Cracknell, A. P., 1995. Operational bi-angle approach to retrieve the Earth surface albedo 2944 from AVHRR data in the visible band. International Journal of Remote Sensing 16, 3, 417429, doi:10.1080/01431169508954410.

2946 Xue, Y., He, X., Xu, H., Guang, J., Guo, J., Mei, L., 2014. China Collection 2.0: The aerosol optical 2947 depth dataset from the synergetic retrieval of aerosol properties algorithm. Atmospheric Environment 95, 45-58, doi:10.1016/j.atmosenv.2014.06.019.

2949 Yamanouchi, T., Treffeisen, R. , Herber, A., Shiobara, M., Yamagata, S., Hara, K., Sato, K., 2950 Yabuki, M., Tomikawa, Y., Rinke, A., Neuber, R., Schumachter, R., Kriews, M., Ström, J., 2951 Schrems, O., Gernandt, H., 2005. Arctic Study of Tropospheric Aerosol and Radiation 2952 (ASTAR) 2000: Arctic haze case study. Tellus B 57, 2, 141-152, doi:10.1111/j.1600-

2954 Yoon, J., von Hoyningen-Huene, W., Kokhanovsky, A. A., Vountas, M., Burrows, J. P., 2012. 2955 Trend analysis of aerosol optical thickness and Ångström exponent derived from the global 2956 AERONET spectral observations. Atmospheric Measurement Techniques 5, 6, 1271-1299, 2957 doi:10.5194/amt-5-1271-2012. 


\section{$2961 \quad$ Figure legends}

Figure 1. Schematic of the main transport pathways of aerosols into the Arctic, as described by Law et al. (2014) [used with permission of the American Meteorological Society].

Figure 2. Part (a): Map of the Arctic with the geographical positions of the ground-based sun2967 photometer stations (solid stars), labelled with the following numbered circles: (1) Barrow, (2) Resolute Bay, (3) Eureka-OPAL, (4) Alert, (5) Thule, (6) Summit, (7) Ittoqqortoormiit, (8) NyÅlesund, (9) Barentsburg, (10) Hornsund, (11) Sodankylä, (12) Tiksi, (13) Andenes/ALOMAR, and

(14) Kiruna. Grey symbols indicate the geographical positions of ship-borne sun-photometer measurements made on clear-sky days during the AERONET/MAN cruises in three different sectors: (i) Northern Greenland-Norwegian Sea (GNS), between $20^{\circ} \mathrm{W}$ and $30^{\circ} \mathrm{E}$ (squares), (ii) Barents Sea and West Siberian Sea (BWS), between $30^{\circ} \mathrm{E}$ and $130^{\circ} \mathrm{E}$ (diamonds), and (iii) Eastern

Chuckci Sea, Beaufort Sea and Amundsen Gulf (NAA), between $170^{\circ} \mathrm{W}$ and $110^{\circ} \mathrm{W}$ (triangles). 2975 Part (b): as in the upper part, for the Antarctic ground-based sun-photometer and/or lidar stations 2976 (crosses), labelled with the following numbered circles: (1) Marambio, (2) Neumayer, (3) Troll, (4) 2977 Novolazarevskaya, (5) Mirny, (6) Syowa, (7) Mario Zucchelli, (8) Dome Concordia, (9) South Pole, 2978 (10) McMurdo, and (11) Dumont d'Urville. Grey symbols indicate the geographical positions of the 2979 ship-borne sun-photometer measurement days during the AERONET/MAN cruises, subdivided into 2980 the four following oceanic sectors: (i) Southern Indian Ocean (IND), between $20^{\circ} \mathrm{E}$ and $150^{\circ} \mathrm{E}$ 2981 (squares), (ii) Southern Pacific Ocean (PAC), between $150^{\circ} \mathrm{E}$ and $75^{\circ} \mathrm{W}$ (upward triangles), (iii) 2982 Southern Atlantic Ocean (ATL), between $50^{\circ} \mathrm{W}$ and $20^{\circ} \mathrm{E}$ (diamonds), and (iv) Antarctic 2983 Peninsula (APE), between $75^{\circ}$ and $50^{\circ} \mathrm{W}$ (downward triangles). 
2985 Figure 3.- Left-hand side: Time-patterns of the monthly mean values and standard deviations 2986 (defined by the grey shaded areas) of aerosol optical thickness $\tau(0.50 \mu \mathrm{m})$ (open squares) and 2987 Ångström wavelength exponent $\alpha$ (solid circles) obtained from both series of multi-year sun2988 photometer measurements conducted at Barrow (Alaska) by (a) GMD/NOAA (Boulder, Colorado, 2989 USA) over the period from March 2000 to September 2012, using the Carter Scott sun-photometers 2990 listed in Table 1, and (b) NASA/GSFC (USA) (in cooperation with the Brookhaven National 2991 Laboratory (Upton, NY, USA)) over the period from March 2002 to September 2013, using the 2992 AERONET Cimel CE-318 sun-photometer having the spectral characteristics given in Table 1. 2993 Right-hand side: Relative frequency histograms of $\tau(0.50 \mu \mathrm{m})$ and exponent $\alpha$ obtained separately 2994 for the winter-spring (Arctic haze) period from December to May (black colour) and the summer2995 autumn (background aerosol) period from June to October (grey colour). The seasonal mean values 2996 and $25^{\text {th }}, 50^{\text {th }}$, and $75^{\text {th }}$ percentiles of $\tau(0.50 \mu \mathrm{m})$ and $\alpha$ are reported in the boxes inserted into the 2997 graphs, as obtained by examining the daily mean values of both optical parameters measured at this 2998 coastal site of the Arctic Ocean in the winter-spring (black italics) and summer-autumn (grey 2999 italics) periods.

3001 Figure 4.- As in Figure 3, for the multi-year sun-photometer measurements of aerosol optical thickness $\tau(0.50 \mu \mathrm{m})$ and exponent $\alpha$ conducted at: (a) Resolute Bay by Environment Canada 3003 (Ontario, Canada) over the period from July 2004 to October 2012, using the 3004 AERONET/AEROCAN Cimel CE-318 sun-photometer having the spectral characteristics given in 3005 Table 1; (b) Eureka-OPAL by CARTEL (Sherbrooke University, Canada) from April 2007 to 3006 September 2011, using the AERONET/AEROCAN Cimel CE-318 sun-photometer having the 3007 spectral characteristics given in Table 1; and (c) Alert by GMD/NOAA (Boulder, Colorado, USA) 3008 from August 2004 to September 2012, using the Carter Scott SP02 sun-photometer, with the 3009 characteristics given in Table 1. 
3011 Figure 5.- As in Figure 3, for the for the multi-year sun-photometer measurements of aerosol optical 3012 thickness $\tau(0.50 \mu \mathrm{m})$ and exponent $\alpha$ conducted at: (a) Thule (North-western Greenland) by 3013 NASA/GSFC (USA) over the period from March 2007 to September 2012, using an AERONET 3014 Cimel CE-318 sun-photometer having the spectral characteristics reported in Table 1; (b) Summit 3015 (Central Greenland) by PMOD/WRC (Switzerland) from January 2001 to October 2011, using a 3016 PFR (No. N34) sun-photometer of the GAW-PFR network, having the spectral characteristics given 3017 in Table 1; and (c) Ittoqqortoormiit (Eastern Greenland) by NASA/GSFC (USA) over the period 3018 from May 2010 to October 2013, using an AERONET Cimel CE-318 sun-photometer having the 3019 spectral characteristics reported in Table 1.

3021 Figure 6.- As in Figure 3, for the sun-photometer measurements of aerosol optical thickness $\tau(0.50$ $3022 \mu \mathrm{m}$ ) and exponent $\alpha$ conducted on Spitsbergen Island (Svalbard, Norway) at: (a) Ny-Ålesund by 3023 AWI (Bremerhaven, Germany) from April 2000 to September 2013, using the sun- and star3024 photometers listed in Table 1; (b) Ny-Ålesund by NILU (Kjeller, Norway) from April 2002 to 3025 September 2004 and from March 2006 to September 2013, using a PFR (No. N18) sun-photometer 3026 of the GAW network; (c) Barentsburg by IAO-SB-RAS (Tomsk, Russia) in the April-August 3027 months of 2011 and 2012, using the SPM portable sun-photometer having the characteristics 3028 reported in Table 1, and (d) Hornsund by NASA/GSFC (USA) in cooperation with the Warsaw 3029 University (PAS, Poland from April 2005 to August 2013, using an AERONET Cimel CE-318 sun3030 photometer having the characteristics reported in Table 1.

3032 Figure 7.- As in Figure 3, for the sun-photometer measurements of aerosol optical thickness $\tau$ - 0.50 $3033 \mu \mathrm{m}$ ) and exponent $\alpha$ conducted at: (a) Sodankylä (Northern Finland) by FMI (Helsinki, Finland) in 3034 the winter-spring and summer-autumn periods from late May 2004 to March 2013, using a PFR 3035 (No. N32) sun-photometer having the characteristics reported in Table 1, (b) Sodankylä by 3036 NASA/GSFC (USA) in cooperation with FMI (Helsinki, Finland) from February 2007 to November 
3037 2013, using an AERONET Cimel CE-318 sun-photometer having the characteristics reported in 3038 Table 1; and (c) Tiksi (North-central Siberia, Russia) by NASA/GSFC (USA) in the summer3039 autumn months (June-October) of 2010, 2011 and 2012, using an AERONET Cimel CE-318 sun3040 photometer having the characteristics given in Table 1. In the first graphs, the time-patterns of the 3041 monthly mean values of $\tau(0.50 \mu \mathrm{m})$ and $\alpha$ (solid and open diamonds, respectively) estimated by 3042 Toledano et al. (2012) at Kiruna from PFR measurements conducted over the 2007-2010 period are 3043 shown with their standard deviations (vertical bars) for comparison with the FMI results found at 3044 Sodankylä. The time-patterns of the monthly mean values of $\tau(0.50 \mu \mathrm{m}$ ) and $\alpha$ (solid and open 3045 triangles, respectively) estimated by Toledano et al. (2012) at Kiruna from the Cimel CE-318 3046 measurements conducted from 2002 to 2007 are shown in the seconda graph for comparison with 3047 those derived from the AERONET measurements carried out at Sodankylä.

3049 Figure 8.- Upper part (a): Scatter plot of the seasonal median values of the Ångström exponent $\alpha$ 3050 versus the corresponding seasonal median values of aerosol optical thickness $\tau(0.50 \mu \mathrm{m})$ 3051 determined from the sun-photometer measurements listed in Table 1. Acronym key: Barrow (BRW3052 NOAA for the GMD/NOAA measurements, and BRW-AER for the NASA/GSFC AERONET 3053 measurements), Resolute Bay (RES), Eureka-0PAL (E0P), Alert (ALE) Thule (THU), Summit 3054 (SUM), Ittoqqortoormiit (ITT), Ny-Ålesund (NYA-AWI and NYA-NILU, for the AWI and NILU 3055 measurements, respectively), Barentsburg (BAR), Hornsund (HOR), Sodankylä (SOD-PFR and 3056 SOD-AER, for the PFR and AERONET measurements, respectively) and Tiksi (TIK). The median 3057 values are represented using grey-solid and grey-and-white open symbols to represent the summer3058 autumn results (as shown in the legend) and solid or black-and-white open symbols to represent the 3059 winter-spring results, showing the background aerosol and Arctic haze optical characteristics, 3060 respectively. The $25^{\text {th }}$ and $75^{\text {th }}$ percentiles are used to define the limits of the vertical and horizontal 3061 dashed bars. Part (b), as in the upper part (a), for the winter-spring (grey symbols) and summer3062 autumn (open symbols) median values of $\alpha$ plotted versus the corresponding median values of 
$3063 \tau(0.50 \mu \mathrm{m})$, as obtained from the seasonal sets of ship-borne sun-photometer measurements 3064 collected over the Arctic Ocean sectors: (i) GNS (Greenland Sea and Norwegian Sea) (diamonds), 3065 (ii) BWS (Barents Sea and West Siberian Sea) (circles), and (iii) NAA (North-American Arctic 3066 ocean, including the East Chukchi Sea, the Bering Strait, the Beaufort Sea and the Amundsen Gulf) 3067 (squares).

Figure 9.- As in Figure 3, for sun-photometer measurements of aerosol optical thickness $\tau(0.50 \mu \mathrm{m})$ 3070 and exponent $\alpha$ conducted during the September-April period at: (a) Marambio in the Seymour3071 Marambio Island (Antarctic Peninsula) by FMI (Helsinki, Finland), using a PFR (No. N29) sun3072 photometer from August 2011 to March 2013; (b) Neumayer on the Akta Bay (Weddel Sea coast) 3073 by AWI (Bremerhaven, Germany), using the sun-photometers SP1A and SP2H, and the star3074 photometer STAR01 listed in Table 2 from September 2000 to April 2007; and (c) Troll located at 3075 Jutulsessen (in the Queen Maud Land, $235 \mathrm{~km}$ from the coast, at $1309 \mathrm{~m}$ a.m.s.1.) by NILU (Kjeller, 3076 Norway), alternately using two PFR (Nos. N40 and N42) sun-photometers from January 2007 to 3077 April 2013

3079 Figure 10.- As in Figure 3, for sun-photometer measurements of aerosol optical thickness $\tau(0.50$ $3080 \mu \mathrm{m}$ ) and exponent $\alpha$ conducted at the Antarctic sites of: (a) Novolazarevskaya in the Schirmaker 3081 Oasis (Quenn Maud Land), $75 \mathrm{~km}$ from the coast, by AARI (St. Petersburg, Russia), using a hand3082 held Microtops calibrated at GSFC (USA) over the periods from December 2008 to February 2009 3083 and from November 2009 to February 2010, and obtaining Level 1.5 cloud-screened data; and (b) 3084 Mirny on the Davis Sea coast by AARI (St. Petersburg, Russia), using the AARI, SPM and 3085 Microtops sun-photometers, having the spectral characteristics given in Table 2, over the period 3086 from March 2000 to October 2013. 
3088 Figure 11. As in Figure 3, for sun-photometer measurements of aerosol optical thickness $\tau(0.50 \mu \mathrm{m})$ 3089 and exponent $\alpha$ conducted at the Antarctic sites of: (a) Syowa (East Ongul Island, Lützow-Holm 3090 Bay) over the period from January 2000 to December 2011 by the Office of Antarctic Observation 3091 (Japan Meteorological Agency, Tokyo, Japan), using the EKO MS-110 sun-photometer, having the 3092 spectral characteristics given in Table 2.

Figure 12. Upper part: as in Figure 3, for sun-photometer measurements of aerosol optical thickness $\tau(0.50 \mu \mathrm{m})$ and exponent $\alpha$ conducted at: (a) the high-altitude site of Dome Concordia (DomeC), on

3099 the Eastern Antarctic Plateau, over the period from September to April, by (i) GMD/NOAA 3100 (Boulder, Colorado, USA) from January to November 2010, using a Carter Scott SP02 sun3101 photometer (squares); (ii) NASA/GSFC (USA) in cooperation with LGGE/CNRS (Grenoble, 3102 France) in January and December of 2003, and in January 2004, using an AERONET Cimel CE3103318 sun-photometer having the spectral characteristics reported in Table 2 (circles); and (iii) OPAR 3104 Institute (University of Réunion, St. Denis, France) in January of 2010, 2011 and 2012, using an 3105 hand-held Microtops II sun-photometer calibrated at GSFC (USA), obtaining Level 1.5 cloud3106 screened data (triangles). Lower part: as in Figure 3, for sun-photometer measurements of aerosol 3107 optical thickness $\tau(0.50 \mu \mathrm{m})$ and exponent $\alpha$ conducted at the high-altitude site of South Pole (SPO) 3108 by (i) GMD/NOAA (Boulder, Colorado, USA), using a Carter Scott SP02 sun-photometer in the 3109 September-March period from November 2001 to March 2012; and (ii) NASA/GSFC (USA) in 3110 cooperation with GMD/NOAA (Boulder, Colorado, USA) using an AERONET Cimel CE-318 sun3111 photometer having the spectral characteristics reported in Table 2 in the November-February period 3112 from November 2007 to December 2012. 
3114 Figure 13.- Part (a): as in Figure 8, but for the sun-photometer measurements listed in Table 2. 3115 Acronym key: Marambio (MAR), Neumayer (NEU), Troll (TRO), Novolazarevskaya (NOV), 3116 Mirny (MIR), Syowa (SYO), Mario Zucchelli (MZS), Dome Concordia (DMC-NOAA, DMC3117 AER, and DMC-OPAR, for the measurement sets collected by GMD/NOAA, AERONET and 3118 OPAR groups, respectively (see Table 4)) and South Pole (SPO-NOAA and SPO-AER, for the 3119 measurement sets collected by GMD/NOAA and AERONET groups, respectively). Part (b): as in 3120 part (a), for the Microtops sun-photometer measurements performed in Antarctic coastal (open 3121 symbols) and off-shore areas (solid symbols) during the cruises conducted in the four following 3122 oceanic sectors: (i) IND (Southern Indian Ocean, squares), (ii) PAC (Southern Pacific Ocean, 3123 upward triangles), (iii) ATL (Southern Atlantic Ocean, diamonds), and (iv) APE (Antarctic 3124 Peninsula, downward triangles).

Figure 14. Part (a): as in Figure 3, for Microtops sun-photometer measurements of aerosol optical thickness $\tau(0.50 \mu \mathrm{m})$ and exponent $\alpha$ performed during the cruises conducted from 2003 to 2012 in 3128 the GNS (Greenland Sea and Norwegian Sea) sector (solid circles), from 2006 to 2012 in the BWS 3129 (Barents Sea and West Siberian Sea) sector (solid squares), and from 2008 to 2011 in the NAA 3130 (Eastern Chuckci Sea, Beaufort Sea and Amundsen Gulf) sector (open triangles) (see also Table 3). 3131 Part (b): relative frequency histograms of the daily mean values of aerosol optical thickness $\tau(0.50$ $3132 \mu \mathrm{m})$ and exponent $\alpha$ determined from the Microtops measurements conducted from March to 3133 September over the GNS (Greenland Sea and Norwegian Sea) sector, and the NAA (North 3134 American Arctic Ocean) sector, including the Eastern Chuckci Sea, Beaufort Sea and Amundsen 3135 Gulf.

3137 Figure 15. Part (a): as in Figure 3, for Microtops sun-photometer measurements of $\tau(0.50 \mu \mathrm{m})$ and $3138 \alpha$ performed during the cruises conducted from late 2005 to spring 2013 in the frame of the 3139 Maritime Aerosol Network (MAN) activities listed in Table 4. The data refer to coastal (open 
3140 symbols) and off-shore (solid symbols) measurements, carried out in the IND sector (Southern 3141 Indian Ocean, circles), PAC sector (Southern Pacific Ocean, upward triangles), ATL sector 3142 (Southern Atlantic Ocean, squares), and APE sector (Antarctic Peninsula, downward triangles). Part 3143 (b): Relative frequency histograms of $\tau(0.50 \mu \mathrm{m})$ and $\alpha$ obtained for the coastal data-sets collected 3144 (i) on 226 measurement days from November to February over the Southern Indian Ocean (IND) 3145 sector; (ii) 63 measurement days from December to April over the Southern Atlantic Ocean (ATL) 3146 sector; and (iii) on 49 measurement days from October to April over the coastal area surrounding 3147 the Antarctic Peninsula (APE sector).

3149 Figure 16. Monthly and bi-monthly averaged vertical profiles of aerosol volume backscatter 3150 coefficient $\beta_{b s}(0.532 \mu \mathrm{m})$ obtained from the KARL lidar measurements conducted at Ny-Ålesund 3151 (AWIPEV station) from 1 November, 2012, to 31 October, 2013.

3153 Figure 17. Time-patterns of the monthly average values of the aerosol volume backscatter 3154 coefficient $\beta_{b s}(0.532 \mu \mathrm{m})$ integrated over the different altitude ranges reported in the legend, as 3155 obtained from the KARL lidar measurements performed at Ny-Ålesund (AWIPEV station) from 1 3156 November, 2012, to 31 October, 2013.

3158 Figure 18 . Time-patterns of the monthly average values of the lidar ratio $S_{a}(0,532 \mu m)=\beta_{\text {ext }}(0.532$ $3159 \mu m) / \beta_{b s}(0.532 \mu m)$ calculated over the whole altitude range (triangles) and the altitude sub-ranges $z$ $3160<3.5 \mathrm{~km}$ (squares) and $z>3.5 \mathrm{~km}(+)$, as obtained from the KARL lidar measurements conducted 3161 at Ny-Ålesund (AWIPEV station) from 1 November, 2012, to 31 October, 2013.

3163 Figure 19. Scatter plots of the monthly and bi-monthly averaged values of the depolarisation ratio 3164 (\%) versus the aerosol backscatter coefficient $\beta_{b s}(0.532 \mu \mathrm{m})$, as obtained from the KARL lidar 
3165 measurements conducted at Ny-Ålesund (AWIPEV station) from 1 November, 2012, to 31 October, 31662013.

3168 Figure 20. Arctic maps of the seasonal average Level-3 aerosol optical thickness $\tau(0.55 \mu m)$ derived 3169 from MODIS/Aqua (upper part) and MODIS/Terra (lower part) satellite data recorded from 2005 to 31702012 during the spring (left-hand side) and summer (right-hand side) 3-month periods.

Figure 21. Antarctic maps of the austral summer Level-3 aerosol optical thickness $\tau(0.55 \mu \mathrm{m})$ 3173 derived from the MODIS/Terra (left-hand side) and MODIS/Aqua (right-hand side) satellite data 3174 recorded over the 2005-2012 period.

Figure 22. Maps of aerosol optical thickness $\tau(0.55 \mu \mathrm{m})$ derived over the Arctic region from the 3177 MODIS/Aqua observations made on 29 March, 2006 (left-hand side) and 3 May, 2006 (right-hand 3178 side) using the method of Mei et al. (2013a).

3180 Figure 23. Upper part: Arctic maps of the seasonal average Level-3 aerosol optical thickness $\tau(0.55$ $3181 \mu \mathrm{m}$ ) derived from the MISR satellite data recorded from 2005 to 2012 during the spring (left-hand 3182 side) and summer (right-hand side) 3-month periods. Lower part: As in the upper part, for the 3183 austral summer average Level-3 aerosol optical thickness $\tau(0.55 \mu \mathrm{m})$ derived from MISR satellite 3184 data recorded from 2005 to 2012 over oceans and land areas not covered by snow and ice.

3186 Figure 24. Time sequence of aerosol optical thickness $\tau(0.55 \mu \mathrm{m})$ retrieved using AATSR data over 3187 sea-ice and snow-covered land surfaces with the algorithm described by Istomina et al. (2011). Left 3188 panel refers to orbit No. 31673 on 21 March, 2008; middle panel to orbit No. 31687 on 22 March, 3189 2008; and right panel to orbit No. 31773 on 28 March, 2008. The increase in $\tau(0.55 \mu m)$ might be 
connected to ozone depletion/bromine explosions observed during March 2008 in the region 3191 (Nghiem et al., 2012; Moore et al., 2014).

Figure 25. Maps of aerosol optical thickness $\tau(0.55 \mu \mathrm{m})$ retrieved from AATSR data taken with 1 $3194 \mathrm{~km} \times 1 \mathrm{~km}$ resolution on 9, 15, 18, and 21 April, 2009, over snow-covered surfaces in west 3195 Greenland using the method of Mei et al. (2013b).

Figure 26. Angular distribution curves of phase function $P(\Theta)$ as a function of the scattering angle $\Theta$ for the 8 unimodal Arctic aerosol extinction models (left) and the 6 unimodal Antarctic aerosol extinction models defined in Table 5.

Figure 27. Left-hand side: examples of bimodal particle size-distribution curves obtained as best-fit linear combinations of aerosol unimodal models for fine and accumulation/coarse particles defined in Table 3 in the following four case studies: (a) the average winter-spring aerosol case determined at Eureka (Nunavut, Northern Canada) for the mean values $\tau(0.50 \mu \mathrm{m})=0.12$ and $\alpha=1.48$; (b) the summer background aerosol case determined at Tiksi (Russia) in North-central Siberia for the mean values $\tau(0.50 \mu \mathrm{m})=0.08$ and $\alpha=1.60$; (c) the Asian dust episode observed at Barrow on 16 April, 32072002 , giving the mean daily values $\tau(0.50 \mu \mathrm{m})=0.22$ and $\alpha=0.26$; and (d) the BFF smoke episode 3208 observed by Stock et al. (2012) at Ny-Ålesund on 23 March, 2008, for the daily mean values $\tau(0.50$ $3209 \mu m)=0.22$ and $\alpha=1.50$. Right-hand side: as on the left, for the following four case studies: (e) the 3210 austral summer coastal aerosol case determined at Mario Zucchelli (MZS) for the mean values $3211 \tau(0.50 \mu \mathrm{m})=0.03$ and $\alpha=0.90$; (f) the austral summer coastal aerosol case determined at 3212 Neumayer (NEU) for the mean values of $\tau(0.50 \mu \mathrm{m})=0.045$ and $\alpha=0.78$; $(\mathrm{g})$ the austral summer 3213 Antarctic Plateau aerosol case determined at South Pole for the mean values $\tau(0.50 \mu \mathrm{m})=0.018$ and 
$3214 \alpha=1.49$; and (h) the austral winter aerosol case assumed at Neumayer for the seasonal average 3215 values $\tau(0.50 \mu \mathrm{m})=0.035$ and $\alpha=0.65$.

3217 Figure 28. Scatter plots of the daily mean values of DARF efficiencies $E_{T O A}$ at the TOA-level 3218 (upper part), $E_{B O A}$ at the BOA-level (middle part), and $E_{A T M}$ in the atmosphere (lower part) shown 3219 versus the broadband albedo calculated by Tomasi et al. (2014) at solar zenith angle $\theta_{o}=60^{\circ}$, for 3220 the BRDF oceanic surface (OS1), vegetation-covered surface (VS1) and snow-covered polar 3221 surface (PS1, PS2, PS3 and PS4) models, and for the 15 polar aerosol types defined in Table 6 and 3222 represented using different symbols. 


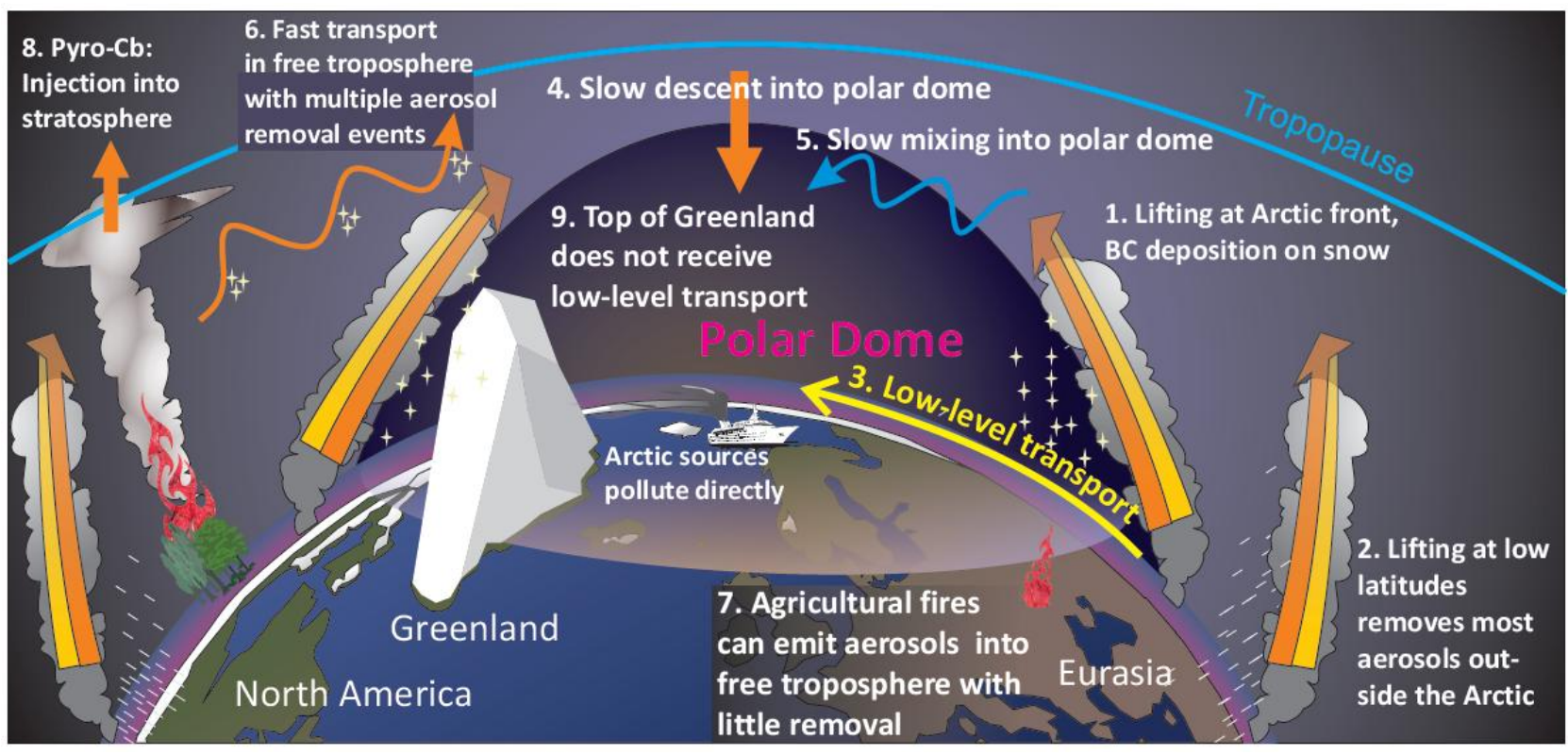

3228 Figure 1. Schematic of the main transport pathways of aerosols into the Arctic, as described by Law 3229 et al. (2014) [used with permission of the American Meteorological Society]. 

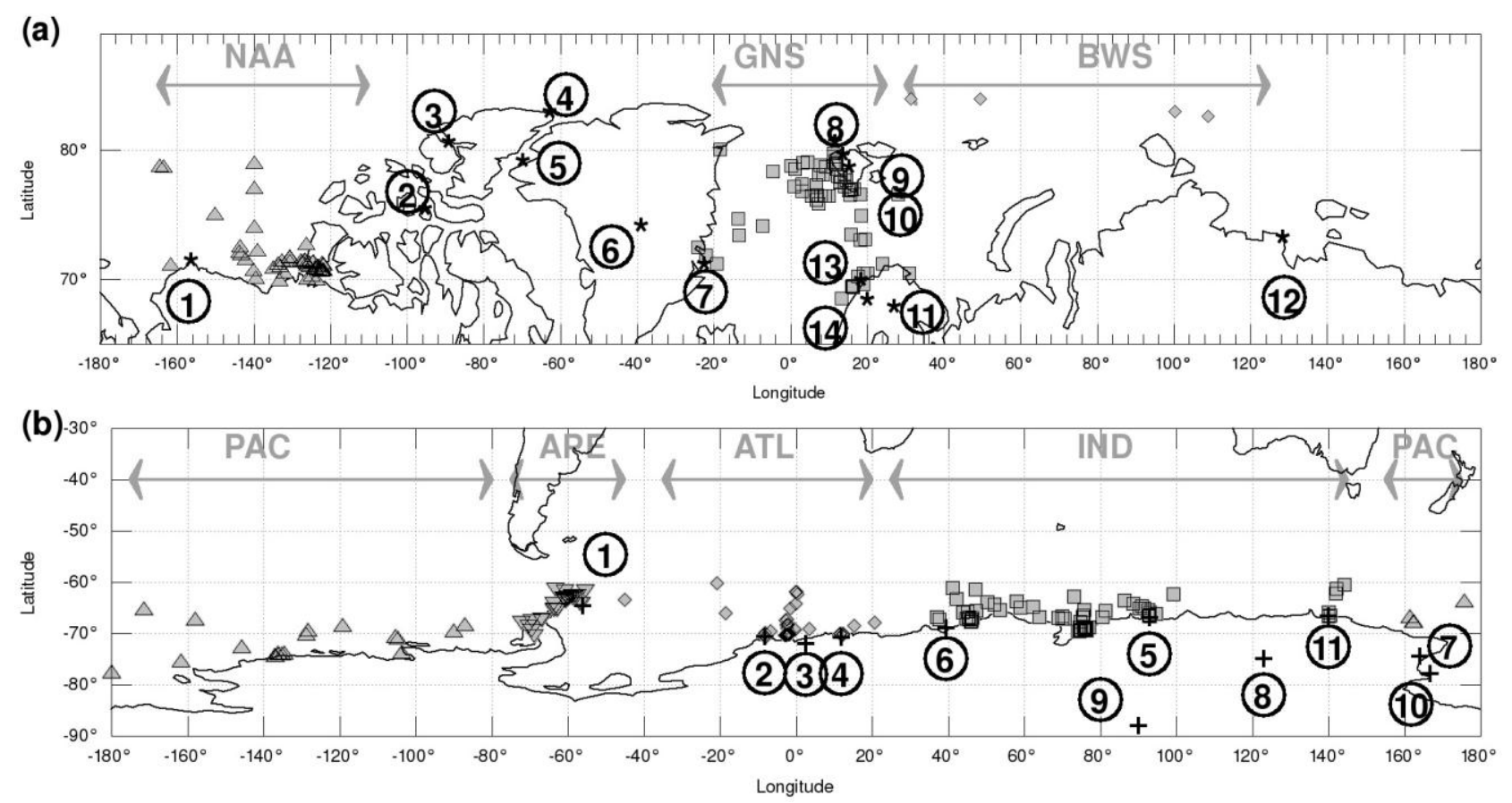

Figure 2. Part (a): Map of the Arctic with the geographical positions of the ground-based sunphotometer stations (solid stars), labelled with the following numbered circles: (1) Barrow, (2) Resolute Bay, (3) Eureka-OPAL, (4) Alert, (5) Thule, (6) Summit, (7) Ittoqqortoormiit, (8) NyÅlesund, (9) Barentsburg, (10) Hornsund, (11) Sodankylä, (12) Tiksi, (13) Andenes/ALOMAR, and (14) Kiruna. Grey symbols indicate the geographical positions of ship-borne sun-photometer measurements made on clear-sky days during the AERONET/MAN cruises in three different sectors: (i) Northern Greenland-Norwegian Sea (GNS), between $20^{\circ} \mathrm{W}$ and $30^{\circ} \mathrm{E}$ (squares), (ii) Barents Sea and West Siberian Sea (BWS), between $30^{\circ} \mathrm{E}$ and $130^{\circ} \mathrm{E}$ (diamonds), and (iii) Eastern Chuckci Sea, Beaufort Sea and Amundsen Gulf (NAA), between $170^{\circ} \mathrm{W}$ and $110^{\circ} \mathrm{W}$ (triangles). Part (b): as in the upper part, for the Antarctic ground-based sun-photometer and/or lidar stations (crosses), labelled with the following numbered circles: (1) Marambio, (2) Neumayer, (3) Troll, (4) Novolazarevskaya, (5) Mirny, (6) Syowa, (7) Mario Zucchelli, (8) Dome Concordia, (9) South Pole, (10) McMurdo, and (11) Dumont d'Urville. Grey symbols indicate the geographical positions of the ship-borne sun-photometer measurement days during the AERONET/MAN cruises, subdivided into the four following oceanic sectors: (i) Southern Indian Ocean (IND), between $20^{\circ} \mathrm{E}$ and $150^{\circ} \mathrm{E}$ (squares), (ii) Southern Pacific Ocean (PAC), between $150^{\circ} \mathrm{E}$ and $75^{\circ} \mathrm{W}$ (upward triangles), (iii) 

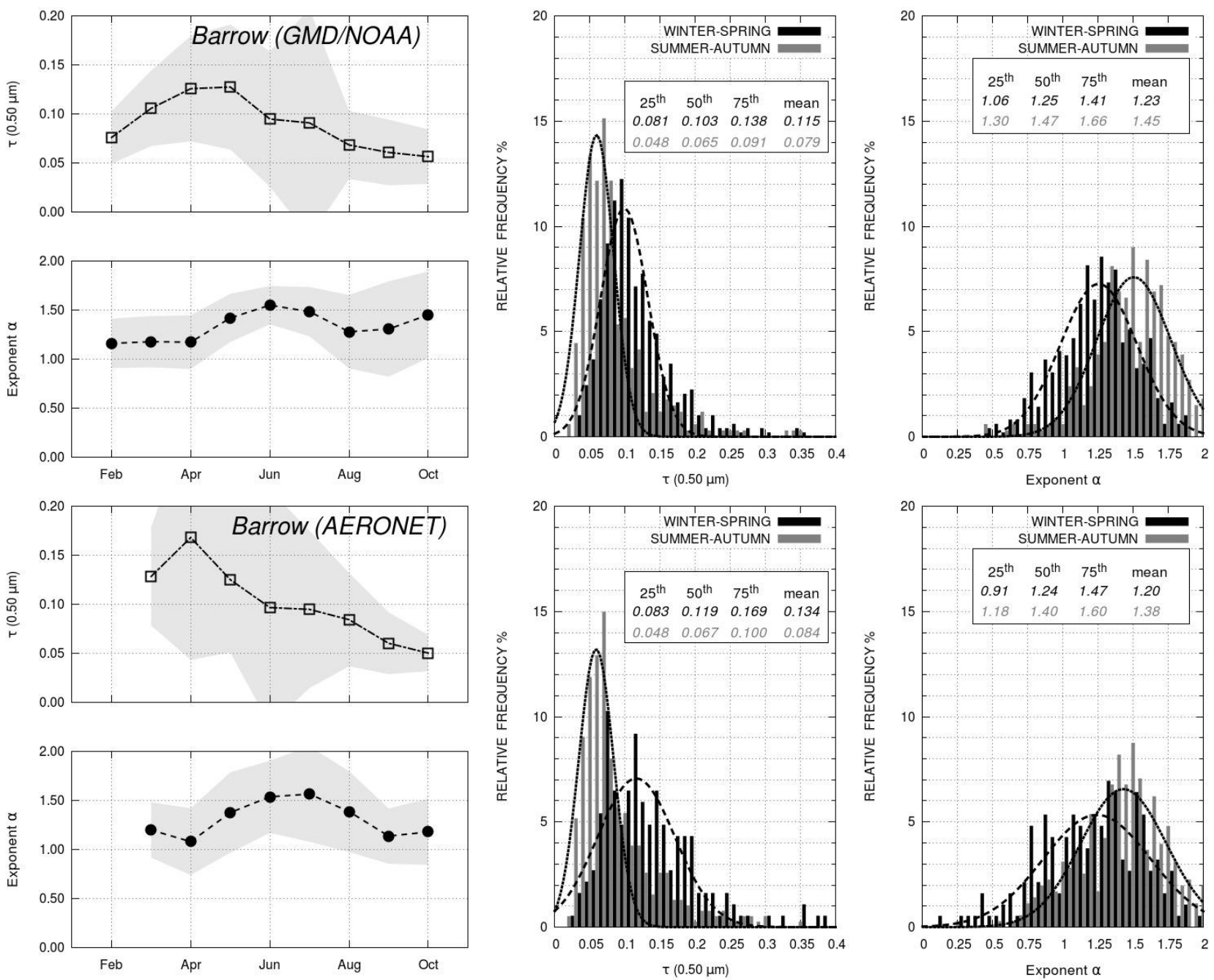

Figure 3.- Left-hand side: Time-patterns of the monthly mean values and standard deviations (defined by the grey shaded areas) of aerosol optical thickness $\tau(0.50 \mu \mathrm{m})$ (open squares) and Ångström wavelength exponent $\alpha$ (solid circles) obtained from both series of multi-year sunphotometer measurements conducted at Barrow (Alaska) by (a) GMD/NOAA (Boulder, Colorado, USA) over the period from March 2000 to September 2012, using the Carter Scott sun-photometers listed in Table 1, and (b) NASA/GSFC (USA) (in cooperation with the Brookhaven National Laboratory (Upton, NY, USA)) over the period from March 2002 to September 2013, using the AERONET Cimel CE-318 sun-photometer having the spectral characteristics given in Table 1. Right-hand side: Relative frequency histograms of $\tau(0.50 \mu \mathrm{m})$ and exponent $\alpha$ obtained separately for the winter-spring (Arctic haze) period from December to May (black colour) and the summerautumn (background aerosol) period from June to October (grey colour). The seasonal mean values and $25^{\text {th }}, 50^{\text {th }}$, and $75^{\text {th }}$ percentiles of $\tau(0.50 \mu \mathrm{m})$ and $\alpha$ are reported in the boxes inserted into the graphs, as obtained by examining the daily mean values of both optical parameters measured at this coastal site of the Arctic Ocean in the winter-spring (black italics) and summer-autumn (grey italics) periods. 

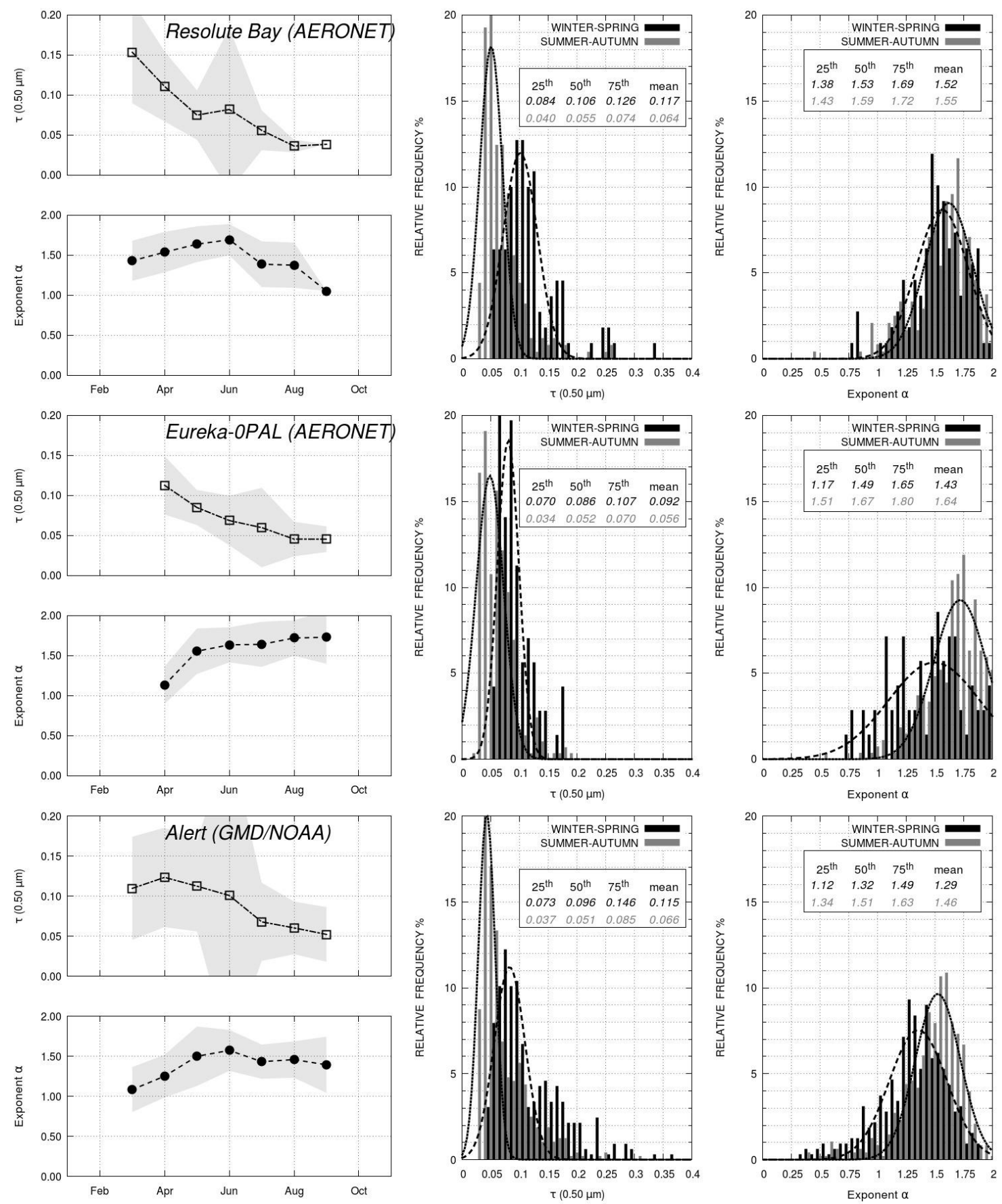

$\tau(0.50 \mu \mathrm{m})$

Exponent $\alpha$

Figure 4.- As in Figure 3, for the multi-year sun-photometer measurements of aerosol optical thickness $\tau(0.50 \mu \mathrm{m})$ and exponent $\alpha$ conducted at: (a) Resolute Bay by Environment Canada (Ontario, Canada) over the period from July 2004 to October 2012, using the AERONET/AEROCAN Cimel CE-318 sun-photometer having the spectral characteristics given in Table 1; (b) Eureka-OPAL by CARTEL (Sherbrooke University, Canada) from April 2007 to September 2011, using the AERONET/AEROCAN Cimel CE-318 sun-photometer having the spectral characteristics given in Table 1; and (c) Alert by GMD/NOAA (Boulder, Colorado, USA) from August 2004 to September 2012, using the Carter Scott SP02 sun-photometer, with the characteristics given in Table 1. 

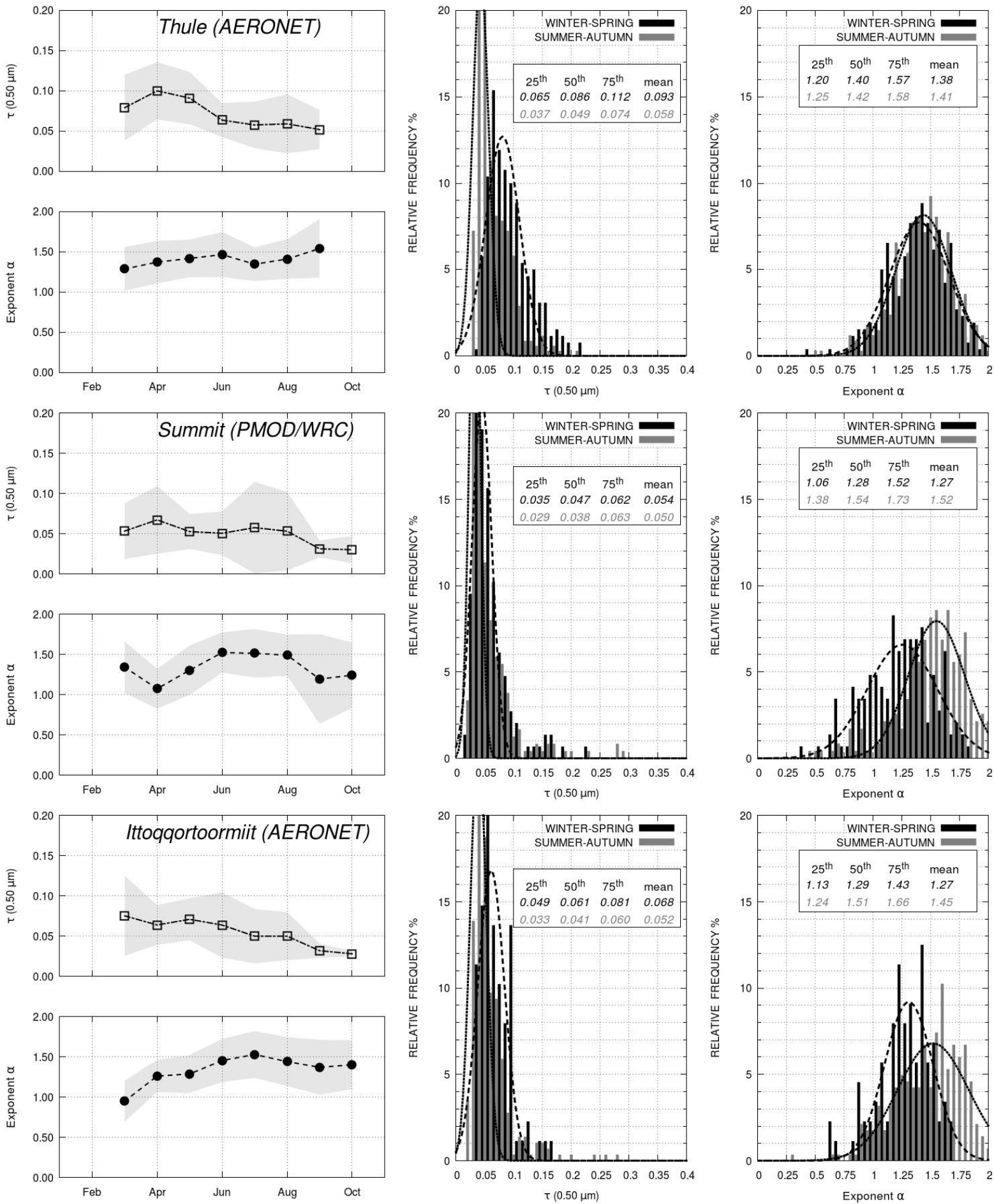
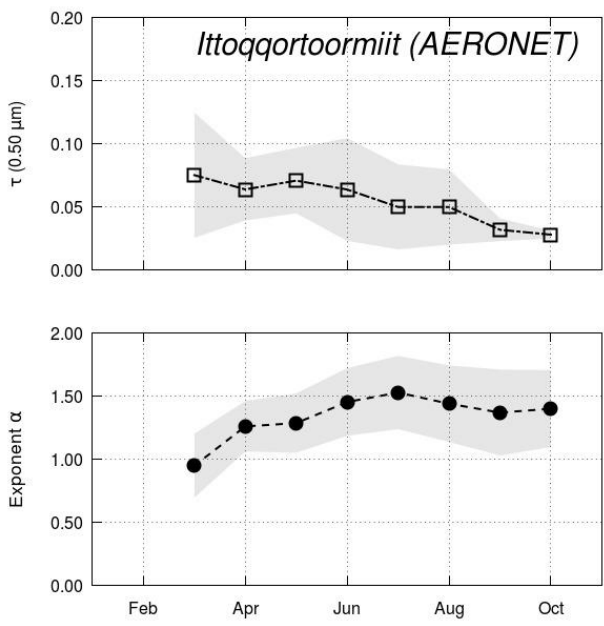

Figure 5.- As in Figure 3, for the for the multi-year sun-photometer measurements of aerosol optical thickness $\tau(0.50 \mu \mathrm{m})$ and exponent $\alpha$ conducted at: (a) Thule (North-western Greenland) by NASA/GSFC (USA) over the period from March 2007 to September 2012, using an AERONET Cimel CE-318 sun-photometer having the spectral characteristics reported in Table 1; (b) Summit (Central Greenland) by PMOD/WRC (Switzerland) from January 2001 to October 2011, using a PFR (No. N34) sun-photometer of the GAW-PFR network, having the spectral characteristics given in Table 1; and (c) Ittoqqortoormiit (Eastern Greenland) by NASA/GSFC (USA) over the period from May 2010 to October 2013, using an AERONET Cimel CE-318 sun-photometer having the spectral characteristics reported in Table 1. 

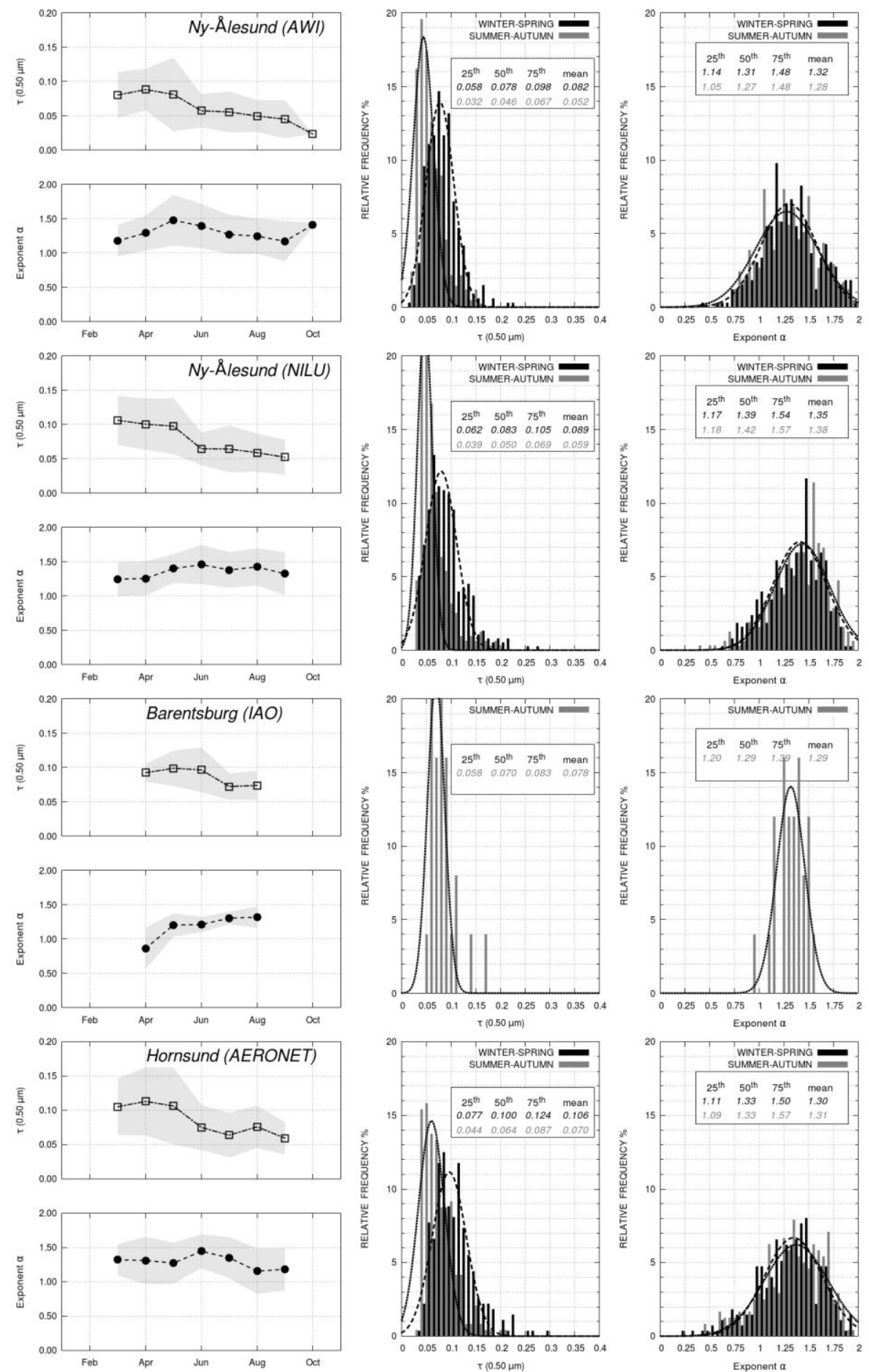

Figure 6.- As in Figure 3, for the sun-photometer measurements of aerosol optical thickness $\tau(0.50$ $\mu \mathrm{m}$ ) and exponent $\alpha$ conducted on Spitsbergen Island (Svalbard, Norway) at: (a) Ny-Ålesund by AWI (Bremerhaven, Germany) from April 2000 to September 2013, using the sun- and starphotometers listed in Table 1; (b) Ny-Ålesund by NILU (Kjeller, Norway) from April 2002 to September 2004 and from March 2006 to September 2013, using a PFR (No. N18) sun-photometer of the GAW network; (c) Barentsburg by IAO-SB-RAS (Tomsk, Russia) in the April-August months of 2011 and 2012, using the SPM portable sun-photometer having the characteristics reported in Table 1, and (d) Hornsund by NASA/GSFC (USA) in cooperation with the Warsaw University (PAS, Poland from April 2005 to August 2013, using an AERONET Cimel CE-318 sunphotometer having the characteristics reported in Table 1. 

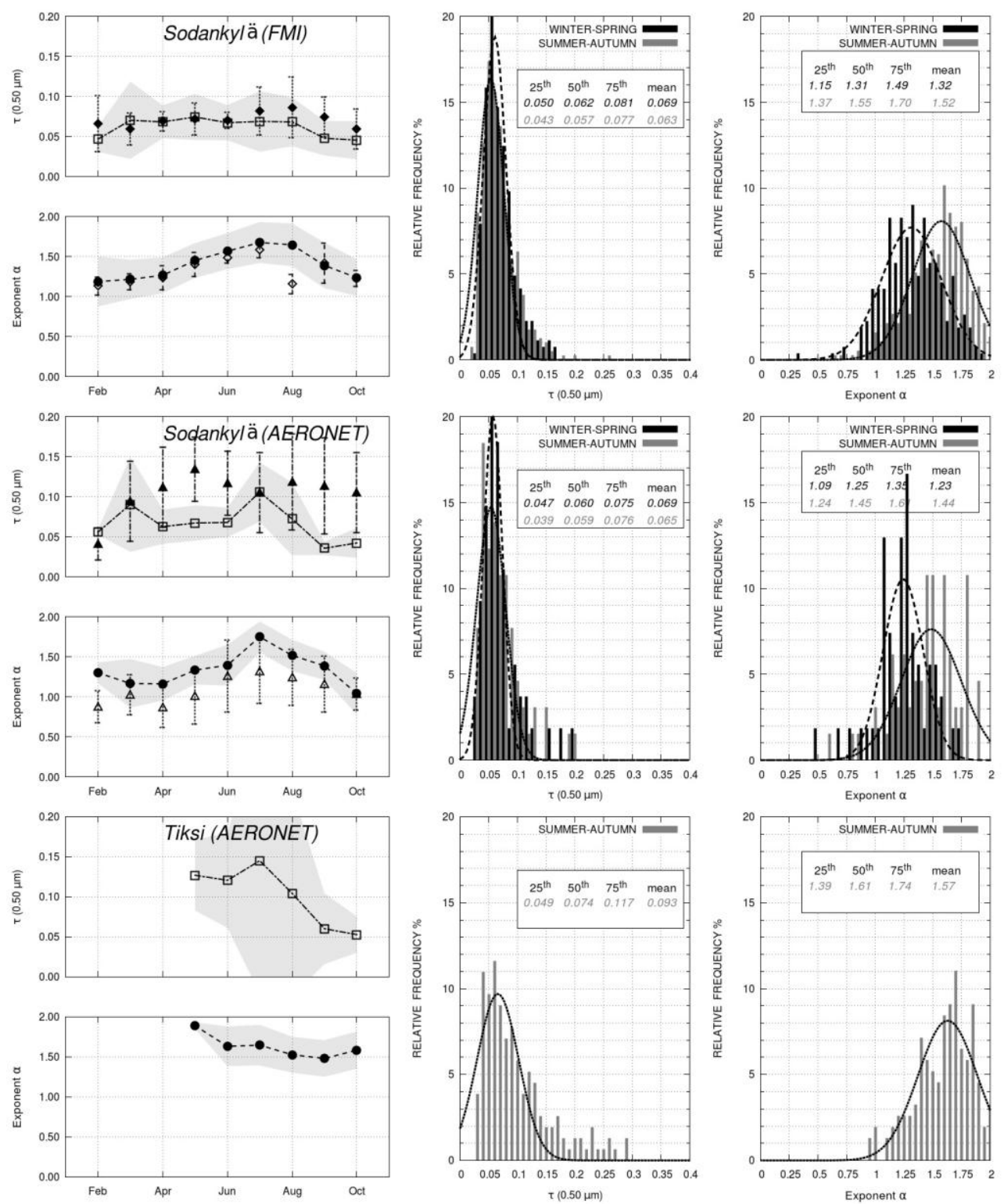

Exponent $\alpha$

Figure 7.- As in Figure 3, for the sun-photometer measurements of aerosol optical thickness $\tau(0.50$ $\mu m$ ) and exponent $\alpha$ conducted at: (a) Sodankylä (Northern Finland) by FMI (Helsinki, Finland) in the winter-spring and summer-autumn periods from late May 2004 to March 2013, using a PFR (No. N32) sun-photometer having the characteristics reported in Table 1, (b) Sodankylä by NASA/GSFC (USA) in cooperation with FMI (Helsinki, Finland) from February 2007 to November 2013, using an AERONET Cimel CE-318 sun-photometer having the characteristics reported in Table 1; and (c) Tiksi (North-central Siberia, Russia) by NASA/GSFC (USA) in the summerautumn months (June-October) of 2010, 2011 and 2012, using an AERONET Cimel CE-318 sunphotometer having the characteristics given in Table 1. In the first graphs, the time-patterns of the monthly mean values of $\tau(0.50 \mu \mathrm{m})$ and $\alpha$ (solid and open diamonds, respectively) estimated by Toledano et al. (2012) at Kiruna from PFR measurements conducted over the 2007-2010 period are shown with their standard deviations (vertical bars) for comparison with the FMI results found at Sodankylä. The time-patterns of the monthly mean values of $\tau(0.50 \mu \mathrm{m})$ and $\alpha$ (solid and open triangles, respectively) estimated by Toledano et al. (2012) at Kiruna from the Cimel CE-318 measurements conducted from 2002 to 2007 are shown in the seconda graph for comparison with those derived from the AERONET measurements carried out at Sodankylä. 

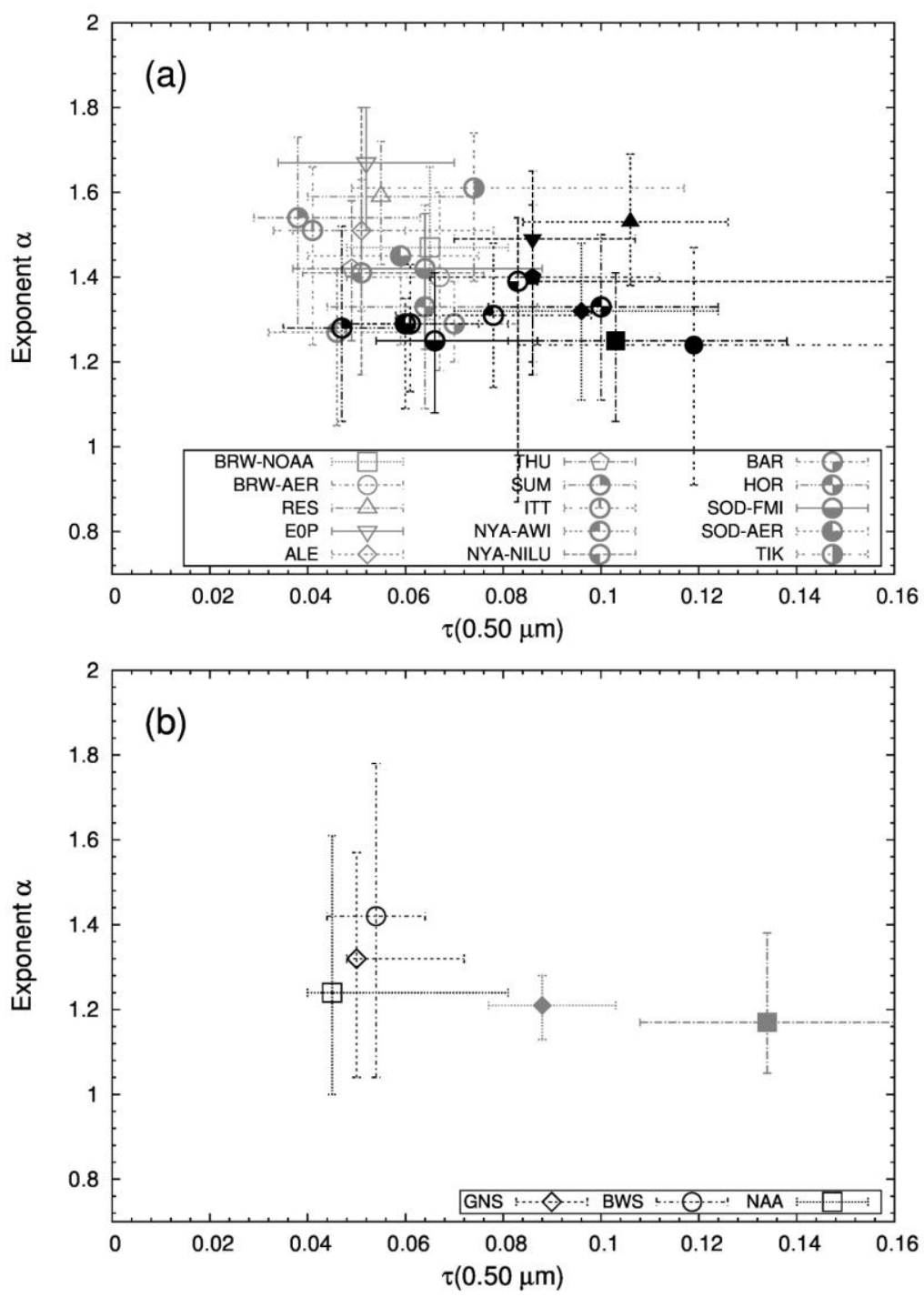

Figure 8.- Upper part (a): Scatter plot of the seasonal median values of the Ångström exponent $\alpha$ versus the corresponding seasonal median values of aerosol optical thickness $\tau(0.50 \mu \mathrm{m})$ determined from the sun-photometer measurements listed in Table 1. Acronym key: Barrow (BRWNOAA for the GMD/NOAA measurements, and BRW-AER for the NASA/GSFC AERONET measurements), Resolute Bay (RES), Eureka-OPAL (E0P), Alert (ALE) Thule (THU), Summit (SUM), Ittoqqortoormiit (ITT), Ny-Ålesund (NYA-AWI and NYA-NILU, for the AWI and NILU measurements, respectively), Barentsburg (BAR), Hornsund (HOR), Sodankylä (SOD-PFR and SOD-AER, for the PFR and AERONET measurements, respectively) and Tiksi (TIK). The median values are represented using grey-solid and grey-and-white open symbols to represent the summerautumn results (as shown in the legend) and solid or black-and-white open symbols to represent the winter-spring results, showing the background aerosol and Arctic haze optical characteristics, respectively. The $25^{\text {th }}$ and $75^{\text {th }}$ percentiles are used to define the limits of the vertical and horizontal dashed bars. Part (b), as in the upper part (a), for the winter-spring (grey symbols) and summerautumn (open symbols) median values of $\alpha$ plotted versus the corresponding median values of $\tau(0.50 \mu \mathrm{m})$, as obtained from the seasonal sets of ship-borne sun-photometer measurements collected over the Arctic Ocean sectors: (i) GNS (Greenland Sea and Norwegian Sea) (diamonds), (ii) BWS (Barents Sea and West Siberian Sea) (circles), and (iii) NAA (North-American Arctic ocean, including the East Chukchi Sea, the Bering Strait, the Beaufort Sea and the Amundsen Gulf) (squares). 

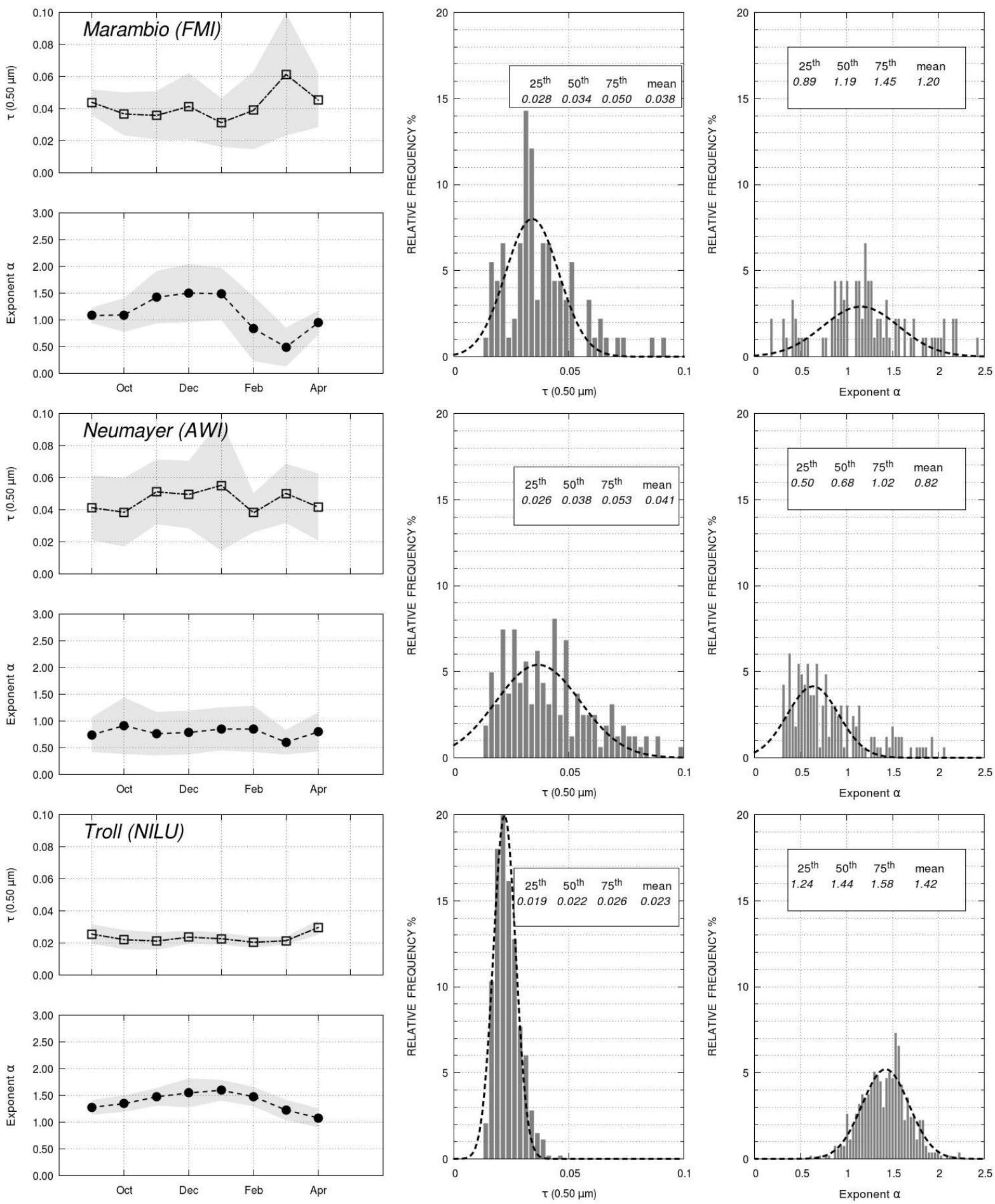

Figure 9.- As in Figure 3, for sun-photometer measurements of aerosol optical thickness $\tau(0.50 \mu \mathrm{m})$ and exponent $\alpha$ conducted during the September-April period at: (a) Marambio in the SeymourMarambio Island (Antarctic Peninsula) by FMI (Helsinki, Finland), using a PFR (No. N29) sunphotometer from August 2011 to March 2013; (b) Neumayer on the Akta Bay (Weddel Sea coast) by AWI (Bremerhaven, Germany), using the sun-photometers SP1A and SP2H, and the starphotometer STAR01 listed in Table 2 from September 2000 to April 2007; and (c) Troll located at Jutulsessen (in the Queen Maud Land, $235 \mathrm{~km}$ from the coast, at $1309 \mathrm{~m}$ a.m.s.l.) by NILU (Kjeller, Norway), alternately using two PFR (Nos. N40 and N42) sun-photometers from January 2007 to April 2013 

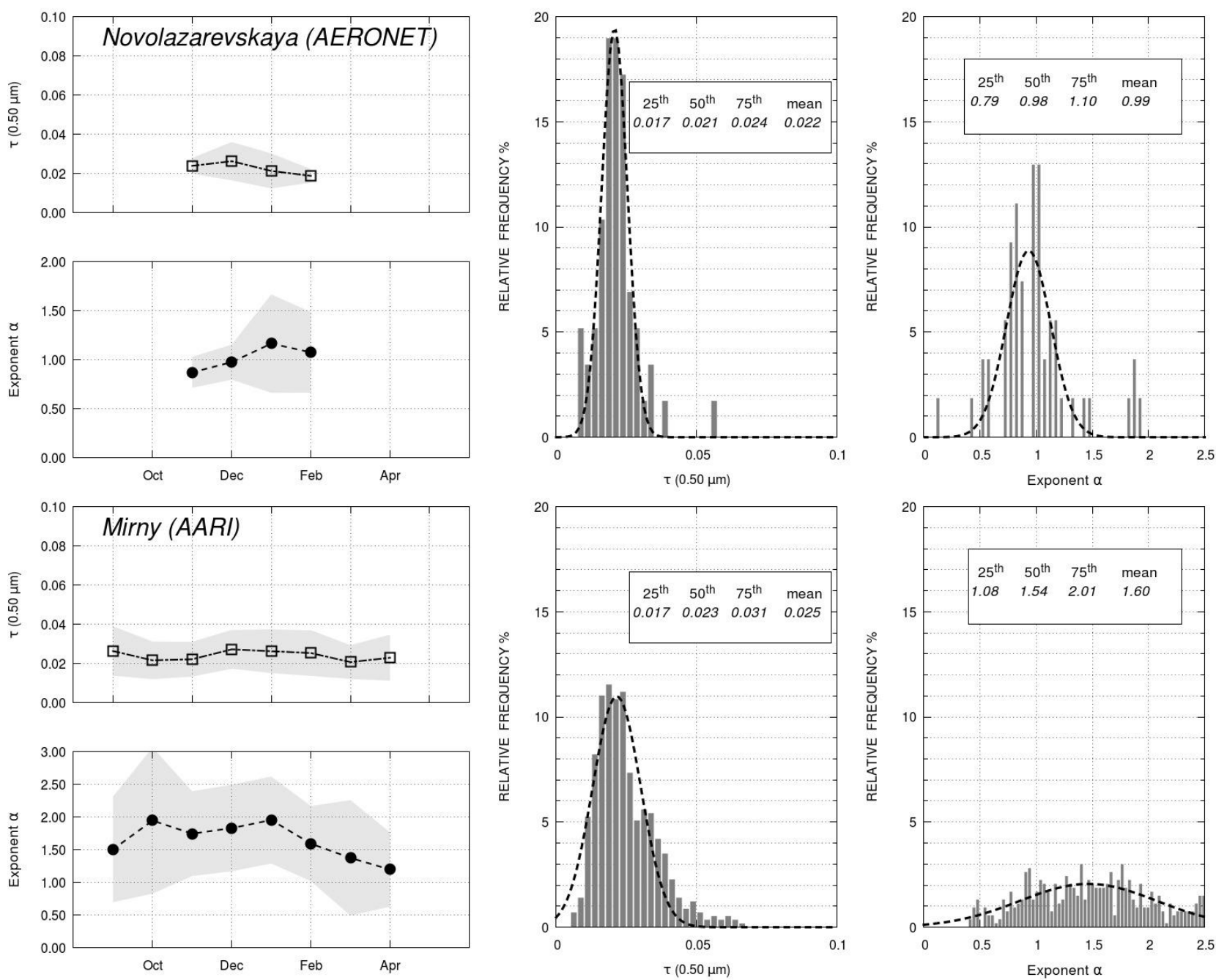

$\tau(0.50 \mu \mathrm{m})$

Figure 10.- As in Figure 3, for sun-photometer measurements of aerosol optical thickness $\tau(0.50$ $\mu \mathrm{m}$ ) and exponent $\alpha$ conducted at the Antarctic sites of: (a) Novolazarevskaya in the Schirmaker Oasis (Quenn Maud Land), $75 \mathrm{~km}$ from the coast, by AARI (St. Petersburg, Russia), using a handheld Microtops calibrated at GSFC (USA) over the periods from December 2008 to February 2009 and from November 2009 to February 2010, and obtaining Level 1.5 cloud-screened data; and (b) Mirny on the Davis Sea coast by AARI (St. Petersburg, Russia), using the AARI, SPM and Microtops sun-photometers, having the spectral characteristics given in Table 2, over the period from March 2000 to October 2013. 

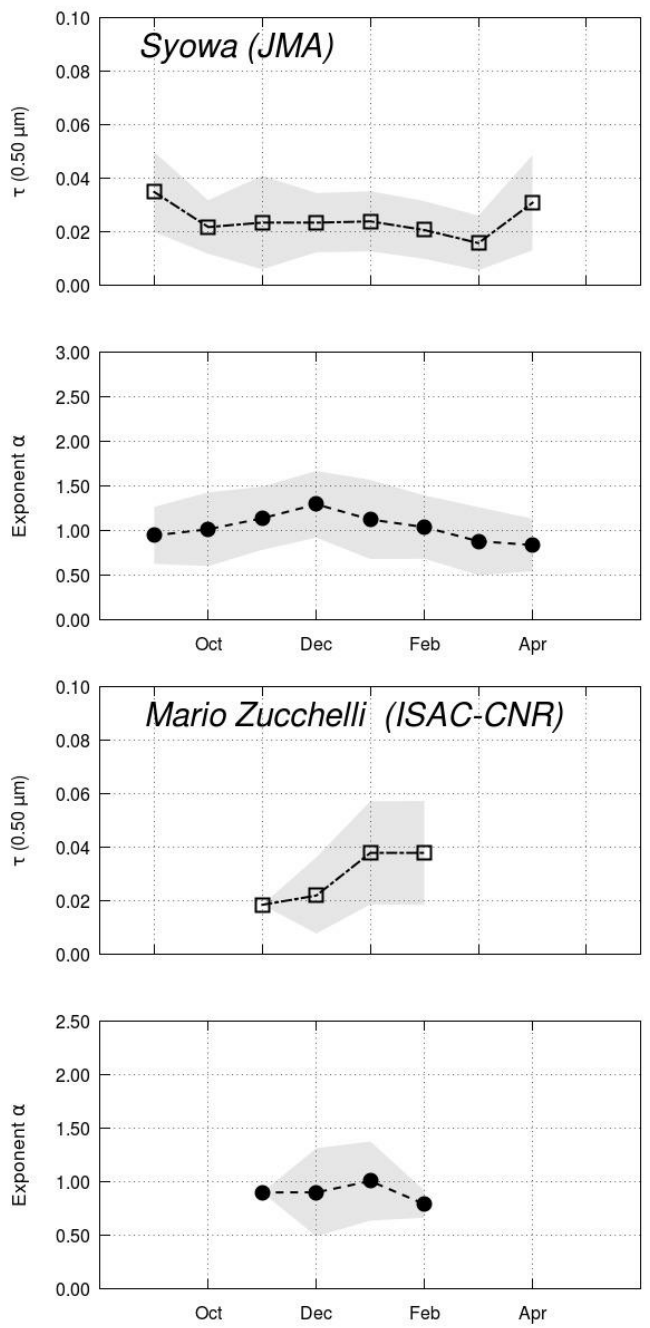
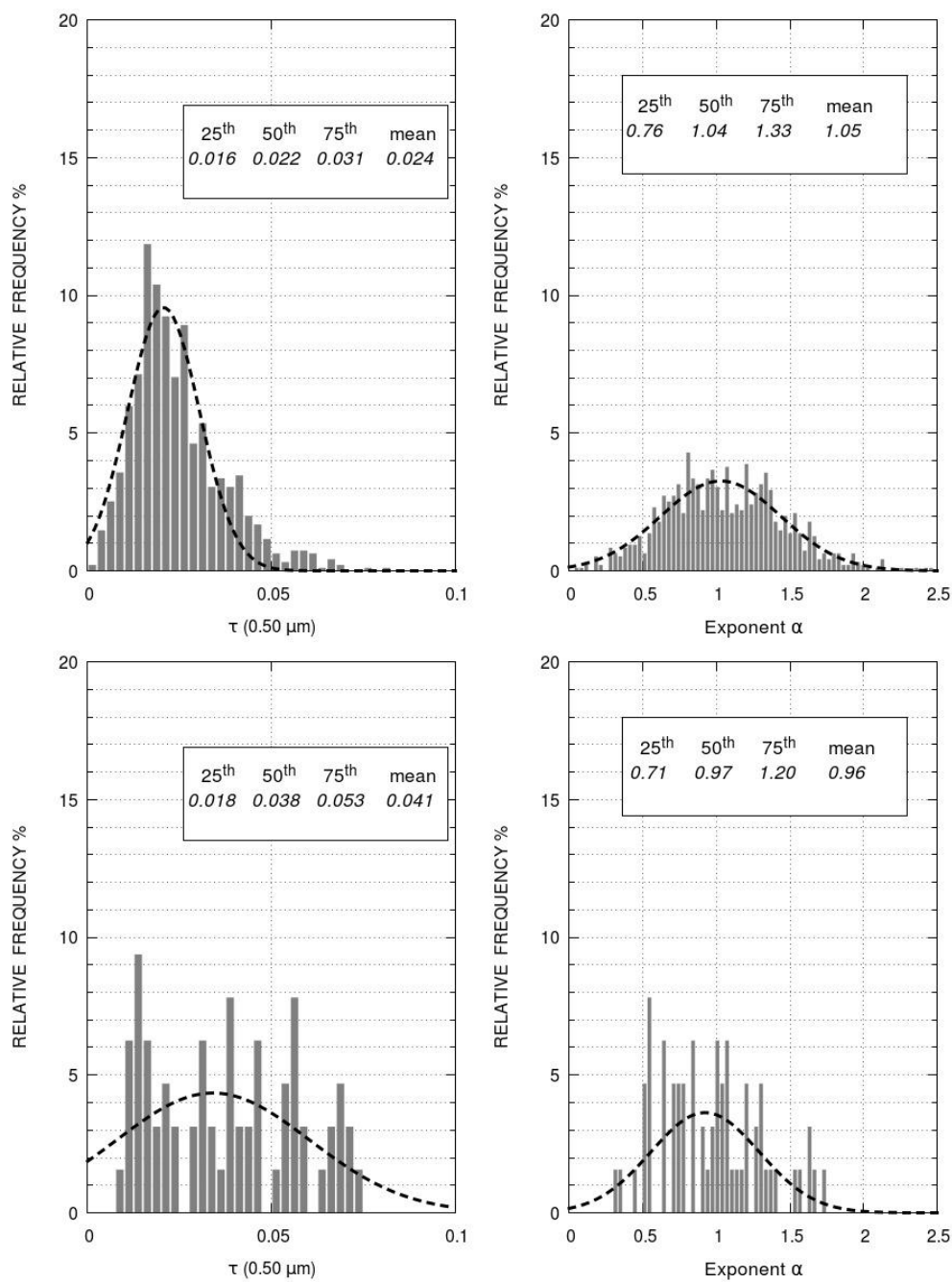

Figure 11. As in Figure 3, for sun-photometer measurements of aerosol optical thickness $\tau(0.50 \mu \mathrm{m})$ and exponent $\alpha$ conducted at the Antarctic sites of: (a) Syowa (East Ongul Island, Lützow-Holm Bay) over the period from January 2000 to December 2011 by the Office of Antarctic Observation (Japan Meteorological Agency, Tokyo, Japan), using the EKO MS-110 sun-photometer, having the spectral characteristics given in Table 2; and (b) Mario Zucchelli on the Terra Nova Bay (Ross Sea, Victoria Land) during the austral summer periods of 2001/2002 and 2005/2006 by ISAC-CNR (Bologna, Italy), using the PREDE POM-01L and the ASP-15WL sun-photometers, having the spectral characteristics given in Table 2 . 

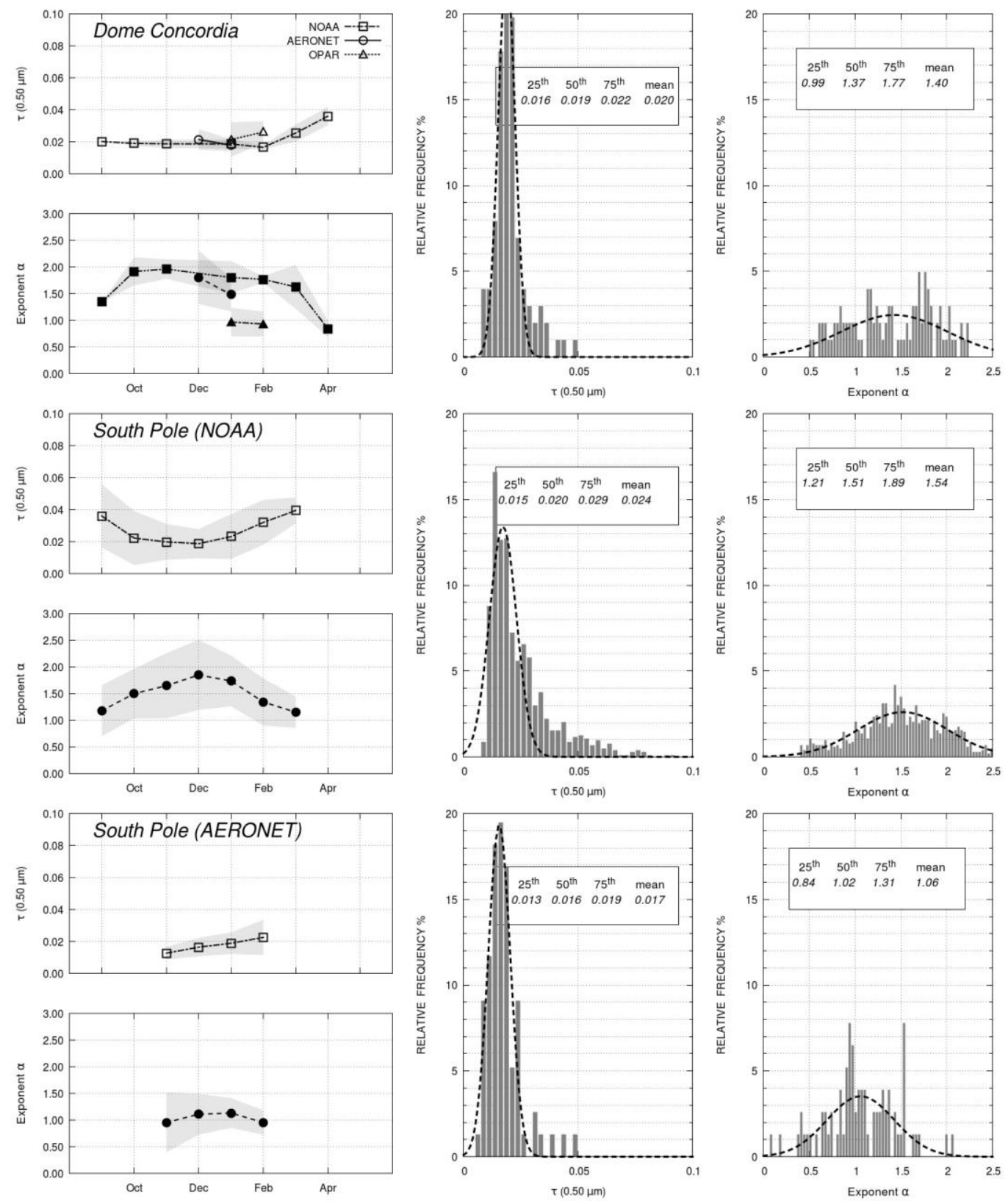

Figure 12. Upper part: as in Figure 3, for sun-photometer measurements of aerosol optical thickness $\tau(0.50 \mu \mathrm{m})$ and exponent $\alpha$ conducted at: (a) the high-altitude site of Dome Concordia (DomeC), on the Eastern Antarctic Plateau, over the period from September to April, by (i) GMD/NOAA (Boulder, Colorado, USA) from January to November 2010, using a Carter Scott SP02 sunphotometer (squares); (ii) NASA/GSFC (USA) in cooperation with LGGE/CNRS (Grenoble, France) in January and December of 2003, and in January 2004, using an AERONET Cimel CE318 sun-photometer having the spectral characteristics reported in Table 2 (circles); and (iii) OPAR Institute (University of Réunion, St. Denis, France) in January of 2010, 2011 and 2012, using an hand-held Microtops II sun-photometer calibrated at GSFC (USA), obtaining Level 1.5 cloudscreened data (triangles). Lower part: as in Figure 3, for sun-photometer measurements of aerosol optical thickness $\tau(0.50 \mu \mathrm{m})$ and exponent $\alpha$ conducted at the high-altitude site of South Pole (SPO) by (i) GMD/NOAA (Boulder, Colorado, USA), using a Carter Scott SP02 sun-photometer in the September-March period from November 2001 to March 2012; and (ii) NASA/GSFC (USA) in cooperation with GMD/NOAA (Boulder, Colorado, USA) using an AERONET Cimel CE-318 sunphotometer having the spectral characteristics reported in Table 2 in the November-February period from November 2007 to December 2012. 

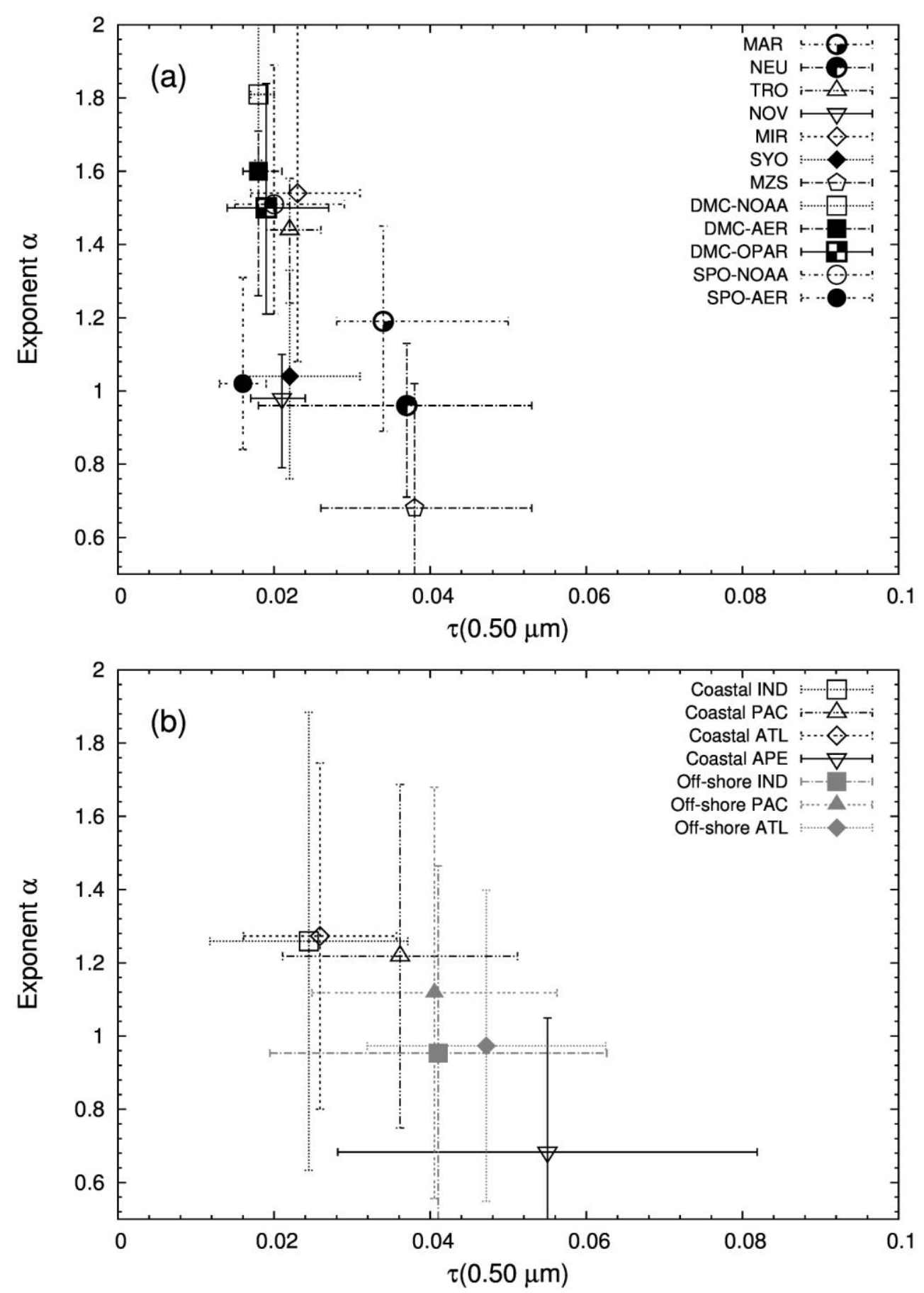

Figure 13.- Part (a): as in Figure 8, but for the sun-photometer measurements listed in Table 2. Acronym key: Marambio (MAR), Neumayer (NEU), Troll (TRO), Novolazarevskaya (NOV), Mirny (MIR), Syowa (SYO), Mario Zucchelli (MZS), Dome Concordia (DMC-NOAA, DMCAER, and DMC-OPAR, for the measurement sets collected by GMD/NOAA, AERONET and OPAR groups, respectively (see Table 4)) and South Pole (SPO-NOAA and SPO-AER, for the measurement sets collected by GMD/NOAA and AERONET groups, respectively). Part (b): as in part (a), for the Microtops sun-photometer measurements performed in Antarctic coastal (open symbols) and off-shore areas (solid symbols) during the cruises conducted in the four following oceanic sectors: (i) IND (Southern Indian Ocean, squares), (ii) PAC (Southern Pacific Ocean, upward triangles), (iii) ATL (Southern Atlantic Ocean, diamonds), and (iv) APE (Antarctic Peninsula, downward triangles). 
(a)
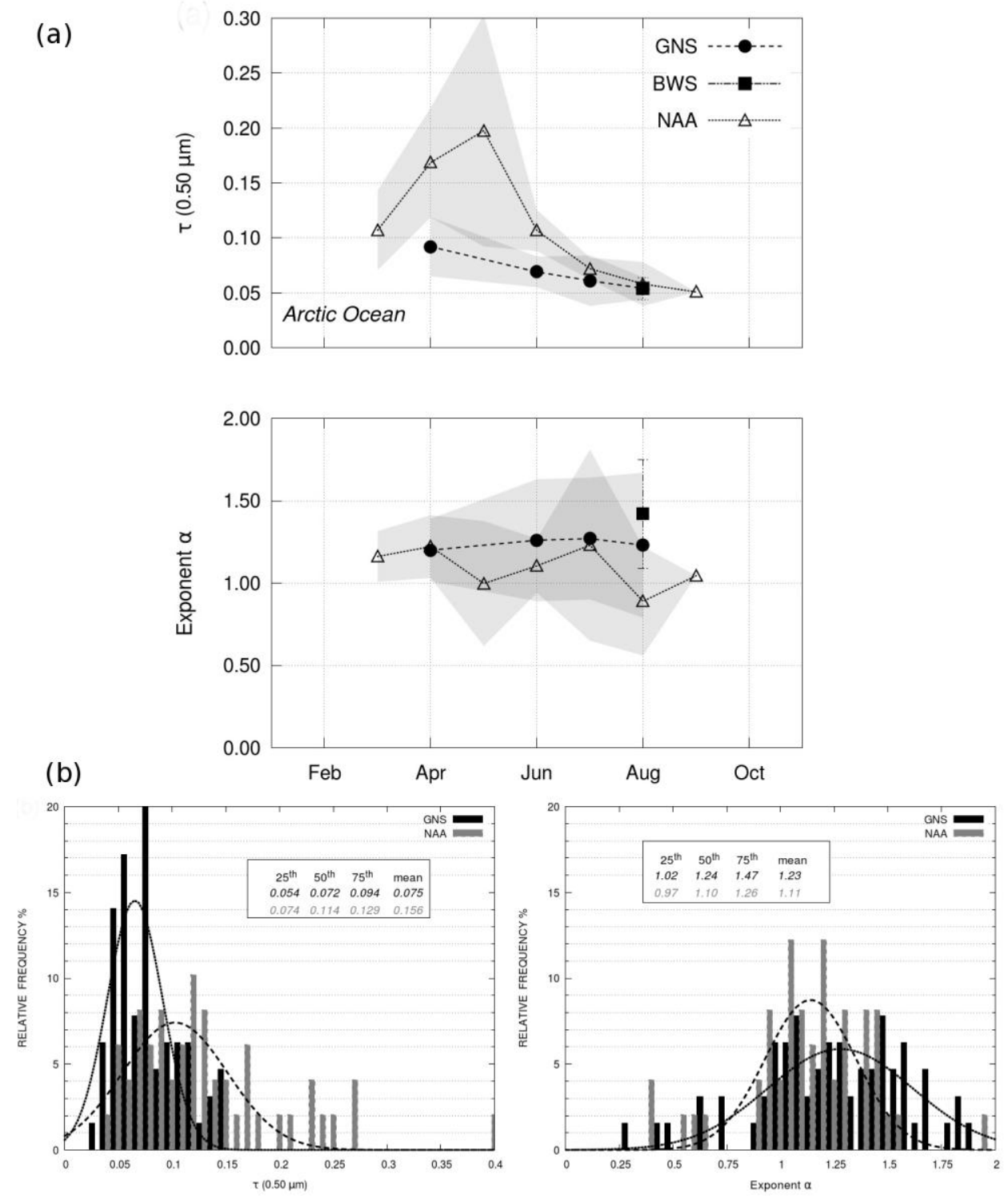

(b)

Figure 14. Part (a): as in Figure 3, for Microtops sun-photometer measurements of aerosol optical thickness $\tau(0.50 \mu \mathrm{m})$ and exponent $\alpha$ performed during the cruises conducted from 2003 to 2012 in the GNS (Greenland Sea and Norwegian Sea) sector (solid circles), from 2006 to 2012 in the BWS (Barents Sea and West Siberian Sea) sector (solid squares), and from 2008 to 2011 in the NAA (Eastern Chuckci Sea, Beaufort Sea and Amundsen Gulf) sector (open triangles) (see also Table 3). $\mu \mathrm{m}$ ) and exponent $\alpha$ determined from the Microtops measurements conducted from March to Gulf. 
(a)
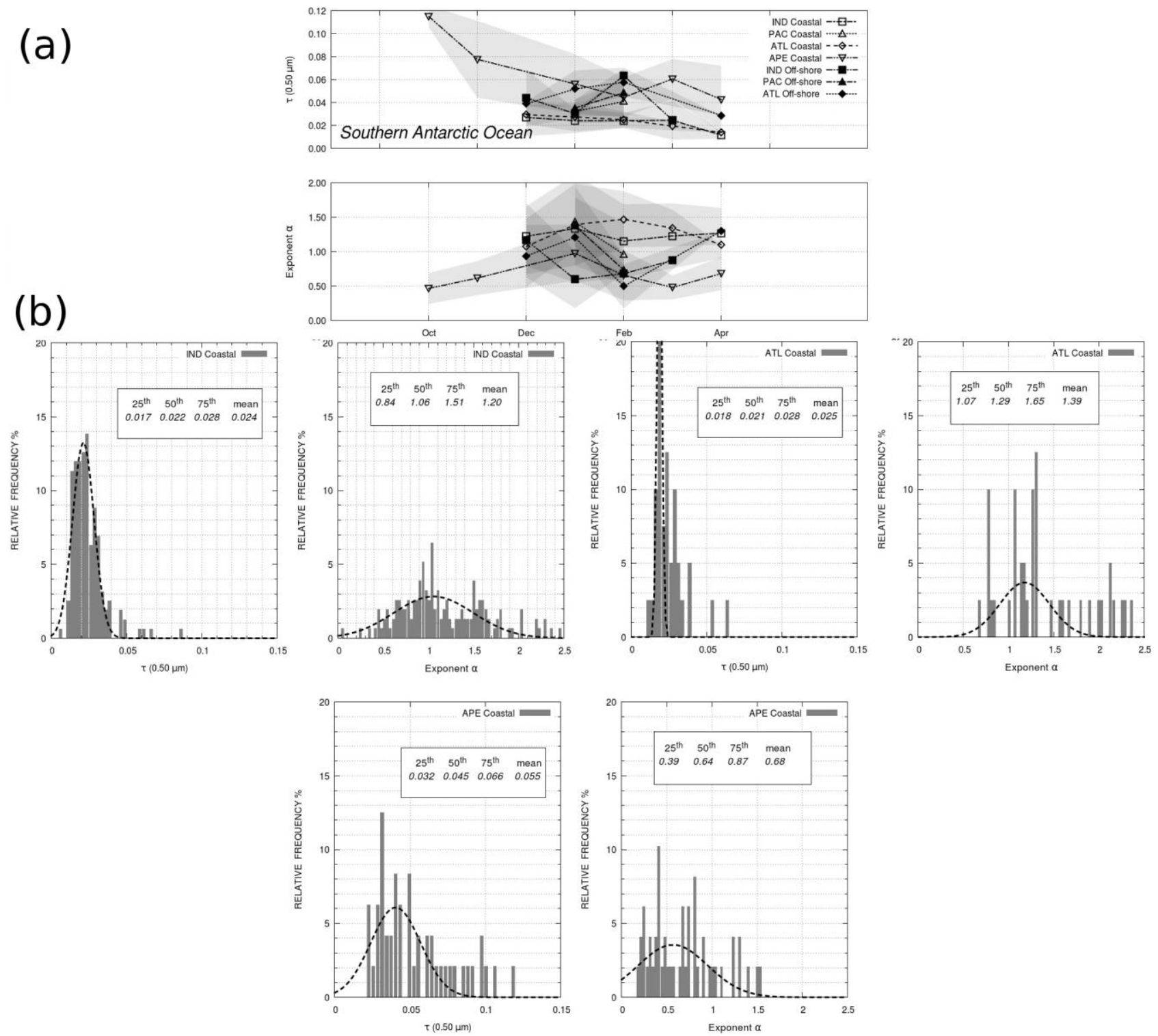

Figure 15. Part (a): as in Figure 3, for Microtops sun-photometer measurements of $\tau(0.50 \mu \mathrm{m})$ and $\alpha$ performed during the cruises conducted from late 2005 to spring 2013 in the frame of the Maritime Aerosol Network (MAN) activities listed in Table 4. The data refer to coastal (open symbols) and off-shore (solid symbols) measurements, carried out in the IND sector (Southern Indian Ocean, circles), PAC sector (Southern Pacific Ocean, upward triangles), ATL sector (Southern Atlantic Ocean, squares), and APE sector (Antarctic Peninsula, downward triangles). Part (b): Relative frequency histograms of $\tau(0.50 \mu \mathrm{m})$ and $\alpha$ obtained for the coastal data-sets collected (i) on 226 measurement days from November to February over the Southern Indian Ocean (IND) sector; (ii) 63 measurement days from December to April over the Southern Atlantic Ocean (ATL) sector; and (iii) on 49 measurement days from October to April over the coastal area surrounding the Antarctic Peninsula (APE sector). 


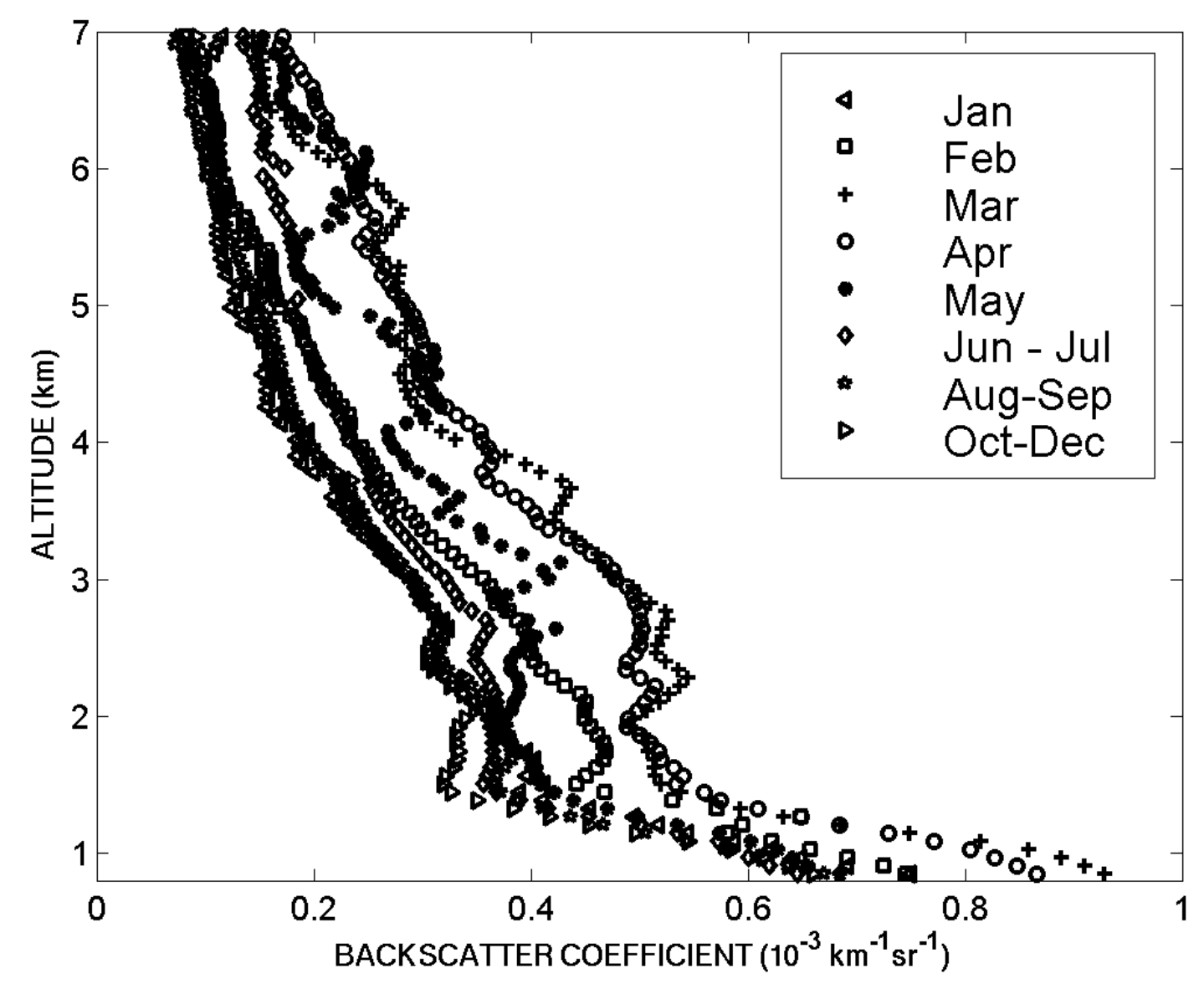

3446 Figure 16. Monthly and bi-monthly averaged vertical profiles of aerosol volume backscatter 3447 3448 3449 


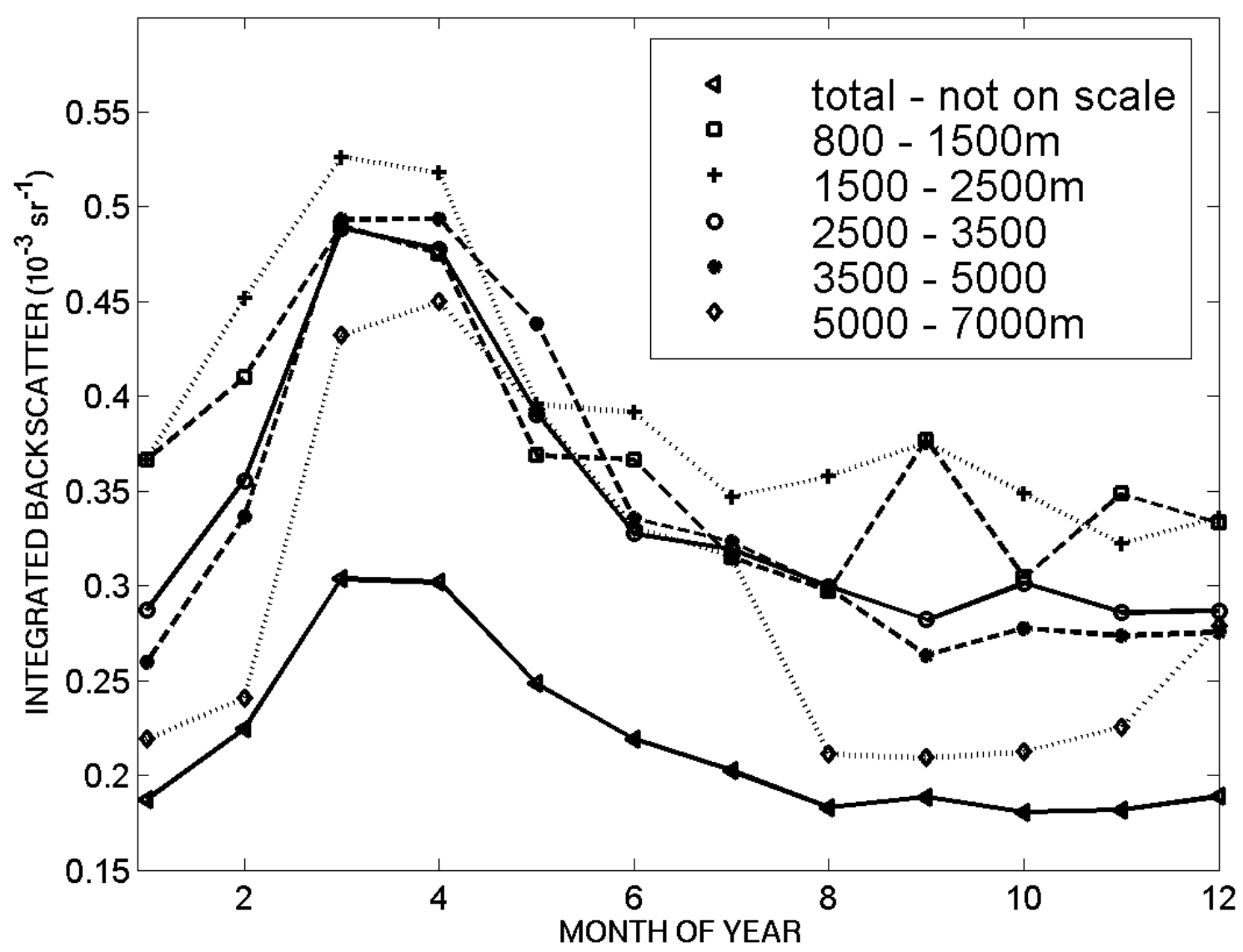

3452 Figure 17. Time-patterns of the monthly average values of the aerosol volume backscatter 3453 coefficient $\beta_{b s}(0.532 \mu \mathrm{m})$ integrated over the different altitude ranges reported in the legend, as obtained from the KARL lidar measurements performed at Ny-Ålesund (AWIPEV station) from 1 3456 


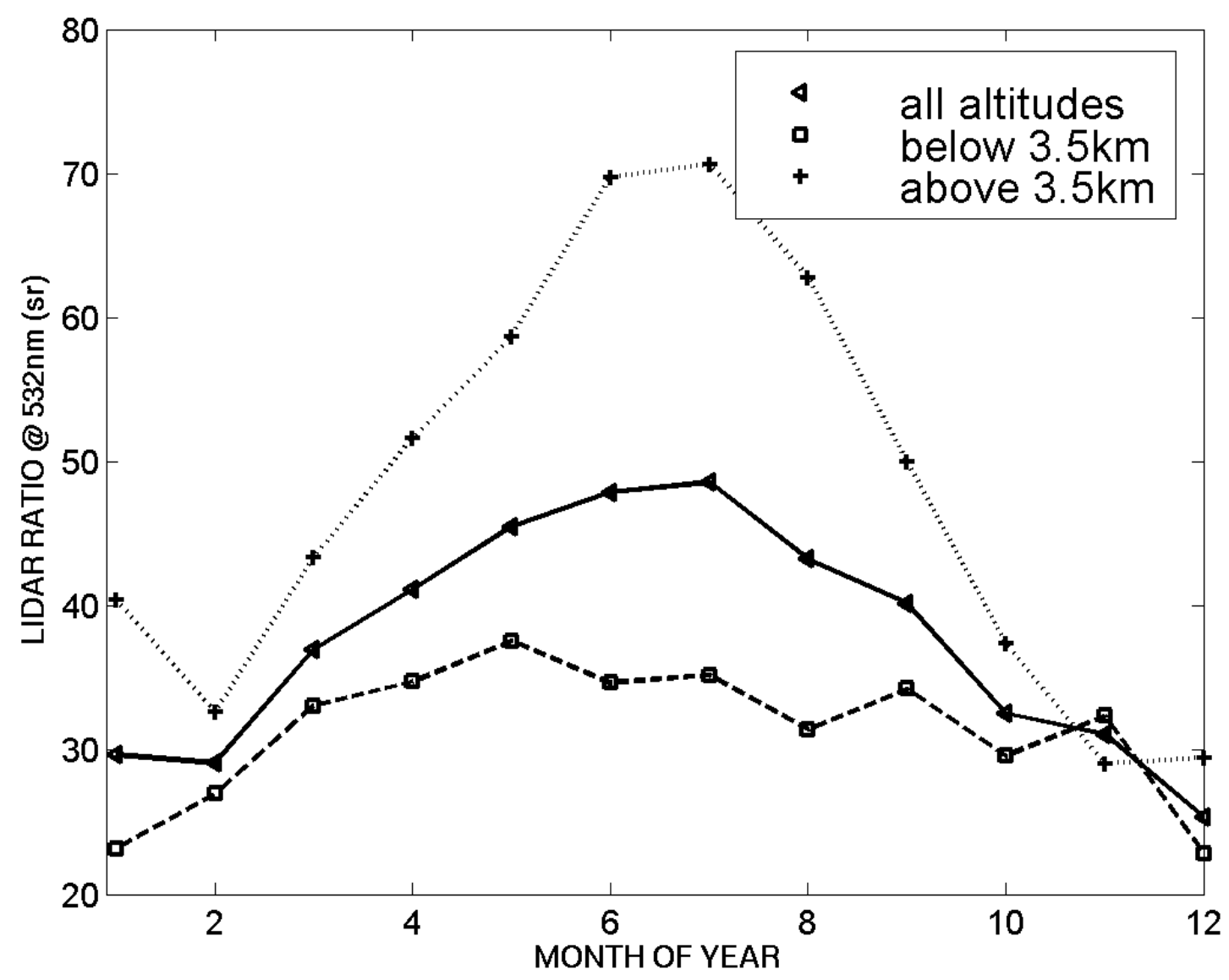

3458

3459 Figure 18. Time-patterns of the monthly average values of the lidar ratio $S_{a}(0,532 \mu m)=\beta_{\text {ext }}(0.532$ $3460 \mu m) / \beta_{b s}(0.532 \mu m)$ calculated over the whole altitude range (triangles) and the altitude sub-ranges $z$ $3461<3.5 \mathrm{~km}$ (squares) and $z>3.5 \mathrm{~km}(+)$, as obtained from the KARL lidar measurements conducted 3462 3463 at Ny-Ålesund (AWIPEV station) from 1 November, 2012, to 31 October, 2013. 


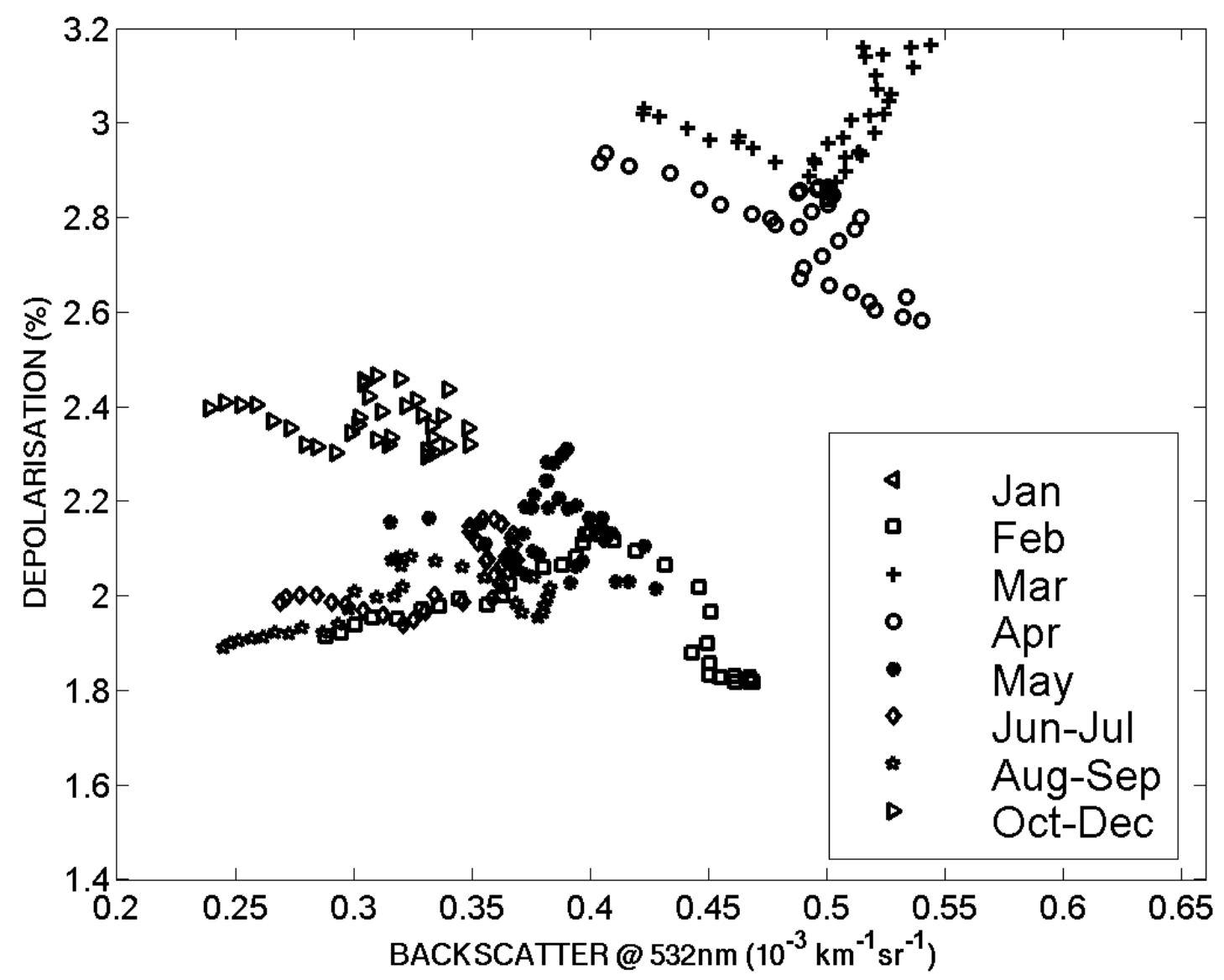

3465

3466 Figure 19. Scatter plots of the monthly and bi-monthly averaged values of the depolarisation ratio 3467 3468 (\%) versus the aerosol backscatter coefficient $\beta_{b s}(0.532 \mu \mathrm{m})$, as obtained from the KARL lidar 3469 2013. 

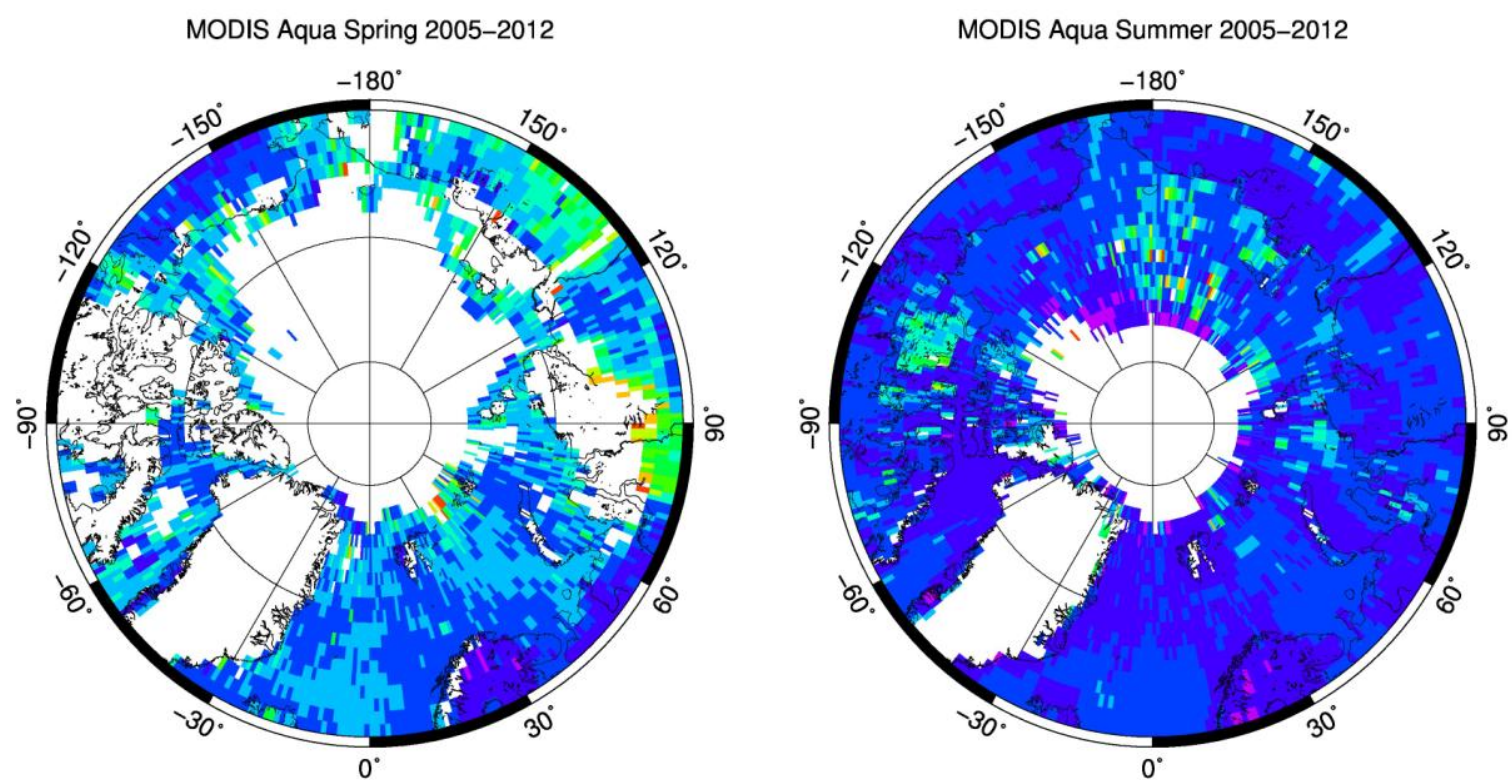

MODIS Terra Spring 2005-2012
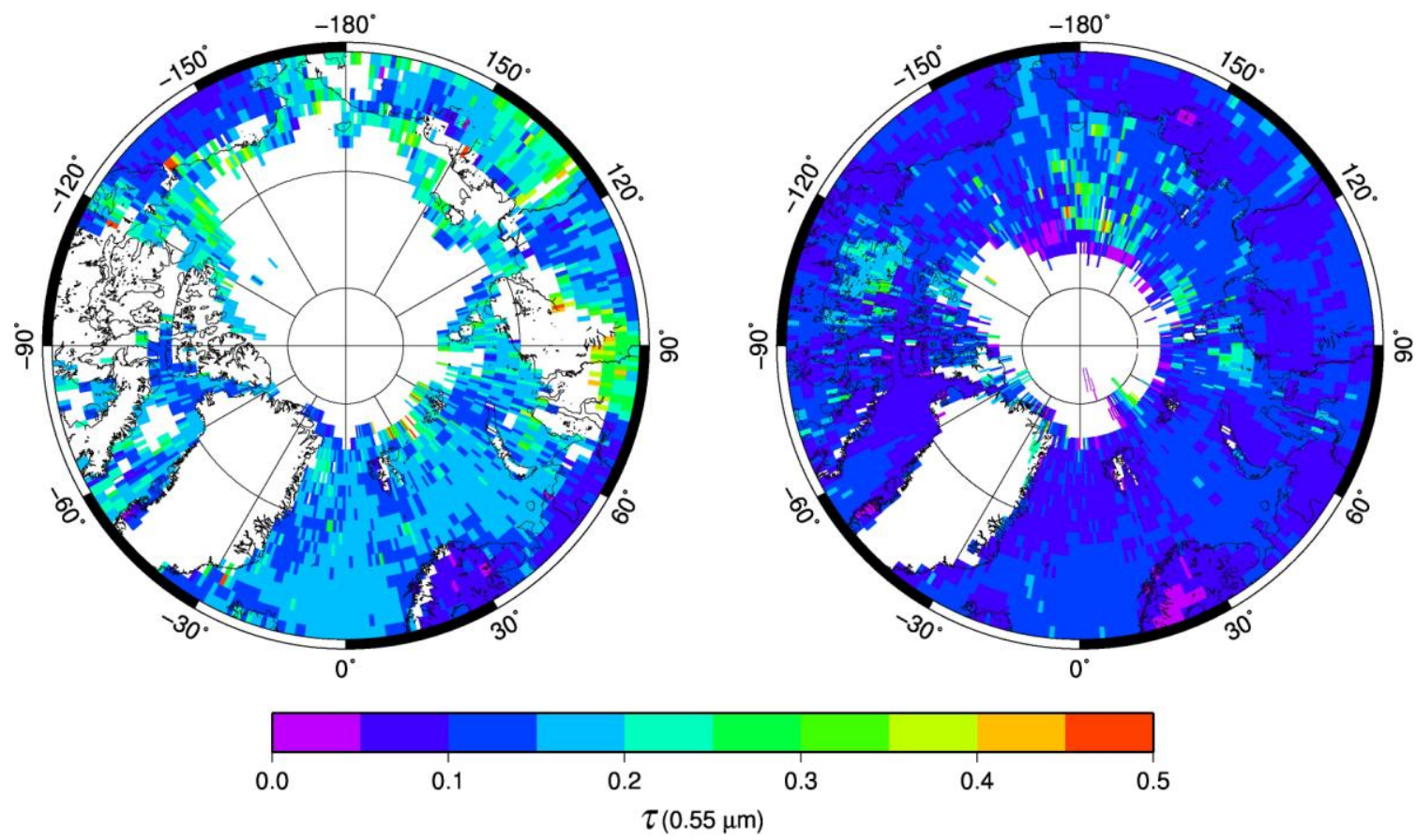

Figure 20. Arctic maps of the seasonal average Level-3 aerosol optical thickness $\tau(0.55 \mu \mathrm{m})$ derived from MODIS/Aqua (upper part) and MODIS/Terra (lower part) satellite data recorded from 2005 to 2012 during the spring (left-hand side) and summer (right-hand side) 3-month periods. 

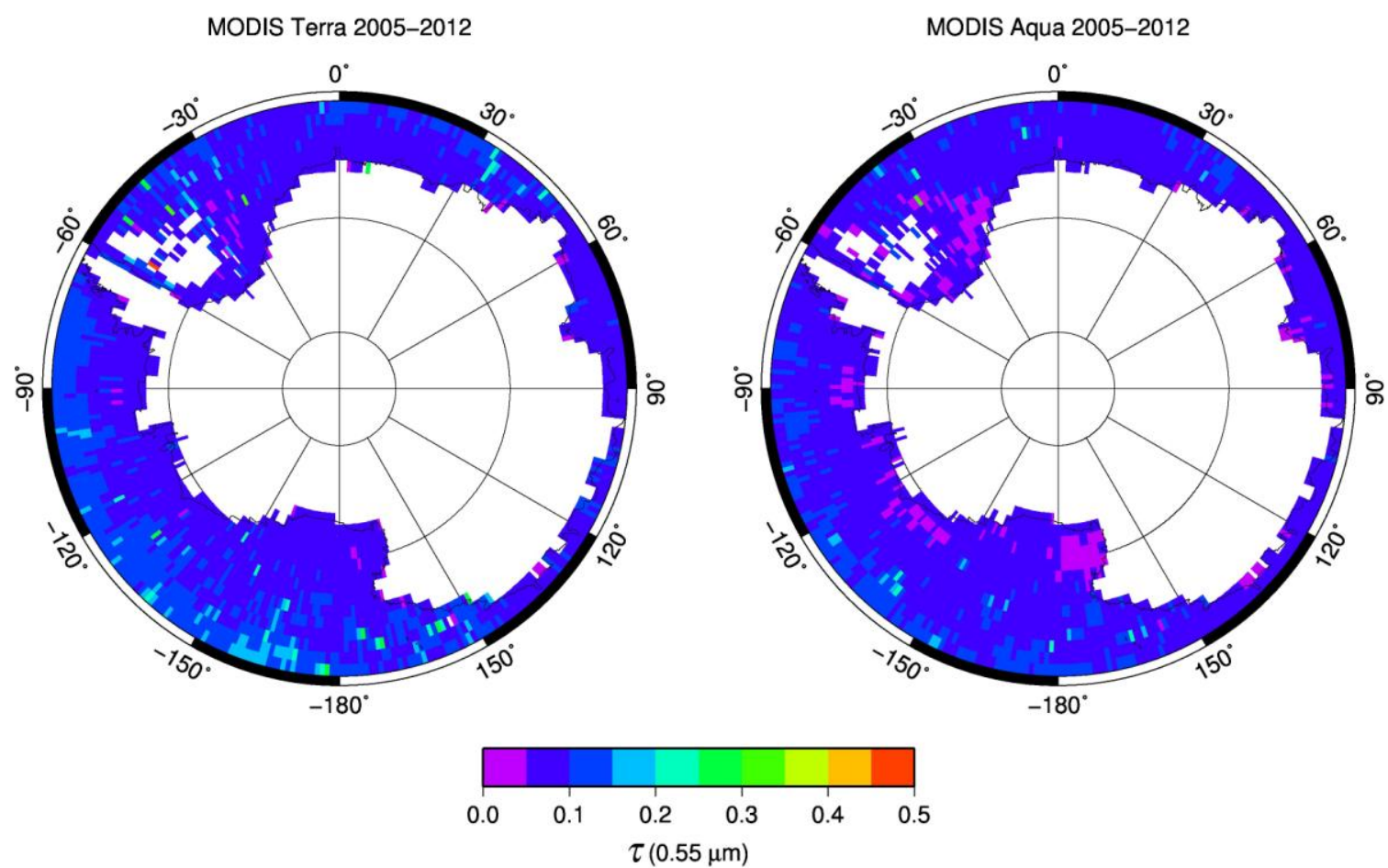

3479 Figure 21. Antarctic maps of the austral summer Level-3 aerosol optical thickness $\tau(0.55 \mu \mathrm{m})$ 3480 derived from the MODIS/Terra (left-hand side) and MODIS/Aqua (right-hand side) satellite data 3481 recorded over the 2005-2012 period. 
MODIS/AQUA AOT [550nm] 29 March,2006 $150^{\circ} 0^{\prime} 0^{\prime \prime} \mathrm{W} \quad 170^{\circ} 0^{\prime} 0^{\prime \prime} \mathrm{E} \quad 140^{\circ} 0^{\prime} 0^{\prime \prime} \mathrm{E}$

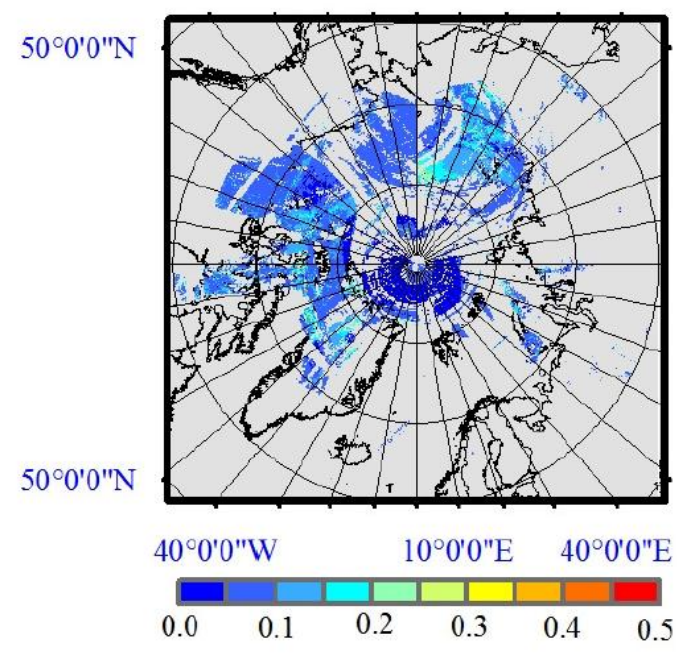

MODIS/AQUA AOT [550nm] 3 May,2006

$150^{\circ} 0^{\prime} 0^{\prime \prime} \mathrm{W} \quad 170^{\circ} 0^{\prime} 0^{\prime \prime} \mathrm{E} \quad 140^{\circ} 0^{\prime} 0^{\prime \prime} \mathrm{E}$

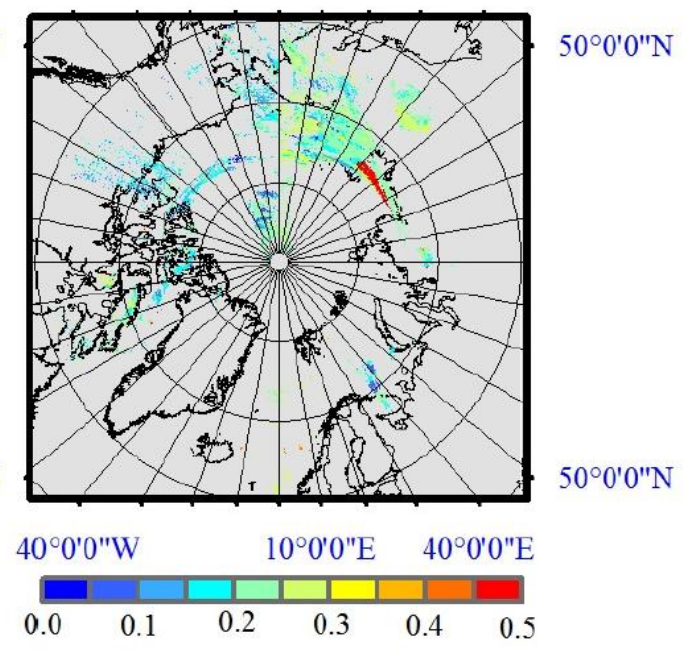

$50^{\circ} 0^{\prime} 0^{\prime \prime} \mathrm{N} \quad 50^{\circ} 0^{\prime} 0^{\prime \prime} \mathrm{N}$ $50^{\circ} 0^{\prime} 0^{\prime \prime} \mathrm{N} \quad 50^{\circ} 0^{\prime} 0^{\prime \prime} \mathrm{N}$

3485 Figure 22. Maps of aerosol optical thickness $\tau(0.55 \mu \mathrm{m})$ derived over the Arctic region from the 3486 MODIS/Aqua observations made on 29 March, 2006 (left-hand side) and 3 May, 2006 (right-hand 3487 side) using the method of Mei et al. (2013a). 

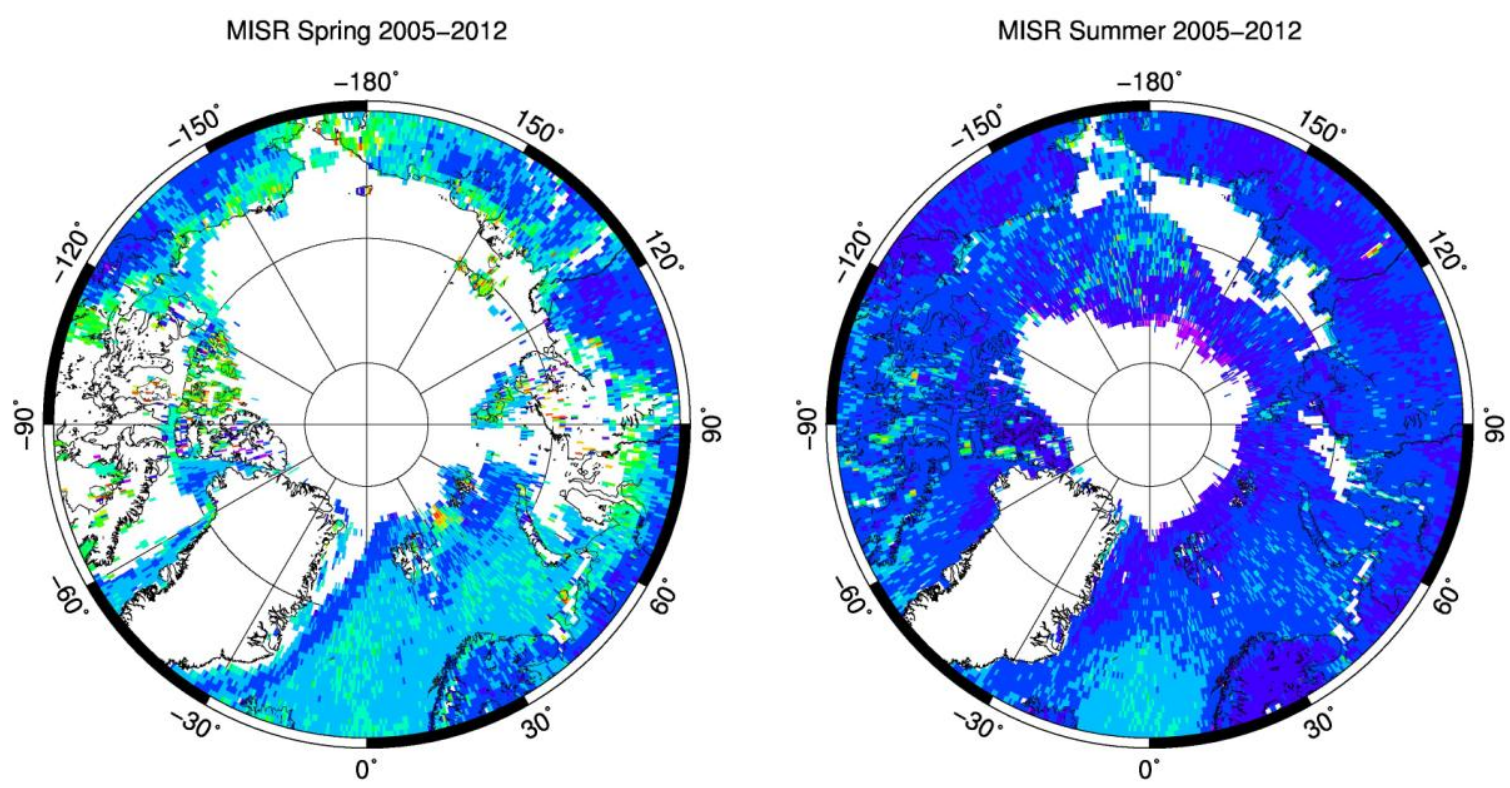

MISR 2005-2012
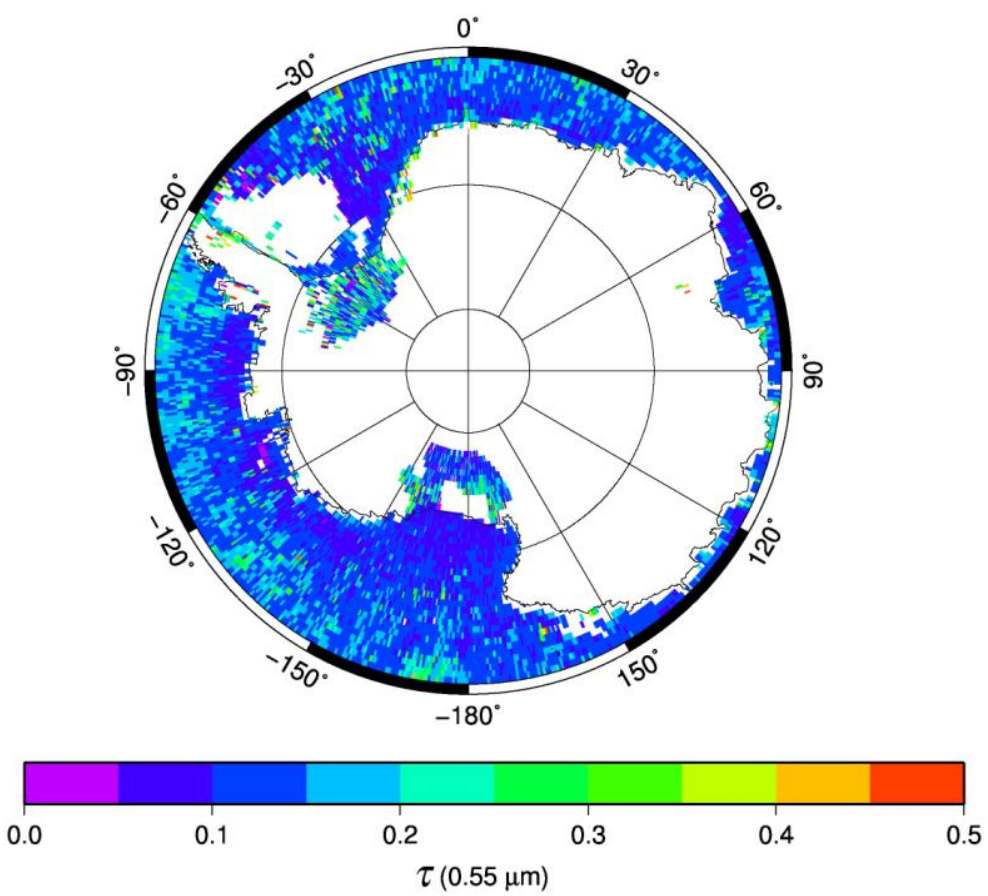

3491 Figure 23. Upper part: Arctic maps of the seasonal average Level-3 aerosol optical thickness $\tau(0.55$ $\mu \mathrm{m})$ derived from the MISR satellite data recorded from 2005 to 2012 during the spring (left-hand side) and summer (right-hand side) 3-month periods. Lower part: As in the upper part, for the austral summer average Level-3 aerosol optical thickness $\tau(0.55 \mu \mathrm{m})$ derived from MISR satellite data recorded from 2005 to 2012 over oceans and land areas not covered by snow and ice. 

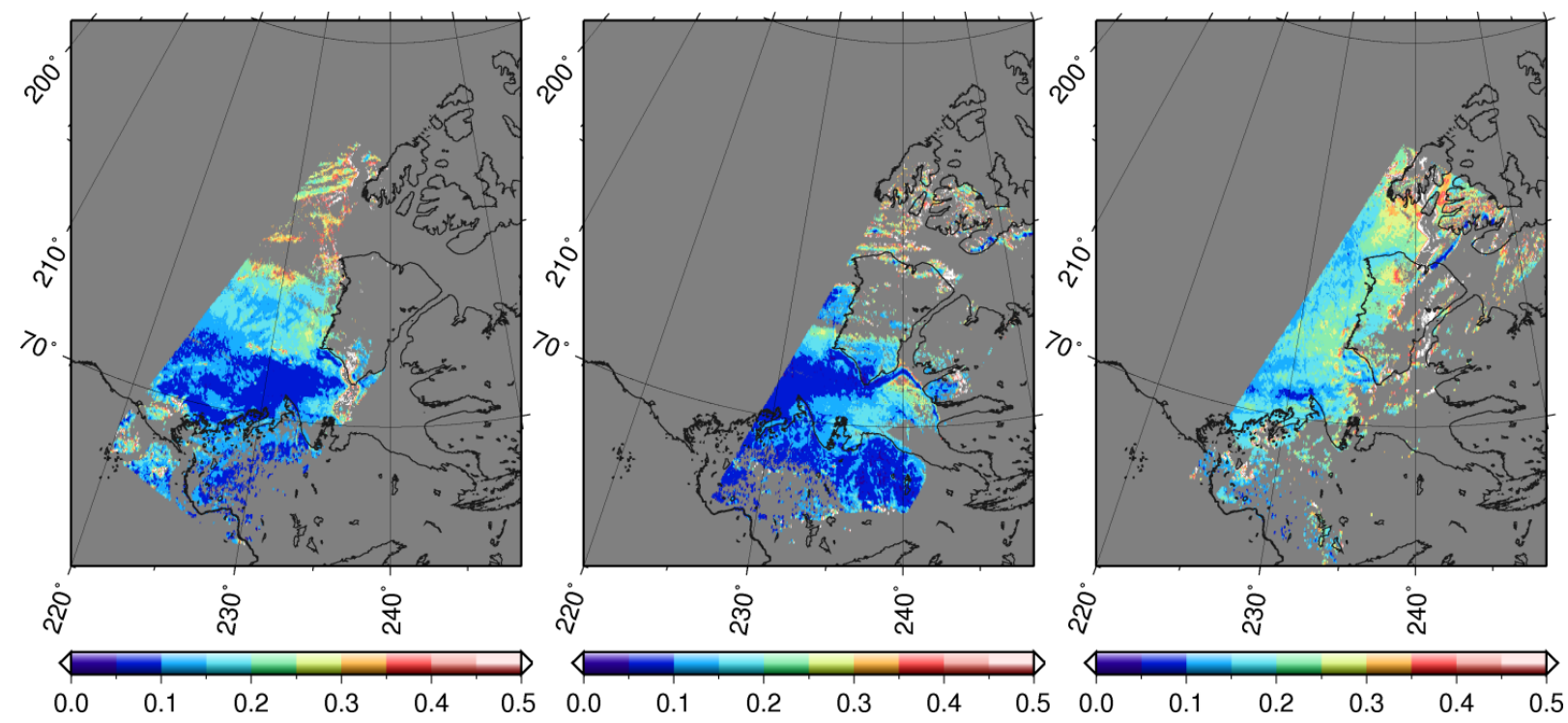

3499 Figure 24. Time sequence of aerosol optical thickness $\tau(0.55 \mu \mathrm{m})$ retrieved using AATSR data over 3500 sea-ice and snow-covered land surfaces with the algorithm described by Istomina et al. (2011). Left panel refers to orbit No. 31673 on 21 March, 2008; middle panel to orbit No. 31687 on 22 March, 2008; and right panel to orbit No. 31773 on $28 \mathrm{March}, 2008$. The increase in $\tau(0.55 \mu \mathrm{m})$ might be connected to ozone depletion/bromine explosions observed during March 2008 in the region 3504 3505 (Nghiem et al., 2012; Moore et al., 2014). 
April 9,2009

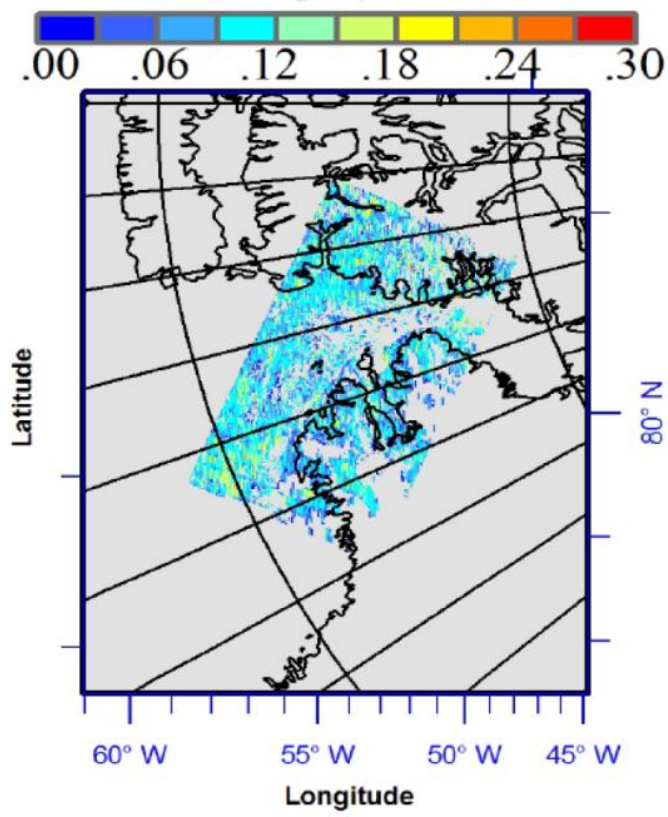

April 18,2009

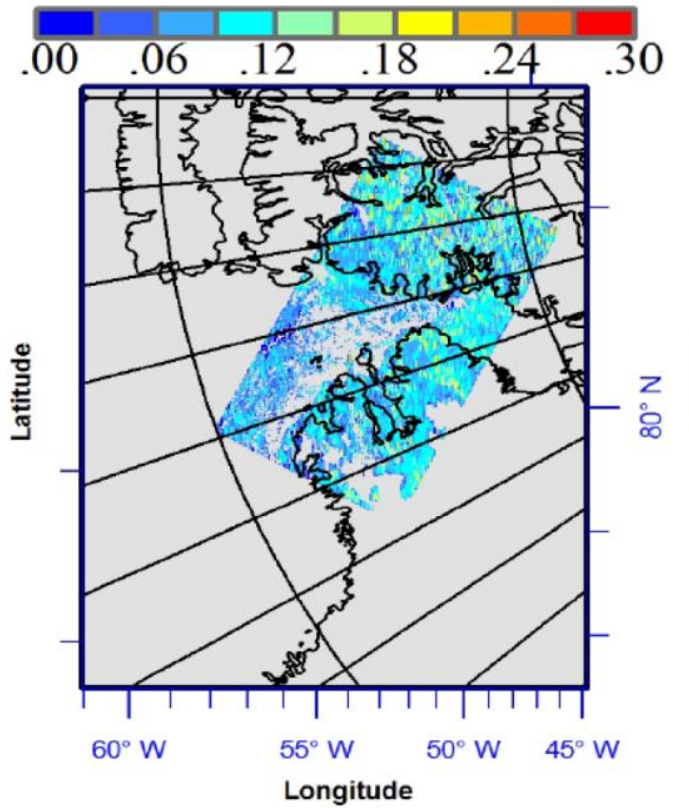

April 15,2009

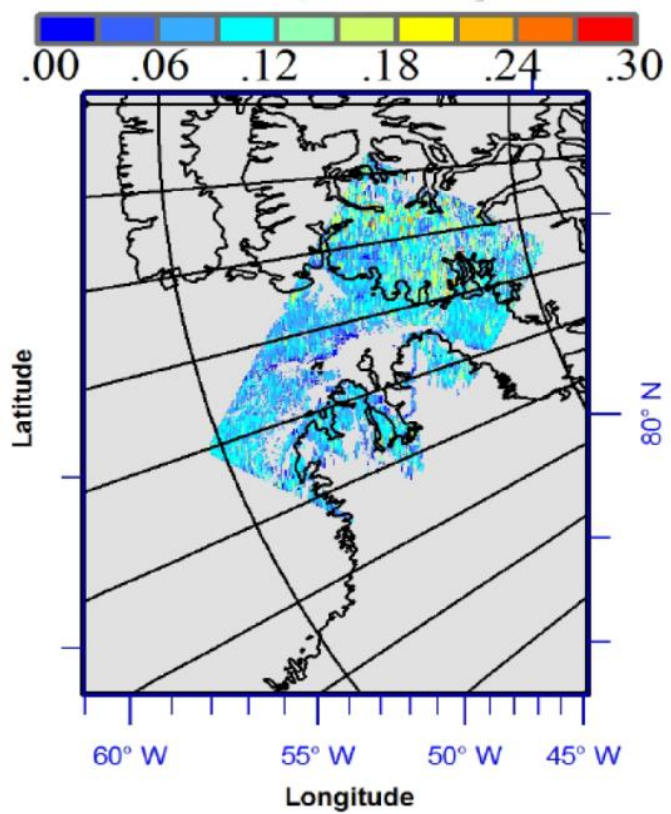

April 21,2009

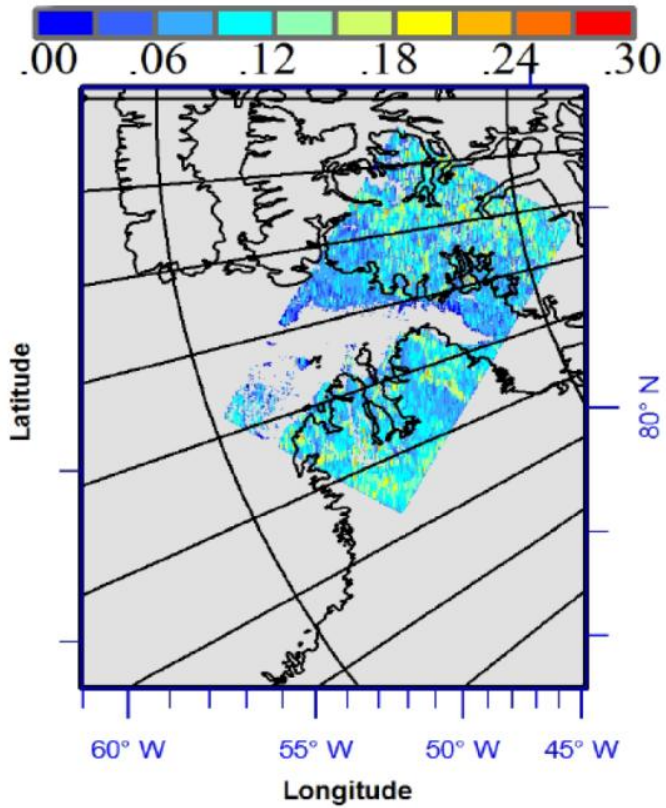

3509 Figure 25. Maps of aerosol optical thickness $\tau(0.55 \mu \mathrm{m})$ retrieved from AATSR data taken with 1 $3510 \mathrm{~km} \times 1 \mathrm{~km}$ resolution on 9, 15, 18, and 21 April, 2009, over snow-covered surfaces in west 3511 Greenland using the method of Mei et al. (2013b). 


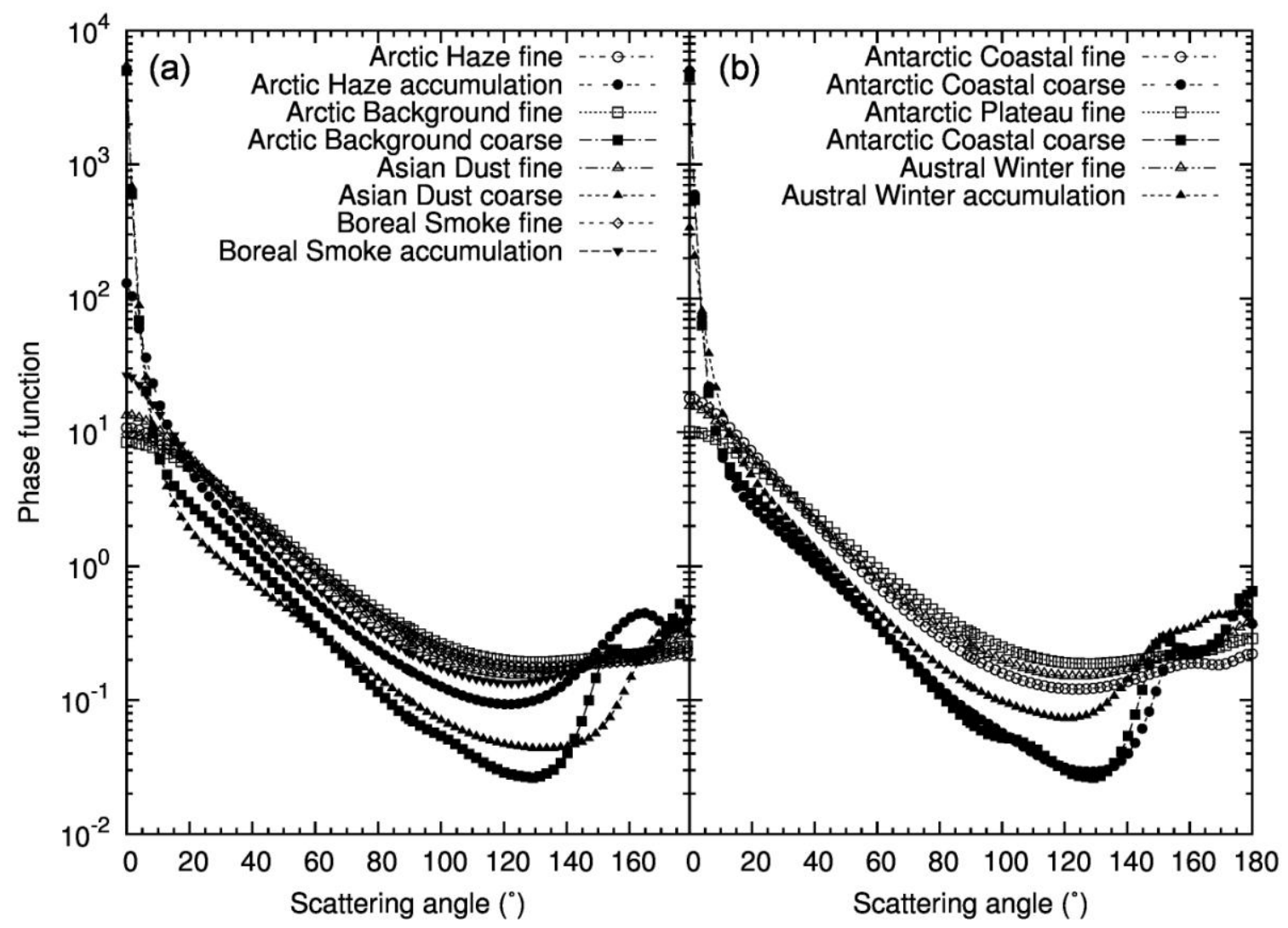

3515 Figure 26. Angular distribution curves of phase function $P(\Theta)$ as a function of the scattering angle $3516 \Theta$ for the 8 unimodal Arctic aerosol extinction models (left) and the 6 unimodal Antarctic aerosol 3517 extinction models defined in Table 5. 


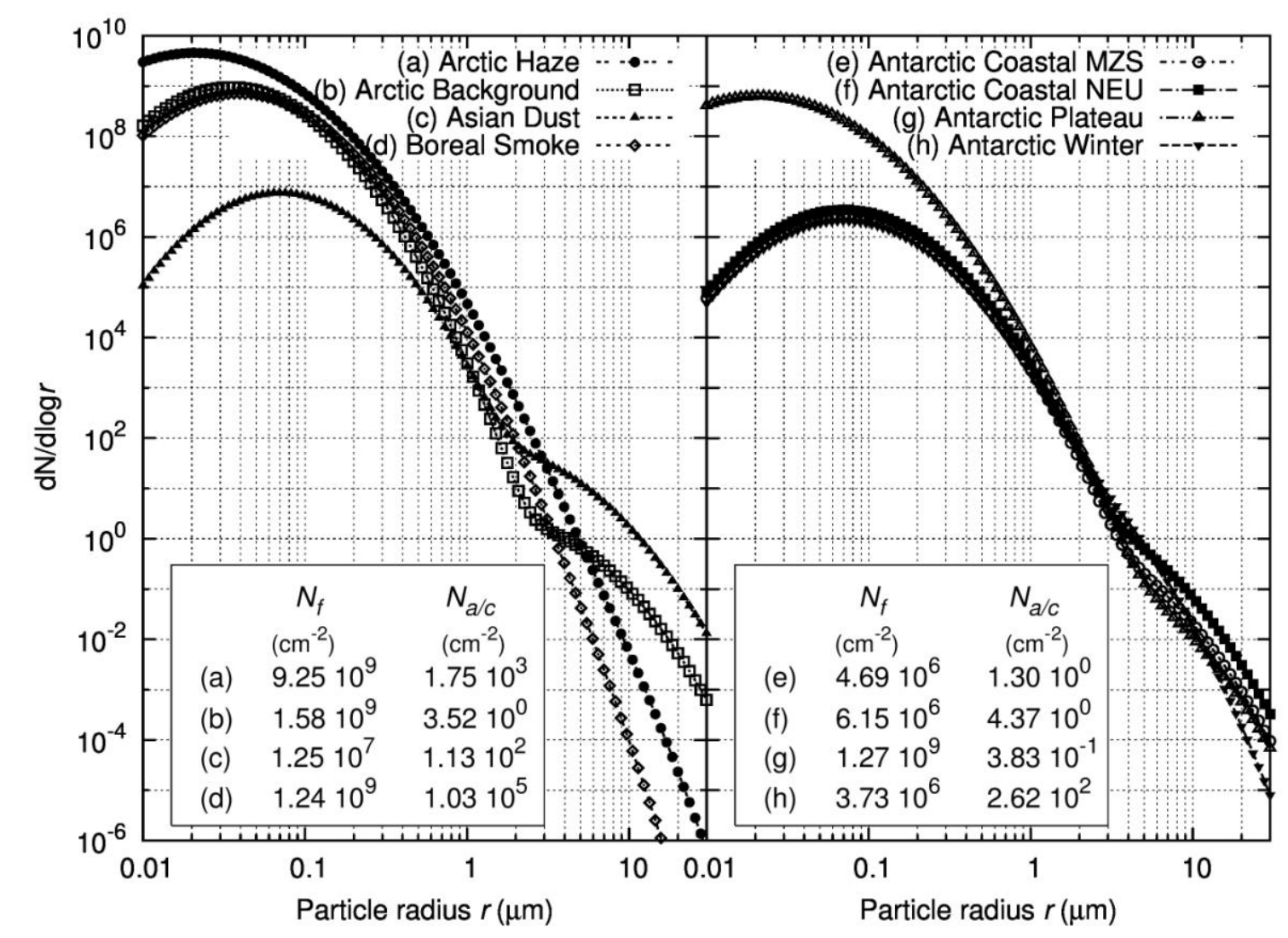

3521 Figure 27. Left-hand side: examples of bimodal particle size-distribution curves obtained as best-fit 3522 linear combinations of aerosol unimodal models for fine and accumulation/coarse particles defined in Table 3 in the following four case studies: (a) the average winter-spring aerosol case determined at Eureka (Nunavut, Northern Canada) for the mean values $\tau(0.50 \mu \mathrm{m})=0.12$ and $\alpha=1.48$; (b) the summer background aerosol case determined at Tiksi (Russia) in North-central Siberia for the mean values $\tau(0.50 \mu \mathrm{m})=0.08$ and $\alpha=1.60$; (c) the Asian dust episode observed at Barrow on 16 April, 2002 , giving the daily mean values $\tau(0.50 \mu m)=0.22$ and $\alpha=0.26$; and (d) the BFF smoke episode observed by Stock et al. (2012) at Ny-Ålesund on 23 March, 2008, for the daily mean values $\tau(0.50$ $\mu m)=0.22$ and $\alpha=1.50$. Right-hand side: as on the left, for the following four case studies: (e) the austral summer coastal aerosol case determined at Mario Zucchelli (MZS) for the mean values $\tau(0.50 \mu \mathrm{m})=0.03$ and $\alpha=0.90$; (f) the austral summer coastal aerosol case determined at Neumayer (NEU) for the mean values of $\tau(0.50 \mu \mathrm{m})=0.045$ and $\alpha=0.78$; $(\mathrm{g})$ the austral summer Antarctic Plateau aerosol case determined at South Pole for the mean values $\tau(0.50 \mu \mathrm{m})=0.018$ and $\alpha=1.49$; and (h) the austral winter aerosol case assumed at Neumayer for the seasonal average values $\tau(0.50 \mu \mathrm{m})=0.035$ and $\alpha=0.65$. 


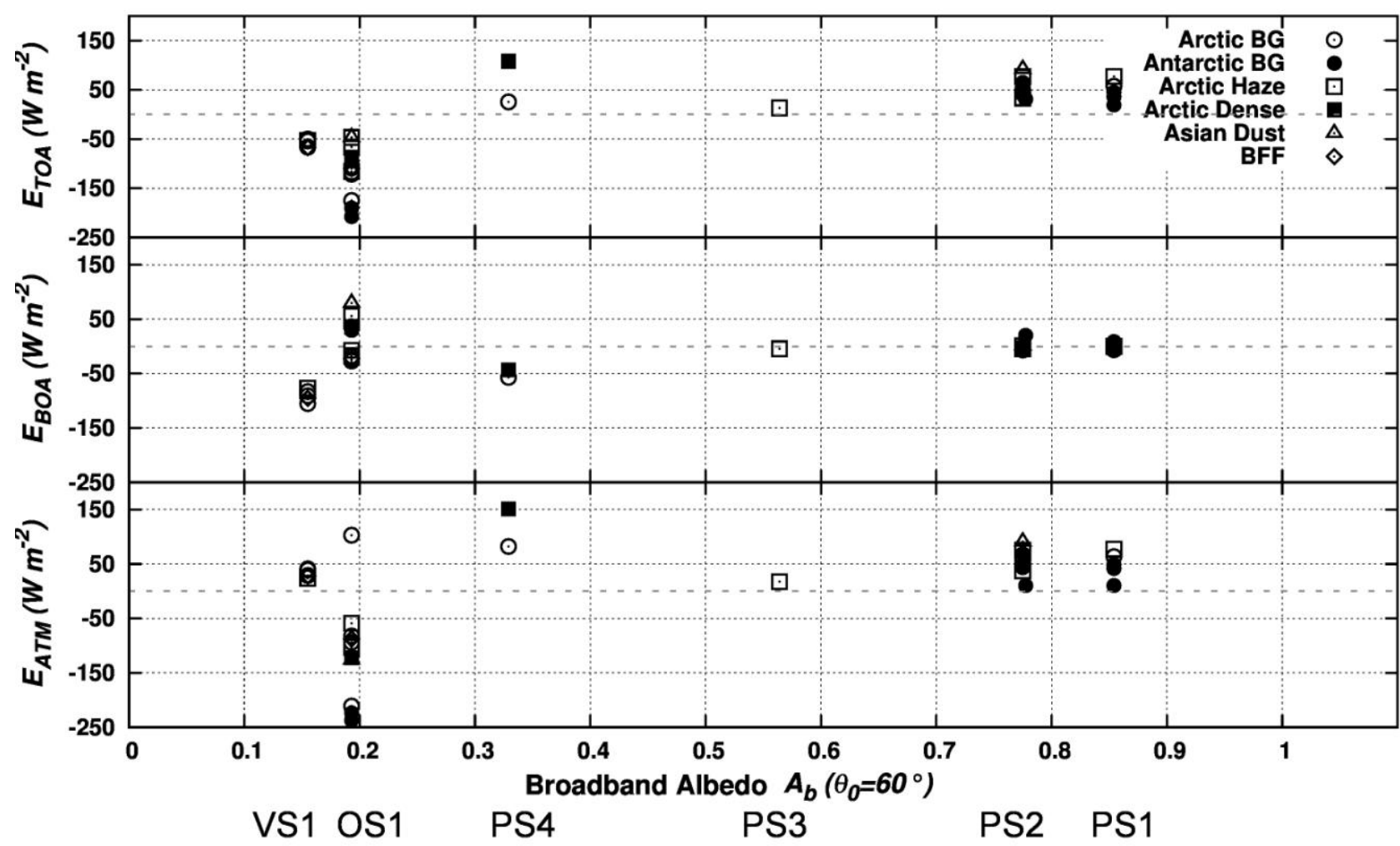

Figure 28. Scatter plots of the daily mean values of DARF efficiencies $E_{T O A}$ at the TOA-level (upper part), $E_{B O A}$ at the BOA-level (middle part), and $E_{A T M}$ in the atmosphere (lower part) shown versus the broadband albedo calculated by Tomasi et al. (2014) at solar zenith angle $\theta_{o}=60^{\circ}$, for the BRDF oceanic surface (OS1), vegetation-covered surface (VS1) and snow-covered polar surface (PS1, PS2, PS3 and PS4) models, and for the 15 polar aerosol types defined in Table 6 and represented using different symbols. 


\section{TABLES}

Table 1. List of the Arctic stations, where regular ground-based sun-photometer measurements have been conducted over the past decades, using different instrument models equipped with a variable number of narrow-band interference filters to determine the spectral values of aerosol optical thickness $\tau(\lambda)$ and Ångström wavelength exponent $\alpha$ in the visible and near-infrared wavelength range.

\begin{tabular}{|c|c|c|c|c|c|c|c|c|}
\hline $\begin{array}{l}\text { Sun-photometer } \\
\text { stations }\end{array}$ & $\begin{array}{l}\text { Managing } \\
\text { institutions }\end{array}$ & $\begin{array}{l}\text { Geographical } \\
\text { coordinates } \\
\text { and altitude }\end{array}$ & $\begin{array}{l}\text { Overall } \\
\text { number of } \\
\text { measurement } \\
\text { days }\end{array}$ & $\begin{array}{l}\text { Measurement } \\
\text { period }\end{array}$ & $\begin{array}{l}\text { Sun-photometer } \\
\text { model }\end{array}$ & $\begin{array}{l}\text { Peak wavelengths } \\
\text { (nm) of the spectral } \\
\text { channels }\end{array}$ & $\begin{array}{l}\text { Spectral } \\
\text { interval } \\
\text { (nm) of } \alpha\end{array}$ & References \\
\hline \multirow[t]{3}{*}{$\begin{array}{l}\text { Barrow, } \\
\text { Alaska (USA) }\end{array}$} & \multirow{3}{*}{$\begin{array}{l}\text { GMD/NOAA, } \\
\text { Boulder, } \\
\text { Colorado, USA }\end{array}$} & \multirow{3}{*}{$\begin{array}{l}71^{\circ} 19^{\prime} \mathrm{N}, \\
156^{\circ} 36^{\prime} \mathrm{W} \\
8 \mathrm{~m} \text { a.m.s.l. }\end{array}$} & \multirow{3}{*}{$\begin{array}{l}832 \text { (cloud- } \\
\text { screened by } \\
\text { GMD/NOAA) }\end{array}$} & \multirow{3}{*}{$\begin{array}{l}\text { March 2000- } \\
\text { September } \\
2012\end{array}$} & $\begin{array}{l}\text { Carter Scott } \\
\text { SP02 }\end{array}$ & $412,500,675,862$ & $412-862$ & \multirow[t]{3}{*}{$\begin{array}{l}\text { Stone } \\
(2002)\end{array}$} \\
\hline & & & & & $\begin{array}{l}\text { Carter Scott } \\
\text { SP01-A }\end{array}$ & $\begin{array}{l}367,610,778, \\
1050\end{array}$ & $367-778$ & \\
\hline & & & & & $\begin{array}{l}\text { Carter Scott } \\
\text { SP022 }\end{array}$ & $\begin{array}{l}368,610,778, \\
1050\end{array}$ & $368-778$ & \\
\hline $\begin{array}{l}\text { Barrow, } \\
\text { Alaska (USA) }\end{array}$ & $\begin{array}{l}\text { AERONET, } \\
\text { NASA/GSFC, } \\
\text { (Greenbelt, } \\
\text { Maryland, USA); } \\
\text { U.S. DoE } \\
\text { Atmospheric } \\
\text { Radiation } \\
\text { Measurement } \\
\text { Program, USA }\end{array}$ & $\begin{array}{l}71^{\circ} 19^{\prime} \mathrm{N} \\
156^{\circ} 40^{\prime} \mathrm{W} \\
0 \text { m a.m.s.l. }\end{array}$ & $\begin{array}{l}579 \text { (Level } \\
2.0)\end{array}$ & $\begin{array}{l}\text { March 2002- } \\
\text { September } \\
2013\end{array}$ & Cimel CE-318 & $\begin{array}{l}340,380,440,500, \\
675,870,1020, \\
1640\end{array}$ & $440-870$ & \multirow[t]{3}{*}{$\begin{array}{l}\text { Holben et } \\
\text { al. (1998) }\end{array}$} \\
\hline $\begin{array}{l}\text { Resolute Bay, } \\
\text { Nunavut } \\
\text { (Canada) }\end{array}$ & $\begin{array}{l}\text { AERONET/ } \\
\text { AEROCAN, } \\
\text { Environment } \\
\text { Canada, } \\
\text { Downsview, } \\
\text { Ontario, Canada }\end{array}$ & $\begin{array}{l}74^{\circ} 44^{\prime} \mathrm{N}, \\
94^{\circ} 54^{\prime} \mathrm{W}, \\
40 \mathrm{~m} \text { a.m.s.l. }\end{array}$ & $\begin{array}{l}361 \text { (Level } \\
2.0)\end{array}$ & $\begin{array}{l}\text { July 2004- } \\
\text { October } 2012\end{array}$ & Cimel CE-318 & $\begin{array}{l}340,380,440,500, \\
675,870,1020, \\
1640\end{array}$ & $440-870$ & \\
\hline Eureka-0PAL, & AERONET/ & $79^{\circ} 59^{\prime} \mathrm{N}$ & 360 (Level & April 2007- & Cimel CE-318 & $340,380,440,500$ & $440-870$ & \\
\hline
\end{tabular}




\begin{tabular}{|c|c|c|c|c|c|c|c|c|}
\hline $\begin{array}{l}\text { Nunavut } \\
\text { (Canada) }\end{array}$ & $\begin{array}{l}\text { AEROCAN, } \\
\text { CARTEL, } \\
\text { University of } \\
\text { Sherbrooke, } \\
\text { Canada }\end{array}$ & $\begin{array}{l}85^{\circ} 56^{\prime} \mathrm{W} \\
0 \mathrm{~m} \text { a.m.s.l. }\end{array}$ & 2.0) & $\begin{array}{l}\text { September } \\
2011\end{array}$ & & $\begin{array}{l}675,870,1020, \\
1640\end{array}$ & & \\
\hline $\begin{array}{l}\text { Alert, Ellesmere } \\
\text { Island, Nunavut } \\
\text { (Canada) }\end{array}$ & $\begin{array}{l}\text { GMD/NOAA, } \\
\text { Boulder, } \\
\text { Colorado, USA }\end{array}$ & $\begin{array}{l}82^{\circ} 28^{\prime} \mathrm{N}, \\
62^{\circ} 30^{\prime} \mathrm{W}, \\
210 \mathrm{~m} \text { a.m.s.l. }\end{array}$ & $\begin{array}{l}810 \text { (cloud- } \\
\text { screened by } \\
\text { GMD/NOAA) }\end{array}$ & $\begin{array}{l}\text { August 2004- } \\
\text { September } \\
2012\end{array}$ & $\begin{array}{l}\text { Carter Scott } \\
\text { SP02 }\end{array}$ & $\begin{array}{l}412,500,675,862, \\
\text { or } 368,610,778, \\
1050\end{array}$ & $\begin{array}{c}412-862 \text { or } \\
368-778\end{array}$ & $\begin{array}{l}\text { Stone } \\
(2002)\end{array}$ \\
\hline $\begin{array}{l}\text { Thule, } \\
\text { NW Greenland }\end{array}$ & $\begin{array}{l}\text { AERONET, } \\
\text { NASA/GSFC, } \\
\text { Greenbelt, } \\
\text { Maryland, USA }\end{array}$ & $\begin{array}{l}76^{\circ} 31^{\prime} \mathrm{N}, \\
68^{\circ} 46^{\prime} \mathrm{W}, \\
225 \mathrm{~m} \text { a.m.s.l. }\end{array}$ & $\begin{array}{l}605 \text { (Level } \\
2.0)\end{array}$ & $\begin{array}{l}\text { March 2007- } \\
\text { September } \\
2012\end{array}$ & Cimel CE-318 & $\begin{array}{l}380,440,500,675 \\
870,1020\end{array}$ & $440-870$ & $\begin{array}{l}\text { Holben at } \\
\text { al. (1998) }\end{array}$ \\
\hline $\begin{array}{l}\text { Summit, Central } \\
\text { Greenland }\end{array}$ & $\begin{array}{l}\text { PMOD/WRC, } \\
\text { Davos, } \\
\text { Switzerland }\end{array}$ & $\begin{array}{l}72^{\circ} 35^{\prime} \mathrm{N}, \\
38^{\circ} 28^{\prime} \mathrm{W} \\
3250 \mathrm{~m} \\
\text { a.m.s.l. }\end{array}$ & $\begin{array}{l}391 \text { (cloud- } \\
\text { screened by } \\
\text { PMOD/WRC) }\end{array}$ & $\begin{array}{l}\text { January } \\
2001- \\
\text { October } 2011\end{array}$ & PFR\#34 & $368,412,500,862$ & $412-862$ & $\begin{array}{l}\text { Wehrli } \\
(2000)\end{array}$ \\
\hline $\begin{array}{l}\text { Ittoqqortoormiit, } \\
\text { Eastern } \\
\text { Greenland }\end{array}$ & $\begin{array}{l}\text { AERONET, } \\
\text { NASA/GSFC, } \\
\text { Greenbelt, } \\
\text { Maryland, USA }\end{array}$ & $\begin{array}{l}70^{\circ} 29^{\prime} \mathrm{N}, \\
21^{\circ} 57^{\prime} \mathrm{W}, \\
68 \mathrm{~m} \text { a.m.s.l. }\end{array}$ & $\begin{array}{l}307 \text { (Level } \\
2.0)\end{array}$ & $\begin{array}{l}\text { May 2010- } \\
\text { October } 2013\end{array}$ & Cimel CE-318 & $\begin{array}{l}340,380,440,500 \\
675,870,1020\end{array}$ & $440-870$ & $\begin{array}{l}\text { Holben at } \\
\text { al. (1998) }\end{array}$ \\
\hline \multirow[t]{3}{*}{$\begin{array}{l}\text { Ny-Ålesund, } \\
\text { Spitsbergen } \\
\text { (Svalbard, } \\
\text { Norway) }\end{array}$} & \multirow[t]{3}{*}{$\begin{array}{l}\text { AWI, } \\
\text { Bremerhaven, } \\
\text { Germany }\end{array}$} & \multirow[t]{3}{*}{$\begin{array}{l}78^{\circ} 54^{\prime} \mathrm{N} \\
11^{\circ} 53^{\prime} \mathrm{E}, \\
5 \mathrm{~m} \text { a.m.s.l. }\end{array}$} & \multirow[t]{3}{*}{$\begin{array}{l}749 \text { (cloud- } \\
\text { screened by } \\
\text { AWI) }\end{array}$} & \multirow[t]{3}{*}{$\begin{array}{l}\text { April 2000- } \\
\text { September } \\
2013\end{array}$} & SP1A & $\begin{array}{l}371,380,416,443, \\
500,532,609,675, \\
778,864,1025, \\
1046,1062\end{array}$ & $443-864$ & \multirow[t]{3}{*}{$\begin{array}{l}\text { Herber et } \\
\text { al. (2002) }\end{array}$} \\
\hline & & & & & SP2H & $\begin{array}{l}367,380,413,441, \\
501,531,605,673, \\
776,862,1023, \\
1045\end{array}$ & $441-862$ & \\
\hline & & & & & STAR01 & $\begin{array}{l}390,441,501,531 \\
605,673,776,862\end{array}$ & $441-862$ & \\
\hline $\begin{array}{l}\text { Ny-Ålesund, } \\
\text { Spitsbergen } \\
\text { (Svalbard, } \\
\text { Norway) }\end{array}$ & $\begin{array}{l}\text { NILU, Kjeller, } \\
\text { Norway }\end{array}$ & $\begin{array}{l}78^{\circ} 54^{\prime} \mathrm{N} \\
11^{\circ} 53^{\prime} \mathrm{E}, \\
5 \mathrm{~m} \text { a.m.s.l. }\end{array}$ & $\begin{array}{l}693 \text { (cloud- } \\
\text { screened by } \\
\text { NILU) }\end{array}$ & $\begin{array}{l}\text { March 2002- } \\
\text { September } \\
\text { 2004, and } \\
\text { March 2006- }\end{array}$ & PFR\#18 & $\begin{array}{l}367.7,411.9 \\
500.6,862.5\end{array}$ & $411.9-862.5$ & $\begin{array}{l}\text { Wehrli } \\
(2000)\end{array}$ \\
\hline
\end{tabular}




\begin{tabular}{|c|c|c|c|c|c|c|c|c|}
\hline & & & & $\begin{array}{l}\text { September } \\
2013\end{array}$ & & & & \\
\hline $\begin{array}{l}\text { Barentsburg, } \\
\text { Spitsbergen } \\
\text { (Svalbard, } \\
\text { Norway) } \\
\end{array}$ & $\begin{array}{l}\text { IAO-SB-RAS, } \\
\text { Tomsk, Russia }\end{array}$ & $\begin{array}{l}78^{\circ} 04^{\prime} \mathrm{N}, \\
14^{\circ} 13^{\prime} \mathrm{E}, \\
20 \mathrm{~m} \text { a.m.s.l. }\end{array}$ & $\begin{array}{l}56 \text { (cloud- } \\
\text { screened by } \\
\text { IAO) }\end{array}$ & $\begin{array}{l}\text { April-August } \\
\text { of } 2011 \text { and } \\
2012\end{array}$ & $\begin{array}{l}\text { New portable } \\
\text { SPM }\end{array}$ & $\begin{array}{l}339,380,442,500, \\
547,675,871, \\
1020,1240,1553, \\
2134\end{array}$ & $442-871$ & $\begin{array}{l}\text { Sakerin et } \\
\text { al. }(2009, \\
2012, \\
2014)\end{array}$ \\
\hline $\begin{array}{l}\text { Hornsund, } \\
\text { Spitsbergen } \\
\text { (Svalbard, } \\
\text { Norway) }\end{array}$ & $\begin{array}{l}\text { AERONET, } \\
\text { NASA/GSFC, } \\
\text { Greenbelt, } \\
\text { Maryland, USA; } \\
\text { Warsaw } \\
\text { University, PAS, } \\
\text { Poland) }\end{array}$ & $\begin{array}{l}77^{\circ} 00^{\prime} \mathrm{N}, \\
15^{\circ} 34^{\prime} \mathrm{E}, \\
10 \mathrm{~m} \text { a.m.s.l. }\end{array}$ & $\begin{array}{l}514 \text { (Level } \\
2.0)\end{array}$ & $\begin{array}{l}\text { April 2005- } \\
\text { August } 2013\end{array}$ & Cimel CE-318 & $\begin{array}{l}380,440,500,675 \\
870,1020\end{array}$ & $440-870$ & $\begin{array}{l}\text { Holben et } \\
\text { al. (1998) }\end{array}$ \\
\hline $\begin{array}{l}\text { Sodankylä, } \\
\text { Northern Finland }\end{array}$ & $\begin{array}{l}\text { FMI, Helsinki, } \\
\text { Finland }\end{array}$ & $\begin{array}{l}67^{\circ} 22^{\prime} \mathrm{N}, \\
26^{\circ} 38^{\prime} \mathrm{E}, \\
184 \mathrm{~m} \text { a.m.s.l. }\end{array}$ & $\begin{array}{l}312 \text { (cloud- } \\
\text { screened by } \\
\text { FMI) }\end{array}$ & $\begin{array}{l}\text { May 2004- } \\
\text { September } \\
2013\end{array}$ & PFR\#32 & $\begin{array}{l}367.6,411.4 \\
500.5,861.6\end{array}$ & $411.4-861.6$ & $\begin{array}{l}\text { Wehrli } \\
(2000)\end{array}$ \\
\hline $\begin{array}{l}\text { Sodankylä, } \\
\text { Northern Finland }\end{array}$ & $\begin{array}{l}\text { AERONET, } \\
\text { NASA/GSFC, } \\
\text { Greenbelt, } \\
\text { Maryland, USA; } \\
\text { FMI, Helsinki, } \\
\text { Finland }\end{array}$ & $\begin{array}{l}67^{\circ} 22^{\prime} \mathrm{N}, \\
26^{\circ} 38^{\prime} \mathrm{E}, \\
184 \mathrm{~m} \text { a.m.s.l. }\end{array}$ & $\begin{array}{l}119 \text { (Level } \\
2.0)\end{array}$ & $\begin{array}{l}\text { February } \\
2007- \\
\text { November } \\
2013\end{array}$ & Cimel CE-318 & $\begin{array}{l}340,380,440,500, \\
675,870,1020, \\
1640\end{array}$ & $440-870$ & $\begin{array}{l}\text { Holben et } \\
\text { al. (1998) }\end{array}$ \\
\hline $\begin{array}{l}\text { Tiksi, Northern- } \\
\text { Central Siberia } \\
\text { (Russia) }\end{array}$ & $\begin{array}{l}\text { AERONET, } \\
\text { NASA/GSFC, } \\
\text { Greenbelt, } \\
\text { Maryland, USA }\end{array}$ & $\begin{array}{l}71^{\circ} 35^{\prime} \mathrm{N} \\
128^{\circ} 55^{\prime} \mathrm{E} \\
0 \mathrm{~m} \text { a.m.s.l. }\end{array}$ & $\begin{array}{l}162 \text { (Level } \\
2.0)\end{array}$ & $\begin{array}{l}\text { June - } \\
\text { October of } \\
2010,2011 \\
\text { and } 2012 \\
\end{array}$ & Cimel CE-318 & $\begin{array}{l}340,380,440,500 \\
675,870,1020\end{array}$ & $440-870$ & $\begin{array}{l}\text { Holben et } \\
\text { al. (1998) }\end{array}$ \\
\hline
\end{tabular}


Table 2. List of the coastal and high-altitude Antarctic stations, where regular ground-based sun-photometer measurements have been conducted over the two past decades, using different instrument models equipped with a variable number of narrow-band interference filters to determine the spectral values of background aerosol optical thickness $\tau(\lambda)$ and Ångström wavelength exponent $\alpha$ in the visible and near-infrared wavelength range.

\begin{tabular}{|c|c|c|c|c|c|c|c|c|}
\hline $\begin{array}{l}\text { Sun-photometer } \\
\text { stations }\end{array}$ & $\begin{array}{l}\text { Managing } \\
\text { institutions }\end{array}$ & $\begin{array}{l}\text { Geographical } \\
\text { coordinates } \\
\text { and altitude }\end{array}$ & $\begin{array}{l}\text { Overall } \\
\text { number of } \\
\text { measurement } \\
\text { days }\end{array}$ & $\begin{array}{l}\text { Measurement } \\
\text { period }\end{array}$ & $\begin{array}{l}\text { Sun- } \\
\text { photometer } \\
\text { model }\end{array}$ & $\begin{array}{l}\text { Peak wavelengths } \\
\text { (nm) of the } \\
\text { aerosol spectral } \\
\text { channels }\end{array}$ & $\begin{array}{l}\text { Spectral } \\
\text { interval } \\
(\mathrm{nm}) \text { of } \alpha\end{array}$ & References \\
\hline $\begin{array}{l}\text { Marambio, } \\
\text { Seymour- } \\
\text { Marambio Island }\end{array}$ & $\begin{array}{l}\text { FMI, } \\
\text { Heksinki, } \\
\text { Finland }\end{array}$ & $\begin{array}{l}64^{\circ} 14^{\prime} \mathrm{S}, \\
56^{\circ} 37^{\prime} \mathrm{W}, \\
205 \mathrm{~m} \text { a.m.s.l. }\end{array}$ & $\begin{array}{l}139 \text { (cloud- } \\
\text { screened by } \\
\text { FMI) }\end{array}$ & $\begin{array}{l}\text { August 2011- } \\
\text { March } 2013\end{array}$ & PFR \#29 & $\begin{array}{l}367.6,411.4 \\
500.5,861.6\end{array}$ & $367.6-861.6$ & Wehrli (2000) \\
\hline \multirow[t]{3}{*}{$\begin{array}{l}\text { Neumayer, } \\
\text { Weddell Sea coast }\end{array}$} & \multirow[t]{3}{*}{$\begin{array}{l}\text { AWI, } \\
\text { Bremerhaven, } \\
\text { Germany }\end{array}$} & \multirow[t]{3}{*}{$\begin{array}{l}70^{\circ} 39^{\prime} \mathrm{S} \\
8^{\circ} 15^{\prime} \mathrm{W} \\
40 \mathrm{~m} \text { a.m.s.l. }\end{array}$} & \multirow[t]{3}{*}{$\begin{array}{l}234 \text { (cloud- } \\
\text { screened by } \\
\text { AWI) }\end{array}$} & \multirow[t]{3}{*}{$\begin{array}{l}\text { September } \\
2000-\text { April } \\
2007\end{array}$} & SP1A & $\begin{array}{l}371,380,416, \\
443,500,532, \\
609,675,778, \\
864,1025,1046, \\
1062\end{array}$ & $443-864$ & \multirow[t]{3}{*}{$\begin{array}{l}\text { Herber et al. } \\
(2002)\end{array}$} \\
\hline & & & & & SP2H & $\begin{array}{l}367,380,413, \\
441,501,531, \\
605,673,776, \\
862,1023,1045 \\
\end{array}$ & $441-862$ & \\
\hline & & & & & STAR01 & $\begin{array}{l}390,441,501, \\
531,605,673, \\
776,862\end{array}$ & $441-862$ & \\
\hline $\begin{array}{l}\text { Troll, Queen Maud } \\
\text { Land }\end{array}$ & $\begin{array}{l}\text { NILU, } \\
\text { Kjeller, } \\
\text { Norway }\end{array}$ & $\begin{array}{l}72^{\circ} 01^{\prime} \mathrm{S} \\
2^{\circ} 32^{\prime} \mathrm{E} \\
1309 \mathrm{~m} \\
\text { a.m.s.l. }\end{array}$ & $\begin{array}{l}547 \text { (cloud- } \\
\text { screened by } \\
\text { NILU) }\end{array}$ & $\begin{array}{l}\text { January 2007- } \\
\text { April } 2013\end{array}$ & $\begin{array}{l}\text { PFR\#40 } \\
\text { PFR\#42 }\end{array}$ & $\begin{array}{l}368.7,411.9 \\
500.6,862.5 \\
368.9,412.1 \\
499.7,862.2\end{array}$ & $\begin{array}{l}411.9-862.5 \\
412.1-862.2\end{array}$ & Wehrli (2000) \\
\hline $\begin{array}{l}\text { Novolazarevskaya, } \\
\text { Queen Maud Land }\end{array}$ & $\begin{array}{l}\text { AARI, San } \\
\text { Petersburg, } \\
\text { Russia; } \\
\text { AERONET, } \\
\text { NASA/GSFC, } \\
\text { Greenbelt, } \\
\text { Maryland, }\end{array}$ & $\begin{array}{l}70^{\circ} 46^{\prime} \mathrm{S}, \\
11^{\circ} 50^{\prime} \mathrm{E}, \\
119 \mathrm{~m} \text { a.m.s.l. }\end{array}$ & $\begin{array}{l}83 \text { (Level 1.5, } \\
\text { cloud-screened } \\
\text { by } \\
\text { NASA/GSFC }\end{array}$ & $\begin{array}{l}\text { December } \\
2008 \text {-February } \\
2009 ; \\
\text { November } \\
\text { 2009-February } \\
2010\end{array}$ & $\begin{array}{l}\text { Hand-held } \\
\text { Microtops, } \\
\text { calibrated } \\
\text { at GSFC }\end{array}$ & $440,500,675,870$ & $440-870$ & $\begin{array}{l}\text { Smirnov et al. } \\
(2009)\end{array}$ \\
\hline
\end{tabular}




\begin{tabular}{|c|c|c|c|c|c|c|c|c|}
\hline & USA. & & & & & & & \\
\hline \multirow[t]{3}{*}{$\begin{array}{l}\text { Mirny, Davis Sea } \\
\text { coast }\end{array}$} & \multirow[t]{3}{*}{$\begin{array}{l}\text { AARI, St. } \\
\text { Petersburg, } \\
\text { Russia }\end{array}$} & \multirow[t]{3}{*}{$\begin{array}{l}66^{\circ} 33^{\prime} \mathrm{S}, \\
93^{\circ} 01^{\prime} \mathrm{E}, \\
40 \mathrm{~m} \text { a.m.s.l. }\end{array}$} & \multirow{3}{*}{$\begin{array}{l}725 \text { (ABAS } \\
\text { and SPM data } \\
\text { cloud-screened } \\
\text { by AARI; } \\
\text { Microtops data } \\
\text { cloud-screened } \\
\text { using the } \\
\text { Smirnov et al. } \\
\text { (2009) } \\
\text { procedure) }\end{array}$} & \multirow[t]{3}{*}{$\begin{array}{l}\text { March 2000- } \\
\text { October 2013 }\end{array}$} & ABAS & $\begin{array}{l}395,408,479 \\
581,651,789, \\
873,1041\end{array}$ & $408-873$ & $\begin{array}{l}\text { Radionov et al. } \\
(2002), \\
\text { Radionov } \\
(2005)\end{array}$ \\
\hline & & & & & SPM & $\begin{array}{l}340,379,443, \\
499,548,676, \\
871,1019,1244, \\
1555,2134\end{array}$ & $443-871$ & $\begin{array}{l}\text { Sakerin et al. } \\
(2009,2012) \\
\text { Tomasi et al. } \\
(2012)\end{array}$ \\
\hline & & & & & Microtops & $440,500,675,870$ & $440-870$ & $\begin{array}{l}\text { Smirnov et al. } \\
(2009)\end{array}$ \\
\hline $\begin{array}{l}\text { Syowa, East Ongul } \\
\text { Island, Lützow- } \\
\text { Holm Bay }\end{array}$ & $\begin{array}{l}\text { Japan } \\
\text { Meteorologic } \\
\text { al Agency } \\
\text { (JMA), } \\
\text { Tokyo, Japan }\end{array}$ & $\begin{array}{l}69^{\circ} 00^{\prime} \mathrm{S}, \\
39^{\circ} 35^{\prime} \mathrm{E}, \\
21 \mathrm{~m} \text { a.m.s.l. }\end{array}$ & $\begin{array}{l}987 \text { (cloud- } \\
\text { screened by } \\
\text { JMA) }\end{array}$ & $\begin{array}{l}\text { January 2000- } \\
\text { December } \\
2011\end{array}$ & $\begin{array}{l}\text { EKO MS- } \\
110 \text { model } \\
\text { (with } 2.5^{\circ} \\
\text { field-of- } \\
\text { view } \\
\text { diameter) }\end{array}$ & $\begin{array}{l}368,500,675 \\
778,862\end{array}$ & $368-862$ & Ohno (2005) \\
\hline \multirow{2}{*}{$\begin{array}{l}\text { Mario Zucchelli, } \\
\text { Terra Nova Bay, } \\
\text { Ross Sea coast, } \\
\text { Victoria Land }\end{array}$} & \multirow[t]{2}{*}{$\begin{array}{l}\text { ISAC-CNR, } \\
\text { Bologna, Italy }\end{array}$} & \multirow[t]{2}{*}{$\begin{array}{l}74^{\circ} 42^{\prime} \mathrm{S}, \\
164^{\circ} 07^{\prime} \mathrm{E}, \\
15 \mathrm{~m} \text { a.m.s.l. }\end{array}$} & \multirow[t]{2}{*}{$\begin{array}{l}87 \text { (cloud- } \\
\text { screened by } \\
\text { ISAC-CNR) }\end{array}$} & $\begin{array}{l}\text { November } \\
\text { 2001-February } \\
2002\end{array}$ & $\begin{array}{l}\text { Prede } \\
\text { POM-01L }\end{array}$ & $\begin{array}{l}400,500,675, \\
870,1020\end{array}$ & $400-870$ & $\begin{array}{l}\text { Di Carmine et } \\
\text { al. (2005) }\end{array}$ \\
\hline & & & & $\begin{array}{l}\text { December } \\
2005 \text {-February } \\
2006\end{array}$ & ASP-15WL & $\begin{array}{l}381,412,451, \\
500,551,610, \\
673,775,861, \\
1026\end{array}$ & $412-861$ & $\begin{array}{l}\text { Tomasi et al, } \\
(2007)\end{array}$ \\
\hline \multirow[t]{3}{*}{$\begin{array}{l}\text { Dome Concordia, } \\
\text { East Antarctic } \\
\text { Plateau }\end{array}$} & $\begin{array}{l}\text { AERONET, } \\
\text { NASA/GSFC, } \\
\text { Greenbelt, } \\
\text { Maryland, } \\
\text { USA }\end{array}$ & $\begin{array}{l}75^{\circ} 05^{\prime} \mathrm{S}, \\
123^{\circ} 18^{\prime} \mathrm{E}, \\
3260 \mathrm{~m} \\
\text { a.m.s.l. }\end{array}$ & $\begin{array}{l}44 \text { (Level } 1.5 \\
\text { data, cloud- } \\
\text { screened by } \\
\text { NASA/GSFC) }\end{array}$ & $\begin{array}{l}\text { January and } \\
\text { December } \\
\text { 2003; January } \\
2004\end{array}$ & $\begin{array}{l}\text { Cimel CE- } \\
318\end{array}$ & $\begin{array}{l}440,675,870, \\
1020\end{array}$ & $440-870$ & $\begin{array}{l}\text { Holben et al. } \\
\text { (1998), Six et } \\
\text { al. (2005) }\end{array}$ \\
\hline & $\begin{array}{l}\text { GMD/NOAA, } \\
\text { Boulder, } \\
\text { Colorado, } \\
\text { USA }\end{array}$ & $\begin{array}{l}75^{\circ} 06^{\prime} \mathrm{S}, \\
123^{\circ} 21^{\prime} \mathrm{E}, \\
3233 \mathrm{~m} \\
\text { a.m.s.l. }\end{array}$ & $\begin{array}{l}65 \text { (cloud- } \\
\text { screened by } \\
\text { GMD/NOAA) }\end{array}$ & $\begin{array}{l}\text { January 2006- } \\
\text { November } \\
2010\end{array}$ & $\begin{array}{l}\text { Carter Scott } \\
\text { SP02 }\end{array}$ & $412,500,675,862$ & $412-862$ & Stone (2002) \\
\hline & OPAR & $75^{\circ} 05^{\prime} \mathrm{E}$ & 39 (Level 1.5 & January, 2010, & Hand-held & $379,441,674,868$ & $441-868$ & Smirnov et al. \\
\hline
\end{tabular}




\begin{tabular}{|c|c|c|c|c|c|c|c|c|}
\hline & $\begin{array}{l}\text { Institute, } \\
\text { (Univ. de la } \\
\text { Réunion - } \\
\text { CNRS, Saint } \\
\text { Denis de la } \\
\text { Réunion, } \\
\text { France), and } \\
\text { NASA/GSFC, } \\
\text { (Greenbelt, } \\
\text { Maryland, } \\
\text { USA) }\end{array}$ & $\begin{array}{l}123^{\circ} 18^{\prime} \mathrm{E}, \\
3260 \mathrm{~m} \\
\text { a.m.s.l. }\end{array}$ & $\begin{array}{l}\text { data, cloud- } \\
\text { screened by } \\
\text { NASA/GSFC) }\end{array}$ & $\begin{array}{l}2011 \text {, and } \\
2012\end{array}$ & $\begin{array}{l}\text { Microtops } \\
\text { calibrated } \\
\text { at the } \\
\text { NASA/ } \\
\text { GSFC } \\
\text { Facility }\end{array}$ & & & (2011) \\
\hline \multirow[t]{2}{*}{$\begin{array}{l}\text { South Pole, } \\
\text { Antarctic Plateau }\end{array}$} & $\begin{array}{l}\text { GMD/NOAA, } \\
\text { Boulder, } \\
\text { Colorado, } \\
\text { USA }\end{array}$ & $\begin{array}{l}90^{\circ} 00^{\prime} \mathrm{S}, \\
00^{\circ} 00^{\prime} \mathrm{E}, \\
2835 \mathrm{~m} \\
\text { a.m.s.l. }\end{array}$ & $\begin{array}{l}1279 \text { (cloud- } \\
\text { screened by } \\
\text { GMD/NOAA) }\end{array}$ & $\begin{array}{l}\text { November } \\
\text { 2001-March } \\
\text { 2012 }\end{array}$ & $\begin{array}{l}\text { Carter Scott } \\
\text { SP02 }\end{array}$ & $412,500,675,862$ & $412-862$ & Stone (2002) \\
\hline & $\begin{array}{l}\text { AERONET, } \\
\text { NASA/GSFC, } \\
\text { Greenbelt, } \\
\text { Maryland, } \\
\text { USA; } \\
\text { GMD/NOAA, } \\
\text { Boulder, } \\
\text { Colorado, } \\
\text { USA }\end{array}$ & $\begin{array}{l}89^{\circ} 59^{\prime} \mathrm{S}, \\
70^{\circ} 18^{\prime} \mathrm{E}, \\
2850 \mathrm{~m} \\
\text { a.m.s.l. }\end{array}$ & $\begin{array}{l}147 \text { (Level } 2.0 \\
\text { data, cloud- } \\
\text { screened by } \\
\text { NASA/GSFC) }\end{array}$ & $\begin{array}{l}\text { November } \\
2007- \\
\text { December } \\
2012\end{array}$ & $\begin{array}{l}\text { Cimel CE- } \\
318\end{array}$ & $\begin{array}{l}340,380,440, \\
500,675,870, \\
1020\end{array}$ & $440-870$ & $\begin{array}{l}\text { Holben et al. } \\
\text { (1998) }\end{array}$ \\
\hline
\end{tabular}


Table 3. List of the 14 cruises undertaken in the Arctic oceanic regions by various managing institutions in different geographical areas (at latitudes $>67$ ${ }^{\circ} \mathrm{N}$ ), where the ship-borne Level 2.0 sun-photometer measurements of the Maritime Aerosol Network (MAN) programme were conducted from 2003 to 2012, using hand-held Microtops sun-photometers calibrated at the NASA/GSFC calibration facility (Smirnov et al., 2009, 2011). The peak-wavelengths of the narrow-band interference filters mounted on the instruments are given, together with the names of the sun-photometer measurement P.I.s.

\begin{tabular}{|c|c|c|c|c|c|}
\hline $\begin{array}{l}\text { Cruises and sun-photometer } \\
\text { managing institutions }\end{array}$ & Geographical area & $\begin{array}{l}\text { Overall number } \\
\text { of measurement } \\
\text { days }\end{array}$ & Measurement period & $\begin{array}{l}\text { Peak wavelengths }(\mathrm{nm}) \\
\text { of the spectral channels } \\
\text { used to measure aerosol } \\
\text { optical thickness } \tau(\lambda)\end{array}$ & $\begin{array}{l}\text { Principal } \\
\text { Investigator and } \\
\text { references }\end{array}$ \\
\hline $\begin{array}{l}\text { RV Oceania } 2003 \\
\text { (IOPAS, Sopot, Poland) }\end{array}$ & $\begin{array}{l}\text { Norwegian Sea, west } \\
\text { Spitsbergen } \\
69^{\circ}-79^{\circ} \mathrm{N}, 2^{\circ}-14^{\circ} \mathrm{E}\end{array}$ & 5 & June-July 2003 & $440,500,675,870$ & $\begin{array}{l}\text { T. Zielinsky } \\
\text { (Tomasi et al., } \\
\text { 2007) }\end{array}$ \\
\hline $\begin{array}{l}\text { RV Oceania } 2006 \\
\text { (IOPAS, Sopot, Poland) }\end{array}$ & $\begin{array}{l}\text { Greenland Sea and } \\
\text { Norwegian Sea, } 69^{\circ}-79^{\circ} \mathrm{N} \text {, } \\
15^{\circ} \mathrm{W}-14^{\circ} \mathrm{E}\end{array}$ & 6 & June-July 2006 & $440,500,675,870$ & $\begin{array}{l}\text { T. Zielinsky } \\
\text { (Tomasi et al., } \\
\text { 2007) }\end{array}$ \\
\hline $\begin{array}{l}\text { RV Oceania } 2007 \\
\text { (IOPAS, Sopot, Poland) }\end{array}$ & $\begin{array}{l}\text { Norwegian Sea, } \\
69^{\circ}-78^{\circ} \mathrm{N}, 1^{\circ}-16^{\circ} \mathrm{E}\end{array}$ & 6 & $\begin{array}{l}\text { July 15-August 11, } \\
2007\end{array}$ & $440,500,675,870$ & T. Zielinsky \\
\hline $\begin{array}{l}\text { CCGS Louis St. Laurent } 2007 \\
\text { (Wood Hole Oceanographic } \\
\text { Institution, Woods Hole, } \\
\text { Massachusetts, USA) }\end{array}$ & $\begin{array}{l}\text { Beaufort Sea, } \\
70^{\circ}-79^{\circ} \mathrm{N}, 125^{\circ}-150^{\circ} \mathrm{W}\end{array}$ & 9 & $\begin{array}{l}\text { July 28-August 25, } \\
2007\end{array}$ & $440,500,675,870$ & A. Proshutinsky \\
\hline $\begin{array}{l}\text { RV Knorr } 2008 \\
\text { (PMEL, NOAA, Seattle, } \\
\text { Washington, USA) }\end{array}$ & $\begin{array}{l}\text { Norwegian Sea, } \\
70^{\circ}-71^{\circ} \mathrm{N}, 19^{\circ}-31^{\circ} \mathrm{E}\end{array}$ & 4 & April 6-10, 2008 & $440,500,675,870$ & P. K. Quinn \\
\hline $\begin{array}{l}\text { CCGS Amundsen } 2008 \\
\text { (Institut Maurice-Lamontagne, } \\
\text { Mont-Joli, Quebec, Canada) }\end{array}$ & $\begin{array}{l}\text { Beaufort Sea, } \\
70^{\circ}-73^{\circ} \mathrm{N}, 121^{\circ}-131^{\circ} \mathrm{W}\end{array}$ & 43 & $\begin{array}{l}\text { March 16-August 2, } \\
2008\end{array}$ & $440,500,675,870$ & P. Larouche \\
\hline $\begin{array}{l}\text { RV Jan Mayen } 2009 \\
\text { (IMEDEA, Esporles, Mallorca, } \\
\text { Spain) }\end{array}$ & $\begin{array}{l}\text { Norwegian Sea, } \\
76^{\circ}-80^{\circ} \mathrm{N}, 11^{\circ}-28^{\circ} \mathrm{E}\end{array}$ & 4 & June 18-22, 2009 & $440,500,675,870$ & C. Duarte \\
\hline $\begin{array}{l}\text { RV Oceania } 2009 \\
\text { (IOPAS, Sopot, Poland) }\end{array}$ & $\begin{array}{l}\text { Norwegian Sea, } \\
73^{\circ}-79^{\circ} \mathrm{N}, 3^{\circ}-16^{\circ} \mathrm{E}\end{array}$ & 11 & June 23-July 13, 2009 & $440,500,675,870$ & T. Zielinsky \\
\hline
\end{tabular}




\begin{tabular}{|l|l|c|l|l|}
\hline $\begin{array}{l}\text { CCGS Amundsen 2009 } \\
\text { (Université du Québec, } \\
\text { Rimouski, Québec, Canada) }\end{array}$ & $\begin{array}{l}\text { Beaufort Sea, } \\
70^{\circ}-72^{\circ} \mathrm{N}, 127^{\circ}-135^{\circ} \mathrm{W}\end{array}$ & 9 & $\begin{array}{l}\text { July 31-August 25, } \\
2009\end{array}$ & $440,500,675,870$ \\
\hline $\begin{array}{l}\text { RV Oceania 2010 } \\
\text { (IOPAS, Sopot, Poland) }\end{array}$ & $\begin{array}{l}\text { Norwegian Sea, } \\
68^{\circ}-80^{\circ} \mathrm{N}, 0^{\circ}-13^{\circ} \mathrm{E}\end{array}$ & 9 & July 6-August 17, 2010 & $380,440,500,675,870$ \\
\hline $\begin{array}{l}\text { RV Oceania 2011 } \\
\text { (IOPAS, Sopot, Poland) }\end{array}$ & $\begin{array}{l}\text { Norwegian Sea, } \\
69^{\circ}-79^{\circ} \mathrm{N}, 3^{\circ}-19^{\circ} \mathrm{E}\end{array}$ & 10 & $\begin{array}{l}\text { June 17-August 13, } \\
2011\end{array}$ & $440,500,675,870$ \\
\hline $\begin{array}{l}\text { USCGC Healy 2011 } \\
\text { (Naval Research Laboratory, } \\
\text { Monterey, California, USA) } \\
\text { Beufort Sea and Arctic } \\
\text { Canadian Ocean, } \\
71^{\circ}-79^{\circ} \mathrm{N}, 142^{\circ}-165^{\circ} \mathrm{W}\end{array}$ & 6 & $\begin{array}{l}\text { August 18-September } \\
24,2011\end{array}$ & $440,500,675,870$ \\
\hline $\begin{array}{l}\text { RV Oceania 2012 } \\
\text { (IOPAS, Sopot, Poland) }\end{array}$ & $\begin{array}{l}\text { Norwegian Sea, } \\
73^{\circ}-78^{\circ} \mathrm{N}, 10^{\circ}-20^{\circ} \mathrm{E}\end{array}$ & 7 & June 27-July 31, 2012 & $440,500,675,870$ \\
\hline $\begin{array}{l}\text { RV Polarstern 2012 } \\
\text { (Institute of Environmental } \\
\text { Physics, University of Bremen, } \\
\text { Bremen, Germany) }\end{array}$ & $\begin{array}{l}\text { Norwegian Sea, Barents } \\
\text { Sea and West Siberian Sea, } \\
70^{\circ}-84^{\circ} \mathrm{N}, 18^{\circ}-109^{\circ} \mathrm{E}\end{array}$ & 5 & August 2-22, 2012 & $440,500,675,870$ \\
\hline
\end{tabular}


Table 4. List of the 18 cruises undertaken in the Antarctic oceanic regions by various managing institutions in different geographical areas (at latitudes $>62{ }^{\circ} \mathrm{S}$ ), where the ship-borne sun-photometer measurements of the Maritime Aerosol Network (MAN) programme were conducted from $2005 / 2006$ to 2012/2013 in the austral summer months, using hand-held Microtops sun-photometers calibrated at the NASA/GSFC calibration facility (Smirnov et al., 2009, 2011). The peak-wavelengths of the narrow-band interference filters mounted on the instruments are given, together with the names of the sun-photometer measurement P.I.s.

\begin{tabular}{|c|c|c|c|c|c|}
\hline $\begin{array}{l}\text { Cruises and sun-photometer } \\
\text { managing institution }\end{array}$ & Geographical area & $\begin{array}{l}\text { Overall number } \\
\text { of measurement } \\
\text { days }\end{array}$ & Measurement period & $\begin{array}{l}\text { Peak wavelengths } \\
(\mathrm{nm}) \text { of the spectral } \\
\text { channels used for } \\
\text { measuring aerosol } \\
\text { optical thickness } \\
\tau(\lambda)\end{array}$ & $\begin{array}{l}\text { Principal } \\
\text { Investigator }\end{array}$ \\
\hline $\begin{array}{l}\text { RV Akademik Fedorov } \\
\text { 2005/2006 } \\
\text { (IAO-SB-RAS, Tomsk, Russia) }\end{array}$ & $\begin{array}{l}\text { Southern Indian Ocean } \\
65^{\circ}-70^{\circ} \mathrm{S}, 44^{\circ}-93^{\circ} \mathrm{E}\end{array}$ & 20 & $\begin{array}{l}\text { December 20, 2005- } \\
\text { January 26, } 2006\end{array}$ & $\begin{array}{l}340,440,500,675 \\
870\end{array}$ & S. M. Sakerin \\
\hline $\begin{array}{l}\text { RV Akademik Fedorov } \\
2006 / 2007 \\
\text { (IAO-SB-RAS, Tomsk, Russia) }\end{array}$ & $\begin{array}{l}\text { Southern Indian Ocean } \\
65^{\circ}-69^{\circ} \mathrm{S}, 46^{\circ}-93^{\circ} \mathrm{E}\end{array}$ & 40 & $\begin{array}{l}\text { December 13, 2006- } \\
\text { March 4, } 2007\end{array}$ & $\begin{array}{l}340,440,500,675 \\
870\end{array}$ & S. M. Sakerin \\
\hline $\begin{array}{l}\text { MV SA Agulhas 2007/2008 } \\
\text { (Climatology Research Group, } \\
\text { University of Witwatersrand, } \\
\text { Johannesburg, South Africa) }\end{array}$ & $\begin{array}{l}\text { Southern Atlantic Ocean, } \\
68^{\circ}-70^{\circ} \mathrm{S}, 2^{\circ} \mathrm{W}-4^{\circ} \mathrm{E}\end{array}$ & 15 & $\begin{array}{l}\text { December } 18,2007- \\
\text { January } 10,2008\end{array}$ & $440,500,675,870$ & $\begin{array}{l}\text { S. Piketh } \\
\text { (Wilson et al. } \\
\text { 2010) }\end{array}$ \\
\hline \multirow{4}{*}{$\begin{array}{l}\text { RV Akademik Fedorov } \\
2007 / 2008 \\
\text { (IAO-SB-RAS, Tomsk, Russia) }\end{array}$} & $\begin{array}{l}\text { Southern Indian Ocean, } \\
66^{\circ}-69^{\circ} \mathrm{S}, 45^{\circ} \mathrm{E}-95^{\circ} \mathrm{E}\end{array}$ & 18 & $\begin{array}{l}\text { December 14, 2007- } \\
\text { January 4, } 2008\end{array}$ & \multirow[t]{4}{*}{$440,500,675,870$} & \multirow[t]{4}{*}{ S. M. Sakerin } \\
\hline & $\begin{array}{l}\text { Southern Pacific Ocean, } \\
68^{\circ}-72^{\circ} \mathrm{S}, 90^{\circ}-163^{\circ} \mathrm{W}\end{array}$ & 14 & $\begin{array}{l}\text { January 24-February } \\
17,2008\end{array}$ & & \\
\hline & $\begin{array}{l}\text { Antarctic Peninsula, } \\
63^{\circ}-65^{\circ} \mathrm{S}, 60^{\circ}-45^{\circ} \mathrm{W}\end{array}$ & 3 & February 20-24, 2008 & & \\
\hline & $\begin{array}{l}\text { Southern Atlantic Ocean, } \\
65^{\circ}-70^{\circ} \mathrm{S}, 50^{\circ} \mathrm{W}-15^{\circ} \mathrm{E}\end{array}$ & 13 & $\begin{array}{l}\text { March 25-April 22, } \\
2008\end{array}$ & & \\
\hline $\begin{array}{l}\text { RV Akademik Fedorov } \\
2008 / 2009 \\
\text { (IAO-SB-RAS, Tomsk, Russia) }\end{array}$ & $\begin{array}{l}\text { Southern Indian Ocean, } \\
66^{\circ}-69^{\circ} \mathrm{S}, 76^{\circ}-93^{\circ} \mathrm{E}\end{array}$ & 11 & $\begin{array}{l}\text { December 22, 2008- } \\
\text { January 6, 2009; } \\
\text { January 25-March 23, } \\
2009\end{array}$ & $440,500,675,870$ & S. M. Sakerin \\
\hline
\end{tabular}




\begin{tabular}{|c|c|c|c|c|c|}
\hline & $\begin{array}{l}\text { Southern Pacific Ocean, } \\
67^{\circ} \mathrm{S}, 161^{\circ} \mathrm{E}\end{array}$ & 1 & January 17, 2009 & & \\
\hline $\begin{array}{l}\text { Vessel RV Astrolabe 2009/2010 } \\
\text { (OPAR, Univ. de Reunion, } \\
\text { Reunion, France) }\end{array}$ & $\begin{array}{l}\text { Southern Indian Ocean } \\
66^{\circ}-67^{\circ} \mathrm{S}, 140^{\circ}-141^{\circ} \mathrm{E}\end{array}$ & 5 & January 5-23, 2010 & $440,500,675,870$ & Y. Courcoux \\
\hline \multirow[t]{3}{*}{$\begin{array}{l}\text { RV Akademik Fedorov } \\
2009 / 2010 \\
\text { (IAO-SB-RAS, Tomsk, Russia) }\end{array}$} & $\begin{array}{l}\text { Southern Indian Ocean, } \\
65^{\circ}-70^{\circ} \mathrm{S}, 70^{\circ}-100^{\circ} \mathrm{E}\end{array}$ & 12 & $\begin{array}{l}\text { December 15, 2009- } \\
\text { January 4, 2010; } \\
\text { March 30-April 6, } 2010\end{array}$ & \multirow[t]{3}{*}{$440,500,675,870$} & \multirow[t]{3}{*}{ S. M. Sakerin } \\
\hline & $\begin{array}{l}\text { Southern Pacific Ocean } \\
65^{\circ}-75^{\circ} \mathrm{S}, 87^{\circ}-172^{\circ} \mathrm{W}\end{array}$ & 7 & January 19-28, 2010 & & \\
\hline & $\begin{array}{l}\text { Antarctic Peninsula, } \\
62^{\circ} \mathrm{S}, 59^{\circ} \mathrm{W}\end{array}$ & 1 & February 6, 2010 & & \\
\hline $\begin{array}{l}\text { Prince Albert II } 2010 \\
\text { (Space Physics Laboratory, } \\
\text { University of Kyiv, Kyiv, } \\
\text { Ukraine) }\end{array}$ & $\begin{array}{l}\text { Antarctic Peninsula } \\
62^{\circ}-67^{\circ} \mathrm{S}, 58^{\circ}-67^{\circ} \mathrm{W}\end{array}$ & 11 & $\begin{array}{l}\text { January 9-February 17, } \\
2010\end{array}$ & $440,500,675,870$ & G. Milinevsky \\
\hline $\begin{array}{l}\text { NP Almirante Maximiano } \\
\text { 2010/2011 } \\
\text { (Rio de Janeiro State University, } \\
\text { Rio de Janeiro, Brazil) }\end{array}$ & $\begin{array}{l}\text { Antarctic Peninsula } \\
62^{\circ}-64^{\circ} \mathrm{S}, 56^{\circ}-61^{\circ} \mathrm{W}\end{array}$ & 7 & $\begin{array}{l}\text { January 7-March 21, } \\
2011\end{array}$ & $440,500,675,870$ & H. Evangelista \\
\hline $\begin{array}{l}\text { RV Akademik Fedorov } \\
\text { 2010/2011 } \\
\text { (AARI, St. Petersburg, Russia) }\end{array}$ & $\begin{array}{l}\text { Southern Indian Ocean } \\
65^{\circ}-69^{\circ} \mathrm{S}, 45^{\circ}-93^{\circ} \mathrm{E}\end{array}$ & 18 & $\begin{array}{l}\text { December } 18,2010- \\
\text { February } 2,2011\end{array}$ & $440,500,675,870$ & V. F. Radionov \\
\hline $\begin{array}{l}\text { RV Astrolabe } 2011 \\
\text { (OPAR Institute, Univ. de la } \\
\text { Réunion, Saint Denis de la } \\
\text { Réunion, France) }\end{array}$ & $\begin{array}{l}\text { Southern Indian Ocean } \\
67^{\circ} \mathrm{S}, 140^{\circ} \mathrm{E}\end{array}$ & 24 & $\begin{array}{l}\text { January 5-March 1, } \\
2011\end{array}$ & $\begin{array}{l}340,440,500,675, \\
870\end{array}$ & Y. Courcoux \\
\hline $\begin{array}{l}\text { MV SA Agulhas 2011/2012 } \\
\text { (Climatology Research Group, } \\
\text { University of Witwatersrand, } \\
\text { Johannesburg, South Africa) }\end{array}$ & $\begin{array}{l}\text { Southern Atlantic Ocean } \\
67^{\circ}-71^{\circ} \mathrm{S}, 0^{\circ}-9^{\circ} \mathrm{W}\end{array}$ & 17 & $\begin{array}{l}\text { December 19, 2011- } \\
\text { February 13, } 2012\end{array}$ & $\begin{array}{l}340,440,500,675, \\
870\end{array}$ & S. Broccardo \\
\hline
\end{tabular}




\begin{tabular}{|c|c|c|c|c|c|}
\hline $\begin{array}{l}\text { NP Almirante Maximiano } \\
2011 / 2012 \\
\text { (Rio de Janeiro State University, } \\
\text { Rio de Janeiro, Brazil) }\end{array}$ & $\begin{array}{l}\text { Antarctic Peninsula, } \\
61^{\circ}-62^{\circ} \mathrm{S}, 55^{\circ}-59^{\circ} \mathrm{W}\end{array}$ & 6 & $\begin{array}{l}\text { October 24, 2011- } \\
\text { November } 14,2011\end{array}$ & $440,500,675,870$ & H. Evangelista \\
\hline \multirow{3}{*}{$\begin{array}{l}\text { RV Akademik Fedorov } \\
\text { 2011/2012 } \\
\text { (AARI, St. Petersburg, Russia) }\end{array}$} & $\begin{array}{l}\text { Southern Indian Ocean } \\
66^{\circ}-69^{\circ} \mathrm{S}, 37^{\circ}-93^{\circ} \mathrm{E}\end{array}$ & 19 & $\begin{array}{l}\text { December 12, 2011- } \\
\text { March 21, } 2012\end{array}$ & \multirow[t]{3}{*}{$440,500,675,870$} & \multirow[t]{3}{*}{ V. F. Radionor } \\
\hline & $\begin{array}{l}\text { Southern Atlantic Ocean } \\
62^{\circ}-70^{\circ} \mathrm{S}, 18^{\circ} \mathrm{W}-20^{\circ} \mathrm{E}\end{array}$ & 8 & March 22-April 7, 2012 & & \\
\hline & $\begin{array}{l}\text { Antarctic Peninsula } \\
62.2^{\circ} \mathrm{S}, 58.9^{\circ} \mathrm{W}\end{array}$ & 2 & April 21 and 22, 2012 & & \\
\hline $\begin{array}{l}\text { RV Astrolabe } 2012 \\
\text { (OPAR Institute, Univ. de la } \\
\text { Réunion, Saint Denis de la } \\
\text { Réunion, France) }\end{array}$ & $\begin{array}{l}\text { Southern Indian Ocean } \\
66^{\circ} 40^{\prime} \mathrm{S}, 140^{\circ} \mathrm{E}\end{array}$ & 14 & $\begin{array}{l}\text { February 20-March 2, } \\
2012\end{array}$ & $\begin{array}{l}380,440,500,675, \\
870\end{array}$ & Y. Courcoux \\
\hline $\begin{array}{l}\text { RV SA Agulhas II 2012/2013 } \\
\text { (Climatology Research Group, } \\
\text { University of Witwatersrand, } \\
\text { Johannesburg, South Africa) }\end{array}$ & $\begin{array}{l}\text { Southern Atlantic Ocean } \\
70^{\circ}-71^{\circ} \mathrm{S}, 1^{\circ}-8^{\circ} \mathrm{W}\end{array}$ & 11 & $\begin{array}{l}\text { December 19, 2012- } \\
\text { February 5, } 2013\end{array}$ & $\begin{array}{l}380,440,500,675, \\
870\end{array}$ & S. Broccardo \\
\hline \multirow{2}{*}{$\begin{array}{l}\text { RV Akademik Fedorov } \\
2012 / 2013 \\
\text { (AARI, St. Petersburg, Russia) }\end{array}$} & $\begin{array}{l}\text { Southern Indian Ocean } \\
66^{\circ}-70^{\circ} \mathrm{S}, 46^{\circ}-93^{\circ} \mathrm{E}\end{array}$ & 24 & $\begin{array}{l}\text { December 13, 2012- } \\
\text { March 15, } 2013\end{array}$ & \multirow[t]{2}{*}{$440,500,675,870$} & \multirow[t]{2}{*}{ V. F. Radionor } \\
\hline & $\begin{array}{l}\text { Southern Atlantic Ocean } \\
67^{\circ}-70^{\circ} \mathrm{S}, 10^{\circ}-12^{\circ} \mathrm{E}\end{array}$ & 3 & March 22-24, 2013 & & \\
\hline $\begin{array}{l}\text { RV Akademik Treshnikov } \\
\text { 2012/2013 } \\
\text { (AARI, St. Petersburg, Russia) }\end{array}$ & $\begin{array}{l}\text { Antarctic Peninsula, } \\
64^{\circ}-70^{\circ} \mathrm{S}, 57^{\circ}-72^{\circ} \mathrm{W}\end{array}$ & 13 & $\begin{array}{l}\text { February 11-March 5, } \\
2013\end{array}$ & $440,500,675,870$ & V. F. Radionov \\
\hline
\end{tabular}


Table 5. Values of shape-parameters $\sigma$ and $r_{c}$ of the log-normal curves adopted to represent the fine, accumulation and coarse particle modes determined at Arctic and Antarctic sites, all normalized to give the value of overall particle number concentration $N_{o}=1000 \mathrm{~cm}^{-3}$. They are given together with the spectral values of real part $n$ and imaginary part $k$ of the complex refractive index at the $0.55 \mu \mathrm{m}$ wavelength, single-scattering albedo $\omega(0.55 \mu \mathrm{m})$, asymmetry factor $g(0.55 \mu \mathrm{m})$, volume extinction coefficient $\beta_{\text {ext }}(0.55 \mu \mathrm{m})$ and Ångström's exponent $\alpha$ calculated over the 0.40 $0.87 \mu \mathrm{m}$ wavelength range for the spectral evaluations of $\beta_{\text {ext }}(\lambda)$ made using the $6 \mathrm{~S}$ radiative transfer code of Vermote et al. (1997a). The $6 \mathrm{~S}$ aerosol components are labelled according to Vermote et al. (1997 b): oceanic (OC), water-soluble (WS), dust-like (DL) and soot (SO).

\begin{tabular}{|c|c|c|c|c|c|c|c|c|c|c|c|c|c|}
\hline \multirow{2}{*}{ Aerosol type } & \multirow[t]{2}{*}{$\begin{array}{c}\text { Log- } \\
\text { normal } \\
\text { mode }\end{array}$} & \multicolumn{4}{|c|}{$\begin{array}{l}\text { Mass percentages of the } \\
\text { basic } 6 \mathrm{~S} \text { dry-air } \\
\text { components }\end{array}$} & \multirow{2}{*}{$\begin{array}{c}\text { Geometric } \\
\text { standard } \\
\text { deviation } \\
\sigma\end{array}$} & \multirow{2}{*}{$\begin{array}{l}\text { Mode } \\
\text { radius } \\
r_{c}(\mu \mathrm{m})\end{array}$} & \multicolumn{2}{|c|}{$\begin{array}{l}\text { Particulate matter } \\
\text { refractive index parts }\end{array}$} & \multirow{2}{*}{$\begin{array}{c}\omega(0.55 \\
\mu m)\end{array}$} & \multirow{2}{*}{$\begin{array}{c}g(0.55 \\
\mu m)\end{array}$} & \multirow{2}{*}{$\begin{array}{c}\beta_{\text {ext }}(0.55 \\
\mu m) \\
\left(\mathrm{km}^{-1}\right)\end{array}$} & \multirow{2}{*}{$\begin{array}{c}\text { Expo- } \\
\text { nent } \\
\alpha\end{array}$} \\
\hline & & $\mathrm{OC}$ & WS & DL & $\mathrm{SO}$ & & & $n(0.55 \mu m)$ & $k(0.55 \mu \mathrm{m})$ & & & & \\
\hline \multirow{2}{*}{$\begin{array}{c}\text { Winter-spring } \\
\text { (Arctic haze) } \\
\text { aerosol }\end{array}$} & Fine & 35 & 39 & 22 & 4 & 2.24 & $2.110^{-2}$ & 1.487 & $2.1710^{-2}$ & 0.864 & 0.637 & $1.22110^{-8}$ & 1.581 \\
\hline & Accum. & 58 & 4 & 38 & - & 2.03 & $3.010^{-1}$ & 1.444 & $3.2810^{-3}$ & 0.937 & 0.745 & $4.08810^{-3}$ & -0.117 \\
\hline \multirow{2}{*}{ Asian dust } & Fine & - & 24 & 76 & - & 1.95 & $7.010^{-2}$ & 1.530 & $7.5210^{-3}$ & 0.956 & 0.666 & $5.09410^{-6}$ & 1.039 \\
\hline & Coarse & 4 & 6 & 90 & - & 2.15 & 1.30 & 1.552 & $7.5610^{-3}$ & 0.673 & 0.860 & 1.385 & -0.058 \\
\hline \multirow{2}{*}{$\begin{array}{l}\text { Boreal forest fire } \\
\text { smoke }\end{array}$} & Fine & - & - & 97.9 & 2.1 & 2.00 & $3.910^{-2}$ & 1.535 & $1.7110^{-2}$ & 0.906 & 0.627 & $1.69810^{-7}$ & 1.556 \\
\hline & Accum. & - & - & 98.4 & 1.6 & 2.00 & $1.210^{-1}$ & 1.534 & $1.4910^{-2}$ & 0.892 & 0.700 & $9.87810^{-5}$ & 0.345 \\
\hline $\begin{array}{c}\text { Austral summer } \\
\text { Antarctic Plateau } \\
\text { aerosol } \\
\end{array}$ & Coarse & 86 & 6 & 8 & - & 2.03 & 1.75 & 1.402 & $1.0010^{-3}$ & 0.900 & 0.831 & 3.204 & -0.056 \\
\hline \multirow{2}{*}{$\begin{array}{l}\text { Antarctic austral } \\
\text { winter aerosol }\left(^{*}\right)\end{array}$} & Fine & - & 90 & 10 & - & 2.03 & $7.010^{-2}$ & 1.530 & $6.2010^{-3}$ & 0.960 & 0.671 & $7.47710^{-6}$ & 0.857 \\
\hline & Accum. & 95 & - & 5 & - & 2.03 & $5.010^{-1}$ & 1.388 & $4.0010^{-4}$ & 0.986 & 0.774 & $2.72410^{-2}$ & -0.157 \\
\hline
\end{tabular}

$\left(^{*}\right)$ for its use at both Antarctic coastal and high-altitude sites. 
Table 6. Multimodal aerosol extinction models based on the OPAC (Hess et al., 1998) components used to represent 4 Arctic and 4 Antarctic columnar contents of polar aerosol, with (i) the mass percentages of the OPAC components of fine and accumulation/coarse particle modes in the atmospheric column; (ii) the values of real part $n$ and imaginary part $k$ of complex refractive index at the $0.55 \mu \mathrm{m}$ wavelength, (iii) the values of aerosol optical thickness $\tau(0.50 \mu \mathrm{m})$ and Ångström's exponent $\alpha$ calculated over the 0.40-0.87 $\mu \mathrm{m}$ wavelength range, and (iv) the values of columnar aerosol single scattering albedo $\omega(0.55 \mu \mathrm{m})$. The last three columns provide the values of diurnal average aerosol radiative forcing terms at the TOA-level $\left(\Delta F_{T O A}\right)$, at the surface $\left(\Delta F_{B O A}\right)$ and within the atmosphere $\left(\Delta F_{A T M}\right)$, estimated for the BRDF surface reflectance models OS1 (oceanic), VS1 (vegetation-covered) and PS1, PS2, PS3 and PS4 (polar ice- and snow-covered) determined by Tomasi et al. (2014). The acronym BG stands for "background". The OPAC aerosol components are indicated by the acronyms WASO (water-soluble), SSAM (sea-salt accumulation mode), SSCM (sea-salt coarse mode), INSO (insoluble), SOOT (soot), and MITR (mineral-transported).

\begin{tabular}{|c|c|c|c|c|c|c|c|c|c|c|c|c|c|c|c|}
\hline \multirow{3}{*}{ Aerosol type } & \multicolumn{6}{|c|}{$\begin{array}{l}\text { Mass percentages of the basic OPAC components } \\
\text { calculated for relative humidity }=50 \% \text { to give form to } \\
\text { the fine and accumulation/coarse particle modes }\end{array}$} & \multicolumn{2}{|c|}{\begin{tabular}{|l|} 
Particulate matter \\
refractive index parts
\end{tabular}} & \multirow{3}{*}{$\begin{array}{c} \\
\text { Aerosol } \\
\text { optical } \\
\text { thickness } \\
\tau(0.50 \mu \mathrm{m})\end{array}$} & \multirow{3}{*}{$\begin{array}{c}\text { Exponent } \\
\alpha\end{array}$} & \multirow{3}{*}{$\begin{array}{c}\omega(0.55 \\
\mu m)\end{array}$} & \multirow{3}{*}{$\begin{array}{l}\text { BRDF } \\
\text { surface } \\
\text { reflectance } \\
\text { model }\end{array}$} & \multirow{2}{*}{\multicolumn{3}{|c|}{$\begin{array}{l}\text { Diurnal average aerosol radiative forcing } \\
\qquad\left(\mathrm{W} \mathrm{m}^{-2}\right)\end{array}$}} \\
\hline & \multirow{2}{*}{ WASO } & \multirow{2}{*}{ SOOT } & \multirow{2}{*}{ SSAM } & \multirow{2}{*}{ SSCM } & \multirow{2}{*}{ INSO } & \multirow{2}{*}{ MITR } & \multirow{2}{*}{$\begin{array}{l}n(0.50 \\
\mu m)\end{array}$} & \multirow{2}{*}{$\begin{array}{c}k(0.50 \\
\mu m)\end{array}$} & & & & & & & \\
\hline & & & & & & & & & & & & & $\Delta F_{T O A}$ & $\Delta F_{B O A}$ & $\Delta F_{A T M}$ \\
\hline $\begin{array}{l}\text { Winter-spring Arctic } \\
\text { haze (Barrow) }\end{array}$ & 95.8 & 4.2 & 22.9 & 37.7 & 39.4 & - & 1.399 & $3.310^{-3}$ & 0.116 & 1.28 & 0.840 & $\begin{array}{l}\text { OS1 } \\
\text { PS1 } \\
\text { PS2 }\end{array}$ & $\begin{array}{l}-5.5 \\
+9.0 \\
+8.8\end{array}$ & $\begin{array}{l}+6.5 \\
+0.0 \\
+0.1\end{array}$ & $\begin{array}{l}-12.0 \\
+8.9 \\
+8.7\end{array}$ \\
\hline $\begin{array}{l}\text { Winter-spring Arctic } \\
\text { haze (Ny-Ålesund) }\end{array}$ & 98.0 & 2.0 & - & 90.9 & 9.1 & - & 1.424 & $7.310^{-3}$ & 0.080 & 1.29 & 0.949 & $\begin{array}{l}\text { OS1 } \\
\text { PS3 }\end{array}$ & $\begin{array}{l}-5.3 \\
+1.0\end{array}$ & $\begin{array}{l}-0.6 \\
-0.4\end{array}$ & $\begin{array}{l}-4.7 \\
+1.4\end{array}$ \\
\hline $\begin{array}{l}\text { Winter-spring Arctic } \\
\text { haze (Sodankylä) }\end{array}$ & 95.3 & 4.7 & 94.8 & 5.2 & - & - & 1.399 & $3.910^{-3}$ & 0.066 & 1.25 & 0.840 & $\begin{array}{l}\text { OS1 } \\
\text { VS1 } \\
\text { PS2 }\end{array}$ & $\begin{array}{l}-7.7 \\
-3.5 \\
+2.2\end{array}$ & $\begin{array}{l}-1.1 \\
-5.3 \\
-0.3\end{array}$ & $\begin{array}{l}-6.6 \\
+1.8 \\
+2.5\end{array}$ \\
\hline $\begin{array}{c}\text { Background summer } \\
\text { aerosol (Barrow) }\end{array}$ & 96.8 & 3.2 & 11.0 & 43.6 & 45.4 & - & 1.444 & $9.210^{-3}$ & 0.078 & 1.40 & 0.978 & $\begin{array}{l}\text { OS1 } \\
\text { VS1 }\end{array}$ & $\begin{array}{l}-9.2 \\
-4.2\end{array}$ & $\begin{array}{l}-1.9 \\
-6.5\end{array}$ & $\begin{array}{l}-7.3 \\
+2.3\end{array}$ \\
\hline $\begin{array}{l}\text { Background summer } \\
\text { aerosol (Ny-Ålesund) }\end{array}$ & 98.0 & 2.0 & - & 50.0 & 50.0 & - & 1,461 & $7.910^{-3}$ & 0.041 & 1.20 & 0.966 & $\begin{array}{l}\text { OS1 } \\
\text { PS4 }\end{array}$ & $\begin{array}{l}-7.2 \\
+1.0\end{array}$ & $\begin{array}{l}+1.5 \\
-2.3\end{array}$ & $\begin{array}{l}-8.6 \\
+3.4\end{array}$ \\
\hline $\begin{array}{l}\text { Arctic dense summer } \\
\text { aerosol (Ny-尺̊lesund) }\end{array}$ & 97.6 & 2.4 & 6.3 & 59.7 & 34.0 & - & 1.437 & $3.710^{-3}$ & 0,120 & 1.00 & 0.852 & $\begin{array}{l}\text { OS1 } \\
\text { PS4 }\end{array}$ & $\begin{array}{l}-10.4 \\
+13.0\end{array}$ & $\begin{array}{l}+4.2 \\
-5.2\end{array}$ & $\begin{array}{l}-14.6 \\
+18.2\end{array}$ \\
\hline $\begin{array}{l}\text { Background summer } \\
\text { aerosol (Summit) }\end{array}$ & 98.0 & 2.0 & - & 50.0 & 50.0 & - & 1.449 & $8.810^{-3}$ & 0.039 & 1.48 & 0.969 & PS1 & +2.2 & -0.2 & +2.5 \\
\hline $\begin{array}{l}\text { Background summer } \\
\text { aerosol (Sodankylä) }\end{array}$ & 98.0 & 2.0 & - & 50.0 & 50.0 & - & 1.452 & $8.610^{-3}$ & 0.060 & 1.42 & 0.965 & $\begin{array}{l}\text { OS1 } \\
\text { VS1 }\end{array}$ & $\begin{array}{l}-6.5 \\
-3.0\end{array}$ & $\begin{array}{l}-1.6 \\
-5.5\end{array}$ & $\begin{array}{l}-4.9 \\
+2.4\end{array}$ \\
\hline
\end{tabular}




\begin{tabular}{|c|c|c|c|c|c|c|c|c|c|c|c|c|c|c|c|}
\hline & & & & & & & & & & & & PS2 & +3.0 & -0.4 & +3.4 \\
\hline $\begin{array}{l}\text { Background summer } \\
\text { aerosol (Tiksi) }\end{array}$ & 98.0 & 2.0 & - & 50.0 & 50.0 & - & 1.444 & $9.210^{-3}$ & 0.085 & 1.60 & 0.977 & $\begin{array}{l}\text { OS1 } \\
\text { VS1 }\end{array}$ & $\begin{array}{l}-10.3 \\
-5.6\end{array}$ & $\begin{array}{l}-1.6 \\
-9.0 \\
\end{array}$ & $\begin{array}{l}-8.7 \\
+3.3 \\
\end{array}$ \\
\hline $\begin{array}{l}\text { Asian dust } \\
\text { (Barrow) }\end{array}$ & 100.0 & - & 5.8 & 2.4 & 56.5 & 35.3 & 1.527 & $6.310^{-3}$ & 0.200 & 0.80 & 0.858 & $\begin{array}{l}\text { OS1 } \\
\text { PS2 }\end{array}$ & $\begin{array}{r}-9.3 \\
+18.5 \\
\end{array}$ & $\begin{array}{l}+16.0 \\
+0.3 \\
\end{array}$ & $\begin{array}{r}-25.3 \\
+18.2 \\
\end{array}$ \\
\hline $\begin{array}{l}\text { Boreal forest fire } \\
\text { smoke (Barrow) }\end{array}$ & 95.5 & 4.5 & 21.7 & 26.1 & 52.2 & - & 1.469 & $2.510^{-3}$ & 0.300 & 1.20 & 0.758 & $\begin{array}{l}\text { OS1 } \\
\text { VS1 }\end{array}$ & $\begin{array}{l}-32.9 \\
-20.2 \\
\end{array}$ & $\begin{array}{c}-6.7 \\
-28.6 \\
\end{array}$ & $\begin{array}{l}-26.2 \\
+8.3 \\
\end{array}$ \\
\hline $\begin{array}{l}\text { Background austral } \\
\text { summer aerosol } \\
\text { (Mario Zucchelli) }\end{array}$ & 99.5 & 0.5 & - & 73.9 & 26.1 & - & 1.468 & $2.310^{-3}$ & 0.030 & 0.90 & 0.964 & $\begin{array}{l}\text { OS1 } \\
\text { PS2 }\end{array}$ & $\begin{array}{l}-6.2 \\
+2.0\end{array}$ & $\begin{array}{l}+0.9 \\
-0.1\end{array}$ & $\begin{array}{l}-7.1 \\
+2.1\end{array}$ \\
\hline $\begin{array}{c}\text { Background austral } \\
\text { summer aerosol } \\
\text { (Neumayer) }\end{array}$ & 99.7 & 0.3 & - & 85.6 & 14.4 & - & 1.457 & $1.310^{-3}$ & 0.043 & 0.68 & 0.975 & $\begin{array}{l}\text { OS1 } \\
\text { PS1 } \\
\text { PS2 }\end{array}$ & $\begin{array}{l}-8.2 \\
+1.9 \\
+2.1\end{array}$ & $\begin{array}{l}+1.4 \\
-0.2 \\
+0.0\end{array}$ & $\begin{array}{l}-9.6 \\
+2.1 \\
+2.1\end{array}$ \\
\hline $\begin{array}{l}\text { Background austral } \\
\text { summer aerosol } \\
\text { (Dome Concordia) }\end{array}$ & 100.0 & - & 4.5 & - & - & 95.5 & 1.441 & $2.010^{-3}$ & 0.019 & 1.77 & 0.999 & $\begin{array}{l}\text { PS1 } \\
\text { PS2 }\end{array}$ & $\begin{array}{l}+0.4 \\
+0.6\end{array}$ & $\begin{array}{l}+0.2 \\
+0.4\end{array}$ & $\begin{array}{l}+0.2 \\
+0.2\end{array}$ \\
\hline $\begin{array}{l}\text { Background austral } \\
\text { summer aerosol } \\
\text { (South Pole) }\end{array}$ & 99.6 & 0.4 & - & 83.6 & 16.4 & - & 1.445 & $3.210^{-3}$ & 0.018 & 1.49 & 0.988 & $\begin{array}{l}\text { PS1 } \\
\text { PS2 }\end{array}$ & $\begin{array}{l}+0.6 \\
+0.7\end{array}$ & $\begin{array}{l}-0.1 \\
-0.1\end{array}$ & $\begin{array}{l}+0.7 \\
+0.8\end{array}$ \\
\hline
\end{tabular}

